
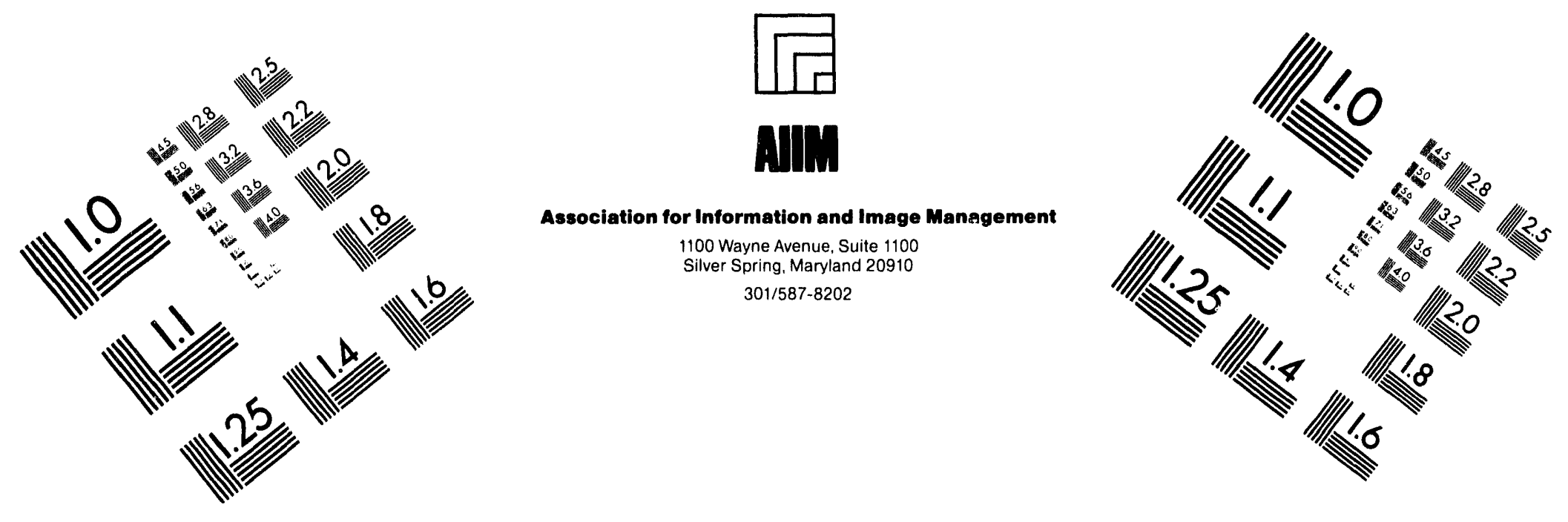

\title{
Centimeter
}

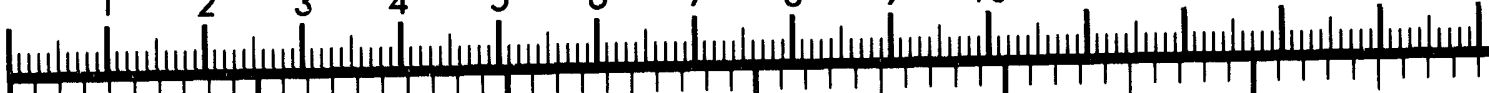
开 Inches
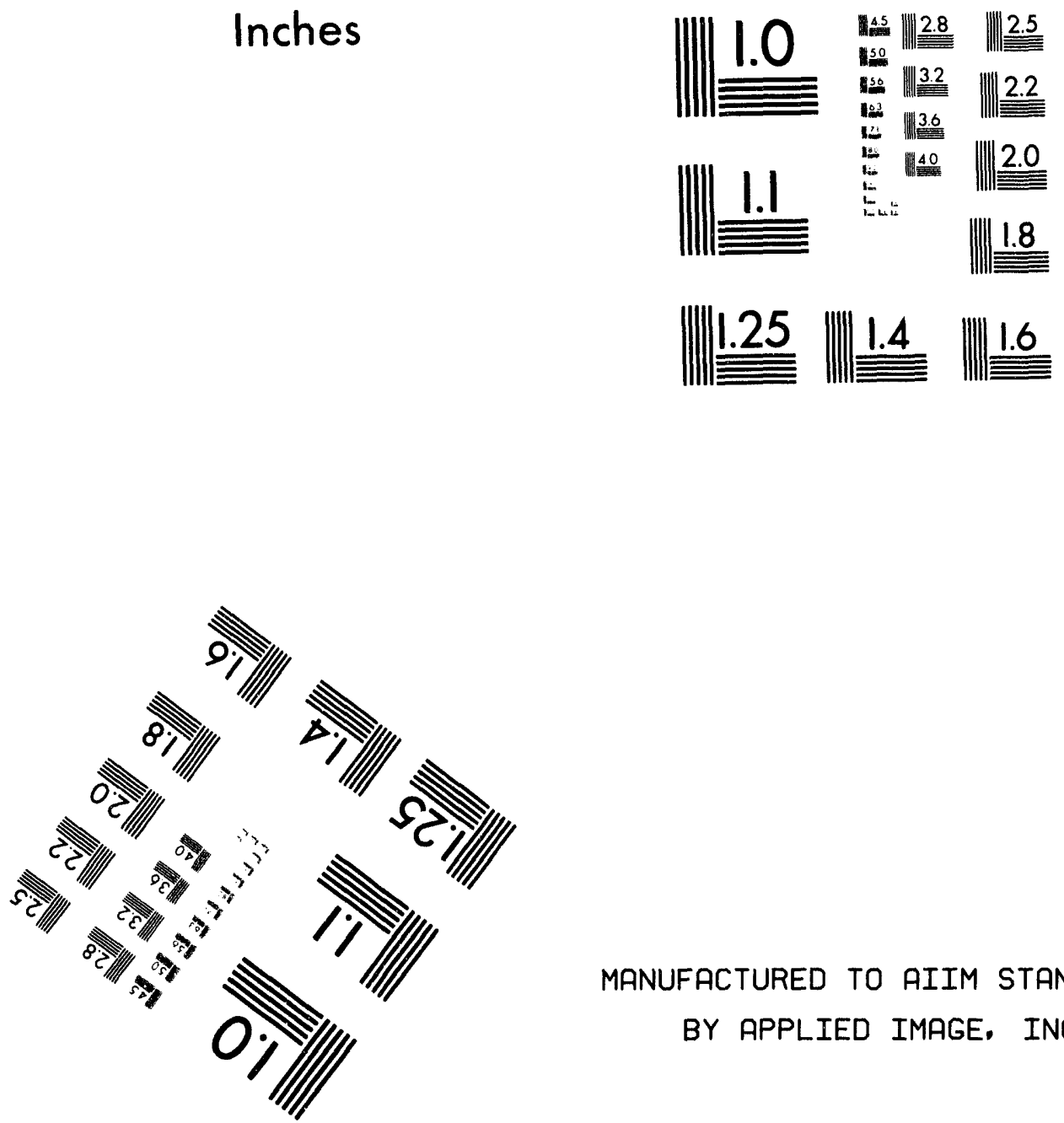

MANUFACTURED TO AIIM STANDARDS

BY APPLIED IMAGE, INC.

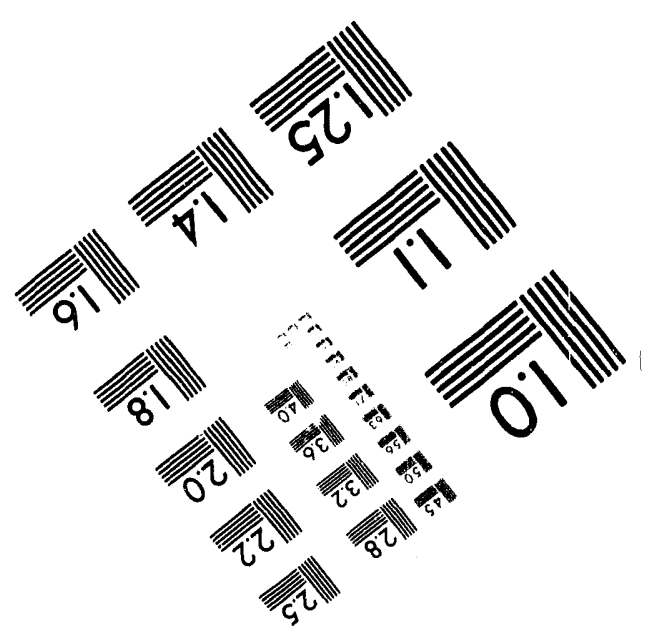



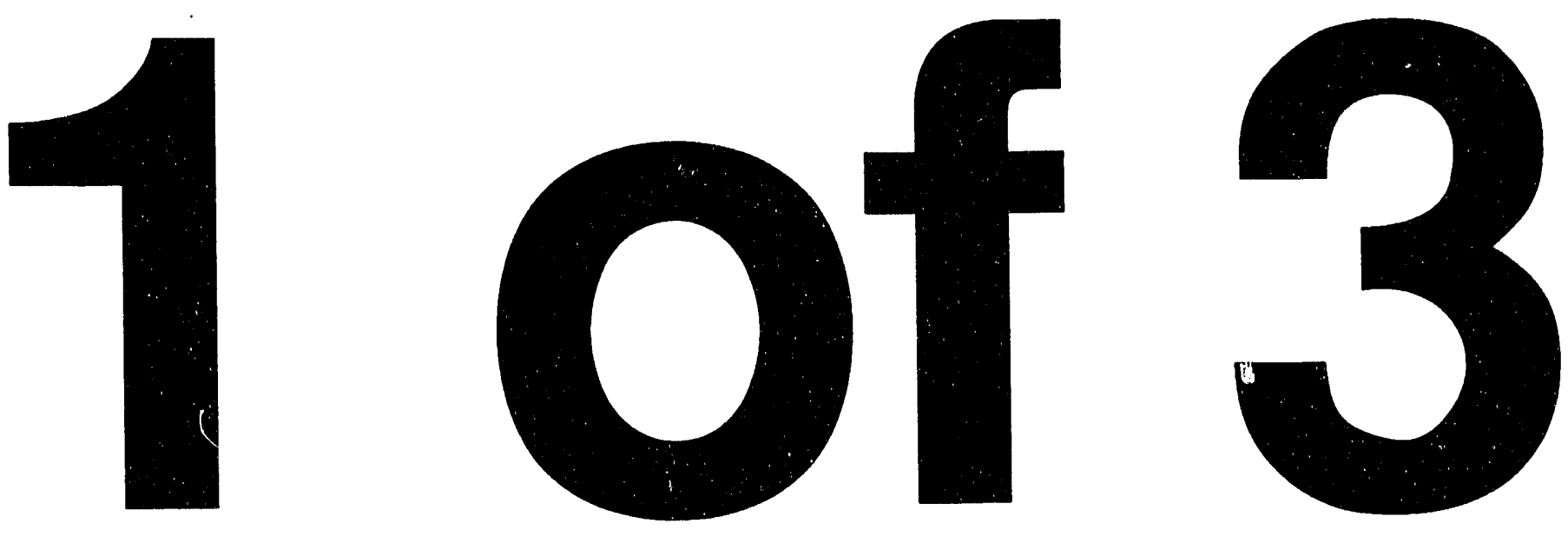


\section{High-Level Waste Storage Tank Farms/242-A Evaporator Standards/Requirements Identification Document (S/RID),} Vol. 7

Date Published

April 1994

Prepared for the U.S. Department of Energy

Office of Environmental Restoration and Waste Management

(QP) Westlnghouse

Hanford Company P.O. Box 1970

Richland, Washington

Hanford Operations and Engineering Contractor for the

U.S. Department of Energy under Contract DE-AC06-87RL 10930

Approved for Public Release

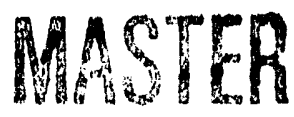




\section{LEGAL DISCLAIMER}

This report was prepared as an account of work sponsored by an agency of the United States Government. Neither the United States Government nor any agency thereof, nor any of their employees, nor any of their contractors, subcontractors or their employees, makes any warranty, express or implied. or assumes any legal liability or responsibility for the accuracy, completeness, or any third party's use or the results of such use of any information, apparatus, product, or process disclosed, or represents that its use would not infringe privately owned rights. Reference herein to any specific commercial product, process, or service by trade name, trademark, manufacturer, or otherwise, does not necessarily constitute or imply its endorsement, recommendation, or favoring by the United States Government or any agency thereof or its contractors or subcontractors. The views and opinions of authors expressed herein do not necessarily state or reflect those of the United States Government or any agency thereot.

This report has been reproduced from the best available copy. Available in paper copy and microfiche.

Available to the U.S. Department of Energy and its contractors from

Office of Scientific and Technical Information

P.O. Box 62

Oak Ridge, TN 37831

(615) $576-8401$

Available to the public from the U.S. Department of Commerce National Technical Information Service

5285 Port Royal Road

Springtield, VA 22161

(703) $487-4650$

Printed in the United States of America

DISCLM-1.CHP (1.91) 


\section{WESTINGHOUSE HANFORD COMPANY}

\section{REQUIREMENTS \\ OSTI}

MAY 311934

\section{IDENTIFICATION}

DOCUMENT

FACILITY:

HIGH LEVEL WASTE STORAGE TANK FARMS/242-A EVAPORATOR
FUNCTIONAL AREA:

Occupational Safety and Health

\section{REVISION 0}


WHC-EP-0750

\section{REQUIREMENTS IDENTIFICATION DOCUMENT \\ HIGH LEVEL WASTE STORAGE TANK FARMS \\ Occupational Safety and Health}

\section{TABLE OF CONTENTS}

17.0 OCCUPATIONAL SAFETY AND HEALTH $\ldots \ldots \ldots \ldots \ldots \ldots \ldots \ldots$

17.1

17.1 .1

17.1 .2

17.1 .3

17.1 .4

17.2

17.2 .1

17.2 .2

17.2 .3

17.2 .4

17.2 .5

17.3

17.3.1

17.3.2

17.3.3

17.3.3.1

17.3.3.2

17.3.4

17.3.5

17.4

17.4.1

17.4 .2

17.4 .3

17.4.4

17.4 .5

17.4 .6

17.4 .7

17.4 .8

17.4 .9

17.5

PROGRAM MANAGEMENT $\ldots \ldots \ldots \ldots \ldots \ldots \ldots \ldots$

Program Policy and Procedures $\ldots \ldots \ldots \ldots \ldots \ldots \ldots 2$

Occupational Safety and Health Goals and Objectives . . . . . . . . . . 5

Management Commitment and Resources .............. 6

Requests for Exemptions $/$ Variances $\ldots \ldots \ldots \ldots \ldots . \ldots . \ldots$

HAZARD ANTICIPATION, IDENTIFICATION, AND EVALUATION $\ldots \ldots 11$

Hazard Assessment Program . . . . . . . . . . . . . . . 11

Hazard Reporting System . . . . . . . . . . . . . . . . . . 14

Investigation of Occurrences, Accidents, and Near Misses . . . . . . 17

Injury and Illness Trend Analysis . . . . . . . . . . . . . 18

Occupational Safety and Health Inventory System $\ldots \ldots \ldots$

OS\&H HAZARD PREVENTION AND CONTROL $\ldots \ldots \ldots \ldots \ldots \ldots$

Facility, Hazard Monitoring, Sampling, and Surveillance . . . . . . . . 24

Engineering Controls . . . . . . . . . . . . . . . . . . . 27

Administrative Controls . . . . . . . . . . . . . . . 30

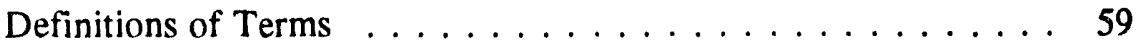

Handling Drums and Containers $\ldots \ldots \ldots \ldots 63$

Personal Protective Equipment . . . . . . . . . . . . . . . 66

Facility and Equipment Safety Inspections and Maintenance . . . . . . 72

OCCUPATIONAL HEALTH PROGRAM $\ldots \ldots \ldots \ldots \ldots \ldots$

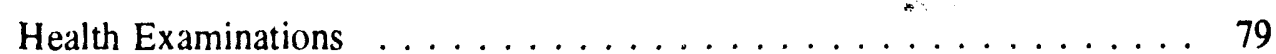

Health Maintenance and Preventive Medicine . . . . . . . . . . 86

Diagnosis and Treatment . . . . . . . . . . . . . . . 88

Fitness for Duty . . . . . . . . . . . . . . . . . . . . 90

Medical Facilities and Equipment ... . . . . . . . . . . 92

Professional Development of Occupational Staff . . . . . . . . . . . 95

Emergency Planning . . . . . . . . . . . . . . . . . . . . . 97

Health Records and Reporting . . . . . . . . . . . . . . . . . . . 97

Medical Staffing . . . . . . . . . . . . . . . . . . . . 101

OCCUPATIONAL SAFETY AND HEALTH TRAINING . . . . . . . . . . 107

17.5.1 OS\&H Program Training $\ldots \ldots \ldots \ldots \ldots \ldots \ldots$ 


\section{REQUIREMENTS IDENTIFICATION DOCUMENT \\ HIGH LEVEL WASTE STORAGE TANK FARMS \\ Occupational Safety and Health}

17.5 .2

17.5 .3

17.6

17.6.1

17.6 .2

17.6 .3

17.7

17.7.1

17.7.2

17.7 .3

17.7.4

17.7.5

17.7.6

17.7 .7

17.7 .8

17.7 .9

17.7.10
HAZWOPER Training . . . . . . . . . . . . . . 113

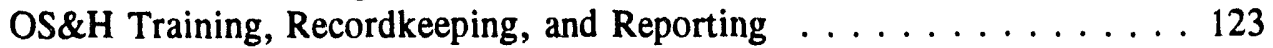

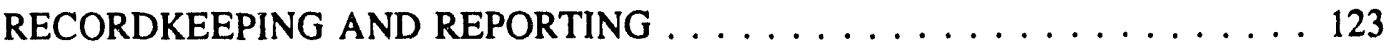

OS\&H Record Management and Exposure Reporting . . . . . . . . 123

Occurrence Reporting . . . . . . . . . . . . . . . . . . . . . . . . 124

Occupational Injury and Illness Reporting . . . . . . . . . . . 124

KEY PROGRAM INTERFACES $\ldots \ldots \ldots \ldots \ldots \ldots \ldots \ldots$

Engineering Design . . . . . . . . . . . . . . . . . . . . 125

Emergency Preparedness and Management (E\&M) . . . . . . . . . 125

Maintenance ......................... 125

Operations . . . . . . . . . . . . . . . . . . . 125

Radiation Protection . . . . . . . . . . . . . . . . . 125

Training and Qualification . . . . . . . . . . . . . . 125

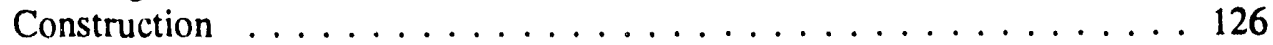

Management Systems . . . . . . . . . . . . . . . . 126

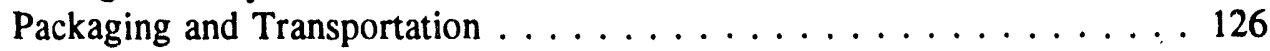

Safeguards and Security $\ldots \ldots \ldots \ldots \ldots \ldots \ldots$ 
WHC-EP-0750

\section{REQUIREMENTS IDENTIFICATION DOCUMENT \\ HIGH LEVEL WASTE STORAGE TANK FARMS \\ Occupational Safety and Health}

\subsection{OCCUPATIONAL SAFETY AND HEALTH}

\section{INTRODUCTION}

This Requirements Identification Document (RID) describes an Occupational Health and Safety Program as defined through the Relevant Doe Orders, regulations (OSHA, WAC, etc.), industry codes/standards, industry guidance documents and, as appropriate, good industry practice. The definition of an Occupational Health and Safety Program as specified by this document is intended to address Defense Nuclear Facilities Safety Board Recommendations 90-2 and 91-1, which call for the strengthening of DOE complex activities through the identification and application of relevant standards which supplement or exceed requirements mandated by DOE Orders.

This RID applies to the activities, personnel, structures, systems, components, and programs involved in maintaining the facility and executing the mission of the Tank Farms. The physical boundaries within which the requirements of this RID apply are the Single Shell Tank Farms, Double Shell Tank Farms, 242-A Evaporator-Crystallizer, 242-S,T Evaporators, Liquid Effluent Retention Facility (LERF), Purgewater Storage Facility (PSWF), and all interconnecting piping, valves, instrumentation, and controls. Also included is all piping, valves, instrumentation, and controls up to and including the most remote valve under Tank Farms control at any other Hanford Facility having an interconnection with the Tank Farms. The boundary of the structures, systems, components, and programs to which this RID applies, is defined by those that are dedicated to and/or under the control of the Tank Farms but excludes general site facilities such as the site electric power system, site telecommunications systems, and roads serving the Hanford Reservation.

The Occupational Health and Safety Program defined in this document is presented in the form of program elements and sub-elements. The accompanying descriptive text briefly addresses the controls necessary for implementation of each element and sub-element. The elements used to outline the basis of a comprehensive Occupational Health and Safety Program are as follows:

- Program Management

- Hazard Anticipation, Identification, and Evaluation

- OS\&H Hazard Prevention and Control

- Occupational Health Program

- Occupational Safety and Health Training

- Recordkeeping and Recording

- Key Program Interfaces

This document shall be used as a baseline to assess the existing Occupational Health and Safety Program at the Tank Farm Facilities. Complete program definition, including overall infrastructure and interfaces, shall be evaluated with regard to the elements and sub-elements identified in this document. 
WHC-EP-0750

\section{REQUIREMENTS IDENTIFICATION DOCUMENT HIGH LEVEL WASTE STORAGE TANK FARMS \\ Occupational Safety and Health}

\section{PROGRAM MANAGEMENT}

This element addresses the management and organizational structure needed for an effective Health and Safety Program. A formal structure is necessary to ensure a high level of performance and safety is achieved during work activities. This element outlines the need for establishing clear and concise Health and Safety policy, goals and objectives. The responsibility that managers, supervisors, and employees are assigned relative to health and safety during the performance of work is also addressed. The necessary management commitment to a safe work environment and the resources required to support such a commitment are also discussed.

\section{FACILITY REQUIREMENT SOURCE: 29CFR1910 Part 120(b)(2)(i)}

"Organizational structure part of the site program. The organizational structure part of the program shall establish the specific chain of command and specify the overall responsibilities of supervisors and employees. It shall include, at a minimum, the following elements:

(A) A general supervisor who has the responsibility and authority to direct all hazardous waste operations.

(B) A site safety and health supervisor who has the responsibility and authority to develop and implement the site safety and health plan and verify compliance.

(C) All other personnel needed for hazardous waste site operations and emergency response and their general functions and responsibilities.

(D) The lines of authority, responsibility, and communication."

\section{FACILITY REQUIREMENT SOURCE: 29CFR1910 Part 120(b)(2)(ii)}

"The organizational structure shall be reviewed and updated as necessary to reflect the current status of waste site operations."

\subsubsection{Program Policy and Procedures}

This sub-element delineates the policy requirements for a Health and Safety Program. The health and safety policy shall be written and clearly communicate management's operating philosophy, standards, and expectations with regard to health and safety. The policy shall also assi $n$ responsibility for the implementation of the stated health ind safety policy.

Specifically, the health and safety program policy shall clearly and concisely state management's expectations concerning health and safety issues that may arise during the performance of work. Management's overall commitment to health and safety shall be clearly communicated, including the relative value management places on health and safety in the work place.

Specific controls which govern the preparation and implementation of program policies are addressed in the Policies and Procedures section of the Management Systems Functional Area. 
WHC-EP-0750

\section{REQUIREMENTS IDENTIFICATION DOCUMENT HIGH LEVEL WASTE STORAGE TANK FARMS Occupational Safety and Health}

\section{FACILITY REQUIREMENT SOURCE: 29CFR1910 Part 120(b)(1)(i)}

"Safety and health program.

General.

Employers shall develop and implement a written safety and health program for their employees involved in hazardous waste operations. The program shall be designed to identify, evaluate, and control safety and health hazards, and provide for emergency response for hazardous waste operations."

\section{FACILITY REQUIREMENT SOURCE: 29CFR1910 Part 120(b)(1)(ii)}

"The written safety and health program shall incorporate the following:

(A) An organizational structure;

(B) A comprehensive workplan;

(C) A site-specific safety and health plan which need not repeat the employer's standard operating procedures required in paragraph $(b)(1)(i i)(F)$ of this section;

(D) The safety and health training program;

(E) The medical surveillance program;

(F) The employer's standard operating procedures for safety and health; and

(G) Any necessary interface between general program and site specific activities."

\section{FACILITY REQUIREMENT SOURCE: 29CFR1910 Part 120(b)(1)(iv)}

"Contractors and sub-contractors. An employer who retains contractor or sub-contractor services for work in hazardous waste operations shall inform those contractors, sub-contractors, or their representatives of the site emergency response procedures and any potential fire, explosion, health, safety or other hazards of the hazardous waste operation that have been identified by the employer, including those identified in the employer's information program."

\section{FACILITY REQUIREMENT SOURCE: 29CFR1910 Part 120(b)(1)(v)}

"Program availability. The written safety and health program shall be made available to any contractor or subcontractor or their representative who will be involved with the hazardous waste operation; to employees; to employee designated representatives; to OSHA personnel, and to personnel of other Federal, state, or local agencies with regulatory authority over the site."

\section{FACILITY REQUIREMENT SOURCE: 29CFR1910 Part 120(g)(1)(iii)}

"The employer shall not implement a schedule of employee rotation as a means of compliance with permissible exposure limits or dose limits except when there is no other feasible way of complying with the airborne or dermal dose limits for ionizing radiation."

\section{FACILITY REQUIREMENT SOURCE: 54FR3904 Part (c)(1)(v)}

"Assign and communicate responsibility for all aspects of the program, so that managers, supervisors, and employees in all parts of the organization know what performance is expected of them." 


\section{REQUIREMENTS IDENTIFICATION DOCUMENT HIGH LEVEL WASTE STORAGE TANK FARMS \\ Occupational Safety and Health}

\section{FACILITY REQUIREMENT SOURCE: 54FR3904 Part 3904.(a)(1)}

"Employers are advised and encouraged to institute and maintain in their establishments a program which provides systematic policies, procedures, and practices that are adequate to recognize and protect their employees from occupational safety and health hazards."

\section{FACILITY REQUIREMENT SOURCE: 54FR3904 Part 3904.(a)(4)}

"The extent to which the program is described in writing is less important than how effective it is in practice. As the size of a worksite or the complexity of a hazardous operation increases, however, the need for written guidance increases to ensure clear communication of policies and priorities and consistent and fair application of rules. ${ }^{*}$

\section{FACILITY REQUIREMENT SOURCE: 54FR3904 Part 3904.(c)(1)(i)}

"State clearly a worksite policy on safe and healthful work and working conditions, so that all personnel with responsibility at the site and personnel at other locations with responsibility for the site understand the priority of safety and health protection in relation to other organizational values."

\section{FACILITY REQUIREMENT SOURCE: ANSI-Z244.1-1982 Section 3.1.1}

"Policy.

The lockout/tagout policy shall require all personnel to comply with the lockout/tagout procedure."

\section{FACILITY REQUIREMENT SOURCE: DOE/EH0135 IH.2.3}

**3. Industrial hygiene policy statements are consistent with the requirements of DOE 5480.10."

\section{FACILITY REQUIREMENT SOURCE: DOE/EH0135 OS.2.3}

"*3. Occupational safety policy statements are consistent with the requirements of applicable DOE Orders."

\section{FACILITY REQUIREMENT SOURCE: DOE/EH0135 PP.2.2}

*2. Written occupational safety and industrial hygiene policies are readily available to all organization elements, periodically reviewed, and kept current."

\section{FACILITY REQUIREMENT SOURCE: DOE/EH0135 PP.2.3}

"3. Personnel protection policy statements are consistent with the requirements of applicable DOE Orders. " 


\section{REQUIREMENTS IDENTIFICATION DOCUMENT HIGH LEVEL WASTE STORAGE TANK FARMS Occupational Safety and Health}

\section{Occupational Safety and Health Goals and Objectives}

This sub-element defines the requirements for establishing Health and Safety Program goals and objectives which support a systematic, long-term approach to performance improvement. These goals and objectives shall also be used as a tool for measuring the effectiveness of the Health and Safety Program. The program goals and objectives shall reflect management's expectations concerning health and safety. The program goals and objectives shall be adequately communicated to all employees and visitors.

Specific health and safety goals and objectives shall be developed based on comparisons with other DOE and commercial facilities. Such goals and objectives shall be auditable, measurable, realistic, and challenging. The purpose of establishing these goals and objectives is to improve and monitor health and safety performance, achieve complete identification of health and safety hazards in the workplace, and limit the consequences associated with a particular hazard to as low as reasonably achievable. Additionally, performance indicators shall be developed and routine reporting initiated to provide a mechanism for measuring workplace performance against the desired goals and objectives.

Meeting the goals and objectives developed in accordance with this sub-element will require proper implementation of the programmatic controls dictated by the other elements and sub-elements contained in this document. For example, a goal may be to reduce electrical shock accidents while performing maintenance. This goal may be partly accomplished through the development and implementation of a more thorough electrical safety training course. This training program would be developed and implemented in accordance with the Training sub-element detailed in this document.

\section{FACILITY REQUIREMENT SOURCE：29CFR1910 Part 120(b)(3)(ii)}

"The comprehensive workplan shall define work tasks and objectives and identify the methods for accomplishing those tasks and objectives."

\section{FACILITY REQUIREMENT SOURCE: 54FR3904 Part (c)(1)(ii)}

"Establish and communicate a clear goal for the safety and health program and objectives for meeting that goal, so that all members of the organization understand the results desired and the measures planned for achieving them. "

\section{FACILITY REQUIREMENT SOURCE: DOE/EH0135 IH.1.8}

"8. Management establishes specific goals and objectives for reducing the frequency and severity of potential exposures to occupational health hazards."

\section{FACILITY REQUIREMENT SOURCE: DOE/EH0135 OS.1.1}

\footnotetext{
"*1. Line management assures the implementation of the occupational safety
} 
WHC-EP-0750

\section{REQUIREMENTS IDENTIFICATION DOCUMENT HIGH LEVEL WASTE STORAGE TANK FARMS Occupational Safety and Health}

programs that effectively maintain workplaces free of safety concerns."

\section{FACILITY REQUIREMENT SOURCE: DOE/EH0135 OS.3.7}

"7. Housekeeping practices and programs reflect a commitment to minimize occupational safety concerns."

\section{Management Commitment and Resources}

This sub-element addresses the need to establish management commitment and provide the resources necessary to fully implement an effective Health and Safety Program. The necessary controls shall be developed to ensure that sufficient staffing, equipment, and facilities are provided to meet the program policy, goals and objectives. These controls shall define the methodology used to determine present and future staffing, equipment, and facility requirements (including budget requests and funding levels). The development and implementation of a process which accurately evaluates current resource levels with respect to desired health and safety performance levels is imperative to this sub-element.

\section{FACILITY REQUIREMENT SOURCE: 54FR3904 Part (c)(1)(iii)}

"Provide visible top management involvement in implementing the program, so that all will understand that management's commitment is serious."

\section{FACILITY REQUIREMENT SOURCE: 54FR3904 Part (c)(1)(vi)}

"(c)(1)(vi) Provide adequate authority and resources to responsible parties, so that assigned responsibilities can be met."

\section{FACILITY REQUIREMENT SOURCE: 54FR3904 Part 3904.(b)(1)}

"Management commitment and employee involvement are complementary. Management commitment provides the motivating force and the resources for organization. In an effective program, management regards worker safety and health as a fundamental value of the organization and applies its commitment to safety and health protection with as much vigor as to other organizational purposes.

Employee involvement provides the means through which workers develop andior express their own commitment to safety and health protection, for themselves and for their fellow workers."

\section{FACILITY REQUIREMENT SOURCE: DOE/EH0135 IH.1.2}

"2. The industrial hygiene staff is organized to assure that the staff has a direct line of communication with top management. Reports and recommendations of the technical staff are not subject to inappropriate non-technical management review and approval." 


\section{REQUIREMENTS IDENTIFICATION DOCUMENT \\ HIGH LEVEL WASTE STORAGE TANK FARMS \\ Occupational Safety and Health}

\section{FACILITY REQUIREMENT SOURCE: DOE/EH0135 IH.1.6}

"6. Resources are allocated and established to meet the operational requirements of the industrial hygiene programs."

\section{FACILITY REQUIREMENT SOURCE: DOE/EH0135 IH.1.7}

"7. Occupational health issues are factors in establishing priorities for spending on capital improvements projects."

\section{FACILIY REQUIREMENT SOURCE: DOE/EH0135 IH.3.10}

"10. Housekeeping practices and programs reflect a commitment to minimize contamination of areas, equipment, and/or personnel. The basic premise is control of the health hazards at the source."

\section{FACILITY REQUIREMENT SOURCE: DOE/EH0135 IH.3.7}

"7. Specialized equipment and technical resources are maintained and operated in a reliable and proper manner."

\section{FACILITY REQUIREMENT SOURCE: DOE/EH0135 OS.1.2}

"2. The occupational safety technical support staff is organized to assure that the staff has a direct line of communication with top management. Reports and recommendations of the technical staff are not subject to inappropriate non-technical management review and approval."

\section{FACILITY REQUIREMENT SOURCE：DOE/EH0135 OS.1.3}

" 3. The staff responsible for the direction and operation of occupational safety programs are professionally qualified and have sufficient time and authority to implement the established program."

\section{FACILITY REQUIREMENT SOURCE: DOE/EH0135 OS.1.7}

"7. Occupational safety issues are factors in establishing priorities for spending on capital improvements projects. "

\section{FACILITY REQUIREMENT SOURCE: DOE/EH0135 OS.3.7}

"7. Housekeeping practices and programs reflect a commitment to minimize occupational safety concerns."

\section{FACILITY REQUIREMENT SOURCE: DOE5480.10 Section 9.d(1)}

"Industrial Hygiene Staff

(1) The staff responsible for the direction and operation of the industrial hygiene program must be professionally qualified, adequate in number, and have sufficient time and authority to design and implement the 


\section{REQUIREMENTS IDENTIFICATION DOCUMENT HIGH LEVEL WASTE STORAGE TANK FARMS Occupational Safety and Health}

industrial hygiene program set forth in this Order."

FACILITY REQUIREMENT SOURCE: DOE5480.10 Section 9.d(2)

"As an alternative to a staff industrial hygienist, consultants qualified in industrial hygiene and knowledgeable of the requirements of this Order may be retained to augment the contractor staff and perform comprehensive or specific industrial hygiene surveys as needed."

\section{Requests for Exemptions/Variances}

This sub-element addresses the programmatic controls necessary to identify and justify exemptions and variances to DOE Orders/Directives or OSHA regulations. The methods used to identify and justify exemptions and variances shall be clearly defined. Preparation of exemptions/variances shall be clearly defined in procedures. Tracking and maintenance of requests for exemptions/variances shall also be clearly defined.

\section{FACILITY REQUIREMENT SOURCE: DOE/EH0135 IH.1.10}

"10. A formal program is established to track the correction of identified deficiencies and deviations from prescribed standards."

FACILITY REQUIREMENT SOURCE: DOE/EH0135 OS.2.9

" 9. A formal program is established to track the correction of identified deficiencies and deviations from prescribed standards."

FACILITY REQUIREMENT SOURCE: DOE5483.1A Chapter I, Section 4.a

"a. Temporary Variances.

(1) A contractor may apply to the appropriate $\mathrm{CO}$ or $\mathrm{CO}$ representative for a temporary variance from the DOE-prescribed OSHA standards. A request for a temporary variance shall contain:

(a) A specification of the standard from which the contractor seeks a variance.

(b) A representation that the contractor is portable to comply with the standard and a detailed statement of the reason: therefor.

(c) A statement of the steps the contractor has taken and will take to protect employees from the hazard covered by the standard, to include the conditions the contractor must maintain and the practices, means, methods, operations, and processes which must be adopted and utilized to the extent they provide protection equivalent to that of the standard for which 


\section{REQUIREMENTS IDENTIFICATION DOCUMENT HIGH LEVEL WASTE STORAGE TANK FARMS Occupational Safety and Health}

the variance is requested.

(d) A certification that the contractor has informed employees of the application by giving a copy thereof to their authorized representative (where applicable), posting a statement, giving a summary of the request, and specifying where a copy may be examined (e.g., at the place or places where notices to employees are normally posted) and by other appropriate means. A description of how employees have been informed shall be contained in the certification. The information to employees also shall inform them that they may comment on the request to the appropriate $\mathrm{CO}$ or $\mathrm{CO}$ representative.

(e) A statement of when the contractor will be able to comply with the standard and what steps have been taken and will be taken by the contractor to come into compliance with the standard.

(2) The CO or $\mathrm{CO}$ representative, the safety and health manager, and other appropriate elements of the field organization shall review the contractor's request and the employees' comments and submit the field organization's recommendation, together with the contractor's request and contractor employee comments, to the Director of Operational Safety (EP-32) within 30 days of receipt of the request. After review and evaluation of the request, comments, and recommendation and after coordination with the appropriate program office(s), EP-32 shall approve a temporary variance if the request establishes that (a) the contractor is unable to comply with the standard because of unavailability of professional or technical personnel materials or equipment funding needed to come into compliance with the standard, or because necessary construction or alteration of facilities must be completed in order to comply; (b) the contractor is taking all available steps to safeguard employees against the hazards covered by the standard; and (c) the contractor has an effective program for coming into compliance with the standard as quickly as practicable.

(3) A temporary variance may be in effect for no longer than the period needed by the contractor to achieve compliance with the standard or 1 year, whichever is shorter, except that in unusual circumstances (e.g., lack of programmatic funding) such a temporary variance may be renewed not more than once. Such a renewal also shall be in effect for no longer than 1 year. An application for renewal must be filed and processed in the manner specified in paragraph $4 a(2)$, above at least 90 days prior to expiration of the temporary variance. Employees also shall be given an opportunity to review and comment on a request for a renewal as outlined on page I-2, paragraph $4 a(1)(d)$.

(4) The Director of Operational Safety shall inform the field organization of the results of the evaluation of the request for a temporary variance or the extension thereof, within 180 days of receipt of the request." 


\title{
REQUIREMENTS IDENTIFICATION DOCUMENT HIGH LEVEL WASTE STORAGE TANK FARMS Occupational Safety and Health
}

\section{FACILITY REQUIREMENT SOURCE: DOE5483.1A Chapter I, Section 4.b}

\author{
"Permanent Variances.
}

(1) DOE contractors may apply to the appropriate $\mathrm{CO}$ or $\mathrm{CO}$ representative for a permanent variance from the prescribed OSHA standards. The request for variance shall contain the same information specified on page I-2, paragraphs $4 a(1)(a)-(d)$. The CO or CO representative, the local safety and health office, and other appropriate elements of the field organization shall review the contractor's request and the employees comments and submit their recommendation together with the contractor's request and contractor employee comments, to the Director of Operational Safety (EP-32) within 30 days of receipt of the request. After review and evaluation of the request, comments, and recommendation, and after coordination with the appropriate program office, EP-32 shall submit a recommendation to the Assistant Secretary, Environmental Protection Safety, and Emergency Preparedness (EP-1), for consideration.

(2) If EP-1 determines that the contractor has demonstrated that the conditions practices, means, methods, operations, or processes to be used will provide employment and a place of employment which is as safe and healthful as those which would prevail if the contractor complied with the standard, a permanent variance shall be approved and the requesting organization shall be notified accordingly, within 180 days of receipt of the request by EP-32.

(3) However, if the permanent variance request is not approved by EP-1, the requesting organization shall be notified of the rationale for the determination, within 180 days of receipt of the request by EP-32."

\section{FACILITY REQUIREMENT SOURCE: WAC-296-24 Section 010}

"Realizing that conditions may exist in operations under which certain state standards will not have practical application, the director of the department of labor and industries or his authorized representative may, pursuant to this section, RCW 49.17.080 and/or 49.17.090 and appropriate administrative rules of this state and the department of labor and industries and upon receipt of application and after adequate investigation by the department, permits variation from these requirements when other means of providing an equivalent measure of protection are afforded. Such variation granted shall be limited to the particular case or cases covered in the application for variance and may be revoked for cause. The permit for variance shall be conspicuously posted on the premises and shall remain posted during the time it is in effect. All requests for variances from safety and health standards included in this or any other chapter o Title 296 WAC, shall be made in writing to the director of the department of labor and industries at Olympia, Washington, or his duly authorized representative, the supervisor of safety, division of industrial safety and health, department of labor and industries, Olympia, Washington. Variance application forms may be obtained from the department upon request." 


\section{REQUIREMENTS IDENTIFICATION DOCUMENT HIGH LEVEL WASTE STORAGE TANK FARMS Occupational Safety and Health}

This element details the programmatic controls necessary to effectively anticipate, identify, and evaluate health and safety hazards. A programmatic approach to hazard identification/assessment, accident/injury investigation, and hazard inventory maintenance is necessary to successfully prevent and/or control health and safety hazards in the workplace.

\section{Hazard Assessment Program}

This sub-element delineates the requirements for establishing a huzard assessment program that ensures anticipation, identification and evaluation of facility health and safety hazards. The types of hazards which shall be assessed include (but are not limited to): chemical, physical, biological, ergonomic, and safety. A programmatic approach to the examination and analysis of facility design, construction, or modification shall be established to ensure that all existing or potential health and safety hazards are identified. This shall also include the necessary controls to ensure a thorough evaluation of operational processes (including materials involved), work practices, and employee working conditions.

The methods used to identify hazards in the workplace shall include comprehensive baseline surveys, periodic baseline update surveys, routine analysis of operational hazards, written hazard communication program, and periodic walk-through surveys.

Potential hazards shall be identified through review of proposed projects, engineering plans and specifications; evaluation of preventative or mitigative design features and associated administrative controls. Methods shall also be implemented to identify and evaluate hazards following configuration changes due to maintenance, modifications, introduction of new chemicals/workpractices, and testing activities.

FACILITY REQUIREMENT SOURCE: 29CFR1910 Part 120(b)(3)(i)

"The comprehensive workplan shall address anticipated clean-up activities as well as normal operating procedures which need not repeat the employer's procedures available elsewhere."

\section{FACILITY REQUIREMENT SOURCE: 29CFR1910 Part 120(b)(3)(iv)}

"The comprehensive workplan shall provide for the implementation of the training required in paragraph (e) of this section."

\section{FACILITY REQUIREMENT SOURCE: 29CFR1910 Part 120(b)(3)(v)}

"The comprehensive workplan shall provide for the implementation of the required informational programs required in paragraph (i) of this section." 
WHC-EP-0750

\section{REQUIREMENTS IDENTIFICATION DOCUMENT \\ HIGH LEVEL WASTE STORAGE TANK FARMS \\ Occupational Safety and Health}

FACILITY REQUIREMENT SOURCE: 29CFR1910 Part 120(b)(4)(i)

"General. The site safety and health plan, which must be kept on site, shall address the safety and health hazards of each phase of site operation and include the requirements and procedures for employee protection."

\section{FACILITY REQUIREMENT SOURCE: 54FR3904 Part (c)(2)(i)}

"So that all hazards are identified: (A) Conduct comprehensive baseline worksite surveys for safety and health and periodic comprehensive update surveys; (B) Analyze planned and new facilities, processes, materials, and equipment; and (C) Perform routine job hazard analyses."

\section{FACILITY REQUIREMENT SOURCE: 54FR3904 Part (c)(2)(ii)}

"Provide for regular site safety and health inspections, so that new or previously missed hazards and failures in hazard controls are identified."

\section{FACILITY REQUIREMENT SOURCE: 54FR3904 Part 3904.(a)(1)}

"Employers are advised and encouraged to institute and maintain in their establishments a program which provides systematic policies, procedures, and practices that are adequate to recognize and protect their employees from occupational safety and health hazards."

\section{FACILITY REQUIREMENT SOURCE: 54FR3904 Part 3904.(a)(2)}

"An effective program includes provisions for the systematic identification, evaluation, and prevention or control of general workplace hazards, specific job hazards, and potential hazards which may arise from foreseeable conditions."

\section{FACILITY REQUIREMENT SOURCE: 54FR3904 Part 3904.(b)(2)}

"Worksite analysis involves a variety of worksite examinations, to identify not only existing hazards but also conditions and operations in which changes might occur to create hazards. Unawareness of a hazard which stems from failure to examine the worksite is a sure sign that safety and health policies and/or practices are ineffective. Effective management actively analyzes the work and worksite, to anticipate and prevent harmful occurrences."

\section{FACILITY REQUIREMENT SOURCE: DOE/EH0135 IH.2.1}

**1. Operating procedures provide direction to ensure that potential hazards are identified for correction, and that industrial hygiene requirements are uniformly implemented."

\section{FACILITY REQUIREMENT SOURCE: DOE/EH0135 OS.3.1}

"*1. There is a documented program for identifying existing and potential 


\section{REQUIREMENTS IDENTIFICATION DOCUMENT HIGH LEVEL WASTE STORAGE TANK FARMS Occupational Safety and Health}

occupational safety concerns through:

- A knowledge and assessment of operations,

- Periodic walk-through surveys by technical and management personnel, and

- Reviews of proposed activities and modifications to existing operations."

\section{FACILITY REQUIREMENT GOURCE: DOE/EH0135 OS.3.2}

"*2. There is a systematic program for evaluating safety concerns once they have been identified, which includes:

- Potential safety concerns are evaluated to assure they are adequately controlled and that standards are met,

- Guidelines are developed for potential safety concerns if no standard exists, and

- Written evaluations giving the conclusions on the adequacy of controls and workplace monitoring data are sent to first level supervisors.

\section{FACILITY REQUIREMENT SOURCE: DOE/EH0135 PP.1.1}

"*1. Line management assures the implementation of the personnel protection programs that effectively maintain workplaces free of health and safety concerns."

\section{FACILITY REQUIREMENT SOURCE: DOE/EH0135 PP.3.1}

"*1. There is a documented program for identifying existing and potential occupational safety and health concerns through:

- A knowledge and assessment of operations;

- Periodic walk-through surveys by technical and management personnel;

- Reviews of proposed activities and modifications to existing operations, including reviews of new or modified processes and chemicals;

- Review of purchase orders; and

- The maintenance of inventories and/or tracking systems." 


\title{
REQUIREMENTS IDENTIFICATION DOCUMENT HIGH LEVEL WASTE STORAGE TANK FARMS Occupational Safety and Health
}

\author{
FACILITY REQUIREMENT SOURCE: DOE5480.10 Section 9.a(3)
}

"Purchasing and Contracting Organizations should be required to: (a) participate as requested by the industrial hygiene staff to assure that potentially hazardous material or equipment being procured are adequately identified, evaluated, and controlled; and (b) require contractors or subcontractors performing potentially hazardous operations within a DOE or DOE-controlled facility to comply with the mandatory industrial hygiene standards of DOE 5480.4 and make provisions to allow the industrial hygiene staff to monitor compliance."

\section{FACILITY REQUIREMENT SOURCE: DOE5480.10 Section 9.b(1)}

"Functions. The industrial hygiene program shall be designed to preserve employee health and well-being. This shall be accomplished by identification, evaluation, and control of environmental factors and stresses found in the workplace. These environmental factors and stresses include: chemical (e.g., liquid, particulate, vapor, and gas); physical (e.g., electromagnetic radiation, noise, vibration, and magnetic fields); biological (e.g., agents of infectious diseases); and ergonomic (e.g., body position in relation to task, repetitive motion, and mental or physical fatigue). The contractor industrial hygiene program must have the following features:

(1) Identification of Health Hazards. The industrial hygiene staff shall identify and document existing and potential occupational health hazards through: knowledge and assessment of the operations; periodic walk-through surveys; information provided by interorganizational communication; the review of proposed projects, facilities, engineering plan, and specifications; and maintenance of a hazards inventory or tracking system."

\section{FACILITY REQUIREMENT SOURCE: DOE5480.10 Section 9.b(2)}

"Hazard Evaluation. Once potential health hazards are identified, the industrial hygiene staff must determine the extent of the hazard through appropriate consultation with other professionals, sound judgment, and the application of established standards or guides and such evaluation techniques as air sampling and bioassay. A report shall be sent to the first level supervisor with the industrial hygiene staff's evaluation of whether occupational exposures are within permissible limits, together with supporting evidence. The permissible exposure limits used in hazard evaluation shall not exceed those in the mandatory industrial hygiene standards of DOE 5480.4, Attachment 2, paragraph 2.d.(3). When a potential health hazard is identified that has no assigned permissible exposure limit, a guideline on evaluation and control should be developed based on the best available information (refer to paragraph 10.a.(1))."

\section{Hazard Reporting System}

This sub-element addresses the requirements for establishing a system for employees to report workplace hazards. Employee insight and experience shall be utilized to quickly identify hazards in the workplace. Employees shall be 


\section{REQUIREMENTS IDENTIFICATION DOCUMENT HIGH LEVEL WASTE STORAGE TANK FARMS \\ Occupational Safety and Health}

encouraged to identify potential hazards and report them, without fear of reprisals. Management shall address employee health and safety concerns and reports in a timely and responsible manner.

Programmatic controls which establish a system for employees to report hazards shall, as a minimum, specify the methods used in the reporting process and the methods used to ensure the confidentiality of the employee. The documentation and actions required following receipt of an employee report of a potential hazard shall be formally defined, including time response requirements.

\section{FACILITY REQUIREMENT SOURCE: 54FR3904 Part (c)(1)(iv)}

"Provide for and encourage employee involvement in the structure and operation of the program and in decisions that affect their safety and health, so that they will commit their insight and energy to achieving the safety and health program's goal and objectives."

\section{FACILITY REQUIREMENT SOURCE: 54FR3904 Part 3904.(b)(1)}

\footnotetext{
"Management commitment and employee involvement are complementary. Management commitment provides the motivating force and the resources for organization. In an effective program, management regards worker safety and health as a fundamental value of the organization and applies its commitment to safety and health protection with as much vigor as to other organizational purposes. Employee involvement provides the means through which workers develop and/or express their own commitment to safety and health protection, for themselves and for their fellow workers."
}

\section{FACILITY REQUIREMENT SOURCE: DOE/EH0135 IH.4.7}

7. There is a system for employees to report potential occupational health concerns that assures prompt assessment and necessary controls."

\section{FACILITY REQUIREMENT SOURCE: DOE/EH0135 OS.4.8}

"8. There is a system for employees to report potential occupational safety concerns that assures prompt assessment and necessary controls."

\section{FACILITY REQUIREMENT SOURCE: DOE/EH0135 PP.1.5}

"5. Necessary information is readily communicated to top management, to all segments of the organization concerned, and to the public and regulatory agencies, as appropriate."

\section{FACILITY REQUIREMENT SOURCE: DOE/EH0135 PP.4.8}

"8. There is a system for employees to report potential occupational safety concerns that assures prompt assessment and necessary controls." 


\title{
REQUIREMENTS IDENTIFICATION DOCUMENT HIGH LEVEL WASTE STORAGE TANK FARMS Occupational Safety and Health
}

\author{
FACILITY REQUIREMENT SOURCE: DOE5480.10 Section 9.a(5)
}

"Employees should be required to: (a) observe all safety and health rules; (b) use all prescribed personal protective equipment; (c) follow established health and safety practices and procedures; and (d) notify supervisors immediately of suspected exposures to harmful agents or conditions. "

\section{FACILITY REQUIREMENT SOURCE: DOE5483.1A Chapter II, 1}

"a. Initially, contractor employees or representatives thereof should attempt resolution of their complaints by submitting to their contractor management, either directly or through their authorized employee representative, reports of any conditions or practices which they consider hazardous to their safety or health, or which they believe are in violation of the DOE-prescribed OSHA standards.

b. Contractor employees or their representatives may submit complaints directly to the DOE field organization safety and health manager or the CO or CO representative, particularly in situations where the complainant wishes to remain anonymous (to the contractor), or where the complainant believes that unsafe/unhealthful conditions still exist or violations of standards still remain after being brought to the attention of and addressed by contractor management.

c. Complaints may be submitted to either contractor management or to the DOE by completing DOE F 5480.4 (Attachment II-1), by sending a letter or telegram, or by cral means. Oral complaints shall be recorded on DOE F 5480.4 by DOE and/or the contractor. Irrespective of the means of submission, the complaint should set forth with reasonable particularity the pertinent facts and circumstances involved. In all situations where the complaint is submitted to DOE and anonymity is requested by the complainant, the DOE shall not divulge the complainant's identity to contractor personnel or to any other persons not essential to the processing and investigation of the complaint."

\section{FACILITY REQUIREMENT SOURCE: DOE5483.1A Chapter II, Section 5}

"5. COMPLAINT RESOLUTION. Contractor employees or representatives thereof who are not satisfied with the adequacy or effectiveness of the field organization's investigation of or response to their complaint allegations may submit a written request for complaint resolution to the Director of Operational Safety (EP-32). The request must include the pertinent facts and particulars, and the basis for the request (e.g., inadequate action taken on violation of a standard, or no employee or representative allowed to participate in inspection), along with a copy of the original complaint and the field organization's response thereto. EP-32 shall conduct an investigation of the situation, in coordination with the appropriate program office(s). Within 30 days of receipt of the request, EP-32 shall provide a written response to the employee or representative thereof, and to the field organization. The response shall indicate the actions taken or planned as a result of the request for complaint resolution." 


\section{REQUIREMENTS IDENTIFICATION DOCUMENT HIGH LEVEL WASTE STORAGE TANK FARMS Occupational Safety and Health}

FACILITY REQUIREMENT SOURCE: DOE5483.1A Chapter III, 1

\section{"1. NONDISCRIMINATION.}

a. No contractor shall discharge or in any manner demote, reduce in pay, coerce, restrain, threaten, or take any other negative actions against any contractor employee as a result of the employee's filing of a complaint, or in any other fashion, exercising on behalf of himself or herself or others any right set forth in this Order.

b. Any employee who believes he or she has been discharged or in any other manner discriminated against, in violation of this Order, may file a complaint with the cognizant $\mathrm{CO}$ or $\mathrm{CO}$ representative within 30 days after the alleged discrimination, setting forth the nature of the alleged discrimination. The $\mathrm{CO}$ or $\mathrm{CO}$ representative, the safety and health director, and other appropriate elements of the field organization shall investigate the complaint, and if it is found that such discrimination has occurred, the field organization shall assure that appropriate measures are taken by the contractor, including rehiring or reinstatement of the employee, restoration of lost seniority, and back pay. The field organization shall report the disposition of the matter to the contractor employee filing the complaint of alleged discrimination within 30 days after receipt of the complaint."

\section{Investigation of Occurrences, Accidents, and Near Misses}

This sub-element addresses the requirements for establishing a program for investigation of occurrences, accidents, and near misses for identification of potential health and safety concerns. Programmatic controls shall he estahlished to ensure that a comprehensive root cause analysis is performed and that appropriate corrective actions are identified following events such as an occurrence, accident, or near miss. Such controls are essential if health and safety hazards are to be effectively identified and corrected following significant events.

The Occurrence/Event Reporting section of the Management Systems Functional Area describes the requirements and controls necessary for an effective Occurrence/Event Reporting program. The Health and Safety organization should participate in the investigation and evaluation of events which are addressed by that functional area.

\section{FACILITY REQUIREMENT SOURCE: 54FR3904 Part (c)(2)(iv)}

"Provide for investigation of accidents and "near miss" incidents, so that their causes and means for their prevention are identified."

\section{FACILITY REQUIREMENT SOURCE: DOE/EH0135 IH.4.2}

"*2. Investigations are conducted for incidents and events that resulted or could have resulted in occupational illness, or death to identify probable causes and judgment of needs to prevent recurrence of similar accidents, in compliance with DOE 5484." 
WHC-EP-0750

\section{REQUIREMENTS IDENTIFICATION DOCUMENT HIGH LEVEL WASTE STORAGE TANK FARMS Occupational Safety and Health}

\section{FACILITY REQUIREMENT SOURCE: DOE/EH0135 OS.4.2}

"2. Accident investigations are conducted for incidents and events that resulted or could have resulted in occupational injuries or death, to identify probable causes and judgement of needs to prevent recurrence of similar accider.ts."

\section{FACILITY REQUIREMENT SOURCE: DOE/EH0135 PP.4.2}

**2. Accident investigations are conducted for incidents and events that resulted or could have resulted in occupational injuries, illness, or death to identify probable causes and judgement of needs to prevent recurrence of similar accidents."

\section{FACILITY REQUIREMENT SOURCE: DOE5483.1A Chapter III, 4}

"4. ACCIDENT INVESTIGATIONS. Accident investigations shall be conducted in accordance with DOE 5484.1, ENVIRONMENTAL PROTECTION, SAFETY, AND HEALTH PROTECTION INFORMATION REPORTING REQUIREMENTS, of 2-24-81."

\section{Injury and Illness Trend Analysis}

This sub-element delineates the requirements for establishing a trend analysis program to document and track injuries and illnesses for possible hazard identification/correlation. Evaluation of recurring occupational injuries and illnesses is essential in identifying workplace health and safety hazards. Programmatic controls shall be instituted that define methods for collection and analysis of occupational injury and illness data. The Occupational Medical Program shall be a key participant in the accurate identification, evaluation, and collection of occupational injury and illness data.

\section{FACILITY REQUIREMENT SOURCE: 54FR3904 Part (c)(2)(v)}

"Analyze injury and illness trends over time, so that patterns with common causes can be identified and prevented."

\section{FACILITY REQUIREMENT SOURCE: DOE/EH0135 IH.4.6}

"6. Analyses of industrial hygiene monitoring data are performed to evaluate performance and identify trends and potential problem areas to be brought to management attention."

\section{FACILITY REQUIREMENT SOURCE: DOE/EH0135 OS.4.7}

"7. Analyses of accident and injury data are performed to evaluate performance and identify trends and potential problem areas to be brought to management attention." 


\section{REQUIREMENTS IDENTIFICATION DOCUMENT HIGH LEVEL WASTE STORAGE TANK FARMS Occupational Safety and Health}

\section{FACILITY REQUIREMENT SOURCE: DOE/EH0135 PP.4.7}

" 7. Analyses of accident, injury, and industrial hygiene monitoring data are performed to evaluate performance and identify trends and potential problem areas to be brought to management attention."

\section{FACILITY REQUIREMENT SOURCE: WAC-296-24 Section 020(2)}

"After the emergency actions following accidents that cause serious injuries that have immediate symptoms, a preliminary investigation of the cause of the accident shall be conducted. The investigation shall be conducted by a person designated by the employer, the immediate supervisor of the injured employee, witnesses, employee representative, and any other person with the special expertise required to evaluate the facts relating to the cause of the accident. The findings of the investigation shall be documented by the employer for reference at any following formal investigation. If the employee representative is the business agent of the employee bargaining unit that is unavailable to participate without delaying the investigation group, the employer may proceed, and satisfy the requirements of subsection (2) of this section by using one of the following alternatives: "

\section{Occupational Safety and Health Inventory System}

This sub-element delineates the requirements for establishing a health and safety hazard inventory system. The hazards identified via the methods described in the previous sub-elements (17.2.1 through 17.2.4) shall be input to a hazard inventory system.

Continuous maintenance of the hazard inventory system is necessary to ensure that identified hazards are eliminated/mitigated, properly documented and tracked to prevent undue hazard exposure or consequence. The system shall maintain a correlation of potential hazards hy location, associated processes, and job classifications/categories. The controls necessary to manage a comprehensive hazard inventory system, including update or revision, shall be established.

Proper implementation and use of a hazard inventory system shall provide the basis for selection of controls to limit hazard exposure, determination of medical surveillance requirements, location of monitoring/sampling equipment, or the determination of employee training requirements.

\section{FACILITY REQUIREMENT SOURCE: 29CFR1910 Part 120(c)(2)}

"Preliminary evaluation. A preliminary evaluation of a site's characteristics shall be performed prior to site entry by a qualified person in order to aid in the selection of appropriate employee protection methods prior to site entry. Immediately after initial site entry, a more detailed evaluation of the site's specific characteristics shall be performed by a qualified person in order to further identify existing site hazards and to further aid in the selection of the appropriate engineering controls and personal protective equipment for the tasks to be performed." 
WHC-EP-0750

\section{REQUIREMENTS IDENTIFICATION DOCUMENT HIGH LEVEL WASTE STORAGE TANK FARMS Occupational Safety and Health}

\section{FACILITY REQUIREMENT SOURCE: 29CFR1910 Part 120(c)(3)}

"Site Characterization. Hazard identification. All suspected conditions that may pose inhalation or skin absorption hazards that are immediately dangerous to life or health (IDLH), or other conditions that may cause death or serious harm, shall be identified during the preliminary survey and evaluated during the detailed survey. Examples of such hazards include, but are not limited to, confined space entry, potentially explosive or flammable situations, visible vapor clouds, or areas where biological indicators such as dead animals or vegetation are located."

\section{FACILITY REQUIREMENT SOURCE: 29CFR1910 Par. 120(c)(4)}

"Required information. The following information to the extent available shall be obtained by the employer prior to allowing employees to enter a site:

(i) Location and approximate size of the site.

(ii) Description of the response activity and/or the job task to be performed.

(iii) Durat' on of the planned employee activity.

(iv) Site opography and accessibility by air and roads.

(v) Safety and health hazards expected at the site.

(vi) Pathways for hazardous substance dispersion.

(vii) Present status and capabilities of emergency response teams that would provide assistance to hazardous waste clean-up site employees at the time of an emergency.

(viii) Hazardous substances and health hazards involved or expected at the site, and their chemical and physical properties."

\section{FACILITY REQUIREMENT SOURCE: ANSI-Z244.1-1982 Section 4.1}

"An initial survey shall be made to identify all energy sources and related exposures to determine if machines, equipment and systems can be isolated."

\section{FACILITY REQUIREMENT SOURCE: DOE/EH0135 PP.2.9}

" 9. A formal program is established to track the correction of identified deficiencies and deviations from prescribed standards."

\section{FACILITY REQUIREMENT SOURCE: DOE5480.10 Section 9.f(1)}

"Recordkeeping Requirements

(1) An inventory of occupational health hazards shall be maintained. The inventory should be a listing of potential chemical, physical, and biological health hazards by location and/or job category of users and indicate when the hazards were present."

\section{FACILITY REQUIREMENT SOURCE: DOE5480.10 Section 9.f(5)}

"Industrial hygiene hazard inventories, reports, and monitoring data shall be readily accessible to the medical organization responsible for operating the medical monitoring program. Records access shall be provided to employees or designated representatives of employees in accordance with OSHA Regulation 29 CFR 1910.20 and DOE Privacy Act Regulation 10 CFR 1008.17(b)(5)." 
WHC-EP-0750

\section{REQUIREMENTS IDENTIFICATION DOCUMENT \\ HIGH LEVEL WASTE STORAGE TANK FARMS \\ Occupational Safety and Health}

OS\&H HAZARD PREVENTION AND CONTROL

This element contains sub-elements which define the programmatic controls necessary to implement appropriate health and safety prevention and control measures. Proper application of the following sub-elements is necessary to prevent or control identified and evaluated hazards.

FACILITY REQUIREMENT SOURCE: 29CFR1910 Part 120(b)(4)(ii)(A)

"Elements. The site safety and health plan, as a minimum, shall address the following: A safety and health risk or hazard analysis for each site task and operation found in the workplan."

\section{FACILTY REQUIREMENT SOURCE: DOE/EH0135 IH.5.11}

"11. Exposures to heat stress conditions conforms to the guidelines of the American Conference of Governmental Industrial Hygienists."

\section{FACILITY REQUIREMENT SOURCE: DOE/EH0135 IH.5.2}

*2. Hazardous noise is controlled in accordance with ACGIH TLVs and the hearing conservation program complies with 29 CFR 1910.95."

\section{FACILITY REQUIREMENT SOURCE: DOE/EH0135 IH.5.3}

"*3. Exposure to chemicals listed as carcinogens by the ACGIH or OSHA are maintained ALARA by applying controls required by standards in 29 CFR 1910 Subpart Z or criteria in DOE 5480.10."

\section{FACILITY REQUIREMENT SOURCE: DOE/EH0135 IH.5.5}

"*5. Procedures used for working in confined spaces comply with 29 CFR 1910-146, June 5, 1989."

\section{FACILITY REQUIREMENT SOURCE: DOE/EH0135 IH.5.6}

"*6. Hazardous waste handling operations and hazardous material emergency response operations comply with 29 CFR 1910.120."

\section{FACILITY REQUIREMENT SOURCE: DOE/EH0135 IH.5.9}

"*9. A documented respiratory protection program, complying with ANSI Z88.21980 , has been implemented to ensure optimum protection against internal exposure of workers to toxic materials, including radioactive substances."

\section{FACILITY REQUIREMENT SOURCE: DOE/EH0135 IH.6.1}

"*1. All hazardous chemicals are appropriately labeled." 
WHC-EP-0750

\section{REQUIREMENTS IDENTIFICATION DOCUMENT HIGH LEVEL WASTE STORAGE TANK FARMS Occupational Safety and Health}

\section{FACILITY REQUIREMENT SOURCE: DOE/EH0135 IH.6.2}

"*2. Material safety data sheets for all hazardous chemicals are readily available. Distribution is appropriate for those who need the information."

\section{FACILITY REQUIREMENT SOURCE: DOE/EH0135 IH.6.8}

"8. Procedural reminders are posted locally (e.g., "Hearing Protection Required")."

\section{FACILITY REQUIREMENT SOURCE: DOE/EH0135 OS.2.1}

"*1. Operating procedures provide direction to ensure that potential safety concerns are identified for correction, and that safety requirements are uniformly implemented."

\section{FACILITY REQUIREMENT SOURCE: DOE/EH0135 OS.2.5}

" 5. Work permits identify potentially hazardous maintenance, construction, experiments, and other non-routine activities and assure the appropriate application of safety expertise to planning and review of the work."

\section{FACILITY REQUIREMENT SOURCE: DOE/EH0135 WS.3.6}

"6. Hazardous waste handling operations and hazardous material emergency response operations comply with 29 CFR 1910.120."

\section{FACILITY REQUIREMENT SOURCE: DOE/EH0135 WS.3.8}

"*8. Chemical handling operations comply with applicable OSHA standards 29 CFR 1910.1000 through 1910.1048."

\section{FACILITY REQUIREMENT SOURCE: DOE/EH0135 WS.4.11}

"11. There are safety rules and requirements for the use of motorized equipment and motor vehicles. Personnel understand and comply with the rules."

\section{FACILITY REQUIREMENT SOURCE: DOE/EH0135 WS.4.13}

"13. Welding, cutting, and brazing operations are conducted in accordance with 29 CFR 1910 Subpart Q."

\section{FACILITY REQUIREMENT SOURCE: DOE/EH0135 WS.4.15}

"15. Telecommunications, and laundry machinery and operations meet the requirements of 29CFR1910 Subpart R." 
WHC-EP-0750

\section{REQUIREMENTS IDENTIFICATION DOCUMENT HIGH LEVEL WASTE STORAGE TANK FARMS \\ Occupational Safety and Health}

\section{FACILITY REQUIREMENT SOURCE: DOE/EH0135 WS.4.3}

"*3. Ladders, guard rails, and fall protection equipment are well-maintained and meet standards prescribed in 29 CFR 1910, Subpart D."

\section{FACILITY REQUIREMENT SOURCE: DOE/EH0135 WS.4.5}

"*5. Exits are properly marked, adequately lighted, and all means of egress are continuous and unobstructed to a way of exit from any point in a building in accordance with 29 CFR 1910, Subpart E."

\section{FACILITY REQUIREMENT SOURCE: DOE/EH0135 WS.5.1}

"*1. There are appropriate danger, warning, and safety information signs throughout the site in accordance with 29 CFR 1926, Subpart G."

\section{FACILITY REQUIREMENT SOURCE: DOE/EH0135 WS.5.10}

"10. There are safety rules and requirements for the use of motorized equipment and motor vehicles. Personnel understand and comply with the rules."

\section{FACILITY REQUIREMENT SOURCE: DOE/EH0135 WS.5.11}

"*11. Chemical, physical, and biological stresses to construction workers are adequately controlled in accordance with 29 CFR 1926, Subpart D."

\section{FACILITY REQUIREMENT SOURCE: DOE/EH0135 WS.5.13}

"*13. Chemical handling operations comply with applicable OSHA standards 29 CFR 1926.55, 1926.57, and 1926.58."

\section{FACILITY REQUIREMENT SOURCE: DOE/EH0135 WS.5.3}

**3. Ladders, guard rails, and fall protection equipment are well-maintained and meet standards prescribed in 29 CFR 1926, Subparts E, L, and M."

\section{FACILITY REQUIREMENT SOURCE: DOE/EH0135 WS.5.4}

"*4. Guarding is available and in place, as specified in 29 CFR 1926, Subpart I, for machines and tools with moving and rotating parts that may present workplace safety concerns."

\section{FACILITY REQUIREMENT SOURCE: DOE/EH0135 WS.5.9}

" 9. Personnel are aware of and follow procedures for lockout and tagout to prevent accidental contact with energized electrical circuits and other hazardous energy sources, in accordance with 29 CFR 1926, Subpart K." 
WHC-EP-0750

\section{REQUIREMENTS IDENTIFICATION DOCUMENT \\ HIGH LEVEL WASTE STORAGE TANK FARMS \\ Occupational Safety and Health}

\section{FACILITY REQUIREMENT SOURCE: DOE/EH0135 WS.6.1}

"*1. Hazardous chemicals are appropriately labeled."

FACILITY REQUIREMENT SOURCE: DOE/EH0135 WS.6.2

"*2. Material safety data sheets for hazardous chemicals are readily available. Distribution is appropriate for those who need the information, and in accordance with 29 CFR 1910.1200, and 29 CFR 1926.5".

\section{FACILITY REQUIREMENT SOURCE: DOE/EH0135 WS.6.7}

"7. Procedural reminders are posted locally (e.g., "Fire Door-Keep Closed At All Times")."

Facility, Hazard Monitoring, Sampling, and Surveillance

This sub-element addresses the requirements for establishing programmatic controls that ensure adequate monitoring and sampling of identified health hazards is performed. Monitoring and sampling of identified health hazards shall be performed where the potential exists for employee exposure. The results of an effective monitoring and sampling program facilitates the selection of proper engineering controls, administrative controls, and/or personal protective equipment.

\section{FACILITY REQUIREMENT SOURCE: 29CFR1910 Part 120(b)(4)(ii)(E)}

"The site safety and health plan, as a minimum shall address the following: Frequency and types of air monitoring, personnel monitoring, and environmental sampling techniques and instrumentation to be used, including methods of maintenance and calibration of monitoring and sampling equipment to be used."

\section{FACILITY REQUIREMENT SOURCE: 29CFR1910 Part 120(c)(1)}

"Site characterization and analysis. General. Hazardous waste sites shall be evaluated in accordance with this paragraph to identify specific site hazards and to determine the appropriate safety and health control procedures needed to protect employees from the identified hazards. "

\section{FACILITY REQUIREMENT SOURCE: 29CFR1910 Part 120(c)(6)}

"Monitoring. The following monitoring shall be conducted during initial site entry when the site evaluation produces information that shows the potential for ionizing radiation or IDLH conditions, or when the site information is not sufficient reasonably to eliminate these possible conditions;

(i) Monitoring with direct reading instruments for hazardous levels of ionizing radiation.

(ii) Monitoring the air with appropriate direct reading test equipment (i.e., combustible gas meters, detector tubes) for IDLH and other conditions that may cause death or serious harm (combustible or explosive atmospheres, oxygen deficiency, toxic substances).

(iii) Visually observing for signs of actual or potential IDLH or other dangerous conditions. 


\section{REQUIREMENTS IDENTIFICATION DOCUMENT HIGH LEVEL WASTE STORAGE TANK FARMS Occupational Safety and Health}

(iv) An ongoing air monitoring program in accordance with paragraph (h) of this section shall be implemented after site characterization has determined the site is safe for the startup of operations."

\section{FACILITY REQUIREMENT SOURCE: 29CFR1910 Part 120(h)(1)(i)}

"Monitoring.

General. Monitoring shall be performed in accordance with this paragraph where there may be a question of employee exposure to hazardous concentrations of hazardous substances in order to assure proper selection of engineering controls, work practices and personal protective equipment so that employees are not exposed to levels which exceed permissible exposure limits, or published exposure levels if there are no permissible exposure limits, for hazardous substances."

\section{FACILITY REQUIREMENT SOURCE: 29CFR1910 Part 120(h)(2)}

"Initial entry. Upon initial entry, representative air monitoring shall be conducted to identify any IDLH condition, exposure over permissible exposure limits or published exposure levels, exposure over a radioactive material's dose limits or other dangerous condition such as the presence of flammable atmospheres or oxygen-deficient environments. "

\section{FACILITY REQUIREMENT SOURCE: 29CFR1910 Part 120(h)(4)}

"Monitoring of high-risk employees. After the actual clean-up phase of any hazardous waste operation commences; for example, when soil, surface water or containers are moved or disturbed; the employer shall monitor those employees likely to have the highest exposures to hazardous substances and health hazards likely to be present above permissible exposure limits or published exposure levels by using personal sampling frequently enough to characterize employee exposures. If the employees likely to have the highest exposure are over permissible exposure limits or published exposure limits, then monitoring shall continue to determine all employees likely to be above those limits. The employer may utilize a representative sampling approach by documenting that the employees and chemicals chosen for monitoring are based on the criteria stated above.

Note to $(h)$ : It is not required to monitor employees engaged in site characterization operations covered by paragraph (c) of this section."

\section{FACILITY REQUIREMENT SOURCE: DOE/EH0135 PP.3.5}

"5. Monitoring data are regularly obtained for potential health and safety concerns and the information is utilized in determining the effectiveness of control measures."

\section{FACILITY REQUIREMENT SOURCE: DOE/EH0135 PP.4.4}

"*4. There is a documented program for periodic monitoring of chemical, physical, and biological stresses to ensure maintenance of satisfactory conditions. Surveillance monitoring ensures that potential personnel exposures are accurately determined and recorded. Monitoring results which evaluate the continuing adequacy of controls are sent to line management and employees on a routine basis. 


\section{REQUIREMENTS IDENTIFICATION DOCUMENT HIGH LEVEL WASTE STORAGE TANK FARMS Occupational Safety and Health}

\section{FACILITY REQUIREMENT SOURCE: DOE/EH0135 WS.2.1}

"*1. There is health and safety surveillance of all construction activities."

\section{FACILITY REQUIREMENT SOURCE: DOE5480.10 Section 9.b(2)}

"Hazard Evaluation. Once potential health hazards are identified, the industrial hygiene staff m'st determine the extent of the hazard through appropriate consultation with other professionals, sound judgment, and the application of established standards or guides and such evaluation techniques as air sampling and bioassay. A report shall be sent to the first level supervisor with the industrial hygiene staff's evaluation of whether occupational exposures are within permissible limits, together with supporting evidence. The permissible exposure limits used in hazard evaluation shall not exceed those in the mandatory industrial hygiene standards of DOE 5480.4, Attachment 2, paragraph 2.d.(3). When a potential health hazard is identified that has no assigned permissible exposure limit, a guideline on evaluation and control should be developed based on the best available information (refer to paragraph 10.a.(1))."

\section{FACILITY REQUIREMENT SOURCE: DOE5480.10 Section 9.b(4)}

"Periodic Review. The satisfactory control of occupational health hazards shall be given continuing attention despite the imposition of control measures. Periodic monitoring is essential to assure maintenance of satisfactory conditions. The industrial hygiene staff shall determine the type and frequency of periodic monitoring. The industrial hygiene staff shall report to line management regarding the continuing adequacy of controls, the need for additional controls, or recommendations for maintenance or reemphasis of administrative controls. Employees of DOE contractor organizations shall be provided the results of the monitoring program for toxic materials or harmful physical agents, upon request. "

\section{FACILITY REQUIREMENT SOURCE: DOE5483.1A Chapter I, Section 5.d}

"All contractor employees shall be informed that the contractor is required to monitor the employee's workplace for radiation exposure and known toxic materials or harmful physical agents which are used or produced at the GOCO facility, and to maintain records of the data as required by Title 29 CFR Part 1910.20, "Access to Employee Exposure and Medical Records." Employees or their authorized representatives are to be provided with an opportunity to observe monitoring or measuring for toxic materials and harmful physical agents and to have access to the results thereof. Each employee or former employee or representative thereof, within 15 days of a written request, shall be provided access to or copies of any records of cumulative recorded occupational radiation dose or any monitoring or bioassay records relevant to potential exposure to toxic materials or harmful physical agents during employment. Employees will be notified of any information indicating that a radiation dose or an exposure to toxic materials or harmful physical agents may have exceedeil the limits specified by the DOE-prescribed OSHA standards." 


\title{
REQUIREMENTS IDENTIFICATION DOCUMENT HIGH LEVEL WASTE STORAGE TANK FARMS Occupational Safety and Health
}

\author{
Engineering Controls
}

This sub-element addresses the requirements for developing and implementing engineering controls for prevention and/or control of identified hazards. Engineering controls shall be applied where there is a potential for employee exposure and shall be the preferred method of hazard prevention and control. In the event that engineering controls are infeasible or too costly then administrative controls and/or personal protective equipment shall be used for hazard prevention and control. Additionally, some situations warrant that all, or a combination of, the above listed controls may be necessary to satisfactory control the hazard.

Specifically, the methods for selecting and evaluating the effectiveness of designed engineering controls shall be defined. Proper documentation shall be maintained of the selection, use, and evaluation of engineering controls for new projects, facilities, and processes.

The selection, design, and use of engineering controls shall be accomplished in accordance with Engineering Design Program procedures. The Engineering Design Functional Area outlines the programmatic controls necessary to govem this activity.

\section{FACILITY REQUIREMENT SOURCE: 29CFR1910 Part 120(g)}

"Engineering controls, work practices, and personal protective equipment for, employee protection. Engineering controis, work practices, personal protective equipment, or a combination of these shall be implemented in accordance with this paragraph to protect employees from exposure to hazardous substances and safety and health hazards."

\section{FACILITY REQUIREMENT SOURCE：29CFR1910 Part 120(g)(1)(i)}

"Engineering controls, work practices and PPE for substances regulated in subparts G and Z. Engineering controls and work practices shall be instituted to reduce and maintain employee exposure to or below the permissible exposure limits for substances regulated by 29 CFR part 1910, to the extent required by subpart Z, except to the extent that such controls and practices are not feasible."

\section{FACILITY REQUIREMENT SOURCE：29CFR1910 Part 120(g)(1)(ii)}

"Whenever engineering controls and work practices are not feasibie or not required, any reasonable combination of engineering controls, work practices and PPE shall be used to reduce and maintain employee exposures to or below the permissible exposure limits or dose limits for substances regulated by 29 CFR part 1910, subpart Z."

\section{FACILITY REQUIREMENT SOURCE: 29CFR1910 Part 120(g)(2)}

"Engineering controls, work practices, and PPE for substances not regulated in sub parts $G$ and $Z$. An appropriate combination of engineering controls, work practices and personal protective equipment shall be used to reduce and maintain employee exposure to or below published exposure levels for hazardous substances and health hazards not regulated by 29 
WHC-EP-0750

\section{REQUIREMENTS IDENTIFICATION DOCUMENT HIGH LEVEL WASTE STORAGE TANK FARMS Occupational Safety and Health}

CFR part 1910, sub parts G and Z. The employer may use the published literature and MSDS as a guide in making the employer's determination as to what level of protection the employer believes is appropriate for hazardous substances and health hazards for which there is no permissible exposure limit or published exposure limit."

\section{FACILITY REQUIREMENT SOURCE: 29CFR1910 Part 147(c)(5)(i)}

"Lockout and Tagout

(i) Locks, tags, chains, wedges, key blocks, adapter pins, self-locking fasteners, or other hardware shall be provided by the employer for isolating, securing or blocking of machines or equipment from energy sources."

\section{FACILITY REQUIREMENT SOURCE: 29CFR1910 Part 147(c)(5)(ii)(A)}

"Lockout and Tagout

(ii) Lockout devices and target devices shall be singularly identified; shall be the only devices(s) used for controlling energy; shall not be used for other purposes; and shall meet the following requirements: (A) Durable (1) Lockout and tagout devices shall be capable of withstanding the environment to which they are exposed for the maximum period of time that exposure is expected. (2) Tagout devices shall be constructed and printed so that exposure to weather conditions or wet and damp locations will not cause the tag to deteriorate or the message on the tag to become illegible. (3) Tags shall not deteriorate when used in corrosive environments such as areas where acid an alkali chemicals are handled and stored."

\section{FACILITY REQUIREMENT SOURCE: 29CFR1910 Part 147(c)(5)(ii)(B)}

"Lockout and Tagout

(B) Standardized. Lockout and tagout devices shall be standardized within the facility in at least one of the following criteria: color; shape; or size; and additionally, in the case of tagout devices, a print and format shall be standardized."

\section{FACILITY REQUIREMENT SOURCE: 29CFR1910 Part 147(c)(5)(ii)(C)(1)}

"Lockout and Tagout

(C) Substantial-(1) Lockout devices. Lockout devices shall be substantial enough to prevent removal without the use of excessive force or unusual techniques, such as with the use of bolt cutters or other metal cutting tools."

\section{FACILITY REQUIREMENT SOURCE: 29CFR1910 Part 147(c)(5)(ii)(C)(2)}

\section{"Lockout and Tagout}

(C) Substantial-(2) Tagout devices, including and their means of attachment, shall be substantial enough to prevent inadvertent or accidental removal. Tagout device attachment means shall be of a non-reusable type, attachable by hand, self-locking, and non-releasable with a minimum unlocking strength of no less than 50 pounds and having the general design and basic characteristics of being at least equivalent to a one-piece, all-environment-tolerant nylon cable tie." 


\section{REQUIREMENTS IDENTIFICATION DOCUMENT HIGH LEVEL WASTE STORAGE TANK FARMS \\ Occupational Safety and Health}

\section{FACILITY REQUIREMENT SOURCE: 29CFR1910 Part 305 (j)(4)(ii).}

"Wiring methods

Disconnecting means. A disconnecting means shall be located in sight from the controller location. However, a single disconnecting means may be located adjacent to a group of coordinated controllers mounted adjacent to each other on a multi-motor continuous process machine. The controller disconnecting means for motor branch circuits over 600 volts, nominal, may be out of sight of the controller, if the controller is marked with a warning label giving the location and identification of the disconnecting means which is to be locked in the open position."

\section{FACILITY REQUIREMENT SOURCE: 29CFR1910 Part 333 (c)(10)}

"Selection and use of work practices (10) Interlocks. Only a qualified person following the requirements of paragraph (c) of this section may defeat an electrical safety interlock, and then only temporarily while he or she is working on the equipment. The interlock system shall be returned to its operable condition when this work is completed."

\section{FACILITY REQUIREMENT SOURCE: 29CFR1910 Part 333 (c)(4)(i)}

"Selection and use of work practices

(4) Illumination (i) Employees may not enter spaces containing exposed energized parts, unless illumination is provided that enables the employees to perform the work safely. (ii) Where lack of illumination or an obstruction precludes observation of the work to be performed, employees may not perform tasks near exposed energized parts. Employees may not reach blindly into areas which may contain energized parts."

\section{SITE REQUIREMENT SOURCE: 29CFR1910 Section 305 (j)(4)(ii)(C)}

"If a motor and the driven machinery are not in sight from the controller location, the installation shall comply with one of the following conditions:

(1) The controller disconnecting means shall be capable of being locked in the open position.

(2) A manually operable switch that will disconnect the motor from its source of supply shall be placed in sight from the motor location."

\section{SITE REQUIREMENT SOURCE: 29CFR1910 Section 305 (j)(4)(ii)(D)}

"The disconnecting means shall plainly indicate whether it is in the open (off) or closed (on) position."

\section{FACILITY REQUIREMENT SOURCE: ANSI-Z244.1-1982 Section 4.3}

"Selection and Procurement of Protective Materials and Hardware.

The requirements for tags, chains, locks, adapters, pins, and the like should be as retained and an adequate supply be maintained, distributed, or assigned as needs dictate. Lockout/tagout devices shall be of distinctive design and appearance and be used solely for the purpose of providing personnel protection." 


\title{
REQUIREMENTS IDENTIFICATION DOCUMENT \\ HIGH LEVEL WASTE STORAGE TANK FARMS \\ Occupational Safety and Health
}

\section{FACILITY REQUIREMINT SOURCE: ANSI-Z244.1-1982 Section 5.1.2}

"Lockout/tagout of energy sources

Equipment Access and Release. A method shall be catablishod to provide a means of gaining access to the equipment/process that involves acknowledgement and release from use by the individual(s) responsible for the equipment/process."

\section{FACILITY REQUIREMENT SOURCE: ANSI-Z244.1-1982 Section 5.1.3}

"Plan.

Where equipment/process complexity or other conditions warrant, a lockout/tugout plan should be developed to serve as a control measure for the duration of the job."

\section{FACILITY REQUIREMENT SOURCE: DOE5480.10 Section 9.c(4)(c)}

\author{
"Engineering controls shall be the primary method used to minimize exposure to \\ carcinogens and to prevent the release of carcinogens into the workroom \\ environment. Provisions shall be made to assure that hazardous levels of \\ contaminated air are not released into adjacent work areas or tho outside \\ environment. All contaminated liquid and solid waste shall be disposed \\ utilizing approved methods (refer to DOE 5480.4, Attachment 1, paragraph \\ 2.b.(11))."
}

\section{SITE REQUIREMENT SOURCE: WHC-SP-0708 Chapter 8, Section 5.3}

"Alignment checks shall be performed after extended shutdowns, maintenance, or as defined by other procedures."

\section{FACILITY REQUIREMENT SOURCE: WHC-SP-0708 Chapter 8, Section 5.3} paragraphs 1 and 2

"Locking devices shall he used on those components over which special administrative control must be established. Paragraph 2 - Locking devices provide some security that a component will be operated only by authorized facility personnel performing required ovolutions in a controlled fashion. Additionally a locking device should alert the operator of the importance of the component and remind the operator that special controls over repositioning are to be maintained. In this respect, all personnel should receive training regarding their responsibilities concerning the manipulation of locked components. "

\section{Administrative Controls}

This sub-element addresses the requirements for establishing and implementing administrative controls. Administrative controls may be applied where engineering controls are insufficient or impractical to effectively limit hazard exposure. In some situations, a combination of engineering controls, administrative controls, and/or personal protective equipment may be necessary to effectively limit hazard exposure.

The methodology for selecting and evaluating the effectiveness of administrative controls shall be clearly defined. The selection, use, and 


\section{REQUIREMENTS IDENTIFICATION DOCUMENT HIGH LEVEL WASTE STORAGE TANK FARMS Occupational Safety and Health}

evaluation of administrative controls shall be properly documented.

Administrative controls shall be proceduralized in accordance with the controls identified in the Policies and Procedures section of the Management Systems Functional Ares.

\section{FACILITY REQUIREMENT SOURCE: 29CFR1910 Part 120(b)(1)(iii)}

"Sito excavation. Sito excavations created during initial site preparation or during hazardous waste operations shall be shored or sloped as appropriate to prevent accidental collapse in accordance with subpart P of 29 CFR part 1926."

\section{FACILITY REQUIREMENT SOURCE: 29CFR1910 Part 120(b)(4)(1)(G)}

"The site safety and health plan, as a minimum shall address the following: Decontamination procedures in accordance with paragraph $(k)$ of this section."

\section{FACILITY REQUIREMENT SOURCE: 29CFR1910 Part 120(b)(4)(ii)(F)}

"The site safety and health plan, as a minimum shall address the following: Site control measures in accordance with the site control program required in paragraph (d) of this section."

\section{FACILITY REQUIREMENT SOURCE: 29CFR1910 Part 120(b)(4)(ii)(I)}

"The sito safety and health plan, as a minimum shall address the following: Confined space entry procedures."

\section{FACILITY REQUIREMENT SOURCE: 29CFR1910 Part 120(b)(4)(ii)(J)}

"The site safety and health plan, as a minimum shall address the following: A spill containment program meeting the requirements of paragraph (j) of this section."

\section{FACILITY REQUIREMENT SOURCE: 29CFR1910 Part 120(b)(4)(iii)}

"The site safety and health plan, as a minimum shall address the following: Pre-entry briefing. The site specific safety and health plan shall provide for pre-entry briefings to be held prior to initiating any site activity, and at such other times as necessary to ensure that employees are apprised of the site safety and health plan and that this plan is heing followed. The information and data obtained from site characterization and analysis work required in paragraph (c) of this section shall be used to prepare and update the site safety and health plan."

\section{FACILITY REQUIREMENT SOURCE: 29CFR1910 Part 120(d)(1)}

"Site control.

Appropriate site control procedures shall be implemented to control employee exposure to hazardous substances before clean-up work begins." 


\section{REQUIREMENTS IDENTIFICATION DOCUMENT \\ HIGH LEVEL WASTE STORAGE TANK FARMS \\ Occupational Safety and Health}

\section{FACILITY REQUTREMENT SOURCE: 29CFR1910 Part 120(d)(2)}

"Site control program. A site control program for protecting employees which is part of the employer's site safety and health program required in paragraph (b) of this section shall be developed during the planning stages of a hazardous waste clean-up operation and modified as necessary as new information becomes available."

\section{FACILITY REQUIREMENT SOURCE: 29CFR1910 Part 120(d)(3)}

"Elements of the site control program. The site control program shall, as a minimum, include: A site map; site work zones; the use of a "buddy system;" site communications including alerting means for emergencies; the standard operating procedures or safe work practices; and, identification of the nearest medical assistance. Where these requirements are covered elsewhere they need not be repeated."

\section{FACILITY REQUIREMENT SOURCE: 29CFR1910 Part 1200)(9)(i)}

"Tank and vault procedures. Tanks and vaults containing hazardous substances shall be handled in a manner similar to that for drums and containers, taking into consideration the size of the tank or vault."

\section{FACILITY REQUIREMENT SOURCE: 29CFR1910 Part 120(j)(9)(ii)}

"Appropriate tank or vault entry procedures as described in the employer's safety and health plan shall be followed whenever employees must enter a tank or vault."

\section{FACILITY REQUIREMENT SOURCE: 29CFR1910 Part 120(k)(1)}

"Decontamination. General. Procedures for all phases of decontamination shall be developed and implemented in accordance with this paragraph."

\section{FACILITY REQUIREMENT SOURCE: 29CFR1910 Part 120(k)(2)(i)}

"Decontamination procedures. A decontamination procedure shall be developed, communicated to employees and implemented before any employees or equipment may enter areas on site where potential for exposure to hazardous substances exists."

\section{FACILITY REQUIREMENT SOURCE: 29CFR1910 Part 120(k)(2)(ii)}

"Decontamination procedures. Standard operating procedures shall be developed to minimize employee contact with hazardous substances or with equipment that has contacted hazardous substances."

\section{FACILITY REQUIREMENT SOURCE: 29CFR1910 Part 120(k)(2)(iii)}

"Decontamination procedures. All employees leaving a contaminated area shall be appropriately decontaminated; all contaminated clothing and equipment leaving a contaminated area shall be appropriately disposed of or decontaminated." 


\section{REQUIREMENTS IDENTIFICATION DOCUMENT HIGH LEVEL WASTE STORAGE TANK FARMS \\ Occupational Safety and Health}

\section{FACILITY REQUIREMENT SOURCE: 29CFR1910 Part 120(k)(2)(iv)}

"Decontamination procedures shall be monitored by the site safety and health supervisor to determine their effectiveness. When such procedures are found to be ineffective, appropriate steps shall be taken to correct any deficiencies."

\section{FACILITY REQUIREMENT SOURCE: 29CFR1910 Part 120(k)(3)}

"Location. Decontamination shall be performed in geographical areas that will minimize the exposure of uncontaminated employees or equipment to contaminated employees or equipment."

\section{FACILITY REQUIREMENT SOURCE: 29CFR1910 Part 120(k)(4)}

"Decontamination procedures. Equipment and solvents. All equipment and solvents used for decontamination shall be decontaminated or disposed of properly."

\section{FACILITY REQUIREMENT SOURCE: 29CFR1910 Part 147 (c)(5)(iii)}

"Lockout and Tagout

Tagout devices shall warn against hazardous conditions if the machine or equipment is energized and shall include a legend such as the following: Do Not Start, Do Not Open, Do Not Close, Do Not Energize, Do Not Operate."

FACILITY REQUIREMENT SOURCE: 29CFR1910 Part 147 (c)(8)

"Lockout and Tagout

(8) Energy isolation. Lockout or tagout shall be performed only by the authorized employees who are performing the servicing or maintenance."

\section{FACILITY REQUIREMENT SOURCE: 29CFR1910 Part 147 (c)(9)}

"Lockout and Tagout

Notification of employees. Affected employees shall be notified by the employer or authorized employee of the application and removal of lockout devices or tagout devices. Notification shall be given before the controls are applied, and after they are removed from the machine or equipment."

\section{FACILITY REQUIREMENT SOURCE: 29CFR1910 Part 147 (d)(1)}

"Lockout and Tagout

The established procedures for the application of energy control (the lockout or tagout procedures) shall cover the following elements and actions and shall be done in the following sequence: $\{[\operatorname{sic}](1),(2),(3),(4),(5),(6)\}$ (1) Preparation for shutdown. Before an authorized or affected employee turns off a machine or equipment the authorized employee shall have knowledge of the type and magnitude of the energy, the hazards of the energy to be controlled, and the method or means to control the energy." 


\section{REQUIREMENTS IDENTIFICATION DOCUMENT HIGH LEVEL WASTE STORAGE TANK FARMS Occupational Safety and Health}

\section{FACILITY REQUIREMENT SOURCE: 29CFR1910 Part 147 (d)(2)}

"Lockout and Tagout

(2) Machine or equipment shutdown. The machine or equipment shall be turned off or shut down using the procedures established for the machine or equipment. An orderly shutdown must be utilized to avoid any additional or increased hazard(s) to employees as a result of the equipment stoppage."

\section{FACILITY REQUIREMENT SOURCE: 29CFR1910 Part 147 (d)(3)}

"Lockout and Tagout

(3) Machine or equipment isolation. All energy isolating devices that are needed to control the energy to the machine or equipment shall be physically located and operated in such a manner as to isolate the machine or equipment from the energy source(s)."

\section{FACILITY REQUIREMENT SOURCE: 29CFR1910 Part 147 (d)(4)}

"Lockout and Tagout (4)(i) Lockout or tagout devices shall be affixed to each energy isolating device by authorized employees. (ii) Lockout devices, where used, shall be affixed in a manner to that will hold the energy isolating devices in a "safe" or "off" position (iii) Tagout devices, where used, shall be affixed in such a manner as will clearly indicate that the operation or movement of energy isolating devices from the "safe" or "off" position is prohibited. (A) Where tagout devices are used with energy isolating devices designed with the capability of being locked, the tag attachment shall be fastened at the same point at which the lock would have been attached. (B) Where a tag cannot be affixed directly to the energy isolating device, the tag shall be located as close as safely possible to the device, in a position that will be immediately obvious to anyone attempting to operate the device."

\section{FACILITY REQUIREMENT SOURCE: 29CFR1910 Part 147 (d)(5)}

"Lockout and Tagout

(5) Stored energy. (i) Following the application of lockout or tagout devices to energy isolating devices, all potentially hazardous stored or residual energy shall be relieved, disconnected, restrained, and other wise rendered safe. (ii) If there is a possibility of reaccumulation of stored energy to a hazardous level, verification of isolation shall be continued until the servicing or maintenance is completed, or until the possibility of such accumulation no longer exists."

\section{FACILITY REQUIREMENT SOURCE: 29CFR1910 Part 147 (d)(6)}

"Lockout and Tagout

(6) Verification of isolation. Prior to starting work on machines or equipment that have been locked out or tagged out, the authorized employee shall verify that isolation and deenergization of the machine or equipment have been accomplished."

\section{FACILITY REQUIREMENT SOURCE: 29CFR1910 Part 147 (e)(1)}

"Lockout and Tagout

(e) Release from lockout or tagout. Before lockout or tagout devices are removed and energy is restored to the machine or equipment, procedures shall be followed and actions taken by the 


\section{REQUIREMENTS IDENTIFICATION DOCUMENT HIGH LEVEL WASTE STORAGE TANK FARMS \\ Occupational Safety and Health}

authorized employee(s) to ensure the following: (1) The machine or equipment. The work area * shall be inspected to ensure that nonessential items have been removed and to ensure that machines or equipment components are operationally intact."

\section{FACILITY REQUIREMENT SOURCE: 29CFR1910 Part 147 (e)(2)}

"Lockout and Tagout

(e)(2) Employees. (i) The machine or equipment. The work area shall be checked to ensure that all employees have ben safely positioned or removed. (ii) After lockout or tagout devices have been removed and before a machine equipment is staited, affected employees shall be notified that the lockout or tagout device(s) have been removed."

\section{FACILITY REQUIREMENT SOURCE: 29CFR1910 Part 147 (e)(3)}

"Lockout and Tagout

(e)(3) Lockout or tagout devices removal. Each lockout or tagout device shall be removed from each energy isolating device by the employee who applied the device. Exception to paragraph (e)(3): When the authorized employee who applied the lockout or tagout device is not available to remove it, that device is not available to remove it, that device may be removed under the direction of the employer, provided that specific procedures and training for such removal have been developed, documented and incorporated into the employer's energy control program. The employer shall demonstrate that the specific procedure provides equivalent safety to the removal of the device by the authorized employee who applied it. The specific procedure shall include at least the following elements: (i) Verification by the employer that the authorized employee who applied the device is not at the facility; (ii) Making all reasonable efforts to contact the authorized employee to inform him/her that his/her lockout or tagout device has been removed; and (iii) Ensuring that the authorized employee has this knowledge before he/she resumes work at that facility."

\section{FACILITY REQUIREMENT SOURCE: 29CFR1910 Part 147(c)(1)}

"Lockout and Tagout

(c) General-1 Energy Control Program. The employer shall establish a program consisting of energy control procedures, employee training and periodic inspections to ensure that before any employee performs any servicing or maintenance on a machine or equipment where the unexpected energizing, start up or release of stored energy could occur and cause injury, the machine or equipment shall be isolated from the energy source, and rendered inoperative."

\section{FACILITY REQUIREMENT SOURCE: 29CFR1910 Part 147(c)(2)(i)}

"Lockout and Tagout

(c) General-2 Lockout/tagout. (i). If an energy isolating device is not capable of being locked out, the employer's energy control program under paragraph (c)(1) of this section shall utilized a tagout system."

\section{FACILITY REQUIREMENT SOURCE: 29CFR1910 Part 147(c)(2)(iii)}

"Lockout and Tagout

(c) General-2 Lockout/tagout. (iii). After January 2, 1990, whenever replacement or major repair, renovation or modification of a machine or equipment is performed, and whenever new 


\section{REQUIREMENTS IDENTIFICATION DOCUMENT HIGH LEVEL WASTE STORAGE TANK FARMS Occupational Safety and Health}

machines or equipment are installed, energy isolating devices for such machine or equipment shall be designed to accept a lockout device."

\section{FACILITY REQUIREMENT SOURCE: 29CFR1910 Part 147(c)(3)(i)}

"Lockout and Tagout

(c) (3) Full employee Protection. (i) When a tagout device is used on an energy isolating device which is capable of being locked out, the tagout device shall be attached at the same location that the lockout device would have been attached, and the employer shall demonstrate that the tagout program will provide a level of safety equivalent to that obtained by using a lockout program."

\section{FACILITY REQUIREMENT SOURCE: 29CFR1910 Part 147(c)(3)(ii)}

\section{"Lockout and Tagout}

(c)(3)(ii) In demonstrating that a level of safety is achieved in the tagout program which is equivalent to the level of safety obtained by using a lockout program, the employer shall demonstrate lull compliance with all tagout related provisions of this standard together with such additional elements as are necessary to provide the equivalent safety available from the use of a lockout device. Additional means to be considered as part of the demonstration of full employee protection shall include the implementation of additional safety measures such as the removal of an isolating circuit element, blocking of a controlling switch, opening of an extra disconnecting device, or the removal of a valve handle to reduce the likelihood of inadvertent energization."

\section{FACILITY REQUIREMENT SOURCE: 29CFR1910 Part 147(c)(4)(i)}

\section{"Lockout and Tagout}

(c)(4) Energy control procedure. (i). Procedures shall be developed, documented and utilized for the control of potentially hazardous energy when employees are engaged in the activities covered by this section. Note: Exception: The employer need not document the required procedure for a particular machine or equipment, when all the following elements exist: (1) the machine or equipment has no potential for stored or residual energy or reaccumulation of stored energy after shut down which could endanger employees: (2) the machine or equipment has a single energy source which can be readily identified and isolated: (3) the isolation and locking out of that energy source will completely deenergize and deactivate the machine or equipment; (4) the machine or equipment is isolated from that energy source and locked out during servicing or maintenance;(5) a single lockout device will achieve a locked-out condition;(6) the lockout device is under the exclusive control of the authorized employee performing the servicing or maintenance: (7) the servicing or maintenance does not create hazards for other employees; and (8) the employee, in utilizing this exception has not had accidents involving the unexpected activation or reenergization of the machine or equipment during servicing or maintenance."

\section{FACILITY REQUIREMENT SOURCE: 29CFR1910 Part 147(c)(4)(ii)}

"Lockout and Tagout

(ii) The procedures shall clearly and specifically outline the scope, purpose, authorization, rules, and techniques to be utilized for the control of hazardous energy, and the means to enforce compliance including, but not limited to, the following: (A) A specific statement of the intended use of the procedure; (B) Specific procedural steps for the shutting down, isolating, 


\section{REQUIREMENTS IDENTIFICATION DOCUMENT HIGH LEVEL WASTE STORAGE TANK FARMS Occupational Safety and Health}

blocking and securing machines or equipment to control hazardous energy; (C) Specific procedural steps for the placement, removal and transfer of lockout devices or tagout devices and the responsibility for them; and (D) Specific requirements for testing a machine or equipment to determine and verify the effectiveness of lockout devices, tagout devices, and other energy control measures."

\section{FACILITY REQUIREMENT SOURCE: 29CFR1910 Part 147(c)(5)(i)}

"Lockout and Tagout

(i) Locks, tags, chains, wedges, key blocks, adapter pins, self-locking fasteners, or other hardware shall be provided by the employer for isolating, securing or blocking of machines or equipment from energy sources."

\section{FACILITY REQUIREMENT SOURCE: 29CFR1910 Part 147(f)(2)}

"Lockout and Tagout

(f) Additional requirements (2) Outside personnel (contractors, etc) (i) Whenever outside servicing personnel are to be engaged in activities covered by the scope and application of this standard, the on-site employer and the outside employer shall inform each other of their respective lockout or tagout procedures. (ii) The on-site employer shall ensure that his/her employees understand and comply with the restrictions and prohibitions of the outside employer's energy control program. "

\section{FACILITY REQUIREMENT SOURCE: 29CFR1910 Part 147(f)(3)}

"Lockout and Tagout

(f) Group lockout or tagout. (i) When servicing and/or maintenance is performed by a crew, craft, department or other group, they shall utilize a procedure which affords the employees a level of protection equivalent to that provided by the implementation of a personal lockout or tagout device. (ii) Group lockout or tagout devices shall be used in accordance with procedures required by paragraph (c)(4) of this section including, but not necessarily limited to, the following specific requirements; (A) Primary responsibility is vested in an authorized employee for a set number of employees working under the protection of a group lockout or tagout device (such as operations lock); (B) Provision for the authorized employee to ascertain the exposure stratus of individual group members with regard to the lockout or tagout of the machine or equipment and (C) When more than one crew, craft, department, etc. is involved, assignment of overall job-associated lockout or tagout control responsibility to an authorized employee designated to coordinate affected work forces and ensure continuity of protection; and (D) Each authorized employee shall affix a personal lockout or tagout device to the group lockout device, group lockhox, or comparable mechanism when he or she begins work, and shall remove those devices when he or she stops working on the machine or equipment being serviced or maintained. "

\section{FACILITY REQUIREMENT SOURCE: 29CFR1910 Part 303 (f)}

"Electrical utilization systems.

(f) Identification of disconnecting means and circuits. Each disconnecting means required by this subpart for motors and appliances shall be legibly marked to indicate its purpose, unless located and arranged so the purpose is evident. Each service, feeder, and branch circuit, at its disconnecting means or over current device, shall be legibly marked to indicate its purpose, 
WHC-EP-0750

\section{REQUIREMENTS IDENTIFICATION DOCUMENT HIGH LEVEL WASTE STORAGE TANK FARMS Occupational Safety and Health}

unless located and arranged so the purpose is evident. These markings shall be of sufficient durability to withstand the environment involved."

\section{FACILITY REQUIREMENT SOURCE: 29CFR1910 Part 305 (j)(4)(1)}

"Wiring methods.

(4) Motors. This paragraph applies to motors, motor circuits, and controllers. (i) In sight from. If specified that one piece of equipment shall be "in sight from " another piece of equipment, one shall be visible and not more than 50 feet from the other."

\section{FACILITY REQUIREMENT SOURCE: 29CFR1910 Part 333 (a)}

"Selection and use of work practices

(a) General. Safety-related work practices shall be employed to prevent electric shock or other injuries resulting from either direct or indirect electrical contacts, when work is performed near or on equipment or circuits which are or may be energized. The specific safety-related work practices shall be consistent with the nature and extent of the associated electrical hazards."

\section{FACILITY REQUIREMENT SOURCE: 29CFR1910 Part 333 (a)(1)}

"Selection and use of work practices

(a)(1) Deenergized parts. Live parts to which an employee may be exposed shall be deenergized before the employee works on or near them, unless the employer can demonstrate that deenergizing introduces additional or increased hazards or is infeasible due to equipment design or operational limitations. Live parts that operate at less than $\mathbf{5 0}$ volts to ground need not to be deenergized if there will be no increased exposure due to electrical arcs. Note 1: Examples of increased or additional hazards include interruption of life support equipment, deactivation of emergency alarm systems, shutdown of hazardous location ventilation equipment, or removal of illumination of an area. Note 2: Examples of work that may be performed on or near energized circuit parts because of infeasibility due to equipment redesign or operational limitation include testing of electric circuits that can only be performed with the circuit energized and work on circuits that form an integral part of a continuous industrial processing a chemical plant that would otherwise need to be completely shut down in order to permit work on one circuit or piece of equipment. Note 3: Work on or near deenergized parts is covered by paragraph (b) of this section."

\section{FACILITY REQUIREMENT SOURCE: 29CFR1910 Part 333 (a)(2)}

"Selection and use of work practices

(a)(2) Energized parts. If the exposed live parts are not deenergized (i.e., for reasons of increased or additional hazards or infeasibility), other safety-related work practices shall be used to protect employees who may be exposed to the electrical hazards involved. Such work practices shall protect employees against contact with energized circuit parts directly with any part of their body or indirectly through some other conductive object. The work practices that are used shall be suitable for the conditions under which the work is to be performed and for the voltage level of the exposed electric conductors or circuit parts. Specific work practice requirements are detailed in paragraph (c) of this section." 


\title{
REQUIREMENTS IDENTIFICATION DOCUMENT HIGH LEVEL WASTE STORAGE TANK FARMS Occupational Safety and Health
}

\author{
FACILITY REQUIREMENT SOURCE: 29CFR1910 Part 333 (b)(1)
}

"Selection and use of work practices

(b) (1)Working on or near exposed deenergized parts. (1) Application. This paragraph applies to work on exposed deenergized parts or near enough to them to expose the employee to any electrical hazard they present. Conductors and parts of electric equipment that have been deenergized but have not been locked out or tagged in accordance with paragraph (b) of this section shall be treated as energized parts, and paragraph (c) of this section applied to work on or near them."

\section{FACILITY REQUIREMENT SOURCE: 29CFR1910 Part 333 (b)(2)(iv)}

"Selection and use of work practice

(2)(iv) Verification of deenergized condition. The requirements of this paragraph shall be met before any circuits or equipment can be considered and worked as deenergized. (A) A qualified person shall operate the equipment operating controls or otherwise verify that the equipment cannot be restarted. (B) A qualified person shall use test equipment to test the circuit element and electrical parts of equipment to which employees will be exposed and shall verify that the circuit elements and equipment parts are deenergized. The test shall also determine if any energized condition exists as a result of inadvertently induced voltage or unrelated voltage back feed even though specific parts of the circuit have been deenergized and presumed to be safe. If the circuit to be tested is over 600 volts, nominal, the test equipment shall be checked for proper operation immediately before and immediately after this test."

\section{FACILITY REQUIREMENT SOURCE: 29CFR1910 Part 333 (b)(2)(v)}

"Selection and use of work practices

(b)(2)(v) Reenergizing equipment. These requirements shall be met, in the order given, before circuits or equipment are reenergized, even temporarily. (A) A qualified person shall conduct tests and visual inspection, as necessary, to verify that all tools, electrical jumpers, shorts, grounds, and other such devices have been removed, so that the circuits and equipment can be safely energized. (B) Employees exposed to the hazards associated with reenergizing the circuit or equipment shall be warned to say clear of circuits and equipment. (C) Each lock and tag shall be removed by the employee who applied it or under his or her direct supervision. However, if this employee is absent from the workplace, then the lock or tag may be removed by a qualified person designated to perform this task. Provided that: (1) The employer ensures that the employee who applied the lock or tag is not available at the workplace, and (2) the employer ensures that the employee is aware that the lock or tag has been removed before he or she resumes work at that workplace. (D) There shall be a visual determination that all employees are clear of the circuits and equipment."

\section{FACILITY REQUIREMENT SOURCE: 29CFR1910 Part 333 (c)(1)}

"Selection and use of work practices

(c) Working on or near exposed energized parts. (1) Application. This paragraph applies to work performed on exposed live parts (involving either direct contact or contact by means of tools or materials) or near enough to them for employees to be exposed to any hazard they present." 


\section{REQUIREMENTS IDENTIFICATION DOCUMENT HIGH LEVEL WASTE STORAGE TANK FARMS Occupational Safety and Health}

\section{FACILITY REQUIREMENT SOURCE: 29CFR1910 Part 333 (c)(2)}

"Selection and use of work practices

(c)(2) Work on energized equipment. Only qualified persons may work on electric circuit parts or equipment that have not been deenergized under the procedures of paragraph (b) of this section. Such persons shall be capable of working safely on energized circuits and shall be familiar with the proper 1;use of special precautionary techniques, personal protective equipment, insulating and shielding materials, land insulated tools."

\section{FACILITY REQUIREMENT SOURCE: 29CFR1910 Part 333 (c)(3)}

"Selection and use of work practices

(c)(3) Overhead lines. If work is to be performed near overhead lines, the lines shall be deenergized and grounded, or other protective measures shall be provided before work is started. If the lines are to be deenergized, arrangements shall be made with the person or organization that operates or controls the electric circuits involved to deenergize and ground them. If protective measures, such as guarding, isolating, or insulating are provided, these precautions shall prevent employees from contacting such lines directly with any part of their body or indirectly through conductive materials, tools, or equipment. Note: The work practices used by qualified persons installing insulating devices on overhead power transmission or distribution lines are not covered by 1910.332 through 1910.335 . Under paragraph (c)(2) of this section, unqualified persons are prohibited from performing this type of work."

\section{FACILITY REQUIREMENT SOURCE: 29CFR1910 Part 333 (c)(3)(i)}

"Selection and use of work practices

(i) Unqualified persons. (A) when an unqualified person is working in an elevated position near overhead lines, the location shall be such that the person and the longest conductive object he or she may contact cannot come closer to any unguarded, energized overhead line than the following distances: (1) For voltages to ground $50 \mathrm{kV}$ or below-10ft. $305 \mathrm{~cm}$; (2) For voltages to ground over $50 \mathrm{kV}-10 \mathrm{ft} .(305 \mathrm{~cm})$ plus 4 in. $(10 \mathrm{~cm})$ for every $10 \mathrm{kV}$ over $50 \mathrm{kV}$. (B) When an unqualified person is working on the ground in the vicinity of overhead lines, the person may not ring any conductive object closer to unguarded, energized overhead lines that the distances given in paragraph $(c)(3)(i)(A)$ of this section. Note: For voltages normally encountered with overhead power lines, objects which do not have an insulating rating for the voltage involved are considered to be conductive."

\section{FACILITY REQUIREMENT SOURCE: 29CFR1910 Part 333 (c)(3)(ii)}

"Selection and use of work practices

(ii) Qualified persons. When a qualified person is working in the vicinity of overhead lines, whether in an elevated position or on the ground, the person may not approach or take any conductive object without an approved insulating handle closer to exposed energized parts than shown in Table S-5 unless: (A) the energized part 'gloves with sleeves if necessary, rated for the voltage involved are considered to be insulation of the person from the energized part on which work is performed), or (B) The energized part is insulated both from all other conductive objects at a different potential and from the person, or (C) The person is insulated from all conductive objects at a potential different from that of the energized part." 


\section{REQUIREMENTS IDENTIFICATION DOCUMENT \\ HIGH LEVEL WASTE STORAGE TANK FARMS Occupational Safety and Health}

\section{FACILITY REQUIREMENT SOURCE: 29CFR1910 Part 333 (c)(5)}

"Selection and use of work practices

(5) Confined spaces or enclosed work spaces. When an employee works in a confined or enclosed space (such as a manhole or vault) that contains expose energized parts, the employer shall provide, and the employee shall use, protective shields, protective barriers, or insulating materials as necessary to avoid inadvertent contact with these parts. Doors, hinged panels, and the like shall be secured to prevent their swinging into an employee and causing the employee to contact exposed energized parts."

\section{FACILITY REQUIREMENT SOURCE: 29CFR1910 Part 333 (c)(6)}

"Selection and use of work practices

(6) Conductive materials and equipment. Conductive materials and equipment that are in contact with any part of an employee's body shall be handled in a manner that will prevent them from contacting exposed energized conductors or circuit parts. If an employee must handle long dimensional conductive objects (such as ducts and pipes) in areas with exposed live parts, the employer shall institute work practices (such as the use of insulation, guarding, and material handling techniques) which will minimize the hazard."

\section{FACILITY REQUIREMENT SOURCE: 29CFR1910 Part 333 (c)(7)}

"Selection and use of work practices

(7) Portable ladders. Portable ladders shall have nonconductive side rails if they are used where the employee or the ladder could contact exposed energized parts."

\section{FACILITY REQUIREMENT SOURCE: 29CFR1910 Part 333 (c)(8)}

"Selection and use of work practices

(8) Conductive apparel. Conductive articles of jewelry and clothing (such as watch bands, bracelets, rings, key chains, necklaces, metalized aprons, cloth with conductive thread, or metal headgear) may not be worn if they might contact exposed energized parts. However, such articles may be worn if they are rendered nonconductive by covering, wrapping, or other insulating means."

\section{FACILITY REQUIREMENT SOURCE: 29CFR1910 Part 333 (c)(9)}

"Selection and use of work practices

(9) Housekeeping duties. Where live parts present an electrical contact hazard, employees may not perform housekeeping duties at such close distances to the parts that there is as possibility of contact, unless adequate safeguards (such as insulating equipment or barriers) are provided. Electrically conductive solids such as steel wool, metalized cloth, and silicon carbide, as well as conductive liquid solutions) may not be used in proximity to energized parts unless procedures are followed which will prevent electrical contact."

\section{FACILITY REQUIREMENT SOURCE: 29CFR1910 Part 333(b)(2)(iii)}

"Selection and use of work practices

A lock and a tag shall be placed on each disconnecting means used to deenergize circuits and equipment on which work is to be performed, except as provided in paragraphs (b)(2)(iii)(C) 


\section{REQUIREMENTS IDENTIFTCATION DOCUMENT HIGH LEVEL WASTE STORAGE TANK FARMS Occupational Safety and Health}

and (b)(2)(iii)(E) of this section. The lock shall be attached 80 as to prevent persons from operating the disconnecting means unless they resort to undue force or the use of tools. (B) Each tag shall contain a statement prohibiting unauthorized operation of the disconnecting means and removal of the tag. (C) If a lock cannot be applied, or if the employer can demonstrate rate that tagging procedures will provide a level of safety equivalent to that obtained by the use of a lock, a tag may be used without a lock. (D) A tag used without a lock, as permitted by paragraph (b)(2)(iii)(C) of this section, shall be supplemented by at least one additional safety measure that provides a level of safety equivalent to that obtained by the use of a lock. Examples of additional safety measures include the removal of an isolating circuit element, blocking of a controlling switch, or opening of an extra disconnecting device. (E) A lock may be placed without a tag only under the following conditions: (1) Only one circuit or piece of equipment is deenergized, and (2) The lockout period does not extend beyond the work shift, and (3) Employees exposed to the hazards associated with reenergizing the circuit or equipment are familiar with this procedure."

\section{SITE REQUIREMENT SOURCE: 29CFR1910 Section 147 (f)(4)}

"Shift or personnel changes. Specific procedures shall be utilized during shift or personnel changes to ensure the continuity of lockout or tagout protection, including provision for the orderly transfer of lockout or tagout device protection between offgoing and oncoming employees, to minimize exposure to hazards from the unexpected energization or startup of the machine or equipment, or the release of stored energy."

\section{FACILITY REQUIREMENT SOURCE: 29CFR1926 Part 417(b)}

"Locking and tagging of circuits

(b) Equipment and circuits. Equipment or circuits that are deenergized shall be rendered inoperative and shall have tags attached at all points where such equipment or circuits can be energized."

\section{FACILITY REQUIREMENT SOURCE: 29CFR1926 Part 417(c)}

"Locking and tagging of circuits

(c) Tags. Tags shall be placed to identify plainly the equipment or circuits being worked on."

\section{FACILITY REQUIREMENT SOURCE: 54FR3904 Part (c)(3)(i)}

"So that all current and potential hazards, however detected, are corrected or controlled in a timely manner, establish procedures for that purpose, using the following measures; (A) Engineering techniques where feasible and appropriate; (B) Procedures for safe work which are understood and followed by all affected parties, as a result of training, positive reinforcement, correction of unsafe performance, and, if necessary, enforcer went through a clearly communicated disciplinary system: (C) Provision of personal protective equipment; and (D) Administrative controls, such as reducing the duration of exposure."

FACILITY REQUIREMENT SOURCE: ANSI-Z244.1-1982 Section 4.2

"Identification of Energy Isolating Devices. 


\section{REQUIREMENTS IDENTIFICATION DOCUMENT HIGH LEVEL WASTE STORAGE TANK FARMS Occupational Safety and Health}

All energy isolating devices shall be adequately labeled or marked to indicate their function, unless they are located and arranged so their purpose is ovident. The identification shall include the following: (1) Equipment supplied (2) Energy type and magnitude."

\section{FACILITY REQUIREMENT SOURCE: ANSI-Z244.1-1982 Section 4.4}

"Assignment of Duties and Responsibilities.

Only knowledgeable individuals, shall prescribe the appropriate duties and responsibilities relating to the actual details effecting the lockout/tagout. Energy isolating devices shall be operated only by authorized individuals or under the direct supervision of authorized individuals."

\section{FACILITY REQUIREMENT SOURCE: ANSI-Z244.1-1982 Section 4.5}

"Preparation of De-energization and Start-Up Sequence(s).

Where system complexity requires, a written sequence in checklist form should be prepared for equipment access, lockout/tagout, clearance, release, and start-up."

\section{FACILITY REQUIREMENT SOURCE: ANSI-Z244.1-1982 Section 5.1.4}

"Pre-job briefing.

Where equipment/process complexity or other conditions warrant, an authorized individual should review the lockout/tagout sequence or plan with personnel affected by the lockout/tagout."

\section{FACILITY REQUIREMENT SOURCE: ANSI-Z244.1-1982 Section 5.2.1}

"Equipment/Process Shutdown.

Using appropriate equipment/process shutdown procedures all operating controls shall be turned off or returned to the neutral mode by authorized individuals."

\section{FACII.ITY REQUIREMENT SOURCE: ANSI-Z244.1-1982 Section 5.2.4}

"Verification of isolation.

One or both of the following actions shall be accomplished after lockout/tagout application to determine if the operation of the energy isolating devices has in fact produced the required isolation of the equipment/process. (1) Operate the equipment/process operating controls (push buttons, switches, etc) to determine that the energy isolation has been effective. CAUTION: Return operating controls to neutral position after each test. (2) Test the equipment/process by use of appropriate test equipment and/or visual inspection to determine that the energy isolation has been effective."

\section{FACILITY REQUIREMENT SOURCE: ANSI-Z244.1-1982 Section 5.3.1}

"Equipment/Process.

Before energy is restored to the equipment/process, a visual inspection of the work area shall be made by an authorized individual to ensure that all nonessential items have been removed and that all components are operationally intact." 
WHC-EP-0750

\section{REQUIREMENTS IDENTIFICATION DOCUMENT HGH LEVEL WASTE STORAGE TANK FARMS \\ Occupational Safety and Health}

\section{FACILITY REQUTREMENT SOURCE: ANSI-Z244.1-1982 Section 5.3.2}

"Personnel.

Before energy is reatored to the equipment/process, a personnel count or administrative technique shall be employed to verify that perzonnel are in the clear. This check-out procedure should be supplemented with a visual verification that personnel are in the clear."

\section{FACILITY REQUTREMENT SOURCE: ANSI-2244.1-1982 Section 6.2}

"Equipment Design and Performance Limitations.

Altemative effective protective techniques shall be employed where the equipment/process design prohibits use of the establishod locknut/tagout devicos."

\section{FACRITY REQUIREMENT SOURCE: ANSI-Z244.1-1982 Section 6.3}

"Exposure of Outside Personnel.

Established lockout/tagout procedures should be employed for the protection of individuals from outside organizations (service representatives, contractor's employees, and other outside personnel), where exposure exists due to their involvement with work in progress. An authorized representative of such outside organizations shall be made aware of established lockout/tagout procedures and informed of the necessity of adapting and enforcing lockout/tagout protection which shall be compatible with existing in-plant lockout/tagout procedures."

\section{FACILITY REQUIREMENT SOURCE: ANSI-Z244.1-1982 Section 6.4}

"Multiple Personnel Protection (Group Lockout/Tagout).

When a crew, craft, department, or other group lockout/tagout device(s) is used, ;it shall afford the affected employee a level of protection equivalent to that provided by personal lockout/tagout devices."

\section{FACILITY REQUIREMENT SOURCE: ANSI-Z244.1-1982 Section 6.6}

"Authorization for Lockout/Tagout Application and Removal.

Where written lockout/tagout plans exist and are used for complex systems, lockout/tagout devices shall be installed and removed only at the direction of the authorized individual who has control of the plan."

\section{FACILITY REQUIREMENT SOURCE: ANSI-Z244.1-1982 Section 6.7}

"Work on Energized Equipment.

Personnel performing the activities listed in 3.1, other than normal operating activities, should do so under de-energized conditions in accordance wit h the lockout/tagout procedures required in this standard (see 5.2.1). Where work on energized equipment is required, acceptable procedures and equipment shall be employed to provide effective protection to personnel."

\section{FACILITY REQUIREMENT SOURCE: ANSI-Z244.1-1982 Section 6.8}

"Production Operations. 


\section{REQUIREMENTS IDENTIFICATION DOCUMENT HIGH LEVEL WASTE STORAGE TANK FARMS Occupational Safety and Health}

Personnel performing the activities listed in 3.1, other than normal operating activities, should do 20 under de-energized conditions in accordance with the lockout/tagout procedures required in this atandard (5.2.1). In the case of required repetitive minor adjuatments where this is not foasible, or in the case of normal production operations, these sctivities shall be accomplished under the protection of specially designed control circuits, control equipment, and operating procedures, that provide proven effective protection for the affected personnel."

\section{FACILITY REQUIREMENT SOURCE: DOE-STD-1030-92 Section 4.2.1, Para. 3}

"Good practices.

Under and individual-controlled lockout/lagout, the individual worker is reoponsible for taking all necessary actions to ensure perzonal eafety and the safoty of others during the maintenance. To aid the worker, OSHA and DOE Order 5480.19 require the following: -Locks will be used whenever possible to secure energy or hazardous material isolating devices. Now equipment and major equipment modifications will be designed to permit the use of locks. Tags should be used to identify the person who placed the lock and the purpose of the lock. If locks cannot be used, danger tags are required. -Management should identify activities that require lockout/tagout. For each activity requiring lockout/tagout, criteria should be provided to identify the locations for locks and tags. -Only authorized personnel should have access to keys for key locks that are installed on control devices. If the operator locks out the energy source by removing the key from the control switch, it is essential to ensure that no additional keys are available to unauthorized personnel. Additionally, the control switch should be tagged. Every isolation from an energy or hazardous material source must be verified. Specific techniques for verification should be established by facility procedures. The verification should include a review of pertinent controlled drawings or manuals, and a hands-on physical check of the equipment. The drawings should be used to help identify the sometimes obscure sources of power or pressu:e (e.g., control power, indication or interlock circuits, sensing lines) that may be present in equipment even though the main (and obvious) sources have heen isolated. If a physical check is not possihle hecause of hazards in the area or an existing lockout/tagout, other verification, such as observation of a reliable position indicator, is required. Periodic checks should he performed to ensure that components are in the proper position and that locking devices are properly attached."

FACIIITY REQUIREMENT SOURCE: DOE-STD-1030-92 Section 4.2.3.1 Para. 1

"General Practices.

A lockout/tagout must isolate all sources of energy or hazardous materials that may cause personnel injury or equipment damage. For example, isolating a pump motor for bearing maintenance should also include shutting and tagging the pump suction and discharge valves to prevent possible rotation from fluid flow."

\section{FACIITY REQUIREMENT SOURCE: DOE-STD-1030-92 Section 4.2.3.1 Para. 2}

"General Practices.

Only controlled drawings, controlled system schematics, or other controlled documents should be used as references for determining or verifying isolation points. In the absence of controlled drawings, a physical walkdown should be performed by a qualified person to verify that isolation has been achieved." 
WHC-EP.0750

\section{REQUIREMENTS IDENTIFICATION DOCUMENT HIGH LEVEL WASTE STORAGE TANK FARMS \\ Occupational Safety and Health}

\section{FACILITY REQUIREMENT SOURCE: DOE-STD-1030-92 Section 4.2.3.1 Para. 4}

-Oeneral Practices.

Some control devices "seal in" when actuated and could cause equipment to start when power is restored. Because of this component trait, the practice of verifying lockout/tagout isolation by operating the controls (0.8., preseing the start button) for the affected equipment should not be permitted."

\section{FACILITY REQUIREMENT SOURCE: DOE-STD-1030-92 Section 4.2.3.1 Para. 5}

"General Practices

Control switches should be tagged in a position corresponding to the desired protective state of the equipment (e.8., OFF, neutral, pull-to-lock), even when another device (e.8., circuit breaker, disconnect switch, valvo in pneumatic supply line) provides the primary isolation from the energy source."

\section{FACILITY REQUIREMENT SOURCE: DOE-STD-1030-92 Section 4.2.3.2}

"Electrical Practices

If electrical grounding devices are required, the location and sequence for installation of each device should be specified in the lockout/tagout procedure. All eloctrical grounding devices used in a lockout/tagout must be danger tagged to ensure that the grounds remain in place until the work is complete, and that they are removed before reenergizing the system."

\section{FACILITY REQUIREMENT SOURCE: DOE-STD-1030-92 Section 4.2.3.3 Para. 1}

\section{"Piping Systems Practices}

Systems, portions of systems, and components that operate at temperatures or pressures above ambient should he vented and, if necessary for the performance of work, drained or cooled hefore the lockout/tagout is issued. Whenever possible, an atmospheric drain and/or vent hetween the component to be worked and sources of pressure to the component should be tagged in the open position to depressurize the equipment and to accommodate thermal expansion or contraction."

\section{FACILITY REQUIREMENT SOURCE: DOE-STD-1030-92 Section 4.2.3.3 Para. 2}

\section{"Piping Systems Practices}

Systems that operate at high temperatures (e.g., greater than 200 degrees $F$ for a water system) or high pressures (e.g.. greater than 500 psig), should be isolated from the work area by two closed valves in series, and a telltale vent or drain valve between the isolation valves should be opened. Systems containing hazardous materials should be isolated by two valves in series and the isolated section should be purged. When any of these conditions exists and two-valve isolation cannot be provided, specific management approval should be obtained before performing work. Exceptions to the two-valve isolation should be documented in the lockout/tagout record and in the work package."

FACILITY REQUIREMENT SOURCE: DOE-STD-1030-92 Section 4.2.3.3 Para. 3

"Piping Systems Practices 


\section{REQUIREMENTS IDENTIFICATION DOCUMENT HIGH LEVEL WASTE STORAGE TANK FARMS Occupational Safety and Health}

Verifying depressurization by breaking flanged connections, loosening valve bonnets, removing instrument tubing, or other similar actions should be avoided unless no other means for verifying depressurization exists. Strict supervisory control and advance planning are required if these methods are used."

\section{FACILITY REQUIREMENT SOURCE: DOE-STD-1030-92 Section 4.2.3.4 Para. 1}

\section{"Valve Practices}

Pneumatically operated valves and solenoid-operated valves may be used as isolation points if the following conditions are met: - A pneumatically or solenoid-operated valve that fails open is NOT considered closed for lockout/tagout purposes, unless its power (air supply is isolated and the valve is forcibly closed with an installed jacking device or gag. The valve and its power (air) supply isolation points must be tagged. - A pneumatically or solenoid-operated valve that fails closed is NOT considered closed for lockout/tagout purposes unless its power (air) supply is isolated and the valve is visually confirmed to be closed. The valve and its power (air) supply isolation points must be tagged."

\section{FACILITY REQUIREMENT SOURCE: DOE-STD-1030-92 Section 4.2.3.4 Para. 2}

"Valve Practices

A pressure operated valve or check valve CANNOT be used as an isolation boundary valve unless it is physically restrained in the required position by a gagging device approved by the facility."

FACILITY REQUIREMENT SOURCE: DOE-STD-1030-92 Section 4.2.3.4 Para. 3

-Valve Practices

A motor operated valve may be used as an isolation boundary point provided that, after the valve has been positioned as required by the lockout/tagout, its power supply is isolated and tagged."

\section{FACILITY REQUIREMENT SOURCE: DOE-STD-1030-92 Section 4.2.3.4 Para. 4}

\section{"Valve Practices}

The local control point (e.g., handwheel, manual operator) for a motor or pneumatically operated valve must be locked/tagged when the valve is used as an isolation boundary point. Any remote control points (e.g., control switches, reach rods) should also be tagged."

FACILITY REQUIREMENT SOURCE: DOE-STD-1030-92 Section 4.2.3.5 Para. 1

"Practices for Injecting Energy Potentials Into Systems and Components. Lockouts/tagouts that are established to isolate a component, portion of a piping system, or electrical circuit for the purpose of injecting an energy potential for testing (e.g., hydrostatic test, local leak-rate-test, electrical insulation test, etc.) within the lockout/tagout boundary required special consideration."

FACILITY REQUIREMENT SOURCE: DOE-STD-1030-92 Section 4.2.3.5 Para. 2

"Practices for Injecting Energy Potentials Into Systems and Components. 


\section{REQUIREMENTS IDENTIFICATION DOCUMENT \\ HIGH LEVEL WASTE STORAGE TANK FARMS Occupational Safety and Health}

The lockout/tagout should be prepared in accordance with an approved written procedure that specifically addresses the conduct of the test."

\section{FACILITY REQUIREMENT SOURCE: DOE-STD-1030-92 Section 4.2.3.5 Para. 3}

"Practices for Injecting Energy Potentials Into Systems and Components.

The initial lockout/tagout boundaries should be established to protect test personnel and test equipment while test equipment is being connected to the system or component. Other work within the area isolated for testing should be suspended, and all lockouts/tagouts within the test boundaries should be released while testing is in progress."

\section{FACILITY REQUIREMENT SOURCE: DOE/EH0135 IH.2.5}

"5. Work permits identify potentially hazardous maintenance, construction, experiments, and other non-routine activities and assure the appropriate application of safety and health expertise to planning and review of the work."

\section{FACILITY REQUIREMENT SOURCE: DOE/EH0135 WS.1.1}

"*1. There is a systematic program for identifying, and evaluating health and safety concerns, which includes:

- Potential health and safety concerns have been identified, and are evaluated to assure that they are adequately controlled and that standards are met;

- Guidelines are developed for potential health and safely concerns if no standard or assigned permissible exposure limit exists;

- Air sampling, bioassay, noise survey, etc., are conducted at the facility as called for by the facility policy statements; and

- Written evaluations giving the conclusions regarding the adequacy of workpiace safety controls, ventilation systems, and workplace monitoring data are sent to first level supervisors."

\section{FACILITY REQUIREMENT SOURCE: DOE/EH0135 WS.1.2}

"*2. Process, operating, mechanical, and/or administrative controls are effective in assuring that the health and safety of employees are adequately controlled:

- Control measures that are implemented are capable of achieving compliance with the applicable standards and DOE Orders, and

- The hierarchy of controls is as follows: engineering controls; process change or material substitution, where feasible; administrative controls; and finally, personnel protective equipment." 
WHC-EP-0750

\section{REQUIREMENTS IDENTIFICATION DOCUMENT HIGH LEVEL WASTE STORAGE TANK FARMS \\ Occupational Safety and Health}

\section{FACILITY REQUIREMENT SOURCE: DOE/EH0135 WS.4.1}

"*1. There are appropriate danger, warning, and safety information signs throughout the facility in accordance with 29 CFR 1910, Subpart J."

\section{FACILITY REQUIREMENT SOURCE: DOE/EH0135 WS.4.10}

"10. Personnel are aware of and follow procedures for lockout and tagout to prevent accidental contact with energized electrical circuits and other hazardous energy sources, in accordance with 29 CFR 1910.147."

\section{FACILITY REQUIREMENT SOURCE: DOE/EH0135 WS.4.8}

"*8. Electrical safety procedures and rules are in place in accordance with 29 CFR 1910, Subpart S."

FACILITY REQUIREMENT SOURCE: DOE/EH0135 WS.5.7

"*7. Electrical safety procedures and rules are in place in accordance with 29 CFR 1926, Subpart K."

\section{FACILITY REQUIREMENT SOURCE: DOE5480.10 Section 9.a(1)}

"The Operating Organization having line safety and health responsibilities should be required to: (a) conduct operations consistent with established health and safety procedures;"

\section{FACILITY REQUIREMENT SOURCE: DOE5480.10 Section 9.c(4)(b)}

"Regulated areas shall be established where chemical carcinogens are used. The characteristics of regulated areas shall be appropriate to assure that access is controlled and will depend on the quantity and physical properties of the material being used and on the operations being performed. A record shall be maintained of all personnel working in regulated areas."

FACILITY REQUIREMENT SOURCE: DOE5480.10 Section 9.c(4)(d)

"Signs warning of the presence of chemical carcinogens shall be posted at all entrances to regulated work areas. Labels should be used on all carcinogen containers to identify the chemical and to warn of the carcinogenic hazard."

FACILITY REQUIREMENT SOURCE: DOE5480.19 Chapter IX, Section C. 2.d.(5)

"Lockout and Tagout Implementation 2.d. (5) When locked components must be unlocked or placed in a position other than the normal locked position, the deviation should be authorized and documented." 
WHC-EP-0750

\section{REQUIREMENTS IDENTIFICATION DOCUMENT HIGH LEVEL WASTE STORAGE TANK FARMS Occupational Safety and Health}

\section{FACILITY REQUIREMENT SOURCE: DOE5480.19 Chapter IX, Section C. 2.d.(0)}

"Lockout and Tagout Implementation, 2.d. (6) Periodic checks of locked components should be performed to ensure that locking devices are properly attached and that the components is in the required position."

\section{FACILITY REQUIREMENT SOURCE: DOE5480.19 Chapter IX, Section C.2.d}

"2.d. The following administrative guidance is an example that could be established to outline acceptable controls over locked components: (1) A list of components that are required to be locked should be established and approved by the operations supervisor or appropriate manager. The list should be separate from the standard alignment checklists."

\section{SITE REQUIREMENT SOURCE: DOE5480.19 Chapter IX, Section C.2.d(1)}

"The following administrative guidance is an example that could be established to outline acceptable controls over locked components:

(1) A list of components that are required to be locked should be established and approved by the operations supervisor or appropriate manager. The list should be separate from the standard alignment checklists."

FACILITY REQUIREMENT SOURCE: DOE5480.19 Chapter IX, Section C.2.d.(2)

"2.d. (2) Criteria for locking of additional components and necessary authorizations should be provided."

FACILITY REQUIREMENT SOURCE: DOE5480.19 Chapter IX, Section C.2.d.(3)

"2.d. (3) When key operated locks are used, access to the keys should be restricted to authorized personnel. Keys should be readily available to appropriate personnel."

FACILITY REQUIREMENT SOURCE: DOE5480.19 Chapter IX, Section C.2.d.(4)

"2.d. (4) Specific techniques for verifying the position of locked components should be established. A hands-on physical check of critical equipment or the observation of a reliable position indicator should be used whenever possible."

\section{SITE REQUIREMENT SOURCE: DOE5480.19 Chapter IX, Section C.4}

"Lockout/Tagout Program

A Lockout/Tagout program should be established consisting of procedures to control potentially hazardous energy and materials and personnel training. This program should ensure that potentially hazardous energy or toxic material sources are isolated and rendered inoperative during servicing or maintenance or in any case where unexpected energizing, startup, or release of stored energy or toxic material can cause injury."

\section{SITE REQUIREMENT SOURCE: DOE5480.19 Chapter IX, Section C.5}

"Procedures for Lockout/Tagout 


\section{REQUIREMENTS IDENTIFICATION DOCUMENT HIGH LEVEL WASTE STORAGE TANK FARMS Occupational Safety and Health}

Procedures should be developed, documented, validated, und utilized for control of potentially hazardous energy or material. Procedures should clearly and specifically state the scope, purpose, authorization, rules, and techniques of the Lockout/Tagout program.

a. Procedures should include, but not be limited to, the following:

(1) Specific statement of intent of use;

(2) Specific procedural steps for isolating, blocking and securing machine or equipment for hazardous energy or material;

(3) Specific procedural steps for the placement, removal, and transfer of the Lockout/Tagout device(s); and

(4) Specific requirements to test machines and to determine and verify the effectiveness of Lockout, Tagout or other control measures.

b. It is not necessary to document the required procedure for a particular machine or equipment, when all of the following elements exist.

(1) The machine or equipment has no potential for stored or residual energy or reaccumulation of stored energy after shutdown which could endanger personnel.

(2) The machine or equipment has a single energy source which can be readily identified and isolated.

(3) The isolation and locking out of that energy source will completely de-energize and de-activate the machine or equipment.

(4) The machine or equipment is isolated from that energy source and locked out during servicing or maintenance.

(5) A single lockout device will achieve a locked out condition.

(6) The lockout device is under the exclusive control of the authorized personnel performing servicing of maintenance.

(7) The servicing or maintenance does not create hazards to other personnel.

(8) The employer, in utilizing the exception, has had no accidents involving the unexpected activation or reenergization of the machine or equipment during servicing or maintenance.

c. Documentation of Lockout/Tagout

Lockout/Tagout placement, activation and removal should be recorded including any information relevant to their occurrence. This record should be maintained by the shift supervisor or appropriate manager to ensure accuracy and completeness. The Lockout/Tagout record should be reviewed periodically by operations and maintenance personnel as guidance.

FACILITY REQUIREMENT SOURCE: DOE5480.19 Chapter IX, Section C.5.(1)(2)(3)(4)

"Procedures for Lockout and Tagout. 5. Procedures should be developed, documented, validated, and utilized for control of potentially hazardous energy or material. Procedures should clearly and specifically state the scope, purpose, authorization, rules, and techniques of the Lockout/Tagout program. a. Procedures should include, but not be limited to, the following: (1) Specific statement of intent of use; (2) Specific procedural steps for isolating, blocking and securing machines or equipment for hazardous energy or materials; (3) Specific procedural steps for the placement, removal, and transfer of the Lockout/Tagout device(s); and (4) Specific requirements to test machines and to determine and verify the effectiveness of Lockout, Tagout or other control measures. "

\section{SITE REQUIREMENT SOURCE: DOE5480.19 Chapter IX, Section C.6}

"Application of Lockout/Tagout 


\section{REQUIREMENTS IDENTIFICATION DOCUMENT HIGH LEVEL WASTE STORAGE TANK FARMS Occupational Safety and Health}

The established procedure for the application of energy control (implementing Lockout/Tagout) should cover the elements and actions in the following sequence:

\section{a. Preparation for Shutdown}

Before a machine is turned off, personnel should be informed of the type and magnitude of the energy, the hazards and the methods of control.

b. Machine or Equipment Shutdown

The equipment should be shutdown using the procedures required by this chapter. An orderly shutdown should be utilized to avoid any added hazard.

c. Equipment Isolation

All Lockout/Tagout devices needed for control are physically located and operated in such a manner as to isolate the equipment from the energy source.

d. Affixing Locks/Tags

Lockout or Tagout devices should be affixed to each isolation device by qualified personnel in a manner that will hold the devices in a "safe" or " off" position or clearly indicate that operation of the device is prohibited.

e. Stored Energy

Upon application of Lockout or Tagout devices, all potentially hazardous stored or residual energy should be relieved, disconnected, restrained, or otherwise rendered safe. If stored energy might re-accumulate to a hazardous level, verification of isolation should be continued until the servicing or maintenance is completed.

f. Verification of Installation

Prior to starting work on equipment that has been locked or tagged out, personnel should verify that isolation and deenergization have been accomplished.

g. Release from Lockout/Tagout

Before Lockout or Tagout devices are removed nd energy restored to the equipment, procedures should be followed and actions taken by personnel to ensure the following:

(1) Equipment/workspace. The machine or equipment is operationally intact. The area has been inspected to ensure that nonessential items have been removed. The individual authorizing tag removal should specify the final component position and, when appropriate, the sequence in which components should be positioned. In addition, the need to check the positioning of other components that ere not locked, or tagged, but are related to the operation of the Lockout/Tagout component, should be determined at this time and appropriate instructions should be developed. These checks should be done when necessary, to ensure that components within the Locked/Tagout boundaries are correctly aligned to support operation.

(2) Personnel. The workspace should be checked to ensure that all personnel have been positioned safely of removed from the area. Before Lockout/Tagout devices are removed and equipment energized, affected personnel should be notified that equipment will be energized.

(3) Lockout/Tagout Device Removal. Each Lockout/Tagout device should be removed from each energy-isolating device by the person who applied the device. He/she should reposition the components in the sequence specified and check the positioning as deemed necessary. The removal of Locks or Tags should be documented. Tags should be returned to the operations supervisor or authorizing manager. The supervisor/manager should be satisfied that all tags and safety devices associated with this Lockout/Tagout are removed and are accountable. When the person who applied the Lockout/Tagout device is not available to remove it, that device may be removed under the direction of the appropriate supervisor/manager, provided that specific procedures and training for such removal have been developed and incorporated into the facility program. The supervisor should demonstrate that the specific procedure provides equivalent safety to the removal of the device by the authorized personnel who applied it. The specific procedure should include the following elements:

Verification by the supervisor/manager that the person who applied the device is not available. 


\section{REQUIREMENTS IDENTIFICATION DOCUMENT HIGH LEVEL WASTE STORAGE TANK FARMS Occupational Safety and Health}

Assurance that all reasonable efforts are made to inform him/her that the device has been removed.

Ensuring that all relevant personnel have this knowledge before he/she resumes work at the facility.

\section{FACILITY REQUIREMENT SOURCE: DOE5480.19 Chapter IX, Section C.9.a.}

"Caution Tags. C.9. Caution tags should not be used for personnel protection (i.e., caution tags should not be used where it is appropriate to use a Lockout or Tagout devise).

Administration of caution tags could however, be accomplished as part of the Lockout/Tagout program or it could be covered separately. The use of caution tags should be restricted to those situation in which a component or system is functional, but when some precaution or item(s) of information is necessary prior to operation. In addition, the program should include the following elements: a. Caution tags should be uniquely identifiable and different in appearance from other station tags. The following information should be included on the tags as an aid in administering the program: (1) caution tag number (2) component name and number; (3) effective date; (4) precaution or information applicable to the particular situation and/or component or system; and (5) signature of authorizing individual and organization."

\section{FACILITY REQUIREMENT SOURCE: DOE5480.19 Chapter IX, Section C.9.b.}

"Caution Tags. C.9. b. Situations that require special operator or maintenance precautions or amplifying information should be brought to the attention of the shift supervisor or appropriate manager. The supervisor or manager should ensure that issuing a caution tag is necessary and that the tag is not being used in place of more appropriate administrative action (such as a temporary procedure change, placing an operator aide, use of the work control system, or issuance of a safety Lockout or Tagout). The supervisor review should also ensure that any instruction contained in the caution $\mathrm{t} z \mathrm{~g}$ does not deviate from established facility procedures, technical specifications, or OSR's."

\section{FACILITY REQUIREMENT SOURCE: DOE5480.19 Chapter IX, Section C.9.c.}

"Caution Tags. C.9. c. Caution tags. A record of all active caution tags and associated amplifying information should be available to the appropriate personnel. This record and associated tags shall be reviewed periodically by qualified personnel. This review should verify the continued need and applicability for each caution tag and ensure that the caution tag index accurately reflects all active caution tags. This review should be documented. Any caution tags remaining in an active status for extended periods (e.g., longer than three months, as appropriate) should be brought to the attention of the operations supervisor or manager. The operations supervisor or manager should determine what action is needed to resolve the continued use of the caution tag."

\section{FACILITY REQUIREMENT SOURCE: DOE5483.1A Chapter I, Section 1 \& 2}

"1. DOE-PRESCRIBED OSHA STANDARDS. As applicable to their work in GOCO facilities, contractors shall comply with the following DOE-prescribed OSHA standards: a. "Occupational Safety and Health Standards," Title 29 CFR Part 1910.

b. "Safety and Health Regulations for Construction," Title 29 CFR Part 1926.

c. "Occupational Safety and Health Standards for shipyard Employees," Title 20 CFR Part 1015. 


\section{REQUIREMENTS IDENTIFICATION DOCUMENT HIGH LEVEL WASTE STORAGE TANK FARMS Occupational Safety and Health}

d. "Safety and Health Regulation for Longshoring," Title 29 CFR Part 1918.

e. "Occupational Safety and Health Standards for Agriculture," Title 20 CFR Part 1920.

2. STANDARDS FILE. Each contractor shall assure that current copies of DOE-prescribed OSHA standards cited in paragraph 1, above, along with the contractor's own safety and health procedures applicable to the workplace, are available in a place and form reasonably accessible to all employees and their authorized representatives. "

\section{FACILITY REQUIREMENT SOURCE: DOE5483.1A Chapter I, Section 5.a.(1)}

"All contractor employees shall be instructed by the contractor to:

(1) Observe the DOE-prescribed OSHA standards applicable to their work and report promptly to the contractor any condition which may lead to a violation of these standards."

\section{FACILITY REQUIREMENT SOURCE: WAC-296-24 Section 11009(3)}

"Lockout or tagout devices removal. Each lockout or tagout device shall be removed from each energy isolating device by the employee who applied the device. Exception: When the authorized employee who applied the lockout or tagout device is not available to remove it, that device may be removed under the direction of the employer, provided that specific procedures and training for such removal have been developed, documented, and incorporated into the employer's energy control program. The employer shall demonstrate that the specific procedure provides equivalent safety to the removal of the device by the authorized employee who applied it. The specific procedure shall include at least the following elements:

(a) Verification by the employer that the authorized employee who applied the device is not at the facility;

(b) Making all reasonable efforts to contact the authorized employee to inform him/her that his/her lockout or tagout device has been removed; and

(c) Ensuring that the authorized employee has this knowledge before he/she resumes work at that facility."

\section{FACILITY REQUIREMENT SOURCE: WAC-296-24 Section 11011(1)}

"Testing or positioning of machines, equipment, or components thereof.

In situations in which lockout or tagout devices must be temporarily removed from the energy isolating device and the machine or equipment energized to test or position the machine, equipment or component thereof, the following sequence of actions shall be followed:

(a) Clear the machine or equipment of tools and materials in accordance with WAC

296-24-11009;

(b) Remove employees from the machine or equipment area in accordance with WAC 296-24-11009;

(c) Remove the lockout or tagout devices as specified in WAC 296-24-11009;

(d) Energize and proceed with testing or positioning;

(e) Deenergize all systems and reapply energy control measures in accordance with WAC 296-24-11007 to continue the servicing and/or maintenance."

\section{FACILITY REQUIREMENT SOURCE: WAC-296-24 Section 11011(2)}

"Outside personnel (contractors, etc.).

(a) Whenever outside servicing personnel are to be engaged in activities covered by the scope and application of this standard, the on-site employer and the outside employer shall inform each other of their respective lockout or tagout procedures. 


\section{REQUIREMENTS IDENTIFICATION DOCUMENT HIGH LEVEL WASTE STORAGE TANK FARMS Occupational Safety and Health}

(b) The outside employer shall assure that his/her employees understand and comply with the restrictions and prohibitions of the on-site employer's energy control program."

\section{FACILITY REQUIREMENT SOURCE: WAC-296-24 Section 11011(3)}

"Group lockout or tagout.

(a) When servicing and/or maintenance is performed by a crew, craft, department or other group, they shall utilize a procedure which affords the employees a level of protection equivalent to that provided by the implementation of a personal lockout or tagout device.

(b) Group lockout or tagout devices shall be used in accordance with the procedures required by WAC 296-24-11005 (4) including, but not necessarily limited to, the following specific requirements:

(i) Primary responsibility is vested in an authorized employee for a set number of employees working under the protection of a group lockout or tagout device (such as an operations lock); (ii) Provision for the authorized employee to ascertain the exposure status of individual group members with regard to the lockout or tagout of the machine or equipment; and

(iii) When more than one crew, craft department, etc., is involved, assignment of overall job-associated lockout or tagout control responsibility to an authorized employee designated to coordinate affected work forces and ensure continuity of protection; and

(iv) Each authorized employee shall affix a personal lockout or tagout device to the group lockout device, group lockbox, or comparable mechanism when he or she begins work, and shall remove those devices when he or she stops working on the machine or equipment being serviced or maintained."

\section{FACILITY REQUIREMENT SOURCE: WHC-SP-0708 Chapter 8, Section 5.3 paragraph 3}

"The following administrative elements shall be established to define acceptable controls over locked components: 1. A list of components that are required to be locked may be established and approved ;by the operations supervisor or appropriate manager. The list shall be separate from the standard alignment checklists. 2. Criteria for locking of additional components and necessary authorizations should be provided. 3 . When key operated locks are used, access to the keys should be readily available and restricted to authorized personnel. 4. Specific techniques for verifying the position of locked components shall be established. A hands-on physical check of critical equipment or the observation of a reliable position indicator should be used whenever possible. 5. When locked components must be unlocked or placed in a position other than the normal locked position, the deviation should be authorized and documented. 6. Periodic checks of locked components shall be performed to ensure that locking devices are properly attached and that the component is in the required position. 7. Lockout or tagout shall accomplished by authorized qualified personnel. 8. All equipment which requires locking and tagging for the protection of personnel from injury, protect equipment from damage, and prevent the release of hazardous material to the environment during maintenance, inspections, tests and abnormal activities shall be locked and tagged in accordance with Chapter 9 Lockouts and Tagouts. "

\section{FACILITY REQUIREMENT SOURCE: WHC-SP-0708 Chapter 9 Section 1.0, Paragraph 2.}

"The Lockout/Tagout program should provide for independent verification of the removal from service and the restoration to service of safety-related and other facility equipment." 
WHC-EP-0750

\title{
REQUIREMENTS IDENTIFICATION DOCUMENT HIGH LEVEL WASTE STORAGE TANK FARMS Occupational Safety and Health
}

\author{
FACILITY REQUIREMENT SOURCE: WHC-SP-0708 Chapter 9 Section 2.0, \\ Paragraph 3.
}

"An effective Lockout/Tagout program should be developed by each facility and should include detailed administrative procedures, training of personnel, and uniquely identifiable tags. The program should also exercise appropriate control over Lockout/Tagout preparation, approval, placement, and removal; provide for adequate documentation; and be consistent with the requirements in 29 CFR 1910."

\section{FACILITY REQUIREMENT SOURCE: WHC-SP-0708 Chapter 9 Section 4.1,}

"Shift Supervisor. Shift supervisor shall assure that required lockouts land tagouts for their area or responsibility are prepared installed and controlled in strict adherence with facility procedures."

\section{FACILITY REQUIREMENT SOURCE: WHC-SP-0708 Chapter 9 Section 5.1}

"Lockout and Tagout Use. Locks and tags shall be placed on controls for safety and or other special administrative reasons. Locks may be built into a switch or may be external locks (e.g., padlock) that are affixed or removed when necessary. Keys and combinations for locks shall be controlled. Tags shall be placed on, or as close as possible to, the control that is tagged out."

\section{FACILITY REQUIREMENT SOURCE: WHC-SP-0708 Chapter 9 Section 5.3, paragraph 4}

\begin{abstract}
"When used as the sole means of preventing operations of an energy isolating device, tagout devices, including their means of attachment shall, in addition to other requirements for their use, be of non-reusable type, attachable by hand, self-locking, and non releasable with a minimum unlocking strength of no less than fifty pounds and having the general design and basic characteristics at least equivalent to a one piece, all-environmental-tolerant nylon cable tie. Tagout device attachment means should be of a non-reusable type attachable by hand, self-locking, and non releasable. Identifiable-Tagout and lockout devices shall indicate the identify of the personnel and the organization applying the device. Warning-Tagout devices should warn against hazardous conditions if the machine or equipment is energized and should include the legend DO NOT OPERATE."
\end{abstract}

\section{FACILITY REQUIREMENT SOURCE: WHC-SP-0708 Chapter 9 Section 5.5}

"Procedures for Lockout and Tagout.

Procedures should be developed, documented, validated, and utilized for control of potentially hazardous energy or material. Procedures should clearly and specifically state the scope, purpose, authorization, rules, and techniques of the Lockout/Tagout program. Procedures should include, but not be limited to the following: 1. Specific statement of intent of use. 2 . Specific procedural steps for isolation blocking and securing machines or equipment for hazardous energy or material. 3. Specific procedural steps for the placement, removal, and transfer of the Lockout/Tagout device(s). 4. Specific requirements to test machines and to determine and verify the effectiveness of Lockout/Tagout or other control measures." 


\title{
REQUIREMENTS IDENTIFICATION DOCUMENT HIGH LEVEL WASTE STORAGE TANK FARMS \\ Occupational Safety and Health
}

\author{
FACILITY REQUIREMENT SOURCE: WHC-SP-0708 Chapter 9, Section 5.10, \\ para 3.c \\ "Caution Tags. A record of all active CAUTION TAGS and associated amplifying information \\ shall be available to the appropriate personnel. This record and associated tags shall be \\ reviewed monthly by authorized qualified personnel."
}

\section{FACILITY REQUIREMENT SOURCE: WHC-SP-0708 Chapter 9, Section 5.10, para 3.d}

"Caution Tags. The record review shall verify the continued need and applicability for each CAUTION TAG and ensure that the CAUTION TAG index accurately reflects all active CAUTION TAGS. This review shall be documented. Any CAUTION TAGS remaining in an active status for extended periods (e.g., longer than three months, or as appropriate) shall be brought to the attention of the Shift Supervisor. The Shift Supervisor shall determine what action is needed to resolve the continued use of the CAUTION TAG."

\section{FACILITY REQUIREMENT SOURCE: WHC-SP-0708 Chapter 9, Section 5.10, para 3.e}

"Caution Tags. CAUTION TAG placement-CAUTION TAGS shall be placed in such a way that they do not interfere with or obscure indications, switches, or the control devices but are readily apparent to an individual before the operation of the tagged device. Placement of CAUTION TAGS shall be documented."

\section{FACILITY REQUIREMENT SOURCE: WHC-SP-0708 Chapter 9, Section 5.11 para 2.e}

"Training and Communication. o When lockout systems are used, personnel shall be trained in the limitations of locks. The following are lock limitations: - Operations of the facility may be hindered (this is significant when local component operations are necessary, such as remove shut down or remote control). - Locks and chains installed on small instrument line isolation valves can contribute to seismic loading and may not have been considered during safety analysis."

\section{FACILITY REQUIREMENT SOURCE: WHC-SP-0708 Chapter 9, Section 5.11, para 1}

"Training and Communication. Training shall be provided and documented to ensure that the purpose and function of the lockout and tagout program is understood by all personnel and that the personnel have the knowledge and skills required for safe application, use, and removal of lockouts and tagouts."

\section{FACILITY REQUIREMENT SOURCE: WHC-SP-0708 Chapter 9, Section 5.2}

"Lockout and Tagout Implementation

If a device has the capability of being locked out, locks shall be used. If the isolating device cannot be locked out, the device shall be tagged out and an alternate method of locking out the isolating device shall be implemented. New equipment design and major modifications to existing equipment should be designed to provide the capability of being locked out. 


\section{REQUIREMENTS IDENTIFICATION DOCUMENT HIGH LEVEL WASTE STORAGE TANK FARMS \\ Occupational Safety and Health}

Experience has shown that the use of miniature tags have proven to be beneficial where circumstances warrant. Miniature tags are tagout dovices that are smaller in size than full size tags yet serve the same function as full size tags. Miniature tags shall bo used on control panels oar other areas that have closely spaced control switches and indicators and/or push-button type control switches where attachment of a full sized tag may obscure switches, indicators, controls, or identification labels."

\section{FACILTY REQUIREMENT SOURCE: WHC-SP-0708 Chapter 9, Section S.6}

"Lockout/tagout placement, activation, and removal shall be recorded, including any information relevant to their occurrence. This record shall be maintained by the Shift Supervisor to ensure accuracy and completeness. Personnel shall review the changes to the lockout and tagout record each shift as part of the shift turnover process.(Chapter 12)."

\section{FACILITY REQUIREMENT SOURCE: WHC-SP-0708 Chapter 9, Section 5.7}

"The established procedure for the application of implementing lockout and tagout shall satisfy the elements of 5.2 and the following actions in sequence."

\section{FACILITY REQUIREMENT SOURCE: WHC-SP-0708 Chapter 9, Section 5.7.2}

"Machine or Equipment Shutdown. The machine or equipment shall be shutdown using approved procedures. An orderly shutdown shall be used to avoid any added hazard."

FACILITY REQUIREMENT SOURCE: WHC-SP-0708 Chapter 9, Section 5.7.7, para 1

"Before lockout or tagout devices are removed and energy restored to the equipment, procedures should be followed to ensure the following: Equipment/Workspace-The machine or equipment is operationally intact. The area has been inspected to ensure that non essential items have been removed. Per the approved procedure, if applicable, the individual authorizing tag removal has specified the final component position and, when appropriate, the sequence in which components should be positioned. In addition, the need to check the positioning of other components that were not locked or tagged, but are related to the operations of the lockout and tagout component, should be determined at this time and appropriate instructions should be developed. When necessary check the position of other components to ensure that components within the lockout/tagout boundaries are correctly aligned to support operation."

FACILITY REQUIREMENT SOURCE: WHC-SP-0708 Chapter 9, Section 5.7.7, paragraph 2

"The Shift Supervisor shall be satisfied that all tags and safety devices associated with the lockout and tagout area are accounted for after removal and destroy the tags."

\section{FACILITY REQUIREMENT SOURCE: WHC-SP-0708 Chapter 9, Section 5.7.8}

"Lineup Verification. Independent verification of systems or component alignment should be performed and documented following removal of tags on safety-related and other important systems. Chapter 10, Independent Verification contains additional guidelines on this subject." 


\section{REQUIREMENTS IDENTIFICATION DOCUMENT HIGH LEVEL WASTE STORAGE TANK FARMS Occupational Safety and Health}

\section{FACILITY REQUIREMENT SOURCE: WHC-SP-0708 Chapter 9, Section 5.9}

"Inspections shall be conducted monthly by authorized qualified pereonnel to dotermine adherence to procedures and to correct any deviations or inadequacies observed. Inspectiona shall include a review of the responsibilities of all personnel. The Shift Supervisor shall certify that the periodic inspections have been performed, documenting the equipment and procedures involved, dates of inspection, personnel participating in the inspections, and personnel performing the inspections."

\section{Definitions of Terms}

This sub, sub-element contains the definitions that are related to the Occupational Safety and Health aspects of the Tank Farms.

\section{SITE REQUIREMENT SOURCE: 29CFR1910 Section 147 (b), Paragraph 1}

"Affected employee. An employee whose job requires him/her to operate or use a machine or equipment on which servicing or msintenance is being performed under lockout or tagout, or whose job requires him/her to work in an area in which such servicing or maintenance is being performed."

\section{SITE REQUIREMENT SOURCE: 29CFR1910 Section 147 (b), Paragraph 10}

"Normal production operations. The utilization of a machine or equipment to perform its intended production functinn."

\section{SITE REQUIREMENT SOURCE: 29CFR1910 Section 147 (b), Paragraph 11}

"Servicing and/or maintenance. Workplace activities such as constructing, installing, setting up, adjusting, inspecting, modifying, and maintaining and/or servicing machines or equipment. These activities include lubrication, cleaning or unjamming of machines or equipment and making adjustments or tool changes, where the employee may be exposed to the unexpected energization or startup of the equipment or release of hazardous energy."

\section{SITE REQUIREMENT SOURCE: 29CFR1910 Section 147 (b), Paragraph 12}

"Setting up. Any work performed to prepare a machine or equipment to perform its normal production operation."

\section{SITE REQUIREMENT SOURCE: 29CFR1910 Section 147 (b), Paragraph 13}

"Tagout. The placement of a tagout device on an energy isolating device, in accordance with an established procedure, to indicate that the energy isolating device and the equipment being controlled may not be operated until the tagout device is removed."

\section{SITE REQUIREMENT SOURCE: 29CFR1910 Section 147 (b), Paragraph 14}

"Tagout device. A prominent warning, device, such as a tag and a means of attachment, which can be securely fastened to an energy isolating device in accordance with an established 
WHC-EP-0750

\section{REQUIREMENTS IDENTIFICATION DOCUMENT HIGH LEVEL WASTE STORAGE TANK FARMS Occupational Safety and Health}

procedure, to indicate that the energy isolating device and the equipment being controlled may not be operated until the tagout dovice is removed."

\section{SITE REQUIREMENT SOURCE: 29CFR1910 Section 147 (b), Paragraph 2}

"Authorized employee. A pereon who locks out or tage out mechines or equipment in order to perform servicing or maintenance on that machine or equipment. An affected employee becomes an authorized employso when that employee's duties include performing servicing or maintenance covered under this section."

\section{SITE REQUIREMENT SOURCE: 29CFR1910 Section 147 (b), Paragraph 3}

"Capable of being locked out. An energy isolating device is capable of being locked out if it has a hasp or other means of attachment to which, or through which, a lock can be affixed, or it has a locking mochenism built into it. Other energy isolating devices are capable of being locked out, if lockout can be achieved without the need to dismentle, rebuild, or replace the energy isolating device or permanently alter its energy control capability."

\section{SITE REQUIREMENT SOURCE: 29CFR1910 Section 147 (b), Paragraph 4}

"Energized. Connected to an energy source or containing residual or stored energy."

\section{SITE REQUIREMENT SOURCE: 29CFR1910 Section 147 (b), Paragraph 5}

"Energy isolating device. A mechanical device that physically prevents the transmission or release of energy, including but not limited to the following: A manually operated electrical circuit breaker; a disconnect switch; a manually operated switch by which the conductors of a circuit can be disconnected from all ungrounded supply conductors, and, in addition, no pole can be operated independently; a line valve; a block; and any similar device used to block or isolate energy. Push buttons, selector switches and other control circuit type devices are not energy isolating devices."

\section{SITE REQUIREMENT SOURCE: 29CFR1910 Section 147 (b), Paragraph 8}

"Lockout. The placement of a lockout device on an energy isolating device, in accordance with an established procedure, ensuring that the energy isolating device and the equipment being controlled cannot be operated until the lockout device is removed."

\section{SITE REQUIREMENT SOURCE: 29CFR1910 Section 147 (b), Paragraph 9}

"Lockout device. A device that utilizes a positive means such as a lock, either key or combination type, to hold an energy isolating device in a safe position and prevent the energizing of a machine or equipment. Included are blank flanges and bolted slip blinds."

\section{SITE REQUIREMENT SOURCE: 29CFR1910 Section 331 (a)(1)}

"Premises wiring. Installations of electric conductors and equipment within or on buildings or other structures, and on other premises such as yards, carnival, parking, and other lots, and industrial substations;" 


\section{REQUIREMENTS IDENTIFICATION DOCUMENT \\ HIGH LEVEL WASTE STORAGE TANK FARMS \\ Occupational Safety and Health}

\section{SITE REQUIREMENT SOURCE: 29CFR1910 Section 331 (a), Paragraph 1}

"Covered work by both qualified and unqualified persons. The provisions of Section 1910.331 through 1910.335 cover electrical anfety-related work practices for both qualified persons (those who have training in avoiding the electrical hazards of working on or near exposed energized parts) and unqualified persons (those with little or no such training) working on, near, or with the following installations: "

\section{SITE REQUIREMENT SOURCE: 29CFR1910 Section 399, Definition - Qualified Person}

"One familiar with the construction and operation of the equipment and the hazards involved. Note 1: Whether an employee is considered to be a "qualified person" will depend upon various circumstances in the workplace. It is possible and, in fact, likely for an individual to be considered "qualified" with regard to certain equipment in the workplace, but "unqualified" as to other equipment. (See 1910.332(b)(3) for training requirements that specifically apply to qualified persons.)

Note 2: An employee who is undergoing on-the-job training and who, in the course of such training, has demonstrated an ability to perform duties safely at his or her level of training and who is under the direct supervision of a qualified person is considered to be a qualified person for the performance of those duties."

\section{FACILITY REQUIREMENT SOURCE: WAC-296-24 Section 11003(1)}

"Affected employee. An employee whose job requires him/her to operate or use a machine or equipment on which servicing or maintenance is being performed under lockout or tagout, or whose job requires him/her to work in an area in which such servicing or maintenance is being performed."

\section{FACILITY REQUIREMENT SOURCE: WAC-296-24 Section 11003(10)}

"Normal production operations. The utilization of a machine or equipment to perform its intended production function."

\section{FACILITY REQUIREMENT SOURCE: WAC-296-24 Section 11003(11)}

"Servicing and/or maintenance. Workplace activities such as constructing, installing, setting up, adjusting, inspecting, modifying, and maintaining and/or servicing machines and equipment. These activities include lubrication, cleaning, or unjamming of machines or equipment and making adjustments or tool changes, where the employee may be exposed to the unexpected energization or startup of the equipment or release of hazardous energy."

\section{FACILITY REQUIREMENT SOURCE: WAC-296-24 Section 11003(12)}

"Setting up. Any work performed to prepare a machine or equipment to perform its normal production operation." 
WHC-EP-0750

\section{REQUIREMENTS IDENTIFICATION DOCUMENT \\ HIGH LEVEL WASTE STORAGE TANK FARMS \\ Occupational Safety and Health}

FACIITY REQUIREMENT SOURCE: WAC-296-24 Section 11003(13)

"Tagout. The placement of a tagout device on an energy isolating device, in accordance with an established procedure, to indicate that the energy isolating device and the equipment being controlled may not be operated until the tagout device is removed."

\section{FACILITY REQUIREMENT SOURCE: WAC-296-24 Section 11003(14)}

"Tagout device. A prominent waming device, such as a tag and a means of attachment, which can be securely fastened to an energy isolating device in accordance with an established procedure, to indicate that the energy isolating device and the equipment being controlled may not be operated until the tagout device is removed."

\section{FACILITY REQUIREMENT SOURCE: WAC-296-24 Section 11003(2)}

"Authorized employee. A person who locks out or tags out machines or equipment in order to perform servicing or maintenance on that machine or equipment. An affected employee becomes an authorized employee when that emplcyee's duties include performing servicing or maintenance covered under this part."

\section{FACILITY REQUIREMENT SOURCE: WAC-296-24 Section 11003(3)}

"Capable of being locked out. An energy isolating device is capable of being locked out if it has a hasp or other means of attachment to which, or through which, a lock can be affixed, or it has a locking mechanism built into it. Other energy isolating devices are capable of being locked out, if lockout can be achieved without the need to dismantle, rebuild, or replace the energy isolating device or permanently alter its energy control capability."

\section{FACILITY REQUIREMENT SOURCE: WAC-296-24 Section 11003(5)}

"Energy isolating device. A mechanical device that physically prevents the transmission or release of energy, including but not limited to the following: A manually operated electrical circuit breaker; a disconnect switch; a manually operated switch by which the conductors of a circuit can be disconnected from all ungrounded supply conductors and, in addition, no pole can be operated independently; a line valve; a block; and any similar device used to block or isolate energy. Push buttons, selector switches, and other control circuit type devices are not energy isolating devices."

FACILITY REQUIREMENT SOURCE: WAC-296-24 Section 11003(0)

"Energy source. Any source of electrical, mechanical, hydraulic, pneumatic, chemical, thermal or other energy, including gravity."

\section{FACILITY REQUIREMENT SOURCE: WAC-296-24 Section 11003(8)}

"Lockout. The placement of a lockout device on an energy isolating device, in accordance with an established procedure, ensuring that the energy isolating device and the equipment being controlled cannot be operated until the lockout device is removed." 
WHC-EP-0750

\section{REQUIREMENTS IDENTIFICATION DOCUMENT HIGH LEVEL WASTE STORAGE TANK FARMS Occupational Safety and Health}

\section{FACILITY REQUIREMENT SOURCE: WAC-296-24 Section 11003(9)}

"Lockout device. A device that utilizes a positive means such as a lock, either key or combination type, to hold an energy isolating device in the safe position and prevents the energizing of a machine or equipment. Included are blank flanges and bolted slip blinds."

\section{Handling Drums and Containers}

The 29CFR1910.120 Occupational Safety and Health Administration (OSHA) has Handling Drums and Containers Requirements." The requirements in this sub sub-element specifically address these requirements.

\section{FACILITY REQUIREMENT SOURCE: 29CFR1910 Part 120(j)(1)(i)}

"Handling drums and containers.

General. Hazardous substances and contaminated soils, liquids, and other residues shall be handled, transported, labeled, and disposed of in accordance with this paragraph."

\section{FACILITY REQUIREMENT SOURCE: 29CFR1910 Part 120(j)(1)(ii)}

"Drums and containers used during the clean-up shall meet the appropriate DOT, OSHA, and EPA regulations for the wastes that they contain."

\section{FACILITY REQUIREMENT SOURCE: 29CFR1910 Part 120(j)(1)(iii)}

"When practical, drums and containers shall be inspected and their integrity shall be assured prior to being moved. Drums or containers that cannot be inspected before being moved because of storage conditions (i.e., buried beneath the earth, stacked several tiers high in a pile, etc.) shall be moved to an accessible location and inspected prior to further handling. "

\section{FACILITY REQUIREMENT SOURCE: 29CFR1910 Part 120(j)(1)(iv)}

"Unlabelled drums and containers shall be considered to contain hazardous substances and handled accordingly until the contents are positively identified and labeled."

\section{FACILITY REQUIREMENT SOURCE: 29CFR1910 Part 120(j)(1)(ix)}

"Drums and containers that cannot be moved without rupture, leakage, or spillage shall be emptied into a sound container using a device classified for the material being transferred."

\section{FACILITY REQUIREMENT SOURCE: 29CFR1910 Part 120(j)(1)(v)}

"Site operations shall be organized to minimize the amount of drum or container movement."

\section{FACILITY REQUIREMENT SOURCE: 29CFR1910 Part 120(j)(1)(vi)}

"Prior to movement of drums or containers, all employees exposed to the transfer operation shall be warned of the potential hazards associated with the contents of the drums or containers." 


\section{REQUIREMENTS IDENTIFICATION DOCUMENT HIGH LEVEL WASTE STORAGE TANK FARMS Occupational Safety and Health}

\section{FACILITY REQUIREMENT SOURCE: 29CFR1910 Part 120(j)(1)(vii)}

"U. S. Department of Transportation specified salvage drums or containers and suitable quantities of proper absorbent shall be kept available and used in areas where spills, leaks, or ruptures may occur."

\section{FACILITY REQUIREMENT SOURCE: 29CFR1910 Part 120(j)(1)(viii)}

"Where major spills may occur, a spill containment program, which is part of the employer's safety and health program required in paragraph (b) of this section, shall be implemented to contain and isolate the entire volume of the hazardous substance being transferred. "

\section{FACILITY REQUIREMENT SOURCE: 29CFR1910 Part 120(j)(1)(x)}

"A ground-penetrating system or other type of detection system or device shall be used to estimate the location and depth of buried drums or containers."

\section{FACILITY REQUIREMENT SOURCE: 29CFR1910 Part 120(j)(1)(xi)}

"Soil or covering material shall be removed with caution to prevent drum or container rupture."

\section{FACILITY REQUIREMENT SOURCE: 29CFR1910 Part 120(j)(2)(i)}

"Where an airline respirator system is used, connections to the source of air supply shall be protected from contamination and the entire system shall be protected from physical damage."

\section{FACILITY REQUIREMENT SOURCE: 29CFR1910 Part 120(j)(2)(ii)}

"Employees not actually involved in opening drums or containers shall be kept a safe distance from the dnums or containers being opened."

\section{FACILITY REQUIREMENT SOURCE: 29CFR1910 Part 120(j)(2)(iv)}

"Controls for drum or container opening equipment, monitoring equipment, and fire suppression equipment shall be located behind the explosion-resistant barrier."

\section{FACILITY REQUIREMENT SOURCE: 29CFR1910 Part 120(j)(2)(v)}

"When there is a reasonable possibility of flammable atmospheres being present, material handling equipment and hand tools shall be of the type to prevent sources of ignition."

\section{FACILITY REQUIREMENT SOURCE: 29CFR1910 Part 120(j)(2)(vi)}

"Drums and containers shall be opened in such a manner that excess interior pressure will be safety relieved. If pressure cannot be relieved from a remote location, appropriate shielding shall be placed between the employee and the drums or containers to reduce the risk of employee injury." 
WHC-EP-0750

\section{REQUIREMENTS IDENTIFICATION DOCUMENT HIGH LEVEL WASTE STORAGE TANK FARMS Occupational Safety and Health}

\section{FACILITY REQUIREMENT SOURCE: 29CFR1910 Part 120(j)(2)(vii)}

"Employees shall not stand upon or work from drums or containers."

\section{FACILITY REQUIREMENT SOURCE: 29CFR1910 Part 120(j)(3)}

"Material handling equipment. Material handling equipment used to transfer drums and containers shall be selected, positioned and operated to minimize sources of ignition related to the equipment from igniting vapors released from ruptured drums or containers."

\section{FACILITY REQUIREMENT SOURCE: 29CFR1910 Part 120(j)(4)}

"Radioactive wastes. Drums and containers containing radioactive wastes shall not be handled until such time as their hazard to employees is properly assessed."

\section{FACILITY REQUIREMENT SOURCE: 29CFR1910 Part 120(j)(5)(i)}

"All non-essential employees shall be evacuated from the area of transfer."

\section{FACILITY REQUIREMENT SOURCE: 29CFR1910 Part 120(j)(5)(ii)}

"Material handling equipment shall be provided with explosive containment devices or protective shields to protect equipment operators from exploding containers."

\section{FACILITY REQUIREMENT SOURCE: 29CFR1910 Part 120(j)(5)(iii)}

"An employee alarm system capable of being perceived above surrounding light and noise conditions shall be used to signal the commencement and completion of explosive waste handling activities."

\section{FACILITY REQUIREMENT SOURCE: 29CFR1910 Part 120(j)(5)(iv)}

"Continuous communications (i.e., portable radios, hand signals, telephones, as appropriate) shall be maintained between the employee-in-charge of the immediate handling area and both the site safety and health supervisor and the command post until such time as the handling operation is completed. Communication equipment or methods that could cause shock sensitive materials to explode shall not be used."

\section{FACILITY REQUIREMENT SOURCE: 29CFR1910 Part 120(j)(5)(v)}

"Drums and containers under pressure, as evidenced by bulging or swelling, shall not be moved until such time as the cause for excess pressure is determined and appropriate containment procedures have been implemented to protect employees from explosive relief of the drum."

\section{FACILITY REQUIREMENT SOURCE: 29CFR1910 Part 120(j)(5)(vi)}

"Drums and containers containing packaged laboratory wastes shall be considered to contain shock-sensitive or explosive materials until they have been characterized." 


\title{
REQUIREMENTS IDENTIFICATION DOCUMENT HIGH LEVEL WASTE STORAGE TANK FARMS Occupational Safety and Health
}

\author{
FACILITY REQUIREMENT SOURCE: 29CFR1910 Part 120(j)(6)(i)
}

"Lab packs shall be opened only when necessary and then only by an individual knowledgeable in the inspection, classification, and segregation of the containers within the pack according to the hazards of the wastes. "

\section{FACILITY REQUIREMENT SOURCE: 29CFR1910 Part 120(j)(6)(ii)}

"If crystalline material is noted on any container, the contents shall be handled as a shock-sensitive waste until the contents are identified."

\section{FACILITY REQUIREMENT SOURCE: 29CFR1910 Furt 120(j)(7)}

"Sampling of drum and container contents. Sampling of containers and drums shall be done in accordance with a sampling procedure which is part of the site safety and health plan developed for and available to employees and others at the specific worksite."

\section{FACILITY REQUIREMENT SOURCE: 29CFR1910 Part 120(j)(8)(i)}

"Shipping and transport. Drums and containers shall be identified and classified prior to packaging for shipment."

\section{FACILITY REQUIREMENT SOURCE: 29CFR1910 Part 120(j)(8)(ii)}

"Drum or container staging areas shall be kept to the minimum number necessary to identify and classify materials safely and prepare them for transport."

\section{FACILITY REQUIREMENT SOURCE: 29CFR1910 Part 120(j)(8)(iii)}

"Staging areas shall be provided with adequate access and egress routes."

\section{FACILITY REQUIREMENT SOURCE: 29CFR1910 Part 120(j)(8)(iv)}

"Bulking of hazardous wastes shall be permitted only after a thorough characterization of the materials has been completed."

\section{Personal Protective Equipment}

This sub-element addresses the requirements for establishing programmatic controls that ensure proper identification, control and utilization of Personal Protective Equipment (PPE) where applicable. PPE shall be used where there is a question of employee hazard exposure and a combination of engineering and administrative controls are insufficient to control hazard exposure. Although PPE is an effective method of limiting hazard exposure, engineering and administrative controls shall be applied to the maximum degree feasible prior to utilizing PPE as a means of minimizing hazard exposure. In some situations a combination of engineering/administrative controls may be necessary to effectively limit hazard exposure. 
WHC-EP-0750

\section{REQUIREMENTS IDENTIFICATION DOCUMENT HIGH LEVEL WASTE STORAGE TANK FARMS Occupational Safety and Health}

Specific measures shall be implemented to manage the use of PPE including: definition of the methods for PPE selection, distribution and use; definition of PPE inventory, maintenance, and storage requirements; definition of PPE required inspections prior to, during, and after PPE use; and evaluation of PPE effectiveness in the identified hazardous environment. Personnel medical requirements shall also be defined and satisfactorily completed prior to PPE issuance.

\section{FACILITY REQUIREMENT SOURCE: 29CFR1910 Part 120(b)(4)(ii)(C)}

"The site safety and health plan, as a minimum shall address the following: Personal protective equipment to be used by employees for each of the site tasks and operations being conducted as required by the personal protective equipment program in paragraph $(g)(5)$ of this section."

\section{FACILITY REQUIREMENT SOURCE: 29CFR1910 Part 120(b)(4)(ii)(H)}

"The site safety and health plan, as a minimum shall address the following: An emergency response plan meeting the requirements of paragraph (1) of this section for safe and effective responses to emergencies, including the necessary PPE and other equipment."

\section{FACILITY REQUIREMENT SOURCE: 29CFR1910 Part 120(c)(5)(i)}

"Personal protective equipment. Personal protective equipment (PPE) shall be provided and used during initial site entry in accordance with the following requirements; Based upon the results of the preliminary site evaluation, an ensemble of PPE shall be selected and used during initial site entry which will provicie protection to a level of exposure below permissible exposure limits and published exposure levels for known or suspected hazardous substances and health hazards, and which will provide protection against other known and suspected hazards identified during the preliminary site evaluation. If there is no permissible exposure limit or published exposure level, the employer may use other published studies and information as a guide to appropriate personal protective equipment."

\section{FACILITY REQUIREMENT SOURCE：29CFR1910 Part 120(c)(5)(ii)}

"If positive-pressure self-contained breathing apparatus is not used as part of the entry ensemble, and if respiratory protection is warranted by the potential hazards identified during the preliminary site evaluation, an escape self-contained breathing apparatus of at least five minute's duration shall be carried by employees during initial site entry."

\section{FACILITY REQUIREMENT SOURCE: 29CFR1910 Part 120(c)(5)(iii)}

"If the preliminary site evaluation does not produce sufficient information to identify the hazards or suspected hazards of the site, an ensemble providing protection equivalent to Level $B$ PPE shall be provided as minimum protection, and direct reading instruments shall be used as appropriate for identifying IDLH conditions. (See appendix B for a description of Level B hazards and the recommendations for Level B protective equipment.)" 


\section{REQUIREMENTS IDENTIFICATION DOCUMENT HIGH LEVEL WASTE STORAGE TANK FARMS Occupational Safety and Health}

\section{FACILITY REQUIREMENT SOURCE: 29CFR1910 Part 120(c)(5)(iv)}

"Once the hazards of the site have been identified, the appropriate PPE shall be selected and used in accordance with paragraph (g) of this section."

\section{FACILITY REQUIREMENT SOURCE: 29CFR1910 Part 120(g)(3)(i)}

"Personal protective equipment selection. Personal protective equipment (PPE) shall be selected and used which will protect employees from the hazards and potential hazards they are likely to encounter as identified during the site characterization and analysis."

\section{FACILITY REQUIREMENT SOURCE: 29CFR1910 Part 120(g)(3)(ii)}

"Personal protective equipment selection 'hall be based on an evaluation of the performance characteristics of the PPE relative to the requirements and limitations of the site, the task-specific conditions and duration, end the hazards and potential hazards identified at the site."

\section{FACILITY REQUIREMENT SOURCE: 29CFR1910 Part 120(g)(3)(iii)}

"Positive pressure self-contained breathing apparatus, or positive pressure air-line respirators equipped with an escape air supply, shall be used when chemical exposure levels present will create a substantial possibility of immediate death, immediate serious illness or injury, or impair the ability to escape."

\section{FACILITY REQUIREMENT SOURCE: 29CFR1910 Part 120(g)(3)(iv)}

"Totally-encapsulating chemical protective suits (protection equivalent to Level A protection as recommended in appendix B) shall be used in conditions where skin absorption of a hazardous substance may result in a substantial possibility of immediate death, immediate serious illness or injury, or impair the ability to escape."

\section{FACILITY REQUIREMENT SOURCE: 29CFR1910 Part 120(g)(3)(v)}

"The level of protection provided by PPE selection shall be increased when additional information on site conditions indicates that increased protection is necessary to reduce employee exposures below permissible exposure limits and published exposure levels for hazardous substances and health hazards. (See appendix B for guidance on selecting PPE ensembles.)"

\section{FACILITY REQUIREMENT SOURCE: 29CFR1910 Part 120(g)(3)(vi)}

"Personal protective equipment shall be selected and used to meet the requirements of 29 CFR part 1910, subpart I, and additional requirements specified in this section."

\section{FACILITY REQUIREMENT SOURCE: 29CFR1910 Part 120(g)(4)(i)}

"Totally-encapsulating chemical protective suits. Totally-encapsulating suits shall protect employees from the particular hazards which are identified during site characterization and analysis." 


\section{REQUIREMENTS IDENTIFICATION DOCUMENT \\ HIGH LEVEL WASTE STORAGE TANK FARMS Occupational Safety and Health}

\section{FACILITY REQUIREMENT SOURCE: 29CFR1910 Part 120(g)(4)(ii)}

"Totally-encapsulating suits shall be capable of maintaining positive air pressure. (See appendix A for a test method which may be used to evaluate this requirement.)"

\section{FACILITY REQUIREMENT SOURCE: 29CFR1910 Part 120(g)(4)(iii)}

"Totally-encapsulating suits shall be capable of preventing inward test gas leakage of more than 0.5 percent. (See appendix A for a test method which may be used to evaluate this requirement.)"

\section{FACILITY REQUIREMENT SOURCE: 29CFR1910 Part 120(g)(5)}

"Personal protective equipment (PPE) program. A written personal protective equipment program, which is part of the employer's safety and health program required in paragraph (b) of this section or required in paragraph $(p)(1)$ of this section and which is also a part of the site-specific safety and health plan shall be established. The PPE program shall address the elements listed below. When elements, such as donning and doffing procedures, are provided by the manufacturer of a piece of equipment and are attached to the plan, they need not be rewritten into the plan as long as they adequately address the procedure or element.

(i) PPE selection based upon site hazards,

(ii) PPE use and limitations of the equipment,

(iii) Work mission duration,

(iv) PPE maintenance and storage,

(v) PPE decontamination and disposal,

(vi) PPE training and proper fitting,

(vii) PPE donning and doffing procedures,

(viii) PPE inspection procedures prior to, during, and after use,

(ix) Evaluation of the effectiveness of the PPE program, and

(x) Limitations during temperature extremes, heat stress, and other appropriate medical considerations."

\section{FACILITY REQUIREMENT SOURCE: 29CFR1910 Part 134(c)}

"Selection of respirators. Proper selection of respirators shall be made according to the guidance of American National Standard Practices for Respiratory Protection Z88.2-1969."

\section{FACILITY REQUIREMENT SOURCE: 29CFR1910 Part 134(d)(1)}

"Air quality.

Compressed air, compressed oxygen, liquid air, and liquid oxygen used for respiration shall be of high $\mathrm{p}$ ity. Oxygen shall meet the requirements of the United States Pharmacopoeia for medical or breathing oxygen. Breathing air shall meet at least the requirements of the specification for Grade D breathing air as described in Compressed Gas Association Commodity Specification G-7.1-1966. Compressed oxygen shall not be used in supplied-air respirators or in open circuit self-contained breathing apparatus that have previously used compressed air. Oxygen must never be used with air line respirators." 


\section{REQUIREMENTS IDENTIFICATION DOCUMENT HIGH LEVEL WASTE STORAGE TANK FARMS Occupational Safety and Health}

\section{FACILITY REQUIREMENT SOURCE: 29CFR1910 Part 134(d)(2)}

"Breathing air may be supplied to respirators from cylinders or air compressors."

FACILITY REQUIREMENT SOURCE: 29CFR1910 Part 134(d)(2)(ii)

"The compressor for supplying air shall be equipped with necessary safety and standby devices. A breathing air-type compressor shall be used. Compressors shall be constructed and situated so as to avoid entry of contaminated air into the system and suitable in-line air purifying sorbent beds and filters installed to further assure breathing air quality. A receiver of sufficient capacity to enable the respirator wearer to escape from a contaminated atmosphere in event of compressor failure, and alarms to indicate compressor failure and overheating shall be installed in the system. If an oil-lubricated compressor is used, it shall have a high-temperature or carbon monoxide alarm, or both. If only a high-temperature alarm is used, the air from the compressor shall be frequently tested for carbon monoxide to insure that it meets the specifications in paragraph (d)(1) of this section."

\section{FACILITY REQUIREMENT SOURCE: 29CFR1910 Part 134(d)(3)}

"Air line couplings shall be incompatible with outlets for other gas systems to prevent inadvertent servicing of air line respirators with nonrespirable gases or oxygen."

\section{FACILITY REQUIREMENT SOURCE: 29CFR1910 Part 134(d)(4)}

"Breathing gas containers shall be marked in accordance with American National Standard Method of Marking Portable Compressed Gas Containers to Identify the Material Contained, Z48.1-1954; Federal Specification BB-A-1034a, June 21, 1968, Air, Compressed for Breathing Purposes; or Interim Federal Specification GG-B-00675b, April 27, 1965, Breathing Apparatus, Self-Contained."

\section{FACILITY REQUIREMENT SOURCE: 29CFR1910 Part 134(e)(1)}

"Use of respirators.

Standard procedures shall be developed for respirator use. These should include all information and guidance necessary for their proper selection, use, and care. Possible emergency and routine uses of respirators should be anticipated and planned for."

\section{FACILITY REQUIREMENT SOURCE: 29CFR1910 Part 134(e)(2)}

"The correct respirator shall be specified for each job. The respirator type is usually specified in the work procedures by a qualified individual supervising the respiratory protective program. The individual issuing them shall be adequately instructed to insure that the correct respirator is issued."

\section{FACILITY REQUIREMENT SOURCE: 29CFR1910 Part 134(e)(3)}

"Written procedures shall be prepared covering safe use of respirators in dangerous atmospheres that might be encountered in normal operations or in emergencies. Personnel shall be familiar with these procedures and the available respirators." 


\section{REQUIREMENTS IDENTIFICATION DOCUMENT HIGH LEVEL WASTE STORAGE TANK FARMS Occupational Safety and Health}

\section{FACILITY REQUIREMENT SOURCE: 29CFR1910 Part 134(e)(3)(i)}

"In areas where the wearer, with failure of the respirator, could be overcome by a toxic or oxygen-deficient atmospherc, at least one additional man shall be present. Communications (visual, voice, or signal line) shall be maintained between both or all individuals present. Planning shall be such that one individual will be unaffected by any likely incident and have the proper rescue equipment to be able to assist the other(s) in case of emergency."

\section{FACILITY REQUIREMENT SOURCE: 29CFR1910 Part 134(e)(3)(ii)}

"When self-contained breathing apparatus or hose masks with blowers are used in atmospheres immediately dangerous to life or health, standby men must be present with suitable rescue equipment."

\section{FACILITY REQUIREMENT SOURCE: 29CFR1910 Part 134(e)(3)(iii)}

"Persons using air line respirators in atmospheres immediately hazardous to life or health shall be equipped with safety hamesses and safety lines for lifting or removing persons from hazardous atmospheres or other and equivalent provisions for the rescue of persons from hazardous atmospheres shall be used. A standby man or men with suitable self-contained breathing apparatus shall be at the nearest fresh air base for emergency rescue."

\section{FACILITY REQUIREMENT SOURCE: 29CFR1910 Part 134(c)(5)(i)}

"Every respirator wearer shall receive fitting instructions including demonstrations and practice in how the respirator should be worn, how to adjust it, and how to determine if it fits properly. Respirators shall not be worn when conditions prevent a good face seal. Such conditions may be a growth of beard, sideburns, a skull cap that projects under the facepiece, or temple pieces on glasses. Also, the absence of one or both dentures can seriously affect the fit of a facepiece. The worker's diligence in observing these factors shall be evaluated by periodic check. To assure proper protection, the facepiece fit shall be checked by the wearer each time he puts on the respirator. This may be done by following the manufacturer's facepiece fitting instructions."

\section{FACILITY REQUIREMENT SOURCE: DOE/EH0135 IH.3.9}

"9. Proper personnel protective equipment is available, its use is enforce, and proper training for its use is provided."

\section{FACILITY REQUIREMENT SOURCE: DOE/EH0135 WS.3.9}

"*9. A documented respiratory protection program, complying with ANSI 288.2-1980, and 29 CFR 1910.134 has been implemented to ensure optimum protection against internal exposure of workers to toxic materials, including radioactive substances."

\section{FACILITY REQUIREMENT SOURCE: DOE5480.10 Section 9.a(5)}

"Employees should be required to: (a) observe all safety and health rules; (b) use all prescribed personal protective equipment; (c) follow established 


\section{REQUIREMENTS IDENTIFICATION DOCUMENT HIGH LEVEL WASTE STORAGE TANK FARMS Occupational Safety and Health}

health and safety practices and procedures; and (d) notify supervisors immediately of suspected exposures to harmful agents or conditions."

\section{FACILITY REQUIREMENT SOURCE: DOES480.10 Section 9.c(4)(e)}

"Good hygiene shall be maintained through work practices, such as: use of protective clothing; availability of showers and change rooms; bans on eating, drinking, and smoking in regulated areas; and use of nonpermeable work surfaces."

\section{FACILITY REQUIREMENT SOURCE: WAC-296-24 Section 07501}

"(1) Application

(a) Protective equipment, including personal protective equipment for eyes face, head, and extremities, protective clothing,respiratory devices, and protective shields and barriers, shall be provided, used, and maintained in a sanitary an reliable condition wherever it is necessary by reason of hazards of processes or environment, chemical hazards, radiological hazards, or mechanical irritants encountered in a manner capable of causing injury or impairment in the function of any part of the body through absorption, inhalation or physical contact.

(b) Employee owned equipment.

Where employees provide their own protective equipment, the employer shall be responsible to assure its adequacy, including proper maintenance, and sanitation of such equipment.

(c) Design. All personal protective equipment shall be of safe design and construction for the work to be performed."

\section{Facility and Equipment Safety Inspections and Maintenance}

This sub-element addresses the requirements for establishing the programmatic controls necessary for performance of facility and equipment maintenance while minimizing the occurrence of safety hazards. This sub-element also addresses the requirements for establishing the programmatic controls necessary to ensure periodic inspections of facilities and equipment are conducted to identify and prevent safety hazards.

\section{FACILITY REQUIREMENT SOURCE: 29CFR1910 Part 120(b)(4)(iv)}

"The site safety and health plan, as a minimum shall address the following: Effectiveness of site safety and health plan. Inspections shall be conducted by the site safety and health supervisor or, in the absence of that individual, another individual who is knowledgeable in occupational safety and health, acting on behalf of the employer as necessary to determine the effectiveness of the site safety and health plan. Any deficiencies in the effectiveness of the site safety and health plan shall be corrected by the employer." 


\section{REQUIREMENTS IDENTIFICATION DOCUMENT HIGH LEVEL WASTE STORAGE TANK FARMS Occupational Safety and Health}

FACILITY REQUIREMENT SOURCE: 29CFR1910 Part 120(k)(5)(l)

"Personal protective clothing and equipment. Protective clothing and equipment shall be decontaminated, cleaned, laundered, maintained or replaced as needed to maintain their effectiveness."

\section{FACILITY REQUIREMENT SOURCE: 29CFR1910 Part 120(k)(5)(ii)}

"Personal protective clothing and equipment. Employees whose non-impermeable clothing becomes wetted with hazardous substances shall immediately remove that clothing and proceed to shower. The clothing shall be disposed of or decontaminated before it is removed from the work zone."

\section{FACILITY REQUIREMENT SOURCE: 29CFR1910 Part 120(k)(6)}

"Unauthorized employees. Unauthorized employees shall not remove protective clothing or equipment from change rooms."

\section{FACILITY REQUIREMENT SOURCE: 29CFR1910 Part 120(k)(7)}

"Commercial laundries or cleaning establishments. Commercial laundries or cleaning establishments that decontaminate protective clothing or equipment shall be informed of the potential harmful effects of exposures to hazardous substances."

\section{FACILITY REQUIREMENT SOURCE: 29CFR1910 Part 120(k)(8)}

"Showers and change rooms. Where the decontamination procedure indicates a need for regular showers and change rooms outside of a contaminated area, they shall be provided and meet the requirements of 29 CFR 1910.141. If temperature conditions prevent the effective use of water, then other effective means for cleansing shall be provided and used."

\section{FACILITY REQUIREMENT SOURCE: 29CFR1910 Part 120(n)(1)(i)}

"An adequate supply of potable water shall be provided on the site."

\section{FACILITY REQUIREMENT SOURCE: 29CFR1910 Part 120(n)(1)(ii)}

"Portable containers used to dispense drinking water shall be capable of being tightly closed, and equipped with a tap. Water shall not be dipped from containers."

\section{FACILITY REQUIREMENT SOURCE: 29CFR1910 Part 120(n)(1)(iii)}

"Any container used to distribute drinking water shall be clearly marked as to the nature of its contents and not used for any other purpose."

\section{FACILITY REQUIREMENT SOURCE: 29CFR1910 Part 120(n)(1)(iv)}

"Where single service cups (to be used but once) are supplied, both a sanitary container for the unused cups and a receptacle for disposing of the used cups shall be provided." 


\section{REQUIREMENTS IDENTIFICATION DOCUMENT \\ HIGH LEVEL WASTE STORAGE TANK FARMS \\ Occupational Safety and Health}

\section{FACIITY REQUIREMENT SOURCE: 29CFR1910 Part 120(n)(2)(1)}

"Nonpotable water. Outlets for nonpotable water, such as water for firefighting purposes, shall be identified to indicate clearly that the water is unsafe and is not to be used for drinking, washing, or cooking purposes."

\section{FACILITY REQUIREMENT SOURCE: 29CFR1910 Part 120(n)(2)(ii)}

Nonpotable water. There shall be no cross-connection, open or potential, between a system furnishing potable water and a system furnishing nonpotable water."

\section{FACILITY REQUIREMENT SOURCE: 29CFR1910 Part 120(n)(3)(ii)}

"Under temporary field conditions, provisions shall be made to assure that at least one toilet facility is available."

\section{FACILITY REQUIREMENT SOURCE: 29CFR1910 Part 120(n)(3)(iii)}

"Hazardous waste sites not provided with a sanitary sewer shall be provided with the following toilet facilities unless prohibited by local codes:

(A) Chemical toilets;

(B) Recirculating toilets;

(C) Combustion toilets; or

(D) Flush toilets."

\section{FACILITY REQUIREMENT SOURCE: 29CFR1910 Part 120(n)(6)}

"Washing facilities. The employer shall provide adequate washing facilities for employees engaged in operations where hazardous substances may be harmful to employees. Such facilities shall be in near proximity to the worksite; in areas where exposures are below permissible exposure limits and published exposure levels and which are under the controls of the employer; and shall be so equipped as to enable employees to remove hazardous substances from themselves."

\section{FACILITY REQUIREMENT SOURCE: 29CFR1910 Part 120(n)(7)}

"Showers and change rooms. When hazardous waste clean-up or removal operations commence on a site and the duration of the work will require six months or greater time to complete, the employer shall provide showers and change rooms for all employees exposed to hazardous substances and health hazards involved in hazardous waste clean-up or removal operations."

\section{FACILITY REQUIREMENT SOURCE: 29CFR1910 Part 120(n)(7)(ii)}

"Change rooms shall be provided and shall meet the requirements of 29 CFR 1910.141(e). Change rooms shall consist of two separate change areas separated by the sirower area required in paragraph $(n)(7)(i)$ of this section. One change area, with an exit leading off the worksite, shall provide employees with a clean area where they can remove, store, and put on street 


\section{REQUIREMENTS IDENTIFICATION DOCUMENT HIGH LEVEL WASTE STORAGE TANK FARMS Occupational Safety and Health}

clothing. The second area, with an exit to the worksite, shall provide employees with an area where they can put on, remove and store work clothing and personal protective equipment."

\section{FACILITY REQUIREMENT SOURCE: 29CFR1910 Part 120(n)(7)(iii)}

"Showers and change rooms shall be located in areas where exposures are below the permissible exposure limits and published exposure lovels. If this cannot be accomplished, then a ventilation system shall be provided that will supply air that is below the permissible exposure limits and published exposure levels."

\section{FACILTY REQUIREMENT SOURCE: 29CFR1910 Part 120(n)(7)(iv)}

"Employers shall assure that employees shower at the end of their work shift and when leaving the hazardous waste site."

FACILITY REQUIREMENT SOURCE: 29CFR1910 Part 147 (c)(6)(i)(A)(B)(C)(D)

"Lockout and Tagout

The employer shall conduct a periodic inspection of the energy control procedure at least annually to ensure that the procedure and the requirements of this standard are followed. (A) The periodic inspection shall be performed by an authorized employee other than the one(s) utilizing the energy control procedure being inspected. (B) The periodic inspection shall be conducted to correct any deviations or inadequacies identified. (C) Where lockout is used for energy control, the periodic inspection shall include a review, between the inspection and each authorized employee, of that employee's responsibilities under the energy control procedure being inspected. (D) Where tagout is used for energy control, the periodic inspection shall include a review, between the inspector and each authorized and affected employee, of that employee's responsibilities under the energy control procedure being inspected, and the elements set forth in paragraph (c)(7)(ii) of this section."

\section{FACILITY REQUIREMENT SOURCE: 29CFR1910 Part 147 (c)(0)(ii)}

"Lockout and Tagout

(ii) The employer shall certify that the periodic inspections have been performed. The certification shall identify the machine or equipment on which the energy control procedure was being utilized, the date of the inspection, the employees included in the inspection, and the person performing the inspection."

\section{FACILITY REQUIREMENT SOURCE: 29CFR1910 Part 147 (I)(1)}

\section{"Lockout and Tagout}

(f) Additional requirements. (1) Testing or positioning of machines, equipment or components thereof. In situations in which lockout or tagout devices must be temporarily removed from the energy isolating device and the machine or equipment energized to test or position the machine, equipment or component thereof, the following sequence of actions shall be followed: (i) Clear the machine or equipment of tools and materials in accordance with paragraph (e)(1) of this section; (ii) Remove employees from the machine or equipment area in accordance with paragraph (e)(2) of this section; (iii) Remove the lockout or tagout devices as specified in paragraph (e)(3) of this section; (iv) Energize and proceed with testing or positioning; (v) 
WHC-EP-0750

\section{REQUIREMENTS IDENTIFICATION DOCUMENT HIGH LEVEL WASTE STORAGE TANK FARMS Occupational Safety and Health}

Deenergize all systems and reapply energy control measure in accordance with paragraph (d) of this section to continue the servicing and/or maintenance."

\section{FACILITY REQUIREMENT SOURCE: 54FR3904 Part (c)(3)(iv)}

"Establish a medical program which incluves availability of first aid on sito and of physician and emergency medical care nearby, so that harni will be minimized if an injury or illness does occur."

\section{FACILITY REQUIREMENT SOURCE: DOE/EH0135 PP.3.3}

"3. Periodic inspection and maintenance programs are established for all mechanical/engineered contaminant control systems.

FACILITY REQUIREMENT SOURCE: DOE/EH0135 WS.4.10

"10. Personnel are aware of and follow procedures for lockout and tagout to prevent accidental contact with energized electrical circuits and other hazardous energy sources, in accordance with 29 CFR 1910.147."

FACILITY REQUIREMENT SOURCE: DOE/EH0135 WS.4.12

"12. Hand and portable power tools, and other hand-held equipment meet the requirements of 29 CFR 1910 Subpart P."

FACILITY REQUIREMENT SOURCE: DOE/EH0135 WS.4.4

"*4. Guarding is available and in place, as specified in 29 CFR 1910, Subpart $O$ for machines and tools with moving and rotating parts that may present workplace safety concerns."

\section{FACILITY REQUIREMENT SOURCE: DOE/EH0135 WS.4.6}

"*6. There is an inspection and preventative maintenance program for powered platforms, hoisting and rigging devices, cranes and other powered tools and machinery. Operational procedures are in compliance with the DOE Hoisting and Rigging Manual, and 29 CFR 1910, Subparts F and N."

\section{FAC'LITY REQUIREMENT SOURCE: DOE/EH0135 WS.4.7}

**7. Compressed gas containers and other high pressure systems are inspected, stored, and maintaitsed to minimize occupational safety concerns in accordance with 29 CFR 1910, Subparts H and M."

\section{FACILITY REQUIREMENT SOURCE: DOE3790.1A Chapter VIII, Section 5.b}

"Preplacement Health Evaluation. Prior to employment, where a hazard is associated with job performance, each employee shall have a complete health evaluation, with special emphasis placed upon the health and physical factors 


\section{REQUIREMENTS IDENTIFICATION DOCUMENT HIGH LEVEL WASTE STORAGE TANK FARMS Occupational Safety and Health}

that relate to the hazards of the position. The purpose of this examination is to determine an employee's health status prior to any exposures associated with a job. In addition, it is to determine the employee's physical capabilities and any required accommodations necessary for safe and healthy job performance. The health evaluation shall be performed by the health services staff at no cost to the employee."

\section{FACILITY REQUIREMENT SOURCE: DOE3790.1A Chapter VIII, Section 5.n}

"Reporting Requirements.

(1) Heads of Field Organizations, the designated Headquarters official, or designees, shall be advised of the results of each health evaluation performed on one of their employees which contains meaningful data relative to physical limitations and/or work restrictions in order to ensure safe placement of the employee.

(2) A monthly summary of the types of treatments performed by the health services staff shall be submitted to the safety and health official of each field organization or Headquarters as appropriate."

\section{FACILITY REQUIREMENT SOURCE: DOE3790.1A Chapter VII, Section 5.o}

"Medical Records.

(1) Field Organizations shall maintain records of employee medical examinations in accordance with instructions of the Office of Personnel Management in the Federal Personnel Manual, chapter 339; DOE 1700.1; and DOE 1800.1A.

(2) Medical records and professional evaluations of current employees and persons selected for appointment will be maintained under the control of health service personnel and for use only by professional personnel, industrial hygienists, and health physicists."

\section{FACILITY REQUIREMENT SOURCE: DOE5480.10 Section 9.b(6)}

"Medical Monitoring. The industrial hygiene staff shall inform the medical organization of potential and existing health hazards identified, the results of hazard evaluations, and other industrial hygiene information needed for operation of a medical monitoring program. The industrial hygiene staff should be available to accompany medical staff on periodic worksite visits (refer to DOE 5480.8))."

\section{FACILITY REQUIREMENT SOURCE: DOE5480.19 Chapter IX, Section C.8.}

"Periodic Inspections

Periodic Inspections. C.8. Periodic inspections should be conducted by authorized personnel, supervisor, or appropriate manager, to determine whether procedures are being followed and to correct any deviations or inadequacies observed. Inspections should include a review of the responsibilities of personnel and supervisors. The supervisor or appropriate manager should certify that the periodic inspections have been performed, documenting the equipment and procedures involved, dates of inspection, personnel participating in the inspections, and personnel performing the inspertions." 
WHC-EP-0750

\section{REQUIREMENTS IDENTIFICATION DOCUMENT HIGH LEVEL WASTE STORAGE TANK FARMS Occupational Safety and Health}

\section{FACILITY REQUIREMENT SOURCE: WHC-SP-0708 Chapter 9, Section 5.8}

"Testing or Positioning of Equipment. Temporary removal of lockout and tagout devices shall be discouraged. However, situations in which lockout and tagout devices must be temporarily removed and the equipment energized, the following sequence of operations shall be followed: 5.8.1 Removal must be approved by supervisor. 5.8.2 Clear the equipment of tools and materials. 5.8.3 Remove personnel from the equipment area. 5.8.4 Remove the lockout and tagout device as directed by procedure. 5.8.5 Energize and proceed with testing or positioning. 5.8.6 de-energize all systems and reinstall lockout and tagout. This lockout and tagout shall be controlled and documented with the same rigor as used in the original lockout/tagout."

\section{OCCUPATIONAL HEALTH PROGRAM}

This element describes the basis of an effective Occupational Medical Program. The Occupational Medical Program is designed and operated to protect and enhance the physical and mental health of employees and to promote public health.

\section{FACILITY REQUIREMENT SOURCE: 29CFR1910 Part 120(b)(3)(v)}

"The comprehensive workplan shall provide for the implementation of the required informational programs required in paragraph (i) of this section."

\section{FACILITY REQUIREMENT SOURCE: 29CFR1910 Part 120(b)(4)(ii)(D)}

"The site safety and health plan, as a minimum shall address the following: Medical surveillance requirements in accordance with the program in paragraph $(f)$ of this section."

\section{FACILITY REQUIREMENT SOURCE: 29CFR1910 Part 120(I)(1)}

"Medical surveillance. General. Employers engaged in operations specified in paragraphs (a)(1)(i) through (a)(1)(iv) of this section and not covered by (a)(2)(iii) exceptions and employers of employees specified in paragraph $(q)(9)$ shall institute a medical surveillance program in accordance with this paragraph."

\section{FACILITY REQUIREMENT SOURCE: 29CFR1910 Part 120(f)(2)}

"Employees covered. The medical surieillance program shall be instituted by the employer for the following employees: (i) All employees who are or may be exposed to hazardous substances or health hazards at or above the permissible exposure limits, or, if there is no permissible exposure limit, above the published exposure levels for these substances, without regard to the use of respirators, for 30 days or more a year;

(ii) All employees who wear a respirator for 30 days or more a year or as required by $\S$ 1910.134;

(iii) All employees who are injured, become ill or develop signs or symptoms due to possible overexposure involving hazardous substances or health hazards from an emergency response or hazardous waste operation; and

(iv) Members of HAZMAT teams." 
WHC-EP-0750

\section{REQUIREMENTS IDENTIFICATION DOCUMENT HIGH LEVEL WASTE STORAGE TANK FARMS \\ Occupational Safety and Health}

\section{FACILITY REQUIREMENT SOURCE: 29CFR1910 Part 120(f)(5)}

"Examination by a physician and costs. All medical examinations and procedures shall be performed by or under the supervision of a licensed physician, preferably one knowledgeable in occupational medicine, and shall be provided without cost to the employee, without loss of pay, and at a reasonable time and place."

\section{Health Examinations}

This sub-element addresses the requirements to provide employees with comprehensive health examinations. Comprehensive health examinations shall assess the health of workers to ensure proper placement and retention of workers in positions commensurate with their physical, mental, and emotional capacities.

\section{FACILITY REQUIREMENT SOURCE: 29CFR1910 Part 120(f)(3)}

"Frequency of medical examinations and consultations. Medical examinations and consultations shall be made available by the employer to each employee covered under paragraph (f)(2) of this section on the following schedules: "

\section{FACILITY REQUIREMENT SOURCE: 29CFR1910 Part 120(f)(3)(i)}

"Frequency of medical examinations and consultations. For employees covered under paragraphs $(f)(2)(i),(f)(2)(i i)$, and $(f)(2)(i v)$ :

(A) Prior to assignment;

(B) At least once every twelve months for each employee covered unless the attending physician believes a longer interval (not greater than biennially) is appropriate;

(C) At termination of employment or reassignment to an area where the employee would not be covered if the employee has not had an examination within the last six months;

(D) As soon as possible upon notification by an employee that the employee has developed signs or symptoms indicating possible overexposure to hazardous substances or health hazards or that the employee has been injured or exposed above the permissible exposure limits or published exposure levels in an emergency situation;

(E) At more frequent times, if the examining physician determines that an increased frequency of examination is medically necessary."

\section{FACILITY REQUIREMENT SOURCE: 29CFR1910 Part 120(f)(6)}

"Information provided to the physician. The employer shall provide one copy of this standard and its appendixes to the attending physician, and in addition the following for each employee:

(i) A description of the employee's duties as they relate to the employee's exposures.

(ii) The employee's exposure levels or anticipated exposure levels.

(iii) A description of any personal protective equipment used or to be used.

(iv) Information from previous medical examinations of the employee which is not readily available to the examining physician.

(v) Information required by $\S 1910.134$." 
WHC-EP-0750

\section{REQUIREMENTS IDENTIFICATION DOCUMENT HIGH LEVEL WASTE STORAGE TANK FARMS \\ Occupational Safety and Health}

FACILITY REQUIREMENT SOURCE: DOE/EH0135 MS.3.5

"5. Medical screening and testing of new, continuing and former employees assures that the health of employees is adequately controlled."

\section{FACILITY REQUIREMENT SOURCE: DOE3790.1A Chapter VIII, Section 5.b}

"Preplacement Health Evaluation. Prior to employment, where a hazard is associated with job performance, each employee shall have a complete health evaluation, with special emphasis placed upon the health and physical factors that relate to the hazards of the position. The purpose of this examination is to determine an employee's health status prior to any exposures associated with a job. In addition, it is to determine the employee's physical capabilities and any required accommodations necessary for safe and healthy job performance. The health evaluation shall be performed by the health services staff at no cost to the employee."

FACILITY REQUIREMENT SOURCE: DOE3790.1A Chapter VIII, Section 5.c

"Health Screening Evaluation. Each employee age 45 and over shall be offered a complete health evaluation annually at no cost to the employee."

FACILITY REQUIREMENT SOURCE: DOE3790.1A Chapter VIII, Section 5.d

"Job Change or Transfer Health Evaluation.

(1) Employees who change or transfer job functions with associated hazards

(e.g., electrician to lineman or lineman to crane operator) shall have their health status and physical fitness reviewed with emphasis on the effects of the position vacated and the health and physical factors that relate to the new job tasks and demands. The evaluation shall be at no cost to the employee.

(2) Employees who change or transfer from a job function with associated hazards to a job function with negligible associated hazards or vice versa (e.g., courier to file clerk or draftsman to lineman) shall have their health status and physical fitness reviewed with emphasis on the effects of the position vacated or the heaith and physical factors that relate to the new job tasks and demands, for whichever involves hazards. The evaluation shall be at no cost to the employee."

\section{FACILITY REQUIREMENT SOURCE: DOE3790.1A Chapter VIII, Section 5.e}

"Retirement or Separation Health Evaluation. The health status of an employee who is retiring or separating from a position where there is an associated hazard shall be determined by a health evaluation, with emphasis placed upon the health and physical factors of that position. The evaluation shall be at no cost to the employee."

\section{FACILITY REQUIREMENT SOURCE: DOE3790.1A Chapter VIII, Section 5.f}

"Return to Work (Fitness-for-Duty) Evaluation. An employee who occupies a 


\section{REQUIREMENTS IDENTIFICATION DOCUMENT HIGH LEVEL WASTE STORAGE TANK FARMS Occupational Safety and Health}

position with an associated hazard, who is absent from work more than 3 consecutive workdays due to either an occupational or a nonoccupational illness or injury, shall submit either a health status report from a personal physician (obtained at the employee's expense) to the employee's supervisor stating that the employee is fit to work, or shall undergo a health evaluation by the health services staff (at no cost to the employee) sufficient to ensure that the employee's return to work will be without undue health hazard or accident risk to the employee or others. "

\section{FACILITY REQUIREMENT SOURCE: DOE3790.1A Chapter VIII, Section 6}

"NONMANDATORY COMPONENTS. In order to enhance the Federal Employee Occupational Medical Program, the following optional health screening is suggested:

a. Employees under age $\mathbf{4 5}$ may be offered a complete health evaluation on a space-available basis at no cost to the employee.

b. Employees in a hazardous occupation should be given priority consideration

for health evaluations. "

\section{FACILITY REQUIREMENT SOURCE: DOE5480.10 Section 9.b(6)}

"Medical Monitoring. The industrial hygiene staff shall inform the medical organization of potential and existing health hazards identified, the results of hazard evaluations, and other industrial hygiene information needed for operation of a medical monitoring program. The industrial hygiene staff should be available to accompany medical staff on periodic worksite visits (refer to DOE 5480.8))."

\section{FACILITY REQUIREMENT SOURCE: DOE5480.10 Section 9.f(5)}

"Industrial hygiene hazard inventories, reports, and monitoring data shall be readily accessible to the medical organization responsible for operating the medical monitoring program. Records access shall be provided to employees or designated representatives of employees in accordance with OSHA Regulation 29 CFR 1910.20 and DOE Privacy Act Regulation 10 CFR 1008.17(b)(5)."

\section{FACILITY REQUIREMENT SOURCE: DOE5480.8A Section 11.b(1)}

"Shall be a physician who is a graduate of an accredited school of medicine or osteopathy and who meets the licensing requirements applicable to the locations in which the physician works. Board certification in occupational medicine is preferred."

\section{FACILITY REQUIREMENT SOURCE: DOE5480.8A Section 11.b(2)}

"(2) Comprehensive Health Examination Content. The comprehensive health examination shall be conducted by an OHE under the direction of a licensed physician, using whatever ancillary assistance is needed in accordance with current, sound, and acceptable medical practices. The minimum content is 


\section{REQUIREMENTS IDENTIFICATION DOCUMENT \\ HIGH LEVEL WASTE STORAGE TANK FARMS Occupational Safety and Health}

described for the preplacement or other required comprehensive examinations. Additions may be needed, as determined by the Site Medical Director, considering the purpose(s) of the examination, health hazards of current and former employment, and personal health-risk factors.

(a) Medical History. The medical history shall include information concerning the employee's current illness or health status, review of systems, past medical history, occupational history, review of a current job task analysis, family history, immunization history, smoking and other lifestyle factors, allergy history, travel history, and history of mental or emotional disorders.

(b) Physical Examination. The physical examination shall include an evaluation of head, neck, eyes, ears, nose, throat, mouth, heart, lungs, abdomen, genitourinary system, vascular and lymphatic systems, skin, musculoskeletal system, a brief neurological examination, and a measurement of height, weight, pulse and blood pressure. A digital rectal and prostate examination shall be offered to males age 40 and above. Both a pelvic and breast examination shall be offered to females. It may include mammography, a pap smear, sigmoidoscopy, and tonometry over 34 years of age to conform to good preventive medicine practices. When the resources and capability will not permit the performance of these specialized examinations, the employee is to be advised as to their value and urged to obtain them from a personal physician.

(c) Laboratory Studies. The basic laboratory work shall include:

1 Vision testing (to include near, distant, color vision, depth perception, and horizontal peripheral field of vision);

2 Complete blood count and blood chemistry profile;

3 Urinalysis and serology when indicated;

4 An audiogram as a baseline, then every 3-5 years unless exposed to noise at or above 85 decibels, then annually;

5 A pulmonary function test as a baseline, then every 3-5 years unless exposed to pulmonary irritants, a history of pulmonary disease, or when OHE deems it necessary; 


\section{REQUIREMENTS IDENTIFICATION DOCUMENT HIGH LEVEL WASTE STORAGE TANK FARMS Occupational Safety and Health}

6 An electrocardiogram as a baseline, then annually for over age 50, a history of heart disease, or when OHE deems it necessary; and

7 Other laboratory tests required by OSHA/DOE shall be obtained.

(d) Guidelines for Use of X-rays. The recommendations and guidance contained in 43 FR 4377, of 2-1-78, should be considered. All radiographs shall be interpreted by a qualified radiologist or as specified by OSHA/DOE.

(e) Review and Evaluation of Examination. The OHE shall discuss the results of the examination with the employee. The OHE shall provide health counseling and advice, especially as related to risk factors that may cause premature morbidity or mortality. Employees shall be encouraged to have private physicians and should be referred to private physicians for any necessary definitive care or followup treatment, and for any necessary additional diagnostic studies that are beyond the scope of the occupational health examination. The health interests of employees are best served by close communication and cooperation between private and occupational health physicians."

FACILITY REQUIREMENT SOURCE: DOE5480.8A Section 11.b(3)(a)

"Preplacement Evaluations.

1 A medical evaluation of an individual shall be conducted after the job offer, but prior to the performance of $j \mathrm{c} b$ duties, and in the case of an employee, prior to a job transfer. The health status and fitness for duty of the individual shall be determined, thereby assuring that assigned duties can be performed in a safe and reliable manner and consistent with the Americans with Disabilities Act of 1990.

2 Contractor management shall provide to the Site Occupational Medical Director a job task analysis pertaining to the applicant/employee to enable the medical examiner to assess the individual as required in $11 \mathrm{~b}(3)(\mathrm{a}) 1$.

3 The scope of the initial preplacement evaluation shall be a comprehensive examination as outlined in paragraph $11 \mathrm{~b}(2)$. The Site Occupational Medical Director shall determine additional examination content, considering such factors as special physical or mental requirements of the job, potential hazardous exposures, or medical surveillance requirements mandated by the Occupational Safety and Health Act, 29 CFR 1910 or 29 CFR 1926.

4 Those contractor operations requiring large numbers of preplacement 


\section{REQUIREMENTS IDENTIFICATION DOCUMENT HIGH LEVEL WASTE STORAGE TANK FARMS Occupational Safety and Health}

evaluations may defer the comprehensive evaluation of individuals not assigned to hazardous work or potentially hazardous exposures after a review of the individual's medical history. The evaluation shall be performed within 6 months of the hire date.

5 The occupational medical department shall be informed of all job transfers. The Occupational Medical Director or designee should determine whether a medical evaluation is necessary."

\section{FACILITY REQUIREMENT SOURCE: DOE5480.8A Section 11.b(3)(b)}

"(b) Medical Surveillance Examinations and Health Monitoring. Standards and requirements for special health examinations and health monitoring of employees who work in jobs involving specific physical, chemical, or biological hazards shall be in accordance with applicable OSHA/DOE standards. When employees are exposed to potential hazards not covered by regulations, appropriate special examinations may be required as determined by the Site Medical Director and approved by the DOE Director, Office of Occupational Medicine."

FACILITY REQUIREMENT SOURCE: DOE5480.8A Section 11.b(3)(c)

"(c) Qualification Examinations.

1 Examinations shall be conducted to qualify employees for specific job assignments for which specific medical qualification standards exist (e.g., drivers, pilots, protective force personnel, and respirator wearers).

2 Special medical evaluations shall be performed in response to contractor management's request to determine employee fitness for duty."

FACILITY REQUIREMENT SOURCE: DOE5480.8A Section 11.b(3)(d)

"(d) Voluntary Periodic Examinations. Voluntary periodic examinations shall be offered; however, it should be recognized that specific work hazards or statutory requirements as outlined in $11 \mathrm{~b}(3)(\mathrm{b})$ and $11 \mathrm{c}$ may dictate more frequent health examinations to maintain an effective occupational medical program. A fundamental purpose of these examinations is to provide employees with the periodic assessment of their health. Accordingly, relevant components of the comprehensive examination, paragraph $11 \mathrm{~b}(2)$, may be included, as well as other preventive health measures such as health-risk appraisals or wellness counseling as authorized by the Site Medical Director.

1 Employees age 50 and over shall be offered a biennial health examination. Content shall be based upon guidelines established by the Site Medical Director, considering work assignment and individual risk factors.

2 Employees age 40-49 shall be offered a health 


\section{REQUIREMENTS IDENTIFICATION DOCUMENT HIGH LEVEL WASTE STORAGE TANK FARMS Occupational Safety and Health}

examination every 3 years.

3 Employees under age 40 shall be offered a health examination every 5 years."

FACILITY REQUIREMENT SOURCE: DOE5480.8A Section 11.b(3)(e)

"(e) Return-to-Work Health Evaluations.

1 Occupational Injury or Illness.

All employees with occupationally-related injuries or illnesses shall be evaluated before returning to work. The scope and content of this evaluation shall be determined by the OHE, based upon the nature and extent of the injury or disease, and shall be sufficient to ensure that the employee may return to work without undue health risk to self or others. Written clearance from the occupational medical department shall be required before such an employee may return to work.

2 Nonoccupational Injury or Illness. Contractor management, in the following situations, shall ensure that employees will not be allowed to return to work until they receive a health evaluation and written clearance from the occupational medical department. Situations warranting evaluation and clearance include nonoccupational-related illnesses or injuries causing absence from work for 5 consecutive workdays or more, procedures or treatments that would affect negatively the employee's ability to perform in a safe and reliable manner, and hospitalization. The employee shall provide relevant medical information from their private physician to assist in this determination. The final decision for health-related work recommendations shall reside with the Site Medical Director if a disagreement exists regarding return-to-work suitability."

\section{FACILITY REQUIREMENT SOURCE: DOE5480.8A Section 11.b(3)(f)}

"(f) Termination Health Evaluations. A health status review shall be made available for all terminating employees. Based upon the information obtained, a health examination (the content to be determined by the Site Occupational Medical Director) shall be conducted, whenever possible, on employees with known occupational illnesses or injuries, documented or presumed exposures required by OSHA regulations, or when more than 1 year has elapsed since the last examination. This should include a review of the medical record, associated exposure information, and a signed response by the employee to each of the following questions:

1 Have there been recent occupational illnesses or injuries not previously reported?

2 Have you ever been informed of an exposure to radiation or toxic materials above permissible limits?

3 Do you have any complaints or concerns related to prior 


\section{REQUIREMENTS IDENTIFICATION DOCUMENT HIGH LEVEL WASTE STORAGE TANK FARMS Occupational Safety and Health}

illnesses, injuries, or exposures?

4 Do you have any current medical complaints?"

\section{Health Maintenunce and Preventive Medicine}

This sub-element addresses the requirements for providing employees with health maintenance and preventive maintenance care. These activities will help increase worker effectiveness through preservation and improvement of worker health. Specifically, the Occupational Medical Program shall provide continuing health education and promote overall fitness.

An Employee Assistance Program (EAP) shall be established to provide rehabilitation assistance to employees who need help with alcohol/drug abuse and/or psychological problems.

\section{FACILITY REQUIREMENT SOURCE: 29CFR1910 Part 120(f)(7)(i)}

"Physician's written opinion. The employer shall obtain and furnish the employee with a copy of a written opinion from the attending physician containing the following:

(A) The physician's opinion as to whether the employee has any detectable medical conditions which would place the employee at increased risk of material impairment of the employee's health from work in hazardous waste operations or emergency response, or from respirator use.

(B) The physician's recommended limitations upon the employee's assigned work.

(C) The results of the medical examination and tests if requested by the employee.

(D) A statement that the employee has been informed by the physician of the results of the medical examination and any medical conditions which require further examination or treatment."

\section{FACILITY REQUIREMENT SOURCE: 29CFR1910 Part 120(f)(7)(ii)}

"Physicians written opinion. The written opinion obtained by the employer shall not reveal specific findings or diagnoses unrelated to occupational exposures."

\section{FACILITY REQUIREMENT SOURCE: DOE/EH0135 MS.5.4}

"4. An active health awareness and wellness program is implemented at the site/facility."

\section{FACILITY REQUIREMENT SOURCE: DOE3790.1A Chapter VIII, Section 5.h}

"Screening Examinations. Tests and immunizations for specific diseases shall be provided as necessary by health services personnel."

\section{FACILITY REQUIREMENT SOURCE: DOE3790.1A Chapter VIII, Section 5.i}

"Health Education and Counseling, provided at no cost to employees, shall include:

(1) Lectures on health and health education materials to promote and 


\title{
REQUIREMENTS IDENTIFICATION DOCUMENT HIGH LEVEL WASTE STORAGE TANK FARMS Occupational Safety and Health
}

encourage employees to improve and maintain personal health;

(2) Individual counseling on health matters; and

(3) Utilization of available Employee Assistance Program services."

\section{FACILITY REQUIREMENT SOURCE: DOE5480.8A Section 11.d(1)}

\author{
"EAP and Wellness Program.
}

(a) The Site Occupational Medical Director shall review and approve the medical aspects which include physical and mental health, stress and emotional/behavioral problems of all contractor-sponsored or supported EAP, as well as alcohol and other substance abuse rehabilitation programs. Program evaluation accountability shall include treatment processes, records, referrals, treatment outcomes, followup (aftercare programs), and staffing.

(b) The Site Occupational Medical Director shall review, approve and coordinate all contractor-sponsored or supported wellness programs as essential components of a preventive medicine program. Health counseling should be available to all employees. Program evaluation and accountability shall address the training/education opportunities provided, lesson plans, class evaluation records, and referral/counseling sessions."

\section{FACILITY REQUIREMENT SOURCE: DOE5480.8A Section 11.d(2)}

"Immunization Program.

(a) Tetanus/Diphtheria immunization shall be available for all employees, consistent with Centers for Disease Control (CDC) guidelines.

(b) Employees involved in foreign travel shall be advised to obtain the immunizations recommended by CDC and the Public Health Service of the U.S. Department of Health and Human Services.

(c) In the interest of saving lost time off the job, elective care, such as serial desensitizations for allergy, may be given at the discretion of the Site Occupational Medical Director with the written advice and consent of the employee's private physician.

(d) Using CDC guidelines, influenza vaccine shall be offered to all employees.

(e) Hepatitis B vaccine shall be offered according to CDC guidelines.

(f) The Site Occupational Medical Director shall ensure that immunization programs for bloodborne pathogens and biohazardous waste conform to OSHA regulations and CDC guidelines for those employees at risk to these forms of exposure."

\section{FACILITY REQUIREMENT SOURCE: EEI Chapter II, Section 10}

Though an effective policy prohibiting alcohol and drug abuse is key to an 


\section{REQUIREMENTS IDENTIFICATION DOCUMENT HIGH LEVEL WASTE STORAGE TANK FARMS Occupational Safety and Health}

effective fitness for duty program, the availability of rehabilitation assistance to individuals who need it can substantially strengthen such a program. Employee Assistance Programs should help employees free themselves from drug and alcohol abuse and/or psychological problems and retum to productive work.

\section{Diagnosis and Treatment}

This sub-element addresses the proper diagnosis and treatment of employee occupational injury and illness is essential to facilitate employee rehabilitation and quick return to work. The Occupational Medical Program shall also provide assistance for employee who become ill while at work (due to non-occupational reasons). Employees shall be encouraged to use private physicians and/or medical facilities for diagnosis and treatment of non-occupational injuries and illnesses, thereby reducing facility health costs. In emergencies, employees shall be given the necessary assistance until referral to a private physician or facility is possible.

\section{FACILITY REQUIREMENT SOURCE: 29CFR1910 Part 120(f)(3)(ii)}

"Frequency of medical examinations and consultations. For employees covered under paragraph (f)(2)(iii) and for all employees including those of employers covered by paragraph (a)(1)(v) who may have been injured, received a health impairment, developed signs or symptoms which may have resulted from exposure to hazardous substances resulting from an emergency incident, or exposed during an emergency incident to hazardous substances at concentrations above the permissible exposure limits or the published exposure levels without the necessary personal protective equipment being used:

(A) As soon as possible following the emergency incident or development of signs or symptoms;

(B) At additional times, if the examining physician determines that follow-up examinations or consultations are medically necessary."

\section{FACILITY REQUIREMENT SOURCE: 29CFR1910 Part 120(I)(4)(i)}

"Content of medical examinations and consultations. Medical examinations required by paragraph $(f)(3)$ of this section shall include a medical and work history (or updated history if one is in the employee's file) with special emphasis on symptoms related to the handling of hazardous substances and health hazards, and to fitness for duty including the ability to wear any required PPE under conditions (i.e., temperature extremes) that may be expected at the work site."

\section{FACILITY REQUIREMENT SOURCE: 29CFR1910 Part 120(f)(4)(ii)}

"Content of medical examinations and consultations. The content of medical examinations or consultations made available to employees pursuant to paragraph ( $f$ ) shall be determined by the attending physician. The guidelines in the Occupational Safety and Health Guidance Manual for Hazardous Waste Site Activities (See appendix D, Reference No. 10) should be consulted." 


\section{PFQUIREMENTS IDENTIFICATION DOCUMENT HIIGH LEVEL WASTE STORAGE TANK FARMS Occupational Safety and Health}

\section{FACILITY REQUIREMENT SOURCE: DOE/EH0135 MS.3.7}

7. Employees receive adequate medical treatment for occupational and nonoccupational injuries and illnesses."

\section{FACILITY REQUIREMENT SOURCE: DOE3790.1A Chapter VIII, Section 5.g}

"Treatment and Medications. The health services staff shall at their discretion administer the following at no cost tho the employee: (1) Vaccines or other medications furnished by the employee and prescribed in writing by the employee's personal physician as reasonably necessary to maintain the employee's health and well-being while at work; and (2) Treatment prescribed by a physician providing medical care in performance-of-duty injury or illness cases under the Federal Employee's Compensation Act."

\section{FACILITY REQUIREMENT SOURCE: DOE3790.1A Chapter VIII, Section 5.j(1)}

"Occupational Injury or Illness. Any employee with an occupationally related injury or illness shall be initially examined and treated to allay pain, discomfort, and anxiety without undue delay and at no cost to the employee. The scope and content of the examination and treatment shall be based upon the nature and extent of the injury or illness, and shall be sufficient to determine whether the employee may return to work without undue health hazard or accident risk to the workforce. If necessary, conveyance of the employee to a local hospital emergency room shall be provided.

\section{FACILITY REQUIREMENT SOURCE: DOE3790.1A Chapter VIII, Section 5.j(2)}

"Nonoccupational Injury or Illness. On-the-job care is given, at no cost to the employee, as necessary to allay pain, discomfort, and anxiety; to allow completion of the workday, and to provide interim care prior to referral of the employee to his or her physician for private medical attention."

\section{FACILITY REQUIREMENT SOURCE: DOE5480.8A Section 11.c(1)}

"(1) Occupational Injury or Disease.

(a) The management of occupational injury or disease shall be in accordance with the laws and regulations of the State in which the facility is located.

(b) Diagnosis and treatment of occupational injury or disease shall be prompt with emphasis placed on rehabilitation and return to work at the earliest time com: $3^{t}$ ible with job safety and employee health.

(c) Contractor management has the responsibility to establish procedures to ensure that all employees with occupational injuries or illnesses receive written clearance from the occupational medical department before being permitted to return to work. 


\section{REQUIREMENTS IDENTIFICATION DOCUMENT HIGH LEVEL WASTE STORAGE TANK FARMS Occupational Safety and Health}

(d) The responsible firstline management and health and safety groups (healt't physics, industrial hygiene, or safety) shall be given notification of unhealthy work situations detected by the occupational medical staff."

\section{FACILITY REQUIREMENT SOURCE: DOES480.8A Section 11.c(2)}

"Nonoccupational Injury and Illness. Employees shall be encouraged to utilize the services of a private physician or medical facility, where these are available, for care of nonoccupational injuries or illnesses. However, the medical department shall assist employees who become ill at work. Care should be available for what may be judged a short-term, self-limited condition. Such a policy will contribute to containment of medical costs and encourage an atmosphere of trust for employees. The objective is to return the worker to a state of health in the shortest possible time consistent with modern medical therapy. Long-term treatment of nonoccupational injury and illness is not considered to be a routine responsibility of an occupational medical program. NOTE: In emergencies, employees shall be given the necessary care required until referred to a private physician or facility."

\section{FACILITY REQUIREMENT SOURCE: DOES480.8A Section 11.c(3)}

"Monitored Care. Monitored care of ill or injured employees by occupational medical physicians is highly desirable to maximize recovery and safe return to work and to minimize lost time and associated costs. Contractor management has the responsibility to advise the occupational medical department when an employee has been absent because of an illness or injury for more than 5 consecutive workdays, or has experienced excessive absenteeism. Worker's compensation cases should be monitored when appropriate through frequent return visits and physician-to-physician communication with private physicians where applicable. The goal is to assist the employees in their recovery and to facilitate their return to duty at the earliest practicable time.

Reasonable accommodations or restrictions may be a part of this rehabilitation process and need to be closely coordinated with the human resources department and line management."

\section{FACILITY REQUIREMENT SOURCE: DOE5480.9 Section 6.a(1)(a)}

"(1) A descriptive outline of the contractor's program encompassing industrial safety, health protection, and fire prevention and protection aspects. The program should be appropriate to the size of the project and associated hazards, and shall include, but not be limited to:

(a) Adequate provisions for emergency aid such as trained medical aid personnel and treatment facilities, and adequate fire protection during all phases of construction."

\section{Fitness for Duty}

This sub-element addresses the requirements for establishing and maintaining an effective Fitness for Duty Program. A properly implemented fitness for 

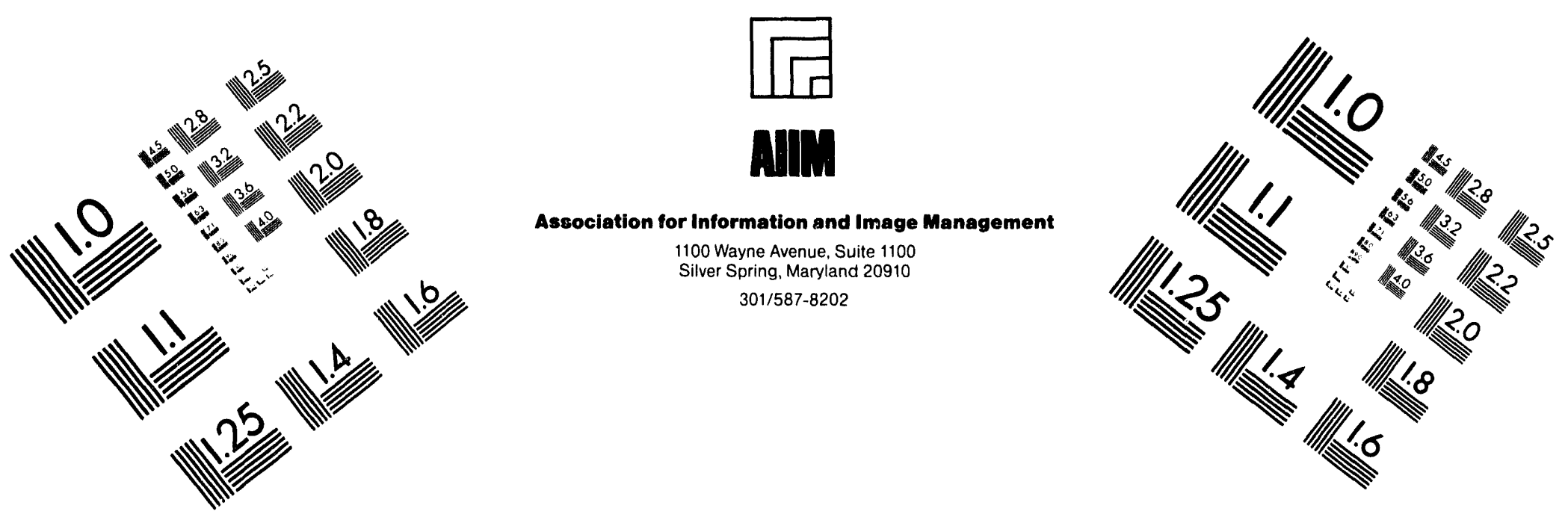

\section{Centimeter}

$\begin{array}{llllllllllllllll}1 & 2 & 3 & 4 & 5 & 6 & 7 & 8 & 9 & 10 & 11 & 12 & 13 & 14 & 15 & \mathrm{~mm}\end{array}$

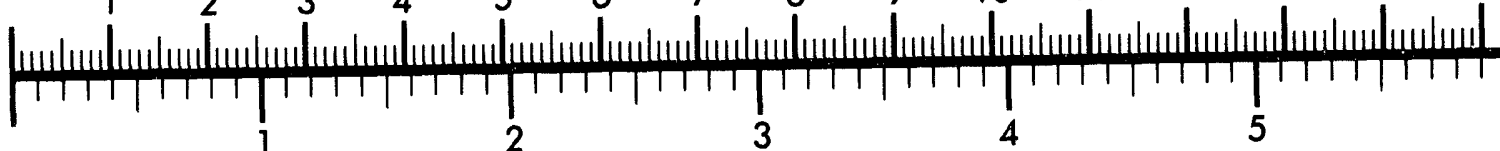
Inches

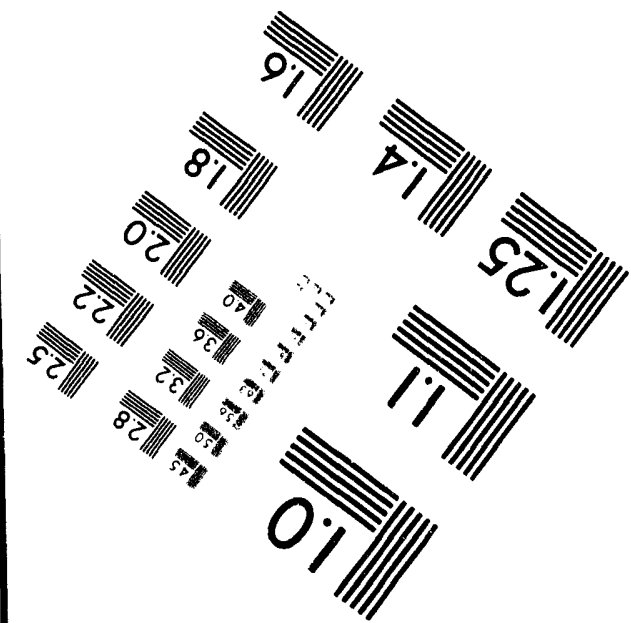

MANUFACTURED TO AIIM STANDARDS

BY APPLIED IMAGE, INC.

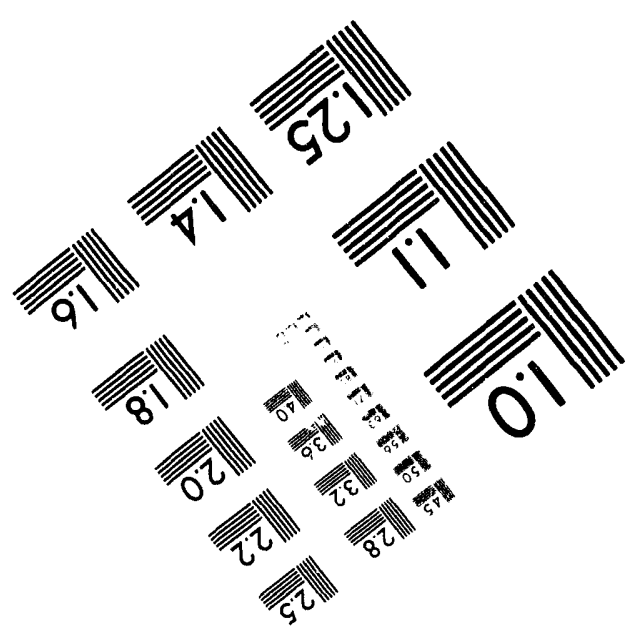



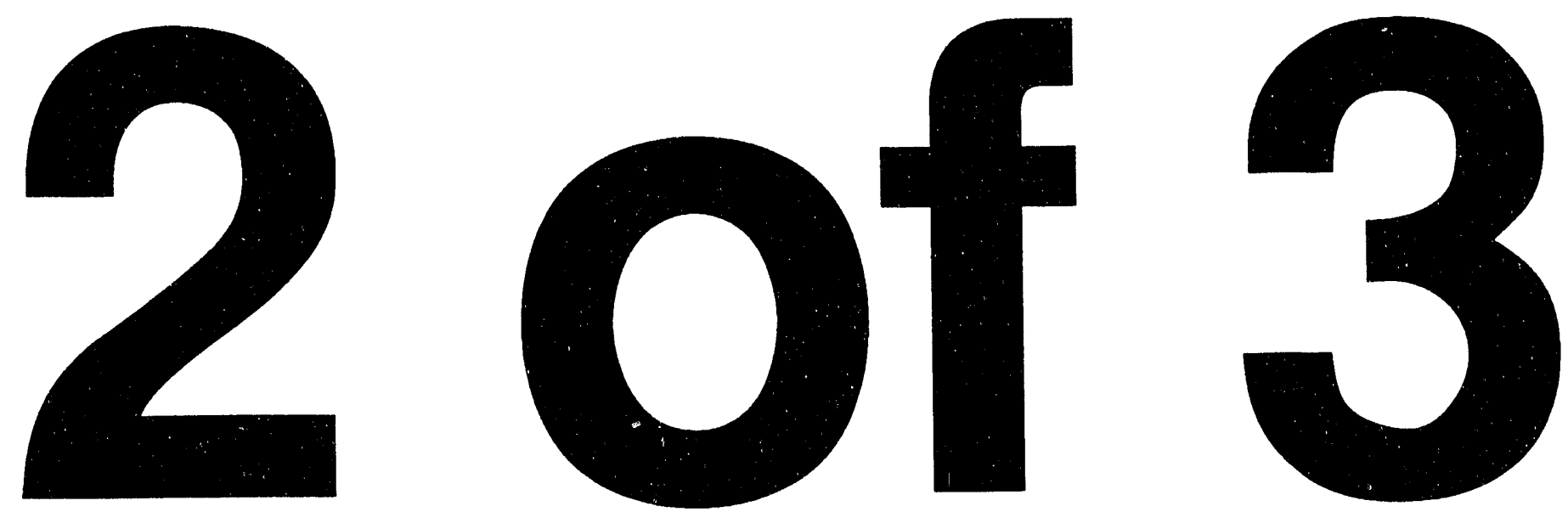


\section{REQUIREMENTS IDENTIFICATION DOCUMENT HIGH LEVEL WASTE STORAGE TANK FARMS Occupational Safety and Health}

duty program provides assurance of a drug and alcohol free workplace and that employees are able to perform their assigned tasks.

The Occupational Health Program defines fitness for duty requirements and develops fitness for duty procedures. The Policies and Procedures section of the Management Systems Functional Area outlines the controls for development, use, and maintenance of fitness for duty policy and procedures. The Safeguards and Security Program interfaces with local law enforcement concerning fitness for duty issues.

\section{FACILITY REQUIREMENT SOURCE: DOE5480.8A Section 11.d(3)}

"(3) Fitness for Continued Duty Assignment. The occupational medical department has the responsibility to make fitness-for-duty determinations on employees for all conditions that may influence performance or work suitability.

(a) A substance abuse (drug and alcohol) identification and rehabilitation program is an integral part of a comprehensive fitness-for-duty program. Any testing proviued shall be in accordance with acceptable practices and applicable regulations. The goal is to promote a safe and healthy work environment and to rehabilitate employees involved with substance abuse.

(b) Employees shall be evaluated for the presence of medical conditions that may be reasonably expected to impair employee's safe, reliable, and trustworthy performance of assigned tasks and, thereby, affect the acceptability of an employee for a specific job assignment.

(c) Occupational medical personnel shall consider the job duties of any employee seeking medical care to determine if the health condition is job related. In addition, an evaluation should be made of the employee's fitness-to-perform job duties safely and reliably."

\section{FACILITY REQUIREMENT SOURCE: EEI Chapter II, Section 1}

A clear definitive policy statement on drug and alcohol abuse as a part of a total fitness for duty program, strongly supported by top management, should be established. The policy should be written and clearly state the responsibilities of management and employees relative to a fitness for duty program, including the consequences which may result from lack of adherence to such a policy.

\section{FACILITY REQUIREMENT SOURCE: EEI Chapter II, Section 3}

The methods used to communicate the fitness for duty policy should be established. This section discusses elements that should be considered when planning how the policy will be communicated. 


\section{REQUIREMENTS IDENTIFICATION DOCUMENT HIGH LEVEL WASTE STORAGE TANK FARMS Occupational Safety and Health}

\section{FACILITY REQUIREMENT SOURCE: EEI Chapter II, Section 7}

Contractors and visitors should be advised that they must abide by the rules established by the fitness for duty program. Clear notification should be given that this is a condition of access to the site/facility and equipment. This section describes methods for notifying contractors/visitors of fitness for duty regulations.

\section{FACILITY REQUIREMENT SOURCE: EEI Chapter II, Section 8}

Local law enforcement officials should be routinely notified upon the discovery of suspected illegal substances. Federal law prohibits the possession, sale or use of controlled substances except by qualified individuals. Any violations of this law must be reported to the proper authorities.

\section{Medical Facilities and Equipment}

Occupational medical activities require adequate facilities and equipment to effectively perform their designated function.

The Engineering Design Functional Area addresses the design criteria for medical facilities. The Occupational Medical Program shall provide the necessary information to the Engineering Design Organization to ensure that medical facility design requirements are sufficient for operational needs (both existing and future).

\section{FACILITY REQUIREMENT SOURCE：DOE/EH0135 MS.1.5}

"5. Adequate resources are provided to support the medical services needed for the facility and site."

\section{FACILITY REQUIREMENT SOURCE: DOE/EH0135 MS.3.3}

" 3. The medical facilities and the medical equipment needed to support the site and facility, both onsite and offsite, are adequate.

\section{FACILITY REQUIREMENT SOURCE: DOE/EH0135 MS.3.4}

"4. Transportation facilities for medical emergencies are adequate."

FACILITY REQUIREMENT SOURCE: DOE5480.8A Section 11.h(1)

"Occupational Medical Facilities. General design criteria for occupational medical facilities are contained in DOE 6430.1A. Specifically, these facilities:

(a) Shall be located in areas readily accessible to employees and to transportation. Accessibility of the occupational medical department is a key 


\section{REQUIREMENTS IDENTIFICATION DOCUMENT HIGH LEVEL WASTE STORAGE TANK FARMS Cccupational Safety and Health}

factor in employee utilization of medical services and is very important to the overall effectiveness of the program.

(b) Shall be sufficiently spacious, well lighted, and ventilated with appropriate climate control.

(c) Shall include waiting, consultation, examining and emergency treatment areas, toilet, and shower or tub facilities adequate to ensure privacy and comfort.

(d) Shall have necessary nedical and laboratory equipment with adequate decontamination facilities.

(e) Shall include a rest or recovery room, dressing rooms, and facilities for the laboratory and radiological examinations performed in the department.

(f) Shall include ambulance services and equipment that meet applicable State or Federal regulations. It is not necessary to assign responsibility for ambulance and rescue personnel, operations, and equipment to the Site Occupational Medical Director.

(g) Shall have access to medical information through a library and/or computerized information systems.

(h) Dispensing, storing and disposing of pharmaceuticals shall be in accordance with appropriate Federal, State and local law.

\section{FACILITY REQUIREMENT SOURCE: DOE5480.8A Section 11.h(2)}

"Equipment.

(a) The Site Occupational Medical Director shall ensure that the medical department equipment is adequate in terms of present-day accepted standards of medical practice and that it is maintained in good working order and is properly calibrated.

(b) The selection of specific kinds and brands of medical office and laboratory equipment shall be determined by the Site Occupational Medical Director. Preference should be given to devices that can provide direct input to computerized data

systems. The following minimum items should be included:

1 Standard distant and near visual acuity eye charts or optical testers;

2 Standard color vision plates (Ishihara, Dvorine, or American Optical);

3 Audiometer with a testing booth which meets OSHA standards; 
WHC-EP_0750

\section{REQUIREMENTS IDENTIFICATION DOCUMENT HIGH LEVEL WASTE STORAGE TANK FARMS Occupational Safety and Health}

4 Electrocardiograph equipment;

5 Pulmonary function equipment;

6 Cardiac defibrillation and related monitoring equipment adequate for portable use;

7 Suction equipment;

8 Pulmonary resuscitation equipment;

9 Adequate equipment for monitoring, handling, and decontamination of radioactively contaminated or chemically contaminated casualties;

10 Physiotherapy equipment as needed; and

11 Emergency power supply."

FACILITY REQUIREMENT SOURCE: DOE6430.1A Section 0110-99.7

"0110-99.7 Occupational Health Facilities

0110-99.7.1 General

In the planning of a new Occupational Health Facility, the estimated case load shall be developed in collaboration with the facility operating group. In addition, the available nearby community medical facilities shall be considered and the requirements of DOE 5480.8 shall be followed.

Where radiological hazards are a factor and an adequate community facility is not available, provisions shall also be made for emergency minor surgical, decontamination, and lifesaving medical care for casualties or injuries resulting from radioactive contamination.

The size and location of the facility shall depend on:

o The number and needs of employees to be served

o Extent of treatment and other activities included within the scope of the occupational health program

o The number of doctors and nurses required in accordance with DOE 5480.8

o Reasonably anticipated expansion

o The distance from hazardous operations

o The radiological conditions to be encountered 
WHC-EP-0750

\section{REQUIREMENTS IDENTIFICATION DOCUMENT \\ HIGH LEVEL WASTE STORAGE TANK FARMS Occupational Safety and Health}

\section{0-99.7.2 Location}

The location of the Occupational Health Facility in an immediate plant area will be influenced by the following factors:

o Noise level of nearby plant components

o Accessibility of the main occupational health facility to the greatest number of employees. Under certain conditions, a location near the main entrance to the plant to facilitate examination of employment applicants may be advantageous.

o Auxiliary Facilities. It may be necessary to place dispensaries or first aid field stations as auxiliary medical units in outlying or hazardous areas. These stations may occupy space in buildings provided primarily for other functions.

\section{0-99.7.3 Space Requirements}

Space shall be provided to fulfill the current and foreseeable feature requirements for the following functions:

o Physical examinations, including preplacement, periodic, and termination examinations

o Diagnosis and pertinent treatment for immediate relief of injured and sick employees

o Preventive care and counseling, immunizations, and health education"

\section{Professional Development of Occupational Staff}

The Occupational Medical Program shall also facilitate the continued professional development of the medical staff; including definition of available training courses, seminars, conferences, laboratory experience, field study, and other learning activities which would assist the occupational medical specialist in the performance of his/her duty.

The Occupational Medical Program shall provide the Training Program with the information and support required to effectively institute the necessary medical/fitness for duty training.

\section{FACILITY REQUIREMENT SOURCE: DOE/EH0135 MS.1.4}

" 4. Medical staff are properly trained and participate in continuing education and skill-development programs." 
WHC-EP-0750

\title{
REQUIREMENTS IDENTIFICATION DOCUMENT HIGH LEVEL WASTE STORAGE TANK FARMS Occupational Safety and Health
}

\author{
FACILITY REQUIREMENT SOURCE: DOE5480.8A Section 11.g(1)(e)
}

"Should have opportunities for continuing medical education, attendance at national occupational medical meetings (including DOE-sponsored meetings and health seminars), and access to medical journals. The physician should also be afforded the opportunity for membership in professional organizations.

FACILITY REQUIREMENT SOURCE: DOE5480.8A Section 11.g(2)(c)

"Should have opportunities for continuing medical education, attendance at national occupational medical meetings (including DOE-sponsored meetings and health seminars), and access to medical journals. They should also be afforded the opportunity for membership in professional organizations as approved by the Site Occupational Medical Director."

FACILITY REQUIREMENT SOURCE: DOE5480.8A Section 11.g(3)(c)

"Should be afforded opportunities for continuing nursing education, including attendance at professional meetings, and access to nursing journals as approved by the Site Medical Director. They should also be afforded the opportunity for membership in professional organizations as approved by the Site Occupational Medical Director."

FACILITY REQUIREMENT SOURCE: DOE5480.8A Section 11.g(4)(c)

"Should be afforded opportunities, as determined by the Site Medical Director, for continuing psychological education related to services provided on the site, including use of psychological evaluation. Psychologists employed fulltime shall be afforded opportunities for membership and participation in professional associations."

FACILITY REQUIREMENT SOURCE: DOE5480.8A Section 11.g(5)(c)

"Counselors employed fulltime should be afforded opportunities for continuing education, membership, and participation in professional associations as approved by the Site Occupational Medical Director. "

\section{FACILITY REQUIREMENT SOURCE: DOE5480.8A Section 11.g(6)(c)}

"Should be afforded opportunities for continuing medical education, including attendance at professional meetings and access to medical journals, as well as organizational memberships as determined by the Site Occupational Medical Director."

\section{FACILITY REQUIREMENT SOURCE: DOE5480.8A Section $11 . \mathrm{g}(7)(\mathrm{c})$}

"Should be afforded opportunities for continuing medical education, including attendance at professional meetings and access to journals, as well as organizational memberships as determined by the Site Occupational Medical 


\title{
REQUIREMENTS IDENTIFICATION DOCUMENT HIGH LEVEL WASTE STORAGE TANK FARMS Occupational Safety and Health
}

\author{
Director."
}

\section{FACILITY REQUIREMENT SOURCE: EEI Chapter II, Section 4}

Supervisors should be given clear responsibility for behavioral observation of their employees and should be given special training to ensure they have the knowledge and ability to perform that task well. Supervisors are in day-to-day contact with their personnel and are most familiar with their normal behavior patterns. Therefore, they are in the best position to detect changes in employees' behavior and to initiate appropriate corrective action in accordance with the fitness for duty program.

\subsection{7}

\section{Emergency Planning}

This sub-element specifics the requirements for the Occupational Medical Program to develop and implement the medical response portion of the applicable emergency/disaster preparedness plans. The medical portion of the emergency and disaster response capability shall be adequate to meet the type and severity of accidents and trauma dictated by the character and history of plant operations and conditions.

The Emergency Preparedness Functional Area contains the controls which govern the development, use, and maintenance of the emergency/disaster plans. The Occupational Medical Program provides the necessary medical information and support for these plans.

\section{FACILITY REQUIREMENT SOURCE: 54FR3904 Part (c)(3)(iv)}

"Establish a medical program which includes availability of first aid on site and of physician and emergency medical care nearby, so that harm will be minimized if an injury or illness does occur."

FACILITY REQUIREMENT SOURCE: WAC-296-24 Section 060(1)

"In addition to RCW 51.36.030, every employer shall comply with the department's requirements for first-aid training and certification."

\section{FACILITY REQUIREMENT SOURCE: WAC-296-24 Section 060(2)}

"There shall be present or available at all times, a person or persons holding a valid certificate of first-aid training. (A valid first-aid certificate is one which is less than three years old.)"

\subsubsection{Health Records and Reporting}

This sub-element addresses the requirements for establishing a medical record documentation and control system. Specifically, the programmatic controls necessary to initiate, maintain, update, distribute, retrieve, and refile medical records shall be clearly defined. The controls necessary for collecting and reporting occupational injury and illness data shall also be 


\section{REQUIREMENTS IDENTIFICATION DOCUMENT \\ HIGH LEVEL WASTE STORAGE TANK FARMS \\ Occupational Safety and Health}

clearly defined.

The Document Control/Records Management section of the Management Systems

Functional Area contains the controls necessary to establish a Medical Record system within the Occupational Medical Program.

\section{FACILITY REQUIREMENT SOURCE: 29CFR1910 Part 120(f)(8)(i)}

"Recordkeeping. An accurate record of the medical surveillance required by paragraph ( $f$ ) of this section shall be retained. This record shall be retained for the period specified and meet the criteria of 29 CFR 1910.20."

\section{FACILITY REQUIREMENT SOURCE: 29CFR1910 Part 120(f)(8)(ii)}

"Medical surveillance. The record required in paragraph (f)(8)(i) of this section shall include at least the following information:

(A) The name and social security number of the employee; (B) Physician's written opinions, recommended limitations, and results of examinations and tests;

(C) Any employee medical complaints related to exposure to hazardous substances; (D) A copy of the information provided to the examining physician by the employer, with the exception of the standard and its appendices."

\section{FACILITY REQUIREMENT SOURCE: DOE/EH0135 MS.2.3}

"3. A system for medical services reporting is documented and implemented."

FACILITY REQUIREMENT SOURCE: DOE3790.1A Chapter VII, Section 4.b(7)(a)

"Maintains records of occupational illnesses in accordance with the recordkeeping requirements of the Act."

FACILITY REQUIREMENT SOURCE: DOE3790.1A Chapter VII, Section 4.b(7)(b)

"Consults with the industrial hygiene staff in the development of adequate methods to detect exposures to harmful environmental agents in the context of periodic physicals or bioassays."

FACILITY REQUIREMENT SOURCE: DOE3790.1A Chapter VII, Section 4.b(7)(c)

"Alerts the industrial hygiene staff to all suspected occupational illnesses to facilitate early evaluations and corrections of problems. "

\section{FACILITY REQUIREMENT SOURCE: DOE3790.1A Chapter VII, Section} 4.b(7)(d)

"Alerts the industrial hygiene staff to all diagnosed occupational illnesses for followup investigations. These followups shall be designed to supply the information required by the Occupational Safety and Health Administration (OSHA) Form No. 200F, "Record or Log of Federal Occupational Injuries and 
WHC-EP-0750

\section{REQUIREMENTS IDENTIFICATION DOCUMENT HIGH LEVEL WASTE STORAGE TANK FARMS Occupational Safety and Health}

Illnesses, " or its equivalent."

\section{FACILITY REQUIREMENT SOURCE: DOE3790.1A Chapter VIII, Section 5.n}

"Reporting Requirements.

(1) Heads of Field Organizations, the designated Headquarters official, or designees, shall be advised of the results of each health evaluation performed on one of their employees which contains meaningful data relative to physical limitations and/or work restrictions in order to ensure safe placement of the employee.

(2) A monthly summary of the types of treatments performed by the health services staff shall be submitted to the safety and health official of each field organization or Headquarters as appropriate."

FACILITY REQUIREMENT SOURCE: DOE3790.1A Chapter VIII, Section 5.o

"Medical Records.

(1) Field Organizations shall maintain records of employee medical examinations in accordance with instructions of the Office of Personnel Management in the Federal Personnel Manual, chapter 339; DOE 1700.1; and DOE 1800.1A.

(2) Medical records and professional evaluations of current employees and persons selected for appointment will be maintained under the control of health service personnel and for use only by professional personnel, industrial hygienists, and health physicists."

\section{FACILITY REQUIREMENT SOURCE: DOE5480.8A Section 11.e}

"Requirements for Medical Records.

(1) Records Maintenance. The maintenance of complete medical records developed by the medical department for each employee from the time of the first examination or treatment is a basic requirement. A personal health record shall be maintained for each employee identifying name, date of birth, and social security number. The contractor may use additional identification systems as desired.

(2) Confidentiality.

(a) The confidentiality of all employee medical records, including the results of health examinations, shall be observed by all members of the occupational medical staff. Such records shall remain in the exclusive custody and control of the occupational medical department. Disclosure of information from an employee's health records shall not be made without written consent, except as permitted by law or Federal regulation.

(b) Computerized or microfilmed medical records and information shall remain under the custody and control 


\section{REQUIREMENTS IDENTIFICATION DOCUMENT HIGH LEVEL WASTE STORAGE TANK FARMS Occupational Safety and Health}

of the Site Occupational Medical Director with disclosure as defined in paragraph $11 \mathrm{e}(2)(\mathrm{a})$ above.

(3) Access to Employee Medical Records. Access to employee medical records shall be in accordance with: (a) The Privacy Act as codified in 10 CFR 1008.17(b)(1); and (b) "Access to Exposure and Medical Records" as codified in 29 CFR 1910.20 (OSHA Standard).

(4) Identification of Medical Records. It shall be the responsibility of contractor management to provide the Site Occupational Medical Director with information to enable the coding or flagging of records to reflect current job titles, specific job certifications or limitations, assigned work areas, and work hazards.

(5) Work Restriction Registry. The Medical Director will advise contractor management of appropriate work restrictions. Contractor management should maintain a central work restriction registry.

(6) Retention of Medical Records. All employee health records shall be retained in accordance with DOE 1324.2A. However, inactive records may be retired to low-cost storage in an onsite records holding area or a Federal Records Center. To protect the confidentiality of the records, the shipping cartons shall be sealed and the transfer documents shall note that access to the records is limited to personnel of the Contractor Medical Department. If resources are available, the files may be microfilmed and the paper records destroyed.

\section{SITE REQUIREMENT SOURCE: DOE5484.1 Chapter IV, Section 3.c}

"Report of Radiation Exposures to Headquarters Employees. Report all recorded external and internal radiation exposures that occur during a visit by Department of Energy Headquarters employees to a field element or contractor facility. Complete appropriate portions of DOE F 5484.8, and submit it to the System Safety Development Center (SSDC), EG\&G Idaho, Inc., within 30 days after the individuals's date of visit or within 30 days after his or her exposure has been determined, whichever is later."

\section{SITE REQUIREMENT SOURCE: WAC-296-62 Section 05207(1)(a)}

"Employee medical records. The medical record for each employee shall be preserved and maintained for at least the duration of employment plus thirty years, except that the following types of records need not be retained for any specific period:

(i) Health insurance claims records maintained separately from the employer's medical program and its records;

(ii) First-aid records (not including medical histories) of one-time treatment and subsequent observation of minor scratches, cuts, burns, splinters, and the like which do not involve medical treatment, loss of 
WHC-EP-0750

\section{REQUIREMENTS IDENTIFICATION DOCUMENT HIGH LEVEL WASTE STORAGE TANK FARMS Occupational Safety and Health}

consciousness, restriction of work or motion, or transfer to another job, if made on-site by a nonphysician and if maintained separately from the employer's medical program and its records; and

(iii) The medical records of employees who have worked for less than one year for the employer need not be retained beyond the term of employment if they are provided to the employee upon the termination of employment."

\section{Medical Staffing}

This sub-element addresses the requirements for organizing and staffing an Occupational Medical Program. The responsibilities and accountabilities of the Medical staff and management/employees shall be clearly defined and communicated. The Occupational Medical Program interfaces with onsite organizations and programs shall be clearly defined.

The Policies and Procedures section of the Management Systems Functional Area contains the necessary controls for preparing organizational charts.

\section{FACILITY REQUIREMENT SOURCE: DOE/EH0135 MS.1.1}

"1. Line management assures adequate medical services are available and adequate to provide needed medical services."

FACILITY REQUIREMENT SOURCE: DOE/EH0135 MS.1.2

"2. Site medical staff has a direct line of communication with top management. Reports and recommendations of the medical staff are not subjected to inappropriate management by non-medical staff."

\section{FACILITY REQUIREMENT SOURCE: DOE/EH0135 MS.1.3}

"3. Appropriate arrangements and agreements are made with off-site providers of medical support."

\section{FACILITY REQUIREMENT SOURCE: DOE/EH0135 MS.1.6}

"6. Management establishes specific goals and objectives for minimizing the demands on medical services by reducing injuries and illnesses."

\section{FACILITY REQUIREMENT SOURCE: DOE/EH0135 MS.2.1}

"1. Procedures provide direction to assure medical services are uniformly and adequately implemented."

\section{FACILITY REQUIREMENT SOURCE: DOE/EH0135 MS.2.2}

"2. Written policies identify the responsibilities and authorities for onsite and offsite medical staff for providing medical services." 


\section{REQUIREMENTS IDENTIFICATION DOCUMENT HIGH LEVEL WASTE STORAGE TANK FARMS Occupational Safety and Health}

\section{FACILITY REQUIREMENT SOURCE: DOE/EH0135 MS.3.1}

"1. The types of medical services needed to support facility and site operations are identified."

\section{FACILITY REQUIREMENT SOURCE: DOE/EH0135 MS.3.2}

"2. The medical staff needed to support the site and facility are available and trained."

\section{FACILITY REQUIREMENT SOURCE: DOE/EH0135 MS.4.1}

"1. Medical policies are audited regularly and when there are major changes in the site or facility activities or the availability of supporting medical organizations that could require modifications to the medical services program."

\section{FACILITY REQUIREMENT SOURCE: DOE/EH0135 MS.5.1}

"1. Medical hazards in the workplace are communicated to employees and visitors to the site/facility."

\section{FACILITY REQUIREMENT SOURCE: DOE/EH0135 MS.5.2}

"2. Employees are provided written notification of monitoring results when an employee's exposure exceeds permissible limits."

\section{FACILITY REQUIREMENT SOURCE: DOE/EH0135 MS.5.3}

"3. Employees are informed of their rights and responsibilities and the employer and DOE resources available to resolve concerns on potential health hazards in the work environment."

\section{FACILITY REQUIREMENT SOURCE: DOE3790.1A Chapter VIII, Section 5.a}

"Health Services Personnel.

(1) Health services shall be provided under the direction of a licensed physician, and nursing services shall be provided by licensed professional nurses. To the maximum extent feasible, such physicians and nurses shall be qualified in occupational medicine and occupational nursing.

(2) As an alternative, Heads of Field Organizations may elect to contract for medical services. When this option is selected, licensed physicians and nurses shall be qualified in occupational medicine and occupational nursing, if possible, and programs shall comply with the requirements of this chapter."

\section{FACILITY REQUIREMENT SOURCE: DOE5480.10 Section 9.a(2)}

"The Medical Organization should be required to: (a) maintain records of occupational illnesses in accordance with the recordkeeping requirements of Title 29 CFR 1904; (b) consult with the industrial hygiene staff on the need 


\section{REQUIREMENTS IDENTIFICATION DOCUMENT HIGH LEVEL WASTE STORAGE TANK FARMS Occupational Safety and Health}

for job-related medical examinations or bioassays; (c) alert the industrial hygiene staff to all suspected occupational illnesses to facilitate early evaluations and correction of problems; and (d) include the industrial hygiene staff, if appropriate, in the investigations of occupational illnesses."

\section{FACILITY REQUIREMENT SOURCE: DOE5480.10 Section 9.b(6)}

"Medical Monitoring. The industrial hygiene staff shall inform the medical organization of potential and existing health hazards identified, the results of hazard evaluations, and other industrial hygiene information needed for operation of a medical monitoring program. The industrial hygiene staff should be available to accompany medical staff on periodic worksite visits (refer to DOE 5480.8))."

\section{FACILITY REQUIREMENT SOURCE: DOE5480.8A Section 10.a}

"Implementation of an onsite occupational medical program shall be the responsibility of the Site Occupational Medical Director. The occupational medical director for each contractor site shall develop a written occupational medical plan detailing the methods and procedures used to implement the minimum requirements of this Order which are set out in paragraph 11."

\section{FACILITY REQUIREMENT SOURCE: DOE5480.8A Section 11.a(1)}

"Occupational physicians and selected medical staff shall make regular visits to worksites and facilities so as to become familiar with employee job tasks, worksite environments, and existing or potential health hazards. Such visits should be coordinated with industrial hygiene, health physics, and safety personnel and management, and should include a review of materials, processes, and procedures used with emphasis on physical, chemical, and biological hazards. The information obtained from these visits may form the basis for recommendations to management for corrective action or preventive measures. The frequency of worksite visits should be determined by the Site Occupational Medical Director, taking into account such factors as the size of the workforce, and the number and types of operations. Other factors should include the nature and amounts of physical, chemical, or biological agents used; the accident and incident rate; and the occupational illness and disability rate. Appropriate medical staff should conduct familiarization visits at selected worksites at least monthly."

\section{FACILITY REQUIREMENT SOURCE: DOE5480.8A Section 11.a(2)}

"Contractor management shall furnish the Site Occupational Medical Director with information on potential, physical, chemical, and biological hazards in the worksite."

\section{FACILITY REQUIREMENT SOURCE: DOE5480.8A Section 11.a(3)}

"Prior to the performance of a periodic health examination, the contractor management shall provide to the OHE a summary of potential exposures to 
WHC-EP-0750

\section{REQUIREMENTS IDENTIFICATION DOCUMENT HIGH LEVEL WASTE STORAGE TANK FARMS Occupational Safety and Health}

hazardous agents or tasks and any worksite exposures in excess of OSHA/DOE permissible exposure limits pertaining to the employees to be examined."

FACILITY REQUIREMENT SOURCE: DOE5480.8A Section 11.a(4)

"Contractor management should afford the Site Occupational Medical Director or designee the opportunity to participate in new materials and process review committees, safety committees, and other health-related meetings."

FACILITY REQUIREMENT SOURCE: DOE5480.8A Section 11.g(1)(b)

"Shall report directly to the Contractor Site Manager, appropriate Laboratory Director, or another management level with sufficient authority to ensure program effectiveness."

FACILITY REQUIREMENT SOURCE: DOE5480.8A Section 11.g(1)(c)

"Shall participate in health and environmental issues at the policy-making levels."

FACILITY REQUIREMENT SOURCE: DOE5480.8A Section 11.g(1)(d)

"Shall be responsible for the development, interpretation, implementation, and administration of the occupational medical program."

FACILITY REQUIREMENT SOURCE: DOE5480.8A Section 11.g(2)(b)

"Shall be directly responsible to the Site Occupational Medical Director or designee."

FACILITY REQUIREMENT SOURCE: DOE5480.8A Section 11.g(3)(b)

"Shall be directly responsible to the Site Occupational Medical Director or designee."

FACILITY REQUIREMENT SOURCE: DOE5480.8A Section 11.g(4)(b)

"Shall be directly responsible to the Site Occupational Medical Director or designee."

FACILITY REQUIREMENT SOURCE: DOE5480.8A Section 11.g(5)(b)

"Shall be responsible to the Site Occupational Medical Director or designee."

FACILITY REQUIREMENT SOURCE: DOE5480.8A Section 11.g(6)(b)

"Shall be responsible to, and work under, the supervision of the Site

Occupational Medical Director or designee." 
WHC-EP-0750

\section{REQUIREMENTS IDENTIFICATION DOCUMENT HIGH LEVEL WASTE STORAGE TANK FARMS \\ Occupational Safety and Health}

FACILITY REQUIREMENT SOURCE: DOE5480.8A Section 11.g(7)(b)

"Shall be responsible to the Site Occupational Medical Director or designee."

FACILITY REQUIREMENT SOURCE: DOE5480.8A Section $11 . g(8)(b)$

"Shall be responsible to the Site Occupational Medical Director or designee."

FACILITY REQUIREMENT SOURCE: DOE5480.8A Section 11.g(9)

"(9) Professional Staffing.

(a) General. The proper ratio of physicians and nurses to the employee population is related to many factors, including the following:

1 Size of employee population;

2 Geographical distribution and location of employees;

3 Shifts worked;

4 Rate of employee turnover;

5 Age and sex distribution of the employee population;

6 Extent of occupational hazards and associated medical surveillance requirements;

7 Types and complexities of job tasks and operations performed;

8 Total number of all health examinations required;

9 Degree of isolation of worksites from community and other medical services; and

10 Degree of employee utilization of occupational health services.

(b) Minimum Physician Staffing. For sites with employee populations greater than 2,500, the Medical Director shall not be included in meeting the physician staffing requirement.

1 At least 1 part-time physician for employee populations between 300 and 1,000;

2 One full-time physician for employee populations over 1,000 and under 1,500 ;

3 One full-time and 1 half-time physicians for employee populations over 1,500 but under 2,000 ;

4 Two full-time and 1 half-time physicians for employee 


\section{REQUIREMENTS IDENTIFICATION DOCUMENT HIGH LEVEL WASTE STORAGE TANK FARMS Occupational Safety and Health}

populations over 2,000 but under 2,500; and

5 An additional physician for each additional increase of 1,000 to 1,500 employees.

(c) Minimum Nurse Staffing.

1 One part-time nurse for up to 100 employees;

2 One full-time nurse for employee populations over 100 and up to 300 ;

3 Two full-time nurses for employee populations over 300 and up to 1,000 ;

4 Three full-time nurses for the first 1,000 employees;

5 One additional full-time nurse for each additional 1,000 employees up to 5,000; and

6 One additional full-time nurse for each additional 2,000 employees over 5,000.

(d) Minimum Requirements for Worksites not Covered by a Physician or Nurse. At worksites with employee populations not warranting a full-time nurse or physician (i.e., less than 100 employees), management shall ensure at least one employee on duty is trained and currently qualified in first aid and cardiopulmonary resuscitation.

(e) Ancillary Staffing. The number and qualifications of physician assistants, nurse practitioners, and other ancillary medical personnel shall be determined by the Site Occupational Medical Director as required to support the occupational medical program. Utilization of these personnel may partially offset the prescribed staffing levels of physicians and nurses.

(f) Psychological Staffing. The Site Occupational Medical Director shall establish consulting relationships with psychiatrists or psychologists as required by the demands of the program. At sites with 2,000 or more employees, 1 full-time equivalent clinical psychologist and/or psychiatrist is suggested. The option of contracting for the services of a part-time clinical psychologist or psychiatrist for facilities with fewer than 2,000 employees or to supplement existing services is acceptable."

\section{FACILITY REQUIREMENT SOURCE: EEI Chapter II, Section 1}

A clear definitive policy statement on drug and alcohol abuse as a part of a total fitness for duty program, strongly supported by top management, should be established. The policy should be written and clearly state the responsibilities of management and employees relative to a fitness for duty program, including the consequences which may result from lack of adherence to such a policy. 


\title{
REQUIREMENTS IDENTIFICATION DOCUMENT HIGH LEVEL WASTE STORAGE TANK FARMS Occupational Safety and Health
}

\author{
FACILITY REQUIREMENT SOURCE: EEI Chapter II, Section 2
}

The effectiveness of a fitness for duty program will depend upon the degree of demonstrated involvement and support from senior management. The established fitness for duty policy should be clearly communicated to employees by management. All violations of the established policy should be enforced both fairly and impartially by management.

\section{OCCUPATIONAL SAFETY AND HEALTH TRAINING}

This element outlines the need for health and safety training to prevent personnel exposure to and control of known physical, biological and chemical hazards. In addition, the documentation of OSH training and the maintenance of those records is discussed.

\section{FACILITY REQUIREMENT SOURCE: DOE3790.1A Chapter VIII, Section 5.k}

"Emergency Training. Employees shall have the opportunity to receive training in the basic elements of first aid and cardiopulmonary resuscitation (CPR) and CPR refresher training, at no cost to the employee."

\section{OS\&H Program Training}

This sub-element addresses the requirements which ensure that general employees, managers/supervisors, and visitors/contractors are properly trained with regard to appropriate health and safety, medical and fitness for duty requirements. The OSH Program shall also facilitate the continued professional development of the health and safety staff; including definition of available training courses, seminars, conferences, laboratory experience, field study, and other learning activities which would assist the OSH specialist in the performance of his/her duty.

\section{FACILITY REQUIREMENT SOURCE: 29CFR1910 Part 120(c)(8)}

"Employee notification. Any information concerning the chemical physical, and toxicologic properties of each substance known or expected to be present on site that is available to the employer and relevant to the duties an employee is expected to perform shall be made available to the affected employees prior to the commencement of their work activities. The employer may utilize information developed for the hazard communication standard for this purpose."

\section{FACILITY REQUIREMENT SOURCE: 29CFR1910 Part 120(e)(1)(ii)}

"Employees shall not be permitted to participate in or supervise field activities until they have been trained to a level required by their job function and responsibility."

\section{FACILITY REQUIREMENT SOURCE: 29CFR1910 Part 120(e)(2)}

"Elements to be covered. The training shall thoroughly cover the following:

(i) Names of personnel and alternates responsible for site safety and health;

(ii) Safety, health and other hazards present on the site;

(iii) use of personal protective equipment; 


\section{REQUIREMENTS IDENTIFICATION DOCUMENT HIGH LEVEL WASTE STORAGE TANK FARMS Occupational Safety and Health}

(iv) Work practices by which the employee can minimize risks from hazards;

(v) Safe use of engineering controls and equipment on the site;

(vi) Medical surveillance requirements, including recognition of symptoms and signs which might indicate overexposure to hazards; and

(vii) The contents of paragraphs (G) through (J) of the site safety and health plan set forth in paragraph (b)(4)(ii) of this section."

\section{FACILITY REQUIREMENT SOURCE：29CFR1910 Part 120(e)(3)(i)}

"Initial training. General site workers (such as equipment operators, general laborers and supervisory personnel) engaged in hazardous substance removal or other activities which expose or potentially expose workers to hazardous substances and health hazards shall receive a minimum of $\mathbf{4 0}$ hours of instruction off the site, and a minimum of three days actual field experience under the direct supervision of a trained, experienced supervisor."

\section{FACILITY REQUIREMENT SOURCE：29CFR1910 Part 120(e)(3)(ii)}

"Initial training.

Workers on site only occasionally for a specific limited task (such as, but not limited to, ground water monitoring, land surveying, or geo-physical surveying) and who are unlikely to be exposed over permissible exposure limits and published exposure limits shall receive a minimum of 24 hours of instruction off the site, and the minimum of one day actual field experience under the direct supervision of a trained, experienced supervisor."

\section{FACILITY REQUIREMENT SOURCE：29CFR1910 Part 120(e)(3)(iii)}

"Initial training. Workers regularly on site who work in areas which have been monitored and fully characterized indicating that exposures are under permissible exposure limits and published exposure limits where respirators are not necessary, and the characterization indicates that there are no health hazards or the possibility of an emergency developing, shall receive a minimum of 24 hours of instruction off the site and the minimum of one day actual field experience under the direct supervision of a trained, experienced supervisor."

\section{FACILITY REQUIREMENT SOURCE: 29CFR1910 Part 120(e)(3)(iv)}

"Initial training Workers with 24 hours of training who are covered by paragraphs (e)(3)(ii) and (e)(3)(iii) of this section, and who become general site workers or who are required to wear respirators, shall have the additional 16 hours and two days of training necessary to total the training specified in paragraph (e)(3)(i)."

\section{FACILITY REQUIREMENT SOURCE: 29CFR1910 Part 120(e)(4)}

"Management and supervisor training. On-site management and supervisors directly responsible for, or who supervise employees engaged in, hazardous waste operations shall receive $\mathbf{4 0}$ hours initial training, and three days of supervised field experience (the training may be reduced to 24 hours and one day if the only area of their responsibility is employees covered by paragraphs (e)(3)(ii) and (e)(3)(iii) and at least eight additional hours of specialized training at the time of job assignments on such topics as, but not limited to, the employer's safety and health program and the associated employee training program, personal protective 


\title{
REQUIREMENTS IDENTIFICATION DOCUMENT HIGH LEVEL WASTE STORAGE TANK FARMS Occupational Safety and Health
}

equipment program, spill containment program, and health hazard monitoring procedure and techniques."

\section{FACILITY REQUIREMENT SOURCE: 29CFR1910 Part 120(e)(5)}

"Qualifications for trainers. Trainers shall be qualified to instruct employees about the subject matter that is being presented in training. Such trainers shall have satisfactorily completed a training program for teaching the subjects they are expected to teach, or they shall have the academic credentials and instructional experience necessary for teaching the subjects. Instructors shall demonstrate competent instructional skills and knowledge of the applicable subject matter."

\section{FACILITY REQUIREMENT SOURCE: 29CFR1910 Part 120(e)(6)}

"Training certification. Employees and supervisors that have received and successfully completed the training and field experience specified in paragraphs (e)(1) through (e)(4) of this section shall be certified by their instructor or the head instructor and trained supervisor as having successfully completed the necessary training. A written certificate shall be given to each person so certified. Any person who has not been so certified or who does not meet the requirements of paragraph (e)(9) of this section shall be prohibited from engaging in hazardous waste operations."

\section{FACILITY REQUIREMENT SOURCE: 29CFR1910 Part 120(e)(7)}

\section{"Training.}

Emergency response. Employees who are engaged in responding to hazardous emergency situations at hazardous waste clean-up sites that may expose them to hazardous substances shall be trained in how to respond to such expected emergencies."

\section{FACILITY REQUIREMENT SOURCE: 29CFR1910 Part 120(e)(8)}

\begin{abstract}
"Refresher training. Employees specified in paragraph (e)(1) of this section, and managers and supervisors specified in paragraph (e)(4) of this section, shall receive eight hours of refresher training annually on the items specified in paragraph (e)(2) and/or (e)(4) of this section, any critique of incidents that have occurred in the past year that can serve as training examples of related work, and other relevant topics."
\end{abstract}

\section{FACILITY REQUIREMENT SOURCE: 29CFR1910 Part 120(e)(9)}

"Equivalent training. Employers who can show by documentation or certification that an employee's work experience and/or training has resulted in training equivalent to that training required in paragraphs (e)(1) through (e)(4) of this section shall not be required to provide the initial training requirements of those paragraphs to such employees and shall provide a copy of the certification or documentation to the employee upon request. However, certified employees or employees with equivalent training new to a site shall receive appropriate, site specific training before site entry and have appropriate supervised field experience at the new site. Equivalent training includes any academic training or the training that existing employees might have already received from actual hazardous waste site work experience." 


\section{REQUIREMENTS IDENTIFICATION DOCUMENT HIGH LEVEL WASTE STORAGE TANK FARMS Occupational Safety and Health}

\section{FACILITY REQUIREMENT SOURCE: 29CFR1910 Part 120(i)}

"Informational programs. Employers shall develop and implement a program, which is part of the employer's safety and health program required in paragraph (b) of this section, to inform employees, contractors, and subcontractors (or their representative) actually engaged in hazardous waste operations of the nature, level and degree of exposure likely as a result of participation in such hazardous waste operations. Employees, contractors and subcontractors working outside of the operations part of a site are not covered by this standard."

\section{FACILITY REQUIREMENT SOURCE: 29CFR1910 Part 147 (c)(7)(i)}

\section{"Lockout and Tagout}

The employer shall provide training to ensure that the purpose and function of the energy control program are understood by employees and that the knowledge and skills required for the safe application, usage, and removal of the energy controls are acquired by employees. the training shall include the following: (A) Each authorized employee shall receive training in the recognition of applicable hazardous energy sources, the type and magnitude of the energy available in the workplace, and the methods and means necessary for energy isolation and control. (B) Each affected employee shall be instructed in the purpose and use of the energy control procedure. (C) All other employees whose work operations are or may be in an area where energy control procedures may be utilized, shall be instructed about the procedure, and about the prohibition relating to attempts to restart or reenergize machines or equipment which are locked out or tagged out."

\section{FACILITY REQUIREMENT SOURCE: 29CFR1910 Part 147 (c)(7)(ii)}

\section{"Lockout and Tagout}

(ii) When tagout systems are used, employees shall also be trained in the following limitations of tags: (A) Tags are essentially warning devices affixed to energy isolating devices, and do not provide the physical restrain on those devices that is provided by a lock. (B) When a tag is attached to an energy isolating means, it is not to be removed without authorization of the authorized person responsible for it, and it is never to be by passed, ignored, or otherwise defeated. (C) Tags must be legible and understandable by all authorized employees, affected employees, and all other employees whose work operations are or may be in the area, in order to be effective. (D) Tags and their means of attachment must be made of materials which will withstand the environmental conditions encountered in the workplace. (E) Tags may evoke a false sense of security, and their meaning needs to be understood as part of the overall energy control program. (F) Tags must be securely attached to energy isolating devices so that they cannot inadvertently or accidentally detached during use."

\section{FACILITY REQUIREMENT SOURCE: 29CFR1910 Part 147 (c)(7)(iii)}

\section{"Lockout and Tagout}

Employee retraining (A) Retraining shall be provided for all authorized and affected employees whenever there is a change in their job assignments, a change in machines, equipment or processes that present a new hazard, or when there is a change in the energy control procedures. (B) Additional retraining shall also be conducted whenever a periodic inspection under paragraph (c)(6) of this section reveals, or whenever the employer has reason to believe, that there are deviations from or inadequacies in the employee's knowledge or use of the energy control procedures. (C) The retraining shall reestablish employee proficiency and introduce new or revised control methods and procedures, as necessary." 


\title{
REQUIREMENTS IDENTIFICATION DOCUMENT HIGH LEVEL WASTE STORAGE TANK FARMS Occupational Safety and Health
}

\author{
FACILITY REQUIREMENT SOURCE: 29CFR1910 Part 332 (b)(3)
}

"Training

(3) Additional requirements for qualified persons. Qualified persons (i.e., those permitted to work on or near exposed energized parts) shall, at a minimum, be trained in and familiar with the following:(i)The skills and techniques necessary to distinguish exposed live parts from other parts of electric equipment, (ii) The skills and techniques necessary to determine the nominal voltage of exposed live parts, and (iii) The clearance distances specified in 29 CFR 1910.333(c) and the corresponding voltages to which the qualified person will be exposed. Note 1: for the purpose of 29 CFR 1910.331 through 1910.335, a person must have the training required by paragraph (b)(3) of this section in order to be considered a qualified person. Note 2: Qualified persons whose work on energized equipment involves either direct contact by means of tools or materials must be also have the training needed to meet 29 CFR 1910.333(c)(2)."

\section{FACILITY REQUIREMENT SOURCE: 54FR3904 Part (c)(4)(i)}

"Ensure that all employees understand the hazards to which they may be exposed and how to prevent harm to themselves and others from exposure to these hazards, so that employees accept and follow established safety and health protections."

\section{FACILITY REQUIREMENT SOURCE: 54FR3904 Part (c)(4)(ii)}

"So that supervisors will carry out their safety and health responsibilities effectively, ensure that they understand those responsibilities and the reasons for them, including: (A) Analyzing the work under their supervision to identify unrecognized potential hazards; (B) Maintaining physical protections in their work areas; and $(C)$ Reinforcing employee training on the nature of potential hazards in their work and on needed protective measures, through continual performance feedhack and, if necessary, through enforcement of safe work practices."

\section{FACILITY REQUIREMENT SOURCE: 54FR3904 Part (c)(4)(iii)}

"Ensure that managers understand their safety and health responsibilities, as described under (c)(1), "Management Commitment and Employee Involvement," so that the managers will effectively carry out those responsibilities."

\section{FACILITY REQUIREMENT SOURCE: 54FR3904 Part 3904.(b)(4)}

"Safety and health training addresses the safety and health responsibilities of all personnel concerned with the site, whether salaried or hourly. It is often most effective when incorporated into other training about performance requirements and job practices. It complexity depends on the size and complexity of the worksite, and the nature of the hazards and potential hazards at the site." 


\section{REQUIREMENTS IDENTIFICATION DOCUMENT HIGH LEVEL WASTE STORAGE TANK FARMS \\ Occupational Safety and Health}

\section{FACILITY REQUIREMENT SOURCE: DOE/EH0135 OS.3.5}

"5. Proper occupational safety equipment is available, its use is enforced, and proper training for its use is provided."

\section{FACILITY REQUIREMENT SOURCE: DOE/EH0135 PP.1.3}

"3. The staff is responsible for the direction and operation of personnel protection programs are professionally qualified and have sufficient time and authority to implement the established program."

\section{FACILITY REQUIREMENT SOURCE: DOE5480.10 Section 9.a(4)}

"First-line Supervisors should be required to: (a) maintain bealthful working conditions within his or her own organization and implement industrial hygiene recommendations; (b) train employees to perform assignments in a safe manner; and (c) follow administrative procedures to allow appropriate disciplinary action to be taken when health and safety rules are violated."

\section{FACILITY REQUIREMENT SOURCE: DOE5480.10 Section 9.b(5)}

"Employee Education. The industrial hygiene staff shall assist the first level supervisor in the development of an employee information and training program whenever a potential health hazard exists requiring engineering controls, administrative procedures, or personal protective equipment. The program shall include written notification of employees of environmental monitoring results when the results indicate that the employees are exposed above permissible limits. Training should include information on operations that may lead to exposure, the potential health effects of the hazard, the content of applicable standards, and the purpose and results of environmental monitoring."

\section{SITE REQUIREMENT SOURCE: DOE5480.20 Chapter I, Section 7.e(1)}

"e. General Employee Training (GET) Requirements.

(1) All persons employed either full- or part-time in DOE reactor and non-reactor nuclear facilities shall be trained in the following areas commensurate with their job duties:

(a) General description of facilities;

(b) Job related policies, procedures, and instructions;

(c) Radiological health and safety program;

(d) Facility emergency plans;

(e) Industrial safety/hygiene program; 


\section{REQUIREMENTS IDENTIFICATION DOCUMENT HIGH LEVEL WASTE STORAGE TANK FARMS Occupational Safety and Health}

(f) Fire protection program;

(g) Security program; and

(h) Quality assurance program.

\section{SITE REQUIREMENT SOURCE: DOE5480.20 Chapter I, Section 7.e(2)}

"Visitors, contracted personnel, and temporary personnel shall be under continuous escort while at the facility unless they have been trained in appropriate areas from the above list to the extent necessary to ensure safe execution of their duties. For example, short-term visitors should be given instruction in items (a), (c), (d), (e), and (g), while contracted and temporarily assigned personnel may need training in additional topics as related to their assignments."

\section{FACILITY REQUIREMENT SOURCE: EEI Chapter II, Section 4}

Supervisors should be given clear responsibility for behavioral observation of their employees and should be given special training to ensure they have the knowledge and ability to perform that task well. Supervisors are in day-to-day contact with their personnel and are most familiar with their normal behavior patterns. Therefore, they are in the best position to detect changes in employees' behavior and to initiate appropriate corrective action in accordance with the fitness for duty program.

\section{FACILITY REQUIREMENT SOURCE: EEI Chapter II, Section 5}

Supervisors should be provided with specific guidelines and training as to what to do if an individual employee appears to be unfit for duty or appears to have drugs or alcohol in his possession. This section illustrates the type of guidance that supervisors should be given.

\section{FACILITY REQUIREMENT SOURCE: WAC-296-24 Section 020(1)(c)}

"Training programs to improve the skill and competency of all employees in the field of occupational safety and health. Such training shall include the on-the-job instructions on the safe use of powered materials handling equipment, machine tool operations, use of toxic materials and operation of utility systems prior to assignments to jobs involving such exposures."

\section{HAZWOPER Training}

This sub, sub-element contains the requirements for content of the Hazardous Waste Operations and Emergency Response Training Programs (HAZWOPER). 
WHC-EP-0750

\section{REQUIREMENTS IDENTIFICATION DOCUMENT HIGH LEVEL WASTE STORAGE TANK FARMS Occupational Safety and Health}

\section{FACILITY REQUIREMENT SOURCE: 29CFR1910 Part 120(b)(4)(ii)(B)}

"The site safety and health plan, as a minimum shall address the following: Employee training assignments to assure compliance with paragraph (e) of this section."

\section{FACILITY REQUIREMENT SOURCE: 29CFR1910 Part 120(c)(8)}

"Employee notification. Any information concerning the chemical physical, and toxicologic properties of each substance known or expected to be present on site that is available to the employer and relevant to the duties an employee is expected to perform shall be made available to the affected employees prior to the commencement of their work activities. The employer may utilize information developed for the hazard communication standard for this purpose."

\section{FACILITY REQUIREMENT SOURCE: 29CFR1910 Part 120(e)(1)(i)}

\section{"Training.}

General. All employees working on site (such as but not limited to equipment operators, general laborers and others) exposed to hazardous substances, health hazards, or safety hazards and their supervisors and management responsible for the site shall receive training meeting the requirements of this paragraph before they are permitted to engage in hazardous waste operations that could expose them to hazardous substances, safety, or health hazards, and they shall receive review training as specified in this paragraph."

\section{FACILITY REQUIREMENT SOURCE: 29CFR1910 Part 120(e)(1)(ii)}

"Employees shall not be permitted to participate in or supervise field activities until they have been trained to a level required by their job function and responsibility."

\section{FACILITY REQUIREMENT SOURCE: 29CFR1910 Part 120(e)(2)}

"Elements to be covered. The training shall thoroughly cover the following:

(i) Names of personnel and alternates responsible for site safety and health;

(ii) Safety, health and other hazards present on the site;

(iii) use of personal protective equipment;

(iv) Work practices by which the employee can minimize risks from hazards;

(v) Safe use of engineering controls and equipment on the site;

(vi) Medical surveillance requirements, including recognition of symptoms and signs which might indicate overexposure to hazards; and

(vii) The contents of paragraphs (G) through (J) of the site safety and health plan set forth in paragraph (b)(4)(ii) of this section."

\section{FACILITY REQUIREMENT SOURCE: 29CFR1910 Part 120(e)(3)(i)}

"Initial training. General site workers (such as equipment operators, general laborers and supervisory personnel) engaged in hazardous substance removal or other activities which expose or potentially expose workers to hazardous substances and health hazards shall receive a minimum of $\mathbf{4 0}$ hours of instruction off the site, and a minimum of three days actual field experience under the direct supervision of a trained, experienced supervisor." 
WHC-EP-0750

\section{REQUIREMENTS IDENTIFICATION DOCUMENT HIGH LEVEL WASTE STORAGE TANK FARMS \\ Occupational Safety and Health}

\section{FACILITY REQUIREMENT SOURCE: 29CFR1910 Part 120(e)(3)(ii)}

"Initial training.

Workers on site only occasionally for a specific limited task (such as, but not limited to, ground water monitoring, land surveying, or geo-physical surveying) and who are unlikely to be exposed over permissible exposure limits and published exposure limits shall receive a minimum of 24 hours of instruction off the site, and the minimum of one day actual field experience under the direct supervision of a trained, experienced supervisor. "

\section{FACILITY REQUIREMENT SOURCE: 29CFR1910 Part 120(e)(3)(iii)}

"Initial training. Workers regularly on site who work in areas which have been monitored and fully characterized indicating that exposures are under permissible exposure limits and published exposure limits where respirators are not necessary, and the characterization indicates that there are no health hazards or the possibility of an emergency developing, shall receive a minimum of 24 hours of instruction off the site and the minimum of one day actual field exper: ence under the direct supervision of a trained, experienced supervisor."

\section{FACILITY REQUIREMENT SOURCE: 29CFR1910 Part 120(e)(3)(iv)}

"Initial training Workers with 24 hours of training who are covered by paragraphs (e)(3)(ii) and (e)(3)(iii) of this section, and who become general site workers or who are required to wear respirators, shall have the additional 16 hours and two days of training necessary to total the training specified in paragraph (e)(3)(i)."

\section{FACILITY REQUIREMENT SOURCE: 29CFR1910 Part 120(e)(4)}

"Management and supervisor training. On-site management and supervisors directly responsible for, or who supervise employees engaged in, hazardous waste operations shall receive 40 hours initial training, and three days of supervised field experience (the training may be reduced to 24 hours and one day if the only area of their responsibility is employees covered by paragraphs (e)(3)(ii) and (e)(3)(iii) and at least eight additional hours of specialized training at the time of job assignments on such topics as, but not limited to, the employer's safety and health program and the associated employee training program, personal protective equipment program, spill containment program, and health hazard monitoring procedure and techniques."

\section{FACILITY REQUIREMENT SOURCE: 29CFR1910 Part 120(e)(5)}

"Qualifications for trainers. Trainers shall be qualified to instruct employees about the subject matter that is being presented in training. Such trainers shall have satisfactorily completed a training program for teaching the subjects they are expected to teach, or they shall have the academic credentials and instructional experience necessary for teaching the subjects. Instructors shall demonstrate competent instructional skills and knowledge of the applicable subject matter."

\section{FACILITY REQUIREMENT SOURCE: 29CFR1910 Part 120(e)(6)}

"Training certification. Employees and supervisors that have received and successfully completed the training and field experience specified in paragraphs (e)(1) through (e)(4) of this 
WHC-EP-0750

\section{REQUIREMENTS IDENTIFICATION DOCUMENT HIGH LEVEL WASTE STORAGE TANK FARMS Occupational Safety and Health}

section shall be certified by their instructor or the head instructor and trained supervisor as having successfully completed the necessary training. A written certificate shall be given to each person so certified. Any person who has not been so certified or who does not meet the requirements of paragraph (e)(9) of this section shall be prohibited from engaging in hazardous waste operations."

\section{FACILITY REQUIREMENT SOURCE: 29CFR1910 Fart 120(e)(7)}

"Training.

Emergency response. Employees who are engaged in responding to hazardous emergency situations at hazardous waste clean-up sites that may expose them to hazardous substances shall be trained in how to respond to such expected emergencies."

\section{FACILITY REQUIREMENT SOURCE: 29CFR1910 Part 120(e)(8)}

"Refresher training. Employees specified in paragraph (e)(1) of this section, and managers and supervisors specified in paragraph (e)(4) of this section, shall receive eight hours of refresher training annually on the items specified in paragraph (e)(2) and/or (e)(4) of this section, any critique of incidents that have occurred in the past year that can serve as training examples of related work, and other relevant topics."

\section{FACILITY REQUIREMENT SOURCE: 29CFR1910 Part 120(e)(9)}

"Equivalent training. Employers who can show by documentation or certification that an employee's work experience and/or training has resulted in training equivalent to that training required in paragraphs $(e)(1)$ through (e)(4) of this section shall not be required to provide the initial training requirements of those paragraphs to such employees and shall provide a copy of the certification or documentation to the employee upon request. However, certified employees or employees with equivalent training new to a site shall receive appropriate, site specific training before site entry and have appropriate supervised field experience at the new site. Equivalent training includes any academic training or the training that existing employees might have already received from actual hazardous waste site work experience."

\section{FACILITY REQUIREMENT SOURCE: 29CFR1910 Part 120(i)}

"Informational programs. Employers shall develop and implement a program, which is part of the employer's safety and health program required in paragraph (b) of this section, to inform employees, contractors, and subcontractors (or their representative) actually engaged in hazardous waste operations of the nature, level and degree of exposure likely as a result of participation in such hazardous waste operations. Employees, contractors and subcontractors working outside of the operations part of a site are not covered by this standard."

\section{SITE REQUIREMENT SOURCE: WAC-296-62 Section 05207(1)(a)}

"Employee medical records. The medical record for each employee shall be preserved and maintained for at least the duration of employment plus thirty years, except that the following types of records need not be retained for any specific period:

(i) Health insurance claims records maintained separately from the 


\section{REQUIREMENTS IDENTIFICATION DOCUMENT HIGH LEVEL WASTE STORAGE TANK FARMS Occupational Safety and Health}

employer's medical program and its records;

(ii) First-aid records (not including medical histories) of one-time treatment and subsequent observation of minor scratches, cuts, burns, splinters, and the like which do not involve medical treatment, loss of consciousness, restriction of work or motion, or transfer to another job, if made on-site by a nonphysician and if maintained separately from the employer's medical program and its records; and

(iii) The medical records of employees who have worked for less than one year for the employer need not be retained beyond the term of employment if they are provided to the employee upon the termination of employment."

\section{FACILITY REQUIREMENT SOURCE: WAC-296-62 Section 3040 (6)(a)(i)}

"Overview of the applicable section of Part P of chapter 296-62 WAC and the elements of an employer's effective occupational safety and health program."

\section{FACILITY REQUIREMENT SOURCE: WAC-296-62 Section 3040 (6)(a)(ii)}

"Effect of chemical exposure to hazardous substances (i.e., toxicity, carcinogens, irritants, sensitizers, etc.)"

FACILITY REQUIREMENT SOURCE: WAC-296-62 Section 3040 (6)(a)(iii)

"Effects of biological and radiological exposures."

FACILITY REQUIREMENT SOURCE: WAC-296-62 Section 3040 (6)(a)(iv)

"Fire and explosion hazards (i.e., flammable and combustible liquids, reactive materials)."

FACILITY REQUIREMENT SOURCE: WAC-296-62 Section 3040 (6)(a)(ix)

"Use of personal protective equipment and the implementation of the personal protective equipment program."

FACILITY REQUIREMENT SOURCE: WAC-296-62 Section 3040 (6)(a)(v)

"General safety hazards, including electrical hazards, powered equipment hazards, walking-working surface hazards and those hazards associated with hot and cold temperature extremes."

FACILITY REQUIREMENT SOURCE: WAC-296-62 Section 3040 (6)(a)(vi)

"Confined space, tank and vault hazards and entry procedures."

\section{FACILITY REQUIREMENT SOURCE: WAC-296-62 Section 3040 (0)(a)(vii)}

"Names of personnel and alternates, where appropriate, responsible for site safety and health at the site." 


\section{REQUIREMENTS IDENTIFICATION DOCUMENT \\ HIGH LEVEL WASTE STORAGE TANK FARMS \\ Occupational Safety and Health}

FACILITY REQUIREMENT SOURCE: WAC-296-62 Section 3040 (6)(a)(viii)

"Specific safety, health, and other hazards that are to be addressed at a site and in the site safety and health plan."

FACILITY REQUIREMENT SOURCE: WAC-296-62 Section 3040 (6)(a)(x)

"Work practices that will minimize employee risk from site hazards."

FACILITY REQUIREMENT SOURCE: WAC-296-62 Section 3040 (6)(a)(xi)

"Safe use of engineering controls and equipment and any new relevant technology or procedure."

FACILITY REQUIREMENT SOURCE: WAC-296-62 Section 3040 (6)(a)(xii)

"Content of the medical surveillance program and requirements, including the recognition of signs and symptoms of overexposure to hazardous substances."

FACILITY REQUIREMENT SOURCE: WAC-296-62 Section 3040 (6)(a)(xiii)

"The contents of an effective site safety and health plan."

FACILITY REQUIREMENT SOURCE: WAC-296-62 Section 3040 (6)(a)(xiv)

"Use of monitoring equipment with "hands-on" experience and the implementation of the employee and site monitoring program."

FACILITY REQUIREMENT SOURCE: WAC-296-62 Section 3040 (6)(a)(xix)

"Methods for handling shock-sensitive wastes."

FACILITY REQUIREMENT SOURCE: WAC-296-62 Section 3040 (6)(a)(xv)

"Implementation and use of the information program. "

FACILITY REQUIREMENT SOURCE: WAC-296-62 Section 3040 (6)(a)(xvi)

"Drum and container handling procedures and the elements of a spill containment program."

FACILITY REQUIREMENT SOURCE: WAC-296-62 Section 3040 (0)(a)(xvii)

"Selection and use of material handling equipment."

FACILITY REQUIREMENT SOURCE: WAC-296-62 Section 3040 (6)(a)(xviii)

"Methods for assessment of risk and handling of radioactive wastes." 
WHC-EP-0750

\section{REQUIREMENTS IDENTIFICATION DOCUMENT \\ HIGH LEVEL WASTE STORAGE TANK FARMS \\ Occupational Safety and Health}

FACILITY REQUIREMENT SOURCE: WAC-296-62 Section 3040 (0)(a)(xx)

"Laboratory waste pack handling procedures."

FACILITY REQUIREMENT SOURCE: WAC-296-62 Section 3040 (6)(a)(xxi)

"Container sampling procedures and safeguards."

FACILITY REQUIREMENT SOURCE: WAC-296-62 Section 3040 (6)(a)(xxii)

"Safe preparation procedures for shipping and transport of containers."

FACILITY REQUIREMENT SOURCE: WAC-296-62 Section 3040 (6)(a)(xxiii)

"Decontamination program and procedures."

FACILITY REQUIREMENT SOURCE: WAC-296-62 Section 3040 (6)(a)(xxiv)

"Emergency response plan and procedures including first aid."

FACILITY REQUIREMENT SOURCE: WAC-296-62 Section 3040 (0)(a)(xxix)

"Sources of reference, additional information and efficient use of relevant manuals and hazard coding systems."

FACILITY REQUIREMENT SOURCE: WAC-296-62 Section 3040 (6)(a)(xxv)

"Safe site illumination levels."

FACILITY REQUIREMENT SOURCE: WAC-296-62 Section 3040 (6)(a)(xxvi)

"Site sanitation procedures and equipment for employee needs."

FACILITY REQUIREMENT SOURCE: WAC-296-62 Section 3040 (6)(a)(xxvii)

"Review of the applicable appendices to Part P of chapter 296-62 WAC."

FACILITY REQUIREMENT SOURCE: WAC-296-62 Section 3040 (6)(a)(xxviii)

"Overview and explanation of WISHA's hazard communication standard Part C of chapter 296-62 WAC."

FACILITY REQUIREMENT SOURCE: WAC-296-62 Section 3040 (0)(a)(xxx)

"Principles of toxicology and biological monitoring."

FACILITY REQUIREMENT SOURCE: WAC-296-62 Section 3040 (6)(a)(xxxi)

"Rights and responsibilities of employees and employers under WISHA and CERCLA." 


\section{REQUIREMENTS IDENTIFICATION DOCUMENT HIGH LEVEL WASTE STORAGE TANK FARMS Occupational Safety and Health}

FACILITY REQUIREMENT SOURCE: WAC-296-62 Section 3040 (6)(a)(xxxii)

"HHands-on" field exercises and demonstrations."

FACILITY REQUIREMENT SOURCE: WAC-296-62 Section 3040 (6)(b)(i)

"Overview of applicable sections of Part P of chapter 296-62 WAC and the elements of the employer's effective occupational safety and health program."

FACILITY REQUIREMENT SOURCE: WAC-296-62 Section 3040 (6)(b)(ii)

"Employee rights and responsibilities under WISHA and CERCLA."

FACILITY REQUIREMENT SOURCE: WAC-296-62 Section 3040 (6)(b)(iii)

"Overview of relevant chemical exposures to hazardous substances (i.e., toxics, carcinogens, irritants, sensitizers, etc.)."

FACILITY REQUIREMENT SOURCE: WAC-296-62 Section 3040 (6)(b)(iv)

"Overview of the principles of toxicology and biological monitoring."

FACILITY REQUIREMENT SOURCE: WAC-296-62 Section 3040 (6)(b)(ix)

"Work practices that will minimize employee risk from site hazards."

FACILITY REQUIREMENT SOURCE: WAC-296-62 Section 3040 (6)(b)(v)

"Use of monitoring equipment with hands-on practice and an overview of a site monitoring program."

FACILITY REQUIREMENT SOURCE: WAC-296-62 Section 3040 (6)(b)(vi)

"Overview of site hazards including fire and explosion, confined spaces, oxygen deficiency, electrical hazards, powered equipment hazards, walking-working surface hazards."

FACILITY REQUIREMENT SOURCE: WAC-296-62 Section 3040 (6)(b)(vii)

"The contents of an effective site safety and health plan."

FACILITY REQUIREMENT SOURCE: WAC-296-62 Section 3040 (6)(b)(viii)

"Use of personal protective equipment and the implementation of the personal protective equipment program."

FACILITY REQUIREMENT SOURCE: WAC-296-62 Section 3040 (6)(b)(x)

"Site simulations with "hands-on" exercises and practice." 
WHC-EP-0750

\section{REQUIREMENTS IDENTIFICATION DOCUMENT HIGH LEVEL WASTE STORAGE TANK FARMS \\ Occupational Safety and Health}

FACILITY REQUIREMENT SOURCE: WAC-296-62 Section 3040 (6)(b)(xi)

"Emergency response planning and response including first aid."

FACILITY REQUIREMENT SOURCE: WAC-296-62 Section 3040 (6)(b)(xii)

"Content of the medical surveillance program and requirements, including the recognition of signs and symptoms of overexposure to hazardous substances."

FACILITY REQUIREMENT SOURCE: WAC-296-62 Section 3040 (0)(b)(xiii)

"Decontamination programs and procedures. "

FACILITY REQUIREMENT SOURCE: WAC-296-62 Section 3040 (6)(b)(xiv)

"Safe use of engineering controls and equipment."

FACILITY REQUIREMENT SOURCE: WAC-296-62 Section 3040 (6)(b)(xv)

"Sources of references and efficient use of relevant manuals and knowledge of hazard coding systems."

FACILITY REQUIREMENT SOURCE: WAC-296-62 Section 3040 (6)(c)(i)

"Relevant chemical exposures to hazardous substances beyond that previously covered."

FACILITY REQUIREMENT SOURCE: WAC-296-62 Section 3040 (6)(c)(ii)

"Site hazards including fire and explosion, confined spaces, oxygen deficiency, electrical, powered equipment, and walking-working surfaces beyond that previously covered."

FACILITY REQUIREMENT SOURCE: WAC-296-62 Section 3040 (6)(c)(iii)

"Names of personnel and alternates responsible for site safety and health at the site, where appropriate."

FACILITY REQUIREMENT SOURCE: WAC-296-62 Section 3040 (6)(c)(iv)

"Use of monitoring equipment and the implementation of the employee and the site monitoring program beyond that previously covered."

FACILITY REQUIREMENT SOURCE: WAC-296-62 Section 3040 (6)(c)(ix)

"Methods for handling shock-sensitive wastes."

FACILITY REQUIREMENT SOURCE: WAC-296-62 Section 3040 (6)(c)(v)

"Implementation and use of the informational program." 
WHC-EP-0750

\section{REQUIREMENTS IDENTIFICATION DOCUMENT HIGH LEVEL WASTE STORAGE TANK FARMS Occupational Safety and Health}

FACILITY REQUIREMENT SOURCE: WAC-296-62 Section 3040 (6)(c)(vi)

"Drum and container handling procedures and the elements of a spill containment program."

FACILITY REQUIREMENT SOURCE: WAC-296-62 Section 3040 (6)(c)(vii)

"Selection and use of material handling equipment."

FACILITY REQUIREMENT SOURCE: WAC-296-62 Section 3040 (6)(c)(viii)

"Methods for assessment of risk and handling of radioactive wastes. "

FACILITY REQUIREMENT SOURCE: WAC-296-62 Section 3040 (6)(c)(x)

"Laboratory waste pack handling procedures."

FACILITY REQUIREMENT SOURCE: WAC-296-62 Section 3040 (6)(c)(xi)

"Container sampling procedures and safeguards."

FACILITY REQUIREMENT SOURCE: WAC-296-62 Section 3040 (0)(c)(xii)

"Safe preparation procedures for shipping and transport of containers."

FACILITY REQUIREMENT SOURCE: WAC-296-62 Section 3040 (6)(c)(xiii)

"Decontamination program and procedures."

FACILITY REQUIREMENT SOURCE: WAC-296-62 Section 3040 (6)(c)(xiv)

"Safety site illumination levels."

FACILITY REQUIREMENT SOURCE: WAC-296-62 Section 3040 (6)(c)(xv)

"Site sanitation procedures and equipment."

FACILITY REQUIREMENT SOURCE: WAC-296-62 Section 3040 (6)(c)(xvi)

"Review of the applicable appendices to Part P of chapter 296-62 WAC."

FACILITY REQUIREMENT SOURCE: WAC-296-62 Section 3040 (6)(c)(xvii)

"Overview and explanation of WISHA's Hazard Communication Standard Part C of chapter 296-62 WAC."

FACILITY REQUIREMENT SOURCE: WAC-296-62 Section 3040 (6)(c)(xviii)

"Sources of reference and additional information." 
WHC-EP-0750

\section{REQUIREMENTS IDENTIFICATION DOCUMENT HIGH LEVEL WASTE STORAGE TANK FARMS Occupational Safety and Health}

FACILTY REQUIREMENT SOURCE: WAC-296-62 Section 3040 (6)(c), Introduction

"16-hour supplemental training for hazardous waste sites. As a minimum, employees who have received 24 hours of training for hazardous waste site operations shall receive training in the following topics before they are allowed to work as general site workers or if they are required to wear respirators: "

FACILITY REQUIREMENT SOURCE: WAC-296-62 Section 3040 (6)(d)(i)

"Management of hazardous wastes and their disposal."

FACILITY REQUIREMENT SOURCE: WAC-296-62 Section 3040 (6)(d)(ii)

"Federal, state, and local agencies to be contacted in the event of a release of hazardous substances."

FACIITY REQUIREMENT SOURCE: WAC-296-62 Section 3040 (6)(d)(iii)

"Management of emergency procedures in the event of a release of hazardous substances."

FACILITY REQUIREMENT SOURCE: WAC-296-62 Section 3040 (6)(d), Introduction

"Additional 8 hours of training for supervisors and managers. Supervisors and managers shall receive an additional eight hours of training in the following subjects:"

\section{OS\&H Training, Recordkeeping, and Reporting}

This sub-element details the proper maintenance of training records and on-site reporting of training. This requirements for these functions are completely addressed within the Training Functional Area.

\section{FACILITY REQUIREMENT SOURCE: 29CFR1910 Part 147 (c)(7)(iv)}

"Lockout and Tagout

The control of hazardous energy (lockout/tagout)

(iv) The employer shall certify that employee training has been accomplished and is being kept up to date. The certification shall contain each employee's name and dates of training."

\section{RECORDKEEPING AND REPORTING}

This element relates to the controls necessary for record generation, record storage, record retention, and employee record accessibility constraints.

\section{OS\&H Record Management and Exposure Reporting}

This sub-element establishes the OSH Record Management and Exposure Reporting 


\section{REQUIREMENTS IDENTIFICATION DOCUMENT HIGH LEVEL WASTE STORAGE TANK FARMS Occupational Safety and Health}

System. The controls necessary for an effective record management program are completely addressed within the Management Systems Functional Area. The requirements for Exposure Reporting are detailed in this sub-olement.

\section{FACIITY REQUIREMENT SOURCE: DOES480.10 Section 9.f(4)}

"Records shall be retained in accordance with DOE 1324.2, RECORDS DISPOSITION."

\section{FACIITY REQUIREMENT SOURCE: DOE5483.1A Chapter I, Section 5.d}

"All contractor employees shall be informed that the contractor is required to monitor the employee's workplace for radiation exposure and known toxic materials or harmful physical agents which are used or produced at the GOCO facility, and to maintain records of the data as required by Title 29 CFR Part 1910.20, "Access to Employee Exposure and Medical Records." Employees or their authorized representatives are to be provided with an opportunity to observe monitoring or measuring for toxic materials and harmful physical agents and to have access to the results thereof. Each employee or former employee or representative thereof, within 15 days of a written request, shall be provided access to or copies of any records of cumulative recorded occupational radiation dose or any monitoring or bioassay records relevant to potential exposure to toxic materials or harmful physical agents during employment. Employees will be notified of any information indicating that a radiation dose or an exposure to toxic materials or harmful physical agents may have exceeded the limits specified by the DOE-prescribed OSHA standards."

\section{Occurrence Reporting}

This sub-element addresses the requirements for reporting, notification, categorization, implementation, review, and follow-up of occurrences. These requirements are completely addressed with the Management Systems Functional Area.

\subsubsection{Occupational Injury and Illness Reporting}

This sub-element details the requirements for reporting of all occupational injuries and illnesses. These controls include methods for: recording/maintaining medical and toxic exposures for the duration of a workers employment and/or lifetime as required; and posting injury and illness data annually as required by OSHA regulations.

\section{FACILITY REQUIREMENT SOURCE: DOE/EH0135 PP.1.5}

"5. Necessary information is readily communicated to top management, to all segments of the organization concerned, and to the public and regulatory agencies, as appropriate."

\section{KEY PROGRAM INTERFACES}

The implementation and administration of an Occupational Health and Safety Program requires the definition of interfaces with other functional areas. All Tank Farm Facility activities are governed by the sitewide Occupational Health and Safety Program. Specific 


\section{REQUIREMENTS IDENTIFICATION DOCUMENT HIGH LEVEL WASTE STORAGE TANK FARMS Occupational Safety and Health}

organizations/functional areas must implement the programa/requirements developed by the Health and Safoty Organization. Soveral functional areas have significant interfaces which are described in the following sections.

The Engineering Design Functional Ares defines the processes neceseary to design engineering controls for health and safety hazards. This interface is essential during the actual design or pre-engineering phase.

Emergency Preparedness and Manaeement (ERM

The Occupational Safety and Health Program provides the Emergency Preparedness and Management Functional Area with the necessary emergency planning support to ensure proper use and delineation of OSH regulations and procedures. The Occupational Safoty and Health Organization shall also provide support for exercises and training.

17.7.3 Maintenance

The Maintenance Functional Area interfaces with the Occupational Safoty and Health Program during all routine and non-routine maintenance activities. All personnel health and safety training shall be completed and hazard controls implemented prior to performing work.

17.7.4 Operations

The Operations Organization depends on the controls outlined in the Health and Safety Program to safety operate. Workplace hazard identification and assessment is accomplished through walkdown inspections, surveys, monitoring and surveillances. Based on the hazards identified the necessary controls are defined and implemented to ensure safe operations. The Operations Organization should work closely with the Occupational Safety and Health

Program on all routine and non-routine operations.

\subsubsection{Radiation Protection}

Personnel working in radiologically controlled areas must adhere to all ALARA policies and OSHA controls. The Radiation Protection Functional Area must coordinate all routine and nonroutine activities with the OSH Program.

Training and Qualification

Training is an integral part of any effective health and safety program. The Occupational Health and Safety Program provides the necessary information and support to the training program to ensure that effective health and safety training is developed and conducted. The training organization shall properly document all health and safety training and maintain all such documentation in accordance with established procedures. 


\section{REQUIREMENTS IDENTIFICATION DOCUMENT \\ HIGH LEVEL WASTE STORAGE TANK FARMS \\ Occupational Safety and Health}

17.7 .7

17.7 .9

17.7 .10

\section{Construction}

All facility construction activities shall adhere to the OSHA regulations incorporated into the Occupational Health and Safoty Program. The facility construction organization shall interface with the Health and Safoty Organization to ensure understanding and adherence with established health and safety controls. Specifically, the construction organization shall adhere to OSHA's "Construction Standards" (29 CFR 1926).

\section{Mangrement Systems}

The Management Systems Functional Aren provides the neceseary controls for developing, using, and maintaining facility policies and procedures. In addition, the Health and Safety Organization shall participate in Occurrence/Event Reporting activities which are included in this area.

\section{Packagine and Transportation}

The Packaging and Transportation of naterials (both nuclear and non-nuclear) involves significant interaction with the OSH Program. Specific subjects of concern include safe handling of hazardous materials and chemicals, hoisting and rigging, Personal Protective Equipment, otc.

\section{Safequards and Security}

The Safeguards and security organization has a limited interaction with the OSH Program conceming the safe handling of firearms and explosives. 


\section{WESTINGHOUSE HANFORD COMPANY}

\section{REQUIREMENTS}

IDENTIFICATION

DOCUMENT

EACILITY:

HIGH LEVEL WASTE STORAGE TANK FARMS/242-A EVAPORATOR
EUNCTIONAL AREA:

Environmental Protection

\section{REVISION 0}




\section{REQUIREMENTS IDENTIFICATION DOCUMENT \\ HIGH LEVEL WASTE STORAGE TANK FARMS \\ Environmental Protection \\ Revision 0}

\section{TABLE OF CONTENTS}

18.0 ENVIRONMENTAL PROTECTION $\ldots \ldots \ldots \ldots \ldots \ldots \ldots \ldots \ldots \ldots \ldots \ldots \ldots \ldots$

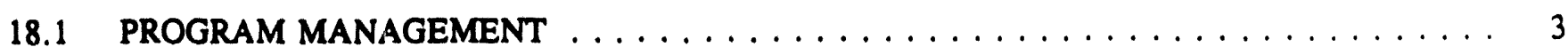

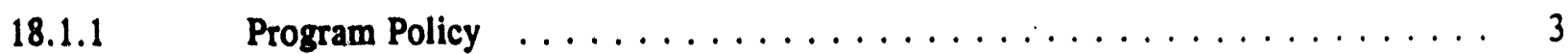

18.1.2 Organization Structure $\ldots \ldots \ldots \ldots \ldots \ldots \ldots \ldots \ldots \ldots \ldots \ldots, \ldots \ldots \ldots$

18.1.3 Personnel Qualifications $\ldots \ldots \ldots \ldots \ldots \ldots \ldots \ldots \ldots \ldots \ldots$

18.2 ENVIRONMENTAL MONTTORING, SURVEILLANCE, AND INSPECTIONS $\ldots \ldots \ldots \ldots$

18.2.1 Monitoring, Surveillance, and Inspection Plans and Procedures . . . . . . . 7

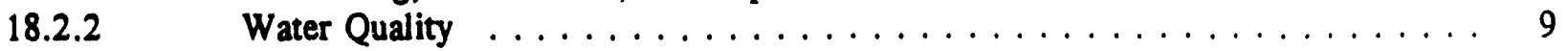

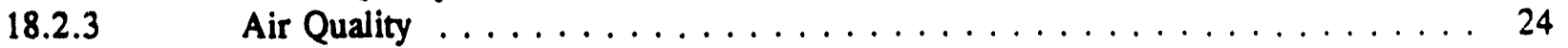

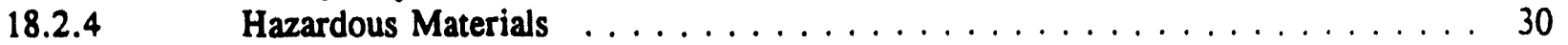

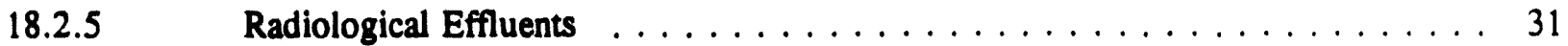

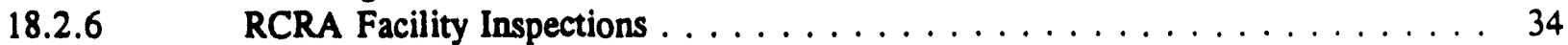

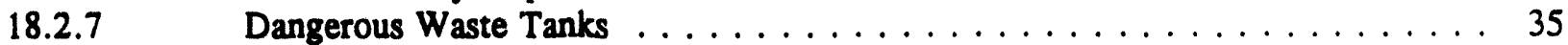

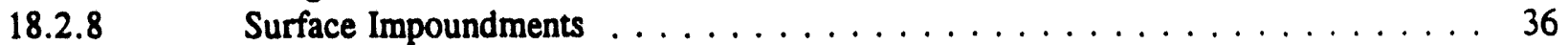

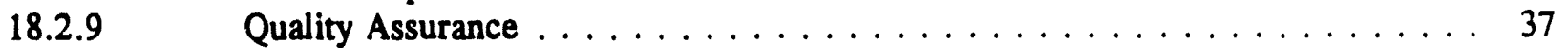

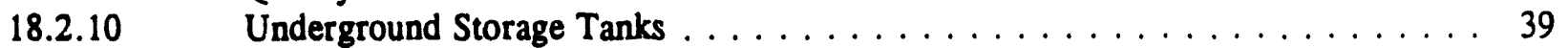

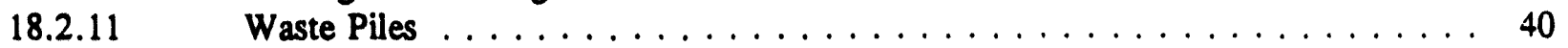

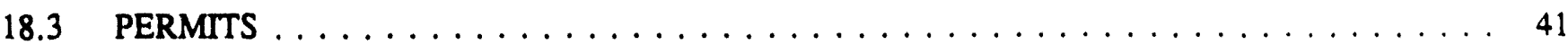

18.3.1 Clean Water Permits $\ldots \ldots \ldots \ldots \ldots \ldots \ldots \ldots \ldots \ldots \ldots$

18.3.2 Clean Air Permits $\ldots \ldots \ldots \ldots \ldots \ldots \ldots \ldots \ldots \ldots \ldots \ldots \ldots$

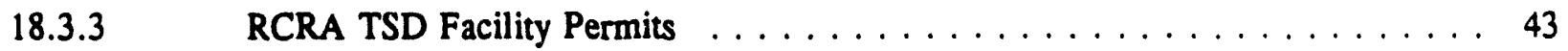

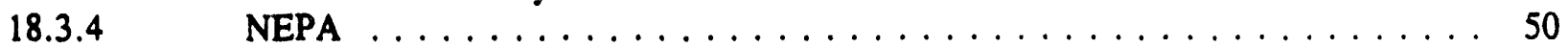

18.4 POLLUTION CONTROL STANDARDS $\ldots \ldots \ldots \ldots \ldots \ldots \ldots \ldots \ldots \ldots \ldots$

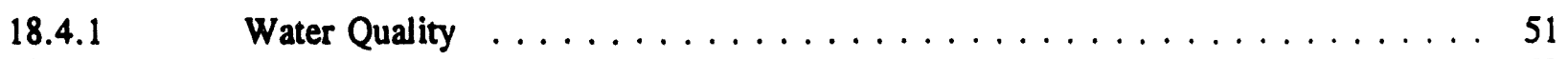

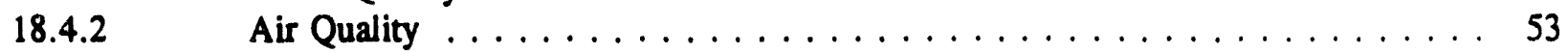

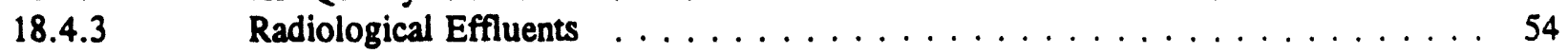

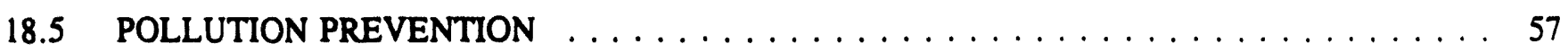

18.6 RECORDKEEPING, REPORTS, AND NOTIFICATIONS $\ldots \ldots \ldots \ldots \ldots \ldots$ 


\section{Environmental Protection}

Revision 0

18.6.1

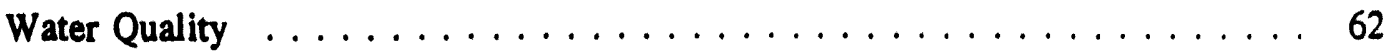

18.6 .2

Air Quality

18.6 .3

Hazardous Materials

66

18.6 .4

Radiological Effluents

68

18.6 .5

Spills and Discharges

71

18.6 .6

Dangerous Waste

18.7 TANK REGULATIONS $\ldots \ldots \ldots \ldots \ldots \ldots \ldots \ldots \ldots \ldots$

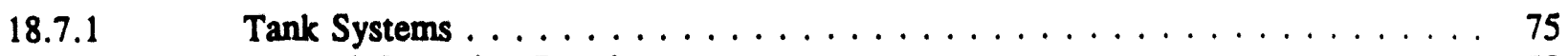

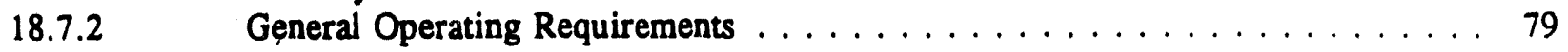

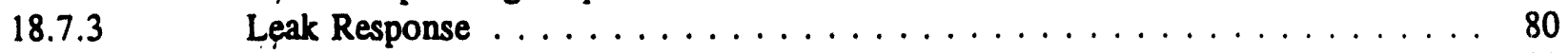

18.7.4 Ignitable, Reactive, and Incompatible Tank Wastes $\ldots \ldots \ldots \ldots 2$

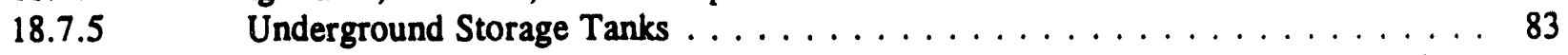

18.8 GENERAL TSD REQUIREMENTS $\ldots \ldots \ldots \ldots \ldots \ldots$

18.8.1 Performance Standards $\ldots \ldots \ldots \ldots \ldots \ldots$

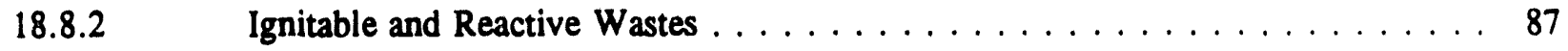

18.9 KEY PROGRAM INTERFACE $\ldots \ldots \ldots \ldots \ldots \ldots \ldots \ldots$

18.9.1 Training and Qualification $\ldots \ldots \ldots \ldots \ldots \ldots \ldots \ldots$

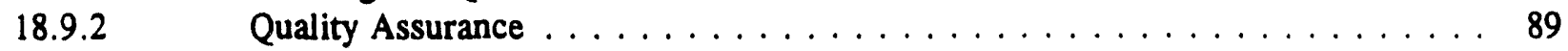

18.10 REFERENCE SECTION $\ldots \ldots \ldots \ldots \ldots \ldots \ldots \ldots \ldots \ldots \ldots \ldots$ 


\section{REQUIREMENTS IDENTIFICATION DOCUMENT \\ HIGH LEVEL WASTE STORAGE TANK FARMS \\ Environmental Protection \\ Revision 0}

\subsection{ENVIRONMENTAL PROTECTION}

\section{INTRODUCTION}

The Environmental Protection (EP) Functional Area includes the technical and programmatic requirements, formal controls, and standards to assure compliance with applicable environmental laws and regulations. The Environmental Protection requirements are typically identified by the applicable law (RCRA, CERCLA, SARA, CAA, CWA, etc.) to which they are related. The Washington Administrative Code is the source of the majority of environmental regulations for permitting, media quality standards, tank specific requirements, and recordkeeping. DOE Orders 5400.1, 5400.5, 5484.1 and DOE/EH-0173T specify requirements for DOE environmental programs and environmental monitoring and surveillance activities. Federal regulations such as 40 CFR 61 are utilized when there are no equivalent regulations promulgated by the state of Washington.

\section{SCOPE}

This functional area applies to the environmental protection programmatic controls, activities, personnel, and programs involved in executing the mission of Tank Farms. The physical boundaries within which the requirements of this functional area apply are the Single Shell Tank Farms, Double Shell Tank Farms, 242-A Evaporator-Crystallizer, 242-S, T Evaporators, Liquid Effluent Retention Facility (LERF), Purgewater Storage Facility (PWSF), and all interconnecting piping, valves, instrumentation, and controls up to and including the last locked valve under Tank Farms control associated with facilities that interface with Tank Farms. Tank Farms facilities also include hazardous waste accumulation areas, a 90-day waste storage area, and underground storage tanks containing diesel fuel.

The waste storage tanks provide for storage of high-level radioactive waste containing hazardous constituents. These tanks continue to receive waste periodically from various generators through piping and transfer truck. Several tanks are confirmed leakers and require an appropriate environmental surveillance and monitoring program. Environmental regulations for tank integrity assessments and operating requirements are applicable.

Tank Farm hazardous waste facilities are managed under interim status and have submitted RCRA Part B permit applications for the selected RCRA units. Hanford has also submitted a sitewide permit application in which all TSD units are treated as a single facility. The Hanford facility permit is being jointly issued by the EPA and the Washington Department of Ecology to DOE-RL and its primary contractors.

The Tank Farms contains high-heat tanks that require internal ventilation for cooling. The ventilation systems are point source air emission sources regulated under NESHAPs. Tank Farms does not have any liquid effluents discharging to surface waters of the State of Washington.

Tank Farms also consists of various contaminated ponds, cribs, and ditches which are inactive. This functional area document does not address the scope of these facilities. 


\section{REQUIREMENTS IDENTIFICATION DOCUMENT \\ HIGH LEVEL WASTE STORAGE TANK FARMS}

\section{Environmental Protection}

Revision 0

The following list identifies the programmatic elements in the EP Functional Area:

1. Program Management

2. Monitoring, Surveillance, and Inspection Plans and Procedures

3. Permits

4. Pollution Control Standards

5. Pollution Prevention

6. Recordkeeping, Reports, and Notifications

7. Tank Regulations

8. General TSD Requirements

9. Key Program Interfaces 


\section{REQUIREMENTS IDENTIFICATION DOCUMENT HIGH LEVEL WASTE STORAGE TANK FARMS \\ Environmental Protection \\ Revision 0}

18.1

$\underline{18.1 .1}$

$\underline{18.1 .2}$

\section{PROGRAM MANAGEMENT}

This elemeat addresses the management and organization of an effective EP Program. Formal organization of the Program is necessary to ensure that a deliberate and controlled approach to Program management and execution is achieved. Establishment of such a formal organization enhances the potential for achievement of improved levels of safety performance, compliance, and efficiency. This element describes the extent of the formal Program organization structure necessary to define and communicate where personnel are assigned, what tasks they are expected to accomplish, methods for accomplishment, and management's expectations for performance.

\section{Program Policy}

3

Communication of site management's commitment to the safety and health of workers, the general public, and for the protection of property and the surrounding environment is accomplished through the development, distribution, and implementation of a EP policy statement. The policy statement describes the scope, general philosophy, and the standards of excelleace under which EP Program activities are to be conducted. The following statements from DOE Order 5400.1 provides the general DOE policy statement and implementation plan.

\section{SITE REQUIREMIENT SOURCE: DOE5400.1 Chapter V, Section a}

"It is DOE policy to conduct its operations in an environmentally safe and sound manner. Protection of the environment and the public are responsibilities of paramount importance and concern to DOE. All DOE activities should recognize and reflect this concem and public trust. To that end, DOE is firmly committed to ensuring incorporation of national environmental protection goals in the formulation and implementation of DOE programs. It has an equal commitment to advance the goals of restoring and enhancing environmental quality, and ensuring public health. Accordingly, it is DOE policy to conduct the Department's operations in compliance with the letter and spirit of applicable environmental statutes, regulations, and standards. In addition, DOE is committed to good environmental management of all its programs and all its facilities to correct existing environmental problems, to minimize risk to the environment or public health, and to anticipate and address potential environmental problems before they pose a threat to the quality of the environment or the public welfare. Finally, it is DOE's policy that efforts to meet environmental obligations be carried out consistently across all operations and among all field organizations and programs."

\section{Organization Structure}

This subelement specifies requirements for organizational structure and personnel responsibilities for radiological monitoring programs. The source of this requirement is NRC Regulatory Guide 4.15 , therefore it is considered a best management practice.

\section{SITE REQUIREMENT SOURCE: NRC-4.15 Section C.1}

\section{"Organizational Structure and Responsibilities of Managerial and Operational Personnel}

The structure of the organization as it relates to the management and operation of the monitoring program(s), including quality assurance policy and functions, should be presented. The authorities, duties, and responsibilities of the positions within this organization down to the first-line supervisory level should be described. This should include responsibilities for 


\section{REQUIREMENTS IDENTIFICATION DOCUMENT HIGH LEVEL WASTE STORAGE TANK FARMS \\ Environmental Protection \\ Revision 0}

review and approval of written procedures and for the preparation, review, and evaluation of monitoring data and reports.

Persons and organizations performing quality assurance functions should have sufficient authority and organizational freedom to identify quality problems; to initiate, recommend, or provide solutions; and to verify implementation of solutions."

\section{Personnel Qualifications}

This subelement specifies requirements for personnel qualification in radiological monitoring programs. The source of this requirement is NRC Regulatory Guide 4.15, therefore it is considered a best management practice.

$$
\text { i }
$$

\section{SITE REQUIREMENT SOURCE: NRC $\mathbf{4} .15$ Section C.2}

\section{"Specification of Qualifications of Personnel}

The qualifications of individuals performing radiological monitoring to carry out their assigned functions should be specified and documented (e.g., as in a job description).

An indoctrination and orientation program, appropriate to the size and complexity of the organization, and to the activities performed, should provide that (a) personnel performing quality-related activities are trained and qualified in the principles and techniques of the activities performed, (b) personnel are made aware of the nature and goals of the quality assurance program, and (c) proficiency of personnel who perform activities affecting quality is made by retraining, re-examining, and recertifying or by periodic performance reviews, as appropriate."

\section{ENVIRONMENTAL MONITORING, SURVEILLANCE, AND INSPECTIONS}

This element includes the creation and implementation of monitoring, surveillance, and inspection plans and specific monitoring and surveillance methods designed to prevent, detect, and mitigate leaks, spills, discharges, etc. Examples include ambient air quality surveillance standards, point source discharge monitoring, and hazardous waste site monitoring. The following programmatic requirements are specified by DOE Order 5400.1 .

\section{FACIITY REQUIREMENT SOURCE: DOE5400.1 Chapter IV, Section 3}

"Preoperational Monitoring of Facilities, Sites, and Operations. An environmental study shall be conducted prior to start up of a new site, facility, or process which has the potential for significant adverse environmental impact. The preoperational study should begin not less than 1 year, and preferably 2 years before start up to evaluate seasonal changes. The study shall serve to: characterize existing physical, chemical, and biological conditions that could be affected; establish background levels of radioactive and chemical components; characterize pertinent environmental and ecologic parameters; and identify potential pathways for human exposure or environmental impact as a basis for determining the nature and extent of the subsequent routine operational and emergency effluent monitoring and environmental surveillance programs. Where time and circumstances do not allow for completion of preoperational monitoring prior to start-up, it shall be conducted concurrent with work on the new site, facility, or process. The preoperational study shall be consistent with NEPA 


\section{REQUIREMENTS IDENTIFICATION DOCUMENT HIGH LEVEL WASTE STORAGE TANK FARMS \\ Environmental Protection \\ Revision 0}

compliance activities. Where appropriate, activities and documentation conducted for NEPA compliance may substitute for compliance with this requirement."

\section{FACILITY REQUIREMENT SOURCE: DOE5400.1 Chapter IV, Section 5.a}

\section{"Effluent Monitoring}

(1) Effluent monitoring shall be conducted at all DOE sites to satisfy the following program objectives:

(a) Verify compliance with applicable Federal, State, and local effluent regulations and DOE Orders.

(b) Determine compliance with commitments made in Environmental Impact Statements, Environmental Assessments, or other official documents.

(c) Evaluate the effectiveness of effluent treatment and control.

(d) Identify potential environmental problems and evaluate the need for remedial actions or mitigation measures.

(e) Support permit revision and/or reissuance.

(f) Detect, characterize, and report unplanned releases."

FACILITY REQUIREMENT SOURCE: DOE5400.1 Chapter IV, Section 5.a.(2)

"(2) Effluent monitoring shall comply with applicable regulations and shall be conducted to provide representative measurements of the quantities and concentrations of pollutants in liquid and airborne discharges, and solid wastes.

(a) Monitoring Stations. Effluents from on-site waste treatment or disposal systems shall be monitored in accordance with applicable regulations. Influents to on-site waste treatment or disposal systems should be monitored as needed.

(b) Sampling. Sample collection programs shall reflect specific facility needs. Type and frequency of sampling shall be adequate to characterize effluent streams.

(c) Sample Analysis. Standard analyses shall be used to analyze samples whenever such methods are required by regulatory programs. Exemptions due to analytical problems or for non-routine analyses may be employed after receiving approval from the appropriate regulatory agency. Analyses not required by regulations may be conducted as determined by site-specific conditions.

(d) Monitoring Data Record keeping. Auditable records shall be established in accordance with the requirements of DOE 5700.6B."

FACILITY REQUIREMENT SOURCE: DOE5400.1 Chapter IV, Section 5.b

"Environmental Surveillance 


\section{REQUIREMENTS IDENTIFICATION DOCUMENT \\ HIGH LEVEL WASTE STORAGE TANK FARMS \\ Environmental Protection}

Revision 0

(1) Environmental surveillance shall be conducted to monitor the effects, if any, of DOE activities on-site and offsite environmental and natural resources. An environmental surveillance screening program shall be undertaken at DOE sites to determine the need for a permanent surveillance program. Environmental surveillance shall be designed to satisfy one or more of the following program objectives:

(a) Verify compliance with applicable environmental laws and regulations;

(b) Verify compliance with environmental commitments made in Environmental Impact Statements, Environmental Assessments, Safety Analysis Reports, or other official DOE documents;

(c) Characterize and define trends in the physical, chemical and biological condition of environmental media;

(d) Establish baselines of environmental quality;

(e) Provide a continuing assessment of pollution abatement programs;

(f) Identify and quantify new or existing environmental quality problems. "

FACIIITY REQUIREMENT SOURCE: DOE5400.1 Chapter IV, Section 5.b.(2)

"Environmental surveillance programs and components should be determined on a site-specific basis by the field organization. Programs should reflect facility characteristics, applicable regulations, hazard potential, quantities and concentrations of materials released, the extent and use of affected air, land, and water, and specific local public interest or concern. Surveillance programs are likely to include one or more of the following:

(a) Monitoring stations;

(b) Sampling and analysis; and

(c) Monitoring data recordkeeping."

FACILITY REQUIREMENT SOURCE: DOE5400.1 Chapter IV, Section 7.a

"Radiological Monitoring - Requirements for the environmental monitoring of radioactive materials are to be found in DOE Orders in the 5400 series dealing with radiation protection of the public and the environment. Airborne radiation and radioactive materials discharged from DOE facilities shall comply with the requirements of 40 CFR Part 61, "National Emission Standards for Hazardous Air Pollutants. " Further, for those radioactive materials not regulated under the Clean Air Act, DOE bas established standards to meet its responsibilities under the Atomic Energy Act."

\section{FACIIITY REQUIREMENT SOURCE: DOE5400.1 Chapter IV, Section 7.b}

\footnotetext{
"An assessment of the potential radiation dose to members of the public which could have resulted from site operations shall be made for facilities required to conduct effluent and environmental radiological monitoring. Assessments shall be made in accordance with the
} 


\section{REQUIREMENTS IDENTIFICATION DOCUMENT HIGH LEVEL WASTE STORAGE TANK FARMS \\ Environmental Protection \\ Revision 0}

requirements of DOE Orders in the 5400 series dealing with radiation protection of the public and the environment."

\section{Monitoring. Surveillance, and Inspection Plans and Procedures}

This subelement addresses the requirements for preparing monitoring, surveillance and inspection plans and procedures. Monitoring plans describe the conduct of routine data collection programs designed to provide required environmental data. Inspection plans describe the conduct of periodic, routine inspections of facilities and equipment used to collect environmental data. Procedures provide the specific instructions for conducting activities under the monitoring, surveillance and inspection plans. The Environmental Monitoring Plan (EMP) and Facility Effluent Monitoring Plan (FEMP) shall contain the rationale, design and operational criteria for monitoring and sampling programs; the extent and frequency of monitoring and sampling; procedures for laboratory analysis; quality assurance requirements; and direction for the preparation and disposition of reports. NRC Regulatory Guide 4.15 provides guidance on monitoring program procedures and is considered a best management practice.

\section{SITE REQUIREMENT SOURCE: DOE/EH0173T Section 10.3.1}

"Required written procedures covering monitoring activities include the following topics:

Environmental and effluent sampling

Ground-water sampling

Continuous environmental and effluent monitoring systems

Laboratory analysis

Data management and calculations

Transport and pathway modeling

Dose calculations

Review and reporting of results"

\section{FACILITY REQUIREMENT SOURCE: DOE5400.1 Chapter IV, Section 4}

"Environmental Monitoring Plans. A written environmental monitoring plan shall be prepared for each site, facility, or process that uses, generates, releases, or manages significant pollutants or hazardous materials. The plan shall contain the rationale and design criteria for the monitoring program, extent and frequency of monitoring and measurements, procedures for laboratory analyses, quality assurance requirements, program implementation procedures, and direction for the preparation and disposition of reports. The plan shall be approved by the appropriate Head of Field Organization, or his or her designee. The plan shall be reviewed annually and updated as needed. The plan shall identify and discuss two major activities: (a) effluent monitoring, and (b) environmental surveillance. The plan shall reflect the importance of monitoring as a critical element of an effective environmental protection program. The plan shall be reviewed annually and updated every 3 years."

\section{FACILITY REQUIREMENT SOURCE: DOE5484.1 Chapter III, Section 4.a}

"Scope and Content of Environmental Monitoring Program, Reports, and Summaries. Environmental Monitoring. Programs for monitoring the environment shall be conducted at Department of Energy sites to determine: 


\section{REQUIREMENTS IDENTIFICATION DOCUMENT \\ HIGH LEVEL WASTE STORAGE TANK FARMS \\ Environmental Protection \\ Revision 0}

(1) Compliance with the requirements of Order DOE 5480.1, Chapters I, XI, and XII.

(2) The background lovels and sito contribution of radioactivity; and, as appropriate, other pollutents, in the site environs.

(3) Complianco with applicable enviroamental quality and public exposure limits and other environmental commitments (0.8., those published in environmental impact statements or other official documents)."

\section{FACIITY REQUTREMENT SOURCE: DOE5484.1 Chapter III, Section 5.c(1)(a)}

"Monitoring Guidelines.

(1) General.

(a) As a general rule, monitoring should be conducted in a manner that provides accurate measurements of the quantity and concentration of liquid and airborne pollutants in effluents as a basis for:

1 Determining compliance with applicable discharge and effluent control limits, including self-imposed administrative limits designed to assure compliance with in-plant operating limits. effluent standards or guides, and with environmental standards or guides.

2 Evaluating the adequacy and effectiveness of containment and waste treatment and control as well as of efforts toward achieving levels of radioactivity which are as low as reasonably achievable considering technical and economical constraints.

3 Compiling an annual inventory of the radioactivity released in effluents and onsite discharges."

\section{FACILITY REQUIREMENT SOURCE: DOE5484.1 Chapter III, Section 5.c(2)}

"Monitoring Locations. Measurements of volume, rate of discharge, content, etc., should be made, insofar as is practical, at the point at which the data most closely represent what is being released. This implies that measurements should be made at the point of discharge, though there are exceptions. Effluents should be monitored at the point at which the applicable standards apply. In the case of onsite discharges, the monitoring location may be the waste treatment or disposal system; and in case of effluents, the monitoring location may be the point of release to the offsite environment after all treatment and control, including retention and decay, have been effected. In many instances, the monitoring location is specified in a discharge or operating permit."

\section{FACILITY REQUIREMENT SOURCE: DOE5484.1 Chapter III, Section 5.c(3)(a)}

"Type and Frequency of Sampling.

(a) Sampling frequency and type should be determined by considering the purpose for which the data are being obtained, e.g., evaluation of the effectiveness of waste treatment and control, compliance with operating limits of applicable effluent or performance standards, compilation of release data, etc. Continuous sampling is desirable and may be necessary where there is wide variation in the concentrations or mixture of potential pollutants in the effluent 


\section{REQUIREMENTS IDENTIFICATION DOCUMENT HIGH LEVEL WASTE STORAGE TANK FARMS \\ Environmental Protection \\ Revision 0}

stream. However, periodic ampling may suffice when the concentration and mixtures are reasonably constant and there is little likelibood of unusual variations. Similarly, proportional sampling may be neceseary when offlueat flow rates fluctuate, whereas a ropresentative grab-sample may suffice for batch discharges. The method of sampling may be specified in the applicable regulation or permit."

\section{FACILITY REQUTREMENT SOURCE: DOES484.1 Chapter III, Section 5.c(3)(b)}

"For purposes of reporting radiological data, gross radioactivity measurements are generally inadequate. They are appropriate only:

1 When gross radioactivity releases are a small fraction of the offsite Radioactivity Concontration Guides (RCG's) for "unidentified mixtures" and are of no health or environmental significance;

2 When the relative concentrations of specific redionuclides are so well known by other means that gross radioactivity measurements are truly indicative of the activity being released; or

3 When the activity of waste streams is so low as to preclude specific nuclide measurements."

\section{SITE REQUIREMENT SOURCE: NRC-4.15 Section C.3, Paragraph 1}

"Written procedures should be prepared, reviewed, and approved for activities involved in carrying out the monitoring program, including sample collection; packaging, shipment, and receipt of samples for offsite analysis; preparation and analysis of samples; maintenance, storage, and use of radioactivity reference standards; calibration and checks of radiation and radioactivity measurement systems; and reduction, evaluation, and reporting of data. Individuals who review and approve these procedures should be knowledgeable in the subjects of the procedures."

\section{Water Quality}

This subelement specifies the requirements to monitor the effects of operations on groundwater quality and discharges from the 242-A evaporator. There are no discharges to surface water from Tank Farms. Requirement sources include DOE 5400.1, DOE/EH-0173T, and WAC 173-303.

\section{SITE REQUIREMENT SOURCE: DOE/EH0173T Section 2.0}

"All liquid effluent streams from DOE facilities should be evaluated and their potential for release of radionuclides assessed. This evaluation is required to adequately control such releases. The results of this assessment provide the basis for the facility's Effluent Monitoring Program (DOE 5400.5), which should be documented in the site Environmental Monitoring Plan (as described in DOE 5400.1), to show:

- Effluent monitoring (sampling or in situ measurement) extraction locations used for providing quantitative effluent release data for each outfall;

- Procedures and equipment used to perform the extraction and measurement: 


\section{REQUIREMENTS IDENTIFICATION DOCUMENT \\ EIGH LEVEL WASTE STORAGE TANK FARMS \\ Environmental Protection \\ Revilon 0}

- Frequency and andyois required for each extraction (continuous monitoring and/or sampling location;

- Minimum detection lovel and accuracy;

- Quality amennesce components;

- Efflueat outfall alarm settings and besis.

Liquid offluent from DOE-controlled facilities that have the potential for radionctive contamination should be monitored in accordance with the requirements of DOE 5400.1 and DOE 5400.5. As appropriate, component systems may be grouped and standard procedures referenced."

\section{STTE REQUTREMENT SOURCE: DOE/EH0173T Section 2.2, Sentence 1}

"The solection or modification of a liquid effluent monitoring system should" be based on a careful characterization of the source(s), pollutant(s) (characteristics and quantities), sample-collection systom(s), treatment system(s), and final release points(s) of the effluents."

\section{SITE REQUIREMENT SOURCE: DOE/EH0173T Section 2.2.1}

"For those effluent streams requiring continuous monitoring/sampling, all data received from the continuous monitoring system should bo used when performing statistical analyses. In the case of discharge points releasing radionuclides emitting alpha or weak beta radiation, with no documentable ratios to beta and/or gamma emitters that could be used as indicator radionuclides (i.e., where it is not technologically feasible to monitor continuously), continuous proportional sampling and analysis can be used as an alternative to continuous monitoring. However, the consideration of now tochnologies to continuously monitor such effluent streams is encouraged."

\section{SITE REQUIREMENT SOURCE: DOE/EH0173T Section 2.2.2}

"Sampling systems should* be sufficient to collect representative samples that provide for an adequate record of releases from a facility, to predict trends, and to satisfy needs to quantify relenses."

\section{SITE REQUIREMENT SOURCE: DOE/EH0173T Section 2.2.3}

"Continuous monitoring and sampling systems should" be calibrated before use and recalibrated any time they are subject to maintenance, modification, or system changes that may affect equipment calibration. In addition they should* be recalibrated at least annually and routinely chocked with known sources to determine that they are consistently functioning properly. Calibration(s) should be performed in a manner consistent with manufacturers' instructions and specifications. Each system should be checked on a routine basis, at least weekly. Sampling systems should be functioning properly before a facility is placed in operation. The use of redundart sampling systems may be necessary to provide adequate sampling capabilities and prevent delays in process operation." 


\section{REQUIREMENTS IDENTIFICATION DOCUMENT HIGE LEVEL WASTE STORAGE TANK FARMS \\ Environmental Protection \\ Revision 0}

\section{STRE REQUTREMENT SOURCE: DOE/DH0173T Section 2.2.4}

"Environmeatal conditions (0.8., temperature, humidity, radiation level, dusts, and vapors) should be considered when locating ampling and monitoring syatoms to avoid conditions that will influence the operation of the aystem. Off-line liquid transporting lines should" be repleced if they become contaminated (to the point where the sensitivity of the system is affected) with radionctive meterials or if they become ineffective in moeting the design basis within the eotablisbed sccuracy/confidence lovels."

\section{STIE REQUTREMENT SOURCE: DOE/EHT0173T Section 2.3.1}

"The following criteris should bo considered when operating a liquid offluent sampling system: .1

- Location of ampling and monitoring systems

- Use of a pump in areas where neceanary to provide a uniform continuous flow in the main sample line

- A redundant sample-collection system or one of the following alternatives to permit continued sampling during replacement or servicing of the systems: 1) a substitute sample-traneport systom, 2) the capability to shut down the system for fast repair, or 3) an altornate mothod for estimating releases when the system is not capable of operating

- Location of sample ports in liquid efflueat lines sufficiently far downstream from the last feeder line to allow complete mixing (as complete as possible) of liquid and design of the sample port to allow intake of a proportional part of the liquid effluent stream

- Capability to Jetermine the effluent stream and sample-line flows within an accuracy of at least $+1-10 \%<$ percent $>$

- Design of the system to minimize deformation and sedimentation and to prevent freezing of effluent sample lines."

\section{SITE REQUTREMENT SOURCE: DOE/EH0173T Section 2.3.3}

"The sampling ports should be 1) positioned downstream from the last component stream entering, in a location that will provide complete mixing; and 2) designed to accommodate a proportional amount of the full range of efflueat flow for transport to the collection system. If proportionality cannot be automated, both the effluent and sample flow rates should be measured."

\section{SITE REQUIREMENT SOURCE: DOE/EH0173T Section 2.3.4}

"The integrity of the junction of the liquid-sample line with the sampling port is important. Liquid offluent lines can expand and contract considerably, depending on the thermal loading variation in the line(s). Consequently, design for such a junction should consider either line snubbers or special fabrications to handle the added mechanical stress." 


\section{REQUTREMENTS IDENTIFICATION DOCUMENT \\ HIGH LEVEL WASTE STORAGE TANK FARMS \\ Environmental Protection \\ Reviaion 0}

\section{SITE REQUTREMENT SOURCE: DOE/DH0173T Section 2.3.5}

-Ualese sufficieatly bigh end constant bydraulic preanure exists within an effluent system, a sampling pump of high reliability should be inatalled. Removal of the sample from the liquid offlueat line where a sampling pump is required sbould be accomplished using a coastrat-volume pump that will maintain a constant flow, regardless of line pressure changes."

\section{STTE REQUTREMENT SOURCE: DOE/EHT0173T Section 2.3.6}

"The deaign of the collector portion of the sampling system should allow for the collection of a ample that is consisteat with the method of analysis. For example, if the effluent stream has a small flow, a small container might be used to obtain a grab sample that is counted directly in the labbratory. If concentration of the sample is neceseary, a large-volume sample will be necesary. If the collection system requires measured aliquots taken sequentially every few minutes, then both the frequeacy and required sensitivity of analysis bave an impact on the size of the contriner to be used. The sample line should be routed back to either the effluent line or a wasto treatmeat syatem. Thus, location of the sample collection system can be based in part on the return flow of the sample line."

\section{STTE REQUIREMENT SOURCE: DOE/EH0173T Section 2.3.8}

"The external eavironmeat surrounding the sampling system and effluent lines must be considered. The sampling system should be protected from adverse environmental factors including unusual operational impacts. At sample collection points, the ambient dose rate originating in the effluent line(s) and the sampling apparatus should be evaluated for compliance with shielding and contamination control requirements necessary for reducing worker exposure. Components of the sampling system should be readily accessible for mantenance."

\section{STTE REQUIREMENT SOURCE: DOE/EH0173T Section 2.4}

-Design considerations for liquid effluent monitoring systems should include the purpose of the monitoring, the types and levels of expected radionuclides, potential background dose rates, expected duration of releases, and environmental effects. One of the primary purposes of using a monitoring system is to utilize its ability to provide a prompt signal if a significant release uccurs. Thus, the output signal from monitoring systems should be continuously monitored by responsible personnel. In addition, written response procedures should be provided describing the action that responsible personnel must take if an abnormal signal is detected. The output signal instrumentation, monitoring system recorders, and alarms should* be in a location that is continuously occupied by operations or security personnel."

\section{SITE REQUTREMENT SOURCE: DOE/EH0173T Section 2.4.5}

"Radioactive material in offluents occasionally originates from a fluctuating source(s). If the content and radioactivity concentration are constant but the rolease is of short duration, the efflueat is considered a "batch" release. Before a batch is released, a representative grab sample should be drawn and analyzed to determine releasability. If the effluent originates from a continuing source(s), it is considered a "continuous" stream and should be continuously monitored and/or sampled." 


\section{REQUIREMENTS IDENTIFICATION DOCUMENT \\ HIGH LEVEL WASTE STORAGE TANK FARMS \\ Environmental Protection \\ Revision 0}

\section{STTE REQUTREMENT SOURCE: DOE/EH0173T Section 2.5}

"To signal the need for corrective actions that may be necessary to prevent public or covironmental exposures from exceeding the limits or recommendations given in DOE 5400.5, when continuous monitoring systems are required, they should* have alarms set to provide timely warnings. To prevent the cumulative impacts of small releases from producing a significant impect, routine grab, continuous, or proportional samples should be collected often enough to detect radionuclides of interest including those with relatively short balflives."

\section{SITE REQUIREMENT SOURCE: DOE/EH0173T Section 2.6}

"As they apply to the monitoring/sampling of liquid effluents, the general quality assurance program provisions of Chapter $10<$ DOE/EH-0173T > should* be followed. Specific quality assurance requirements for the facility's liquid effluent monitoring program are to be contained in the Quality Assurance Plan associated with the facility."

FACIITY REQUTREMENT SOURCE: DOE5400.1 Chapter IV, Section 8.d(1)

"Water Monitoring - Environmental Surveillance

(1) Ambient water quality monitoring should be conducted through a network of fixed stations from which data will establish well-defined histories of the physical, biological, and chemical conditions of local bodies of water and sediments. The data obtained from this network should be coordinated with other monitoring activities. Water quality data may be obtained from existing State and local monitoring stations."

\section{FACILITY REQUIREMENT SOURCE: DOE5400.1 Chapter IV, Section 8.d(2)}

"Analysis of data collected from a fixed station monitoring network should support:

(a) Characterizing and defining trends in the physical, chemical, and biological condition of surface waters;

(b) Establishing baselines of water quality;

(c) A continuing assessment of water pollution control programs;

(d) Ideatifying now water quality problems; and

(o) Detecting, characterizing, and reporting unplanned releases and their effects on water quality."

\section{FACIIITY REQUIREMENT SOURCE: DOE5400.1 Chapter IV, Section 8.d(3)}

"Monitoring networks should be operated and maintained in a uniform manner, i.e., through established procedures that allow comparative evaluations of data from monitoring sites. Receiving water characteristics will determine the location of stations. A reconnaissance survey might be sufficient in sitting stations. Under complex circumstances, mathematical models could be needed to select stations sites." 


\section{REQUIREMENTS IDENTIFICATION DOCUMENT HIGH LEVEL WASTE STORAGE TANK FARMS \\ Environmental Protection \\ Revision 0}

FACILITY REQUIREMENT SOURCE: DOE5400.1 Chapter IV, Section 8.d(4)

"Monitoring programs are best served by fixed station networks. However, a network of offluent monitoring and selected mobile monitoring stations could satisfy the needs at some facilities."

FACIITY REQUTREMENT SOURCE: DOES400.1 Chapter IV, Section 8.d(5)

"Surface water sampling performed at fixed monitoring stations will characterize physical and chemical properties of the water column andl sediments, and biological species in the water column and benthos. Types of sampling performed should depend upon local conditions and the variability of stream characteristics and water quality."

FACIITY REQUIREMENT SOURCE: DOE5400.1 Chapter IV, Section 8.d(0)

"The monitoring frequency at a fixed network station is a function of the variability of the chemical, physical, and biological conditions of the water body. Data collected shall be representative of the variations in water quality and changes in pollutant loads. Varying sampling frequencies could be required to accurately reflect seasonal changes, variable pollution sources, time of water travel between stations, and tidal and diumal variations."

FACIITY REQUIREMENT SOURCE: DOE5400.1 Chapter IV, Section 8.d(7)

"Ambient water quality monitoring serves to confirm compliance with the Clean Water Act. An understanding of the Water Quality Management (WQM) process implemented by EPA, the States, interstate agencies, and area-wide, local and Regional planning organizations is essential to the design of a water quality monitoring program. The elements of the WQM processes are described in 40 CFR Part 130. Test procedures for pollutant analyses are listed in the 40 CFR Part 136."

\section{FACILITY REQUIREMENT SOURCE: DOE5400.1 Chapter IV, Section 9}

"Groundwater Monitoring Program. Groundwater that is or could be affected by DOE activities shall be monitored to determine and document the effects of operations on groundwater quality and quantity and to demonstrate compliance with DOE requirements and applicable Foderal, State, and local laws and regulations."

\section{FACILITY REQUIREMENT SOURCE: DOE5400.1 Chapter IV, Section 9.a}

"Groundwater Monitoring Plans. A groundwater monitoring plan shall be developed as a specific element of all environmental monitoring plans and the Groundwater Protection Management Program required in page III-2, subparagraph 4.a. The plan shall identify all DOE requirements and regulations appliceble to groundwater protection and include monitoring strategy. The elements of the groundwater monitoring program shall be specified (sampling plan, sampling, analysis, and data management), as shall the rationale or purpose for selecting these elements."

\section{FACILITY REQUIREMENT SOURCE: DOE5400.1 Chapter IV, Section 9.b}

"General Requirements - Groundwater monitoring programs shall be conducted on-site and in the vicinity of DOE facilities tn: 


\section{REQUIREMENTS IDENTIFICATION DOCUMENT \\ HIGH LEVEL WASTE STORAGE TANK FARMS \\ Environmental Protection \\ Revision 0}

(1) Obtain data for the purpose of determining baseline conditions of groundwater quality and quantity;

(2) Demonstrate compliance with and implementation of all applicable regulations and DOE Orders;

(3) Provide data to permit the early detection of groundwater pollution or contamination;

(4) Provide a reporting mechanism for detected groundwater pollution or contamination;

(5) Identify existing and potential groundwater contamination sources and to maintain surveillance of these sources;

(6) Provide data upon which decisions can be made concerning land disposal practices and the management and protection of groundwater resources."

FACIITY REQUIREMENT SOURCE: DOE5400.1 Chapter IV, Section 9.c

"Site-specific characteristics shall determine monitoring needs. Where appropriate, groundwater monitoring programs shall be designed and implemented in accordance with 40 CFR Part 264, Subpart F, or 40 CFR Part 265, Subpart F. For sites with multiple groundwater pollutant sources, extensive groundwater pollution or other unique site problems, groundwater monitoring programs could require more extensive information than those specified in 40 CFR Parts 264 and 265. Monitoring for radionuclides shall be in accordance with DOE Orders in the 5400 series dealing with radiation protection of the public and the environment."

FACILITY REQUTREMENT SOURCE: DOE5820.2A Chapter I, Section 3.b(3)(f)

"A system of ground water or vadose zone monitoring wells meeting the Resource Conservation and Recovery Act requirements per 40 CFR 264 shall be installed, as a minimum, around clusters of liquid waste storage tanks."

SITE REQUIREMENT SOURCE: WAC-173-303 Section 645 (10)

"Compliance monitoring program. An owner or operator required to establish a compliance monitoring program under this section must, at a minimum, discharge the responsibilities described in this subsection.

645 (10) (a) The owner or operator must monitor the ground water to determine whether regulated units are in compliance with the ground water protection standard under subsection (3) of this section. The department will specify the ground water protection standard in the facility permit, including:

645 (10) (a) (i) A list of the dangerous constituents and parameters identified under subsection (4) of this section;

645 (10) (a) (ii) Concentration limits under subsection (5) of this section for each of those dangerous constituents and parameters;

645 (10) (a) (iii) The compliance point under subsection (6) of this section; and 


\section{REQUIREMENTS IDENTIFICATION DOCUMENT HIGH LEVEL WASTE STORAGE TANK FARMS \\ Environmental Protection \\ Revision 0}

645 (10) (a) (iv) The compliance period under subsection (7) of this section.

645 (10) (b) The owner or operator must install a ground water monitoring system at the compliance point as specified under subsection (6) of this section. The ground water monitoring system must comply with subsection (8)(a)(ii), (b), and (c) of this section.

645 (10) (c) The department will specify the sampling procedures and statistical methods appropriate for the constituents and the facility, consistent with subsection (8)(g) and (h) of this section.

645 (10) (c) (i) The owner or operator must conduct \& sampling program for each chemical parameter or dangerous constituent in accordance with subsection $(8)(g)$ of this section.

645 (10) (c) (ii) The owner or operator must record ground water analytical data as measured and in form necessary for the determination of statistical significance under subsection (8)(h) of this section for the compliance period of the facility.

645 (10) (d) The owner or operator must determine whether there is statistically significant evidence of increased contamination for any chemical parameter or dangerous constituent specified in the permit, pursuant to (a) of this subsection, at a frequency specified under (f) of this subsection.

645 (10) (d) (i) In determining whether statistically significant evidence of increased contamination exists, the owner or operator must use the method(s) specified in the permit under subsection (8)(b) of this section. The method(s) must compare data collected at the compliance point(s) to a concentration limit developed in accordance with subsection (5) of this section.

645 (10) (d) (ii) The owner or operator must determine whether there is statistically significant evidence of increased contamination at each monitoring well at the compliance point within a reasonable time period after completion of sampling. The department will specify that time period in the facility permit, after considering the complexity of the statistical test and the availability of laboratory facilities to perform the analysis of ground water samples.

645 (10) (e) The owner or operator must determine the rate and direction of ground water flow in the uppermost aquifer at least annually.

645 (10) (f) The department will specify the frequencies for collecting samples and conducting statistical tests to determine statistically significant evidence of increased contamination in accordance with subsection (8) of this section. A sequence of at least four samples from each well (background and compliance wells) must be collected at least semiannually during the compliance period of the facility.

645 (10) (g) The owner or operator must analyze samples from all monitoring wells at the compliance point for all constituents contained in Appendix IX of Part 264 at least annually to determine whether additional dangerous constituents are present in the uppermost aquifer and, if so, at what concentration, pursuant to procedures in (f) of this subsection. If the owner or operator finds Appendix IX constituents in the ground water that are not already identified in the permit as monitoring constituents, the owner or operator may resample within one month and repeat the Appendix IX analysis. If the second analysis confirms the presence of new constituents, the owner or operator must report the concentration of these additional constituents to the department within seven days after the completion of the second analysis 


\section{REQUIREMENTS IDENTIFICATION DOCUMENT HIGH LEVEL WASTE STORAGE TANK FARMS \\ Environmental Protection \\ Revision 0}

and add them to the monitoring list. If the owner or operator chooses not to resample, then he or she must report the concentrations of these additional constituents to the department within seven days after completion of the initial analysis and add them to the monitoring list. If the owner or operator determines, pursuant to (d) of this subsection, that any concentration limits under subsection (5) of this section are being exceeded at any monitoring well at the point of compliance, he must:

645 (10) (g) (i) Notify the department of this finding in writing within seven days. The notification must indicate what concentration limits have been exceeded;

645 (10) (g) (ii) Submit to the department an application for a permit modification to establish a corrective action program meeting the requirements of subsection (11) of this section, within ninety. days, or within sixty days if an engineering feasibility study has been previously submitted to the department under subsection $(9)(h)(v)$ of this section. For regulated units managing EHW, time frames of sixty days and forty-five days, respectively will apply. However, if the department finds that the full extent of the ninety/sixty-day or the sixty/forty-five-day time periods will increase the likelihood to cause a threat to public health, or the environment, it can at its discretion reduce their duration. In specifying shorter limits. the department will consider the following factors:

645 (10) (g) (A) The physical and chemical characteristics of the dangerous constituents and parameters in the ground water;

645 (10) (g) (B) The hydrogeological characteristics of the facility and of the surrounding land;

645 (10) (g) (C) The rate of movement and direction of flow of the affected ground water;

645 (10) (g) (D) The proximity to and withdrawal rates of ground water users downgradient; and

$645(10)(g)(E)$ The current and future uses of ground water in the concerned area; and

$645(10)(\mathrm{g})(\mathrm{E})(\mathrm{g})(\mathrm{E})$ (iii) The application must at a minimum include the following information:

645 (10) (g) (E) (iii) (A) A detailed description of corrective actions that will achieve compliance with the ground water protection standard specified in the permit; and

645 (10) (g) (E) (iii) (B) A plan for a ground water monitoring program that will demonstrate the effectiveness of the corrective action.

645 (10) (i) If the owner or operator determines, pursuant to (d) of this subsection, that the ground water concentration limits under this section are being exceeded at any monitoring well at the point of compliance, he may demonstrate that a source other than a regulated unit caused the contamination or that the detection is an artifact caused by an error in sampling, analysis, or statistical evaluation, or natural variation in the ground water. In making a demonstration under this subsection, the owner or operator must:

645 (10) (i) (i) Notify the department in writing within seven days that he intends to make a demonstration under this subsection; 


\section{REQUIREMENTS IDENTIFICATION DOCUMENT HIGH LEVEL WASTE STORAGE TANK FARMS Environmental Protection}

Revision 0

645 (10) (i) (ii) Within forty-five days, submit a report to the department which demonstrates that a source other than a regulated unit caused the standard to be exceeded or that the apparent noncompliance with the standards resulted from error in sampling, analysis, or evaluation;

645 (10) (i) (iii) Within forty-five days, submit to the department an application for a permit modification to make appropriate changes to the compliance monitoring program at the facility; and

645 (10) (i) (iv) Continue to monitor in accord with the compliance monitoring program established under this section.

645 (10) (j) If the owner or operator determines that the compliance monitoring program no longer satisfies the requirements of this section, he must, within forty-five days, submit an application for a permit modification to make any appropriate changes to the program."

\section{SITE REQUIREMENT SOURCE: WAC-173-303 Section 645 (8)}

"General ground water monitoring requirements. The owner or operator must comply with the requirements of this subsection for any ground water monitoring program developed to satisfy subsections (9), (10), or (11) of this section.

645 (8) (a) The ground water monitoring system must consist of a sufficient number of wells, installed at appropriate locations and depths to yield ground water samples from the uppermost aquifer that:

645 (8) (a) (i) Represent the quality of background water that has not been affected by leakage from a regulated unit; and

645 (8) (a) (i) (A) A determination of background quality may include sampling of wells that are not hydraulically upgradient of the waste management area where:

645 (8) (a) (i) (A) (I) Hydrogeologic conditions do not allow the owner or operator to determine what wells are hydraulically upgradient; and

645 (8) (a) (i) (A) (II) Sampling at other wells will provide an indication of background ground water quality that is representative or more representative than that provided by the upgradient wells; and

645 (8) (a) (ii) Represent the quality of ground water passing the point of compliance.

645 (8) (a) (iii) Allow for the detection of contamination when dangerous waste or dangerous constituents have migrated from the waste management area to the uppermost aquifer.

645 (8) (b) If a facility contains more than one regulated unit, separate ground water monitoring systems are not required for each regulated unit, provided that provisions for sampling the ground water in the uppermost aquifer will enable detection and measurement at the compliance point of dangerous constituents from the regulated units that bave entered the ground water in the uppermost aquifer.

645 (8) (c) All monitoring wells must be cased in a manner that maintains the integrity of the monitoring well bore hole. This casing must allow collection of representative ground water 


\section{REQUIREMENTS IDENTIFICATION DOCUMENT HIGH LEVEL WASTE STORAGE TANK FARMS Environmental Protection}

Revision 0

samples. Wells must be constructed in such a manner as to prevent contamination of the samples, the sampled strata, and between aquifers and water bearing strata. Wells must meet the requirements set forth in Parts 1 and 3 of chapter 173-160 WAC, "Minimum standards for construction and maintenance of wells."

645 (8) (d) The ground water monitoring program must include at a minimum, procedures and techniques for:

645 (8) (d) (i) Decontamination of drilling and sampling equipment;

645 (8) (d) (ii) Sample collection;

645 (8) (d) (iii) Sample preservation and shipment;

645 (8) (d) (iv) Analytical procedures and quality assurance; and

645 (8) (d) (v) Chain of custody control.

645 (8) (e) The ground water monitoring program must include consistent sampling and analytical methods that ensure reliable ground water sampling, accurately measure dangerous constituents and indicator parameters in ground water samples, and provide a reliable indication of groundwater quality below the waste management area.

645 (8) (f) The ground water monitoring program must include a determination of the ground water surface elevation each time ground water is sampled.

645 (8) (g) In detection monitoring or where appropriate in compliance monitoring, data on each dangerous constituent specified in the permit will be collected from background wells and wells at the compliance point(s). The number and kinds of samples collected to establish background shall be appropriate for the form of statistical test employed, following generally accepted statistical principles. The sample size shall be as large as necessary to ensure with reasonable confidence that a contaminant release to ground water from a facility will be detected. The owner or operator will determine an appropriate sampling procedure and interval for each hazardous constituent listed in the facility permit which shall be specified in the unit permit upon approval by the department. This sampling procedure shall be:

645 (8) (g) (i) A sequence of at least four samples, taken at an interval that assures, to the greatest extent technically feasible, that an independent sample is obtained, by reference to the uppermost aquifer's effective porosity, hydraulic conductivity and hydraulic gradient, and the fate and transport characteristics of the potential contaminants; or

645 (8) (g) (ii) An alternate sampling procedure proposed by the owner or operator and approved by the department.

645 (8) (h) The owner or operator will specify one of the following statistical methods to be used in evaluating ground water monitoring data for each hazardous constituent which, upon approval by the department, will be specified in the unit permit. The statistical test chosen shall be conducted separately for each dangerous constituent in each well. Where practical quantification limits (pql's) are used in any of the following statistical procedures to comply with (i)(v) of this subsection, the pql must be proposed by the owner or operator and approved by the department. Use of any of the following statistical methods must be protective of human 


\section{REQUIREMENTS IDENTIFICATION DOCUMENT HIGH LEVEL WASTE STORAGE TANK FARMS \\ Environmental Protection \\ Revision 0}

bealth and the environment and must comply with the performance standards outlined in (i) of this subsection.

645 (8) (h) (i) A parametric analysis of variance (ANOVA) followed by multiple comparisons procedures to identify statistically significant evidence of contamination. The method must include estimation and testing of the contrasts between each compliance well's mean and the background mean levels for each constituent.

645 (8) (h) (ii) An analysis of variance (ANOVA) based on ranks followed by multiple comparisons procedures to identify statistically significant evidence of contamination. The method must include estimation and testing of the contrasts between each compliance well's mediar and the background median levels for each constituent.

.$j$

645 (8) (h) (iii) A tolerance or prediction interval procedure in which an interval for each constituent is established from the distribution of the background data, and the level of each constituent in each compliance well is compared to the upper tolerance or prediction limit.

645 (8) (h) (iv) A control chart approach that gives control limits for each constituent.

645 (8) (h) (v) Another statistical test method submitted by the owner or operator and approved by the department.

645 (8) (i) Any statistical method chosen under (h) of this subsection for specification in the unit permit shall comply with the following performance standards, as appropriate:

645 (8) (i) (i) The statistical method used to evaluate ground water monitoring data shall be appropriate for the distribution of chemical parameters or dangerous constituents. If the distribution of the chemical parameters or dangerous constituents is shown by the owner or operator to be inappropriate for a normal theory test, then the data should be transformed or a distribution-free theory test should be used. If the distributions for the constituents differ, more than one statistical method may be needed.

645 (8) (i) (ii) If an individual well comparison procedure is used to compare an individual compliance well constituent concentration with background constituent concentrations or a ground water protection standard, the test shall be done at a Type I error level no less than 0.01 for each testing period. If a multiple comparisons procedure is used, the Type I experimentwise error rate for each testing period shall be no less than 0.05 ; however, the Type I error of no less than 0.01 for individual well comparisons must be maintained. This performance standard does not apply to tolerance intervals, prediction intervals, or control charts.

645 (8) (i) (iii) If a control chart approach is used to evaluate ground water monitoring data, the specific type of control chart and its associated parameter values shall be proposed by the owner or operator and approved by the department if it is protective of human health and the environment.

645 (8) (i) (iv) If a tolerance interval or a prediction interval is used to evaluate ground water monitoring data, the levels of confidence and, for tolerance intervals, the percentage of the population that the interval must contain, shall be proposed by the owner or operator and approved by the department if it finds these parameters to be protective of buman health and the environment. These parameters will be determined after considering the number of samples 


\section{REQUIREMENTS IDENTIFICATION DOCUMENT HIGH LEVEL WASTE STORAGE TANK FARMS Environmental Protection}

\section{Revision 0}

in the background data base, the data distribution, and the range of the concentration values for each constituent of concern.

645 (8) (i) (v) The statistical method shall account for data below the limit of detection with one or more statistical procedures that are protective of human health and the environment. Any practical quantification limit (pql) approved by the department under (h) of this subsection that is used in the statistical method shall be the lowest concentration level that can be reliably achieved within specified limits of precision and accuracy during routine laboratory operating conditions that are available to the facility.

645 (8) (i) (vi) If necessary, the statistical method shall include procedures to control or correct for seasonal and spatial variability as well as temporal correlation in the data.

.)

645 (8) (i) (j) Ground water monitoring data collected in accordance with (g) of this subsection including actual levels of constituents must be maintained in the facility operating record. The department will specify in the permit when the data must be submitted for review."

\section{SITE REQUIREMENT SOURCE: WAC-173-303 Section 645 (9)}

"Detection monitoring program. An owner or operator required to establish a detection monitoring program under this subsection must, at a minimum, discharge the responsibilities described in this subsection.

645 (9) (a) The owner or operator must monitor for indicator parameters (e.g., pH, specific conductance, total organic carbon (TOC), total organic halogen (TOX), or heavy metals), waste constituents, or reaction products that provide a reliable indication of the presence of dangerous constituents, in ground water. The department will specify the parameters or constituents to be monitored in the facility permit, after considering the following factors:

645 (9) (a) (i) The types, quantities, and concentrations of constituents in wastes managed at the regulated unit;

645 (9) (a) (ii) The mobility, stability, and persistence of waste constituents or their reaction products in the unsaturated zone beneath the waste management area;

645 (9) (a) (iii) The detectability of indicator parameters, waste constituents, and reaction products in ground water; and

645 (9) (a) (iv) The concentrations or values and coefficients of variation of proposed monitoring parameters or constituents in the ground water background.

645 (9) (b) The owner or operator must install a ground water monitoring system at the compliance point, as specified under subsection (6) of this section. The ground water monitoring system must comply with subsection (8)(a)(ii), (b), and (c) of this section.

645 (9) (c) The owner or operator must conduct a ground water monitoring program for each chemical parameter and dangerous constituent specified in the permit pursuant to (a) of this subsection in accordance with subsection $(8)(\mathrm{g})$ of this section. The owner or operator must maintain a record of ground water analytical data as measured and in a form necessary for the determination of statistical significance under subsection (8)(h) of this section. 


\section{REQUIREMENTS IDENTIFICATION DOCUMENT HIGH LEVEL WASTE STORAGE TANK FARMS Environmental Protection \\ Revision 0}

645 (9) (d) The department will specify the frequencies for collecting samples and conducting statistical tests to determine whether there is statistically significant evidence of contamination for any parameter or dengerous constituent specified in the permit under (a) of this subsection in accordance with subsection (8)(8) of this section. A sequence of at least four samples from each well (background and compliance wells) must be collected at least semiannually during detection monitoring.

645 (9) (e) The owner or operator must determine the ground water flow rate and direction in the uppermost aquifer at least annually.

$645(9)(f)$ The owner or operator must determine whether there is statistically significant evidence of contamination for any chemical parameter of dangerous constituent specified in the permit pursuant to (a) of this subsection at a frequency specified under (d) of this subsection.

645 (9) (f) (i) In determining whether statistically significant evidence of contamination exists, the owner or operator must use the method(s) specified in the permit under subsection (8)(h) of this section. These method(s) must compare data collected at the compliance point(s) to the background ground water quality data.

645 (9) (f) (ii) The owner or operator must determine whether there is statistically significant evidence of contamination at each monitoring well as the compliance point within a reasonable period of time after completion of sampling. The department will specify in the facility permit what period of time is reasonable after considering the complexity of the statistical test and the availability of laboratory facilities to perform the analysis of ground water samples.

645 (9) (g) If the owner or operator determines pursuant to (f) of this subsection that there is statistically significant evidence of contamination for chemical parameters or dangerous constituents specified pursuant to (a) of this subsection at any monitoring well at the compliance point, he or she must:

645 (9) (g) (i) Notify the department of this finding in writing within seven days. The notification must indicate what chemical parameters or dangerous constituents have shown statistically significant evidence of contamination.

645 (9) (g) (ii) Immediately sample the ground water in all monitoring wells and determine whether constituents in the list of Appendix IX of Part 264 are present, and if so, in what concentration.

645 (9) (g) (iii) For any Appendix IX compounds found in the analysis pursuant to (g)(ii) of this subsection, the owner or operator may resample within one month and repeat the analysis for those compounds detected. If the results of the second analysis confirm the initial results, then these constituents will form the basis for compliance monitoring. If the owner or operator does not resample for the compounds found pursuant to (g)(ii) of this subsection, the dangerous constituents found during this initial Appendix IX analysis will form the basis for compliance monitoring.

645 (9) (g) (iv) Within ninety days, submit to the department an application for a permit modification to establish a compliance monitoring program meeting the requirements of subsection (10) of this section. The application must include the following information:

645 (9) (g) (iv) (A) An identification of the concentration or any Appendix IX constituent detected in the ground water at each monitoring well at the compliance point; 


\section{REQUIREMENTS IDENTIFICATION DOCUMENT HIGH LEVEL WASTE STORAGE TANK FARMS Environmenta: Protection \\ Revision 0}

645 (9) (g) (iv) (B) Any proposed changes to the ground water monitoring system at the facility necesenry to meet the requirements of subsection (10) of this section;

645 (9) (iv) (C) Any proposed additions or changes to the monitoring frequency, sampling and analysis procedures or mothods, or statistical mothods used at the facility necessary to meet the requirements of subsection (10) of this section;

645 (9) (g) (iv) (D) For each dangerous constitueat detected at the compliance point, a proposed concentration limit under subsection (5)(a)(i) or (ii) of this section, or a notice of inteat to seek an alternate concentration limit under subsection (5)(b) of this section; and

645 (9),(g) (v) Within one hundred eighty days, submit to the department:

645 (9) (g) (v) (A) All data necessary to justify and alternate concentration limit sought under subsection (5)(b) of this section; and

645 (9) (g) (v) (B) An engineering feasibility plan for a corrective action program necessary to meet the requirement of subsection (11) of this section unless:

645 (9) (g) (v) (B) (I) All dangerous constituents identified under (G)(ii) of this subsection are listed in Table I of subsection (5) of this section and their concentrations do not exceed the respective values given in that Table; or

645 (9) (g) (v) (B) (II) The owner or operator has sought an alternate concentration limit under subsection (5)(b) of this section for every dangerous constituent identified under (g)(ii) of this subsection.

645 (9) (g) (vi) If the owner or operator determines, pursuant to ( $f$ ) of this subsection, that there is a statistically significant difference for chemical parameters or dangerous constituents specified pursuant to (a) of this subsection at any monitoring well at the compliance point, he or she may demonstrate that a source other than a regulated unit caused the contamination or that the detoction is an artifact caused by an error in sampling, analysis, or statistical evaluation or natural variation in the ground water. The owner or operator may make a demonstration under this subsection in addition to, or in lieu of, submitting a permit modification application under (g)(iv) of this subsection; however, the owner or operator is not relieved of the requirement to submit a permit modification application within the time specified in (g)(iv) of this subsection unless the demonstration made under this subsection successfully shows that a source other than a regulated unit caused the increase, or that the increase resulted from error in sampling, analysis, or evaluation. In making a demonstration under this subsection, the owner or operator must:

645 (9) (g) (vi) (A) Notify the department in writing within seven days of determining statistically significant evidence of contamination at the compliance point that he intends to make a demonstration under this subsection;

645 (9) (g) (vi) (B) Within ninety days, submit a report to the department which demonstrates that a source other than a regulated unit caused the contamination or that the contamination resulted from error in sampling, analysis, or evaluation;

645 (9) (g) (vi) (C) Within ninety days, submit to the department an application for a permit modification to make any appropriate changes to the detection monitoring program facility; and 


\section{REQUTREMENTS IDENTIFICATION DOCUMENT HIGH LEVEL WASTE STORAGE TANK FARMS \\ Environmental Protection \\ Reviaion 0}

645 (9) (g) (vi) (D) Continue to monitor in accordance with the detection monitoring program established undor this soction.

645 (9) (b) If the owner or operator determines that the detection monitoring program no longer satiofies the requirements of this section, he or she must, within ninety days, submit an application for a permit modification to make any appropriate changes to the program."

Air Ouality

This subelement specifies the requirements for monitoring of air quality. Technical guidance is provided in DOE/EH-0173T. Tank Farms currently includes 8 tanks listed as containing greater than or equal to 10 weight perceat (dry basis) organics expressed as sodium acetate with 2 inth tank recommended to be added to the list. Therefore, the requirements of $40 C F R$ Subpart BB, "Air Emission Standards for Equipmeat Leaks" applies to these tanks.

\section{FACIITY REQUIREMENT SOURCE: 40CFR265.1052 Part 265.1052}

"Standards: Pumps in light liquid service.

(a)(1) Each pump in light liquid service sball be monitored monthly to detect leaks by the methods specified in $265.1063(\mathrm{~b})$, except as provided in paragraphs (d), (e), and (f) of this section.

(2) Each pump in light liquid service shall be checked by visual inspection each calendar week for indications of liquids dripping from the pump seal.

(b)(1) If an instrument reading of $10,000 \mathrm{ppm}$ or greater is measured, a leak is detected.

(2) If there are indications of liquids dripping from the pump seal, a leak is detected.

(c)(1) When a leak is detected, it shall be repaired as soon as practicable, but not later than 15 calendar days after it is detected, except as provided in 265.1059.

(2) A first attempt at repair (e.g. tightening the packing gland) shall be made no later than 5 calendar days after each leak is detected.

(d) Each pump equipped with a dual mechanical seal system that includes a barrier fluid system is exempt from the requirements of paragraph (a) of this section provided, the following requirements are met:

(1) Each dual mechanical seal system must be:

(i) Operated with the barrier fluid at a pressure that is at all times greater than the pump stuffing box pressure, or

(ii) Equipped with a barrier fluid degassing reservoir that is connected by a closed-vent system to a conirol device that complies with the requirements of 265.1060 , or

(iii) Equipped with a system that purges the barrier fluid into a hazardous waste stream with no detectable emissions to the atmosphere. 


\section{REQUTREMENTS IDENTIFICATION DOCUMENT HIGH LEVEL WASTE STORAGE TANK FARMS \\ Environmental Protection \\ Revision 0}

(2) The barrier fluid aystom munt not be a bazardow waste with organic concentrations 10 percent or greater by weight.

(3) Each barrier fluid system must be equipped with a seasor that will detect failure of the seal system, the barrier fluid system, or both.

(4) Each pump must be cbecked by virual inspection, each calendar week, for indications of liquids dripping from the pump seals.

(5)(i) Each seassor as deacribod in paragraph (d)(3) of this section must be checked daily or be equipped with an audible alarm that must be checked monthly to ensure that it is functioning properly.

(ii) The owner or operator must determine, based on design considerations and operating experiense, a criterion that indicates failure of the seal system, the barrier fluid system, or both.

(6)(i) If there are indications of liquids dripping from the pump seal or the sensor indicates failure of the seal system, the barrier fluid system, or both based on the criterion determined in paragraph (d)(5)(ii) of this section, a leak is detected.

(ii) When a leak is detected, it shall be repaired as soon as practicable, but not greater than 15 calendar days after it is detected, except as provided in 265.1059 .

(iii) A first attempt at repair (e.g. relapping the seal) shall be made no later than 5 calendar days after each leak is detected.

(o) Any pump that is designated, as described in 265.1064(g)(2), for no detectable emissions, as indicated by an instrumeat reading of less than $500 \mathrm{ppm}$ above background, is exempt from the requirements of paragraphs (a), (c), and (d) of this soction if the pump meets the following requirements:

(1) Must bave no externally actuated shaft penetrating the pump housing.

(2) Must operate with no detectable emissions as indicated by an instrument reading of less than $500 \mathrm{ppm}$ above background as measured by the methods specified in 265.1063 (c).

(3) Must be tested for compliance with paragraph (e)(2) of this section initially upon designation, annually, and at other times as requested by the Regional Administrator.

(f) If any pump is equipped with a closed-vent system capable of capturing and transporting any leakage from the seal or seais to a control device that complies with the requirements of 265.1060 , it is exempt from the requirements of paragraphs (a) through (e) of this section."

\section{FACILITY REQUIREMENT SOURCE: 40CFR265.1054 Part 265.1054}

"Standards: Pressure Relief Devices in Gas/Vapor Service

(a) Except during pressure releases, each pressure relief device in gas/vapor service shall be operated with no detectable emissions, as indicated by an instrument reading of less than 500 ppm above background, as measured by the method specified in 265.1063(c). 


\section{REQUIREMENTS IDENTIFICATION DOCUMENT HIGE LEVEL WASTE STORAGE TANK FARMS \\ Environmental Protection \\ Reviaion 0}

(b)(1) After each preapure release, the preacure relief device stall be returned to a condition of Do detectable emiestions, as indicated by an inatrumeat reading of leas than 500 ppm above background, as soon as precticable, but no later than 5 calendar days after each pressure releace, except as provided in 265.1059.

(2) No later then 5 caleadar days after the preanure release, the pressure relief device shall be monitored to confirm the condition of no detectable emissions, as indicated by an instrument reading of leae then $500 \mathrm{ppm}$ above beckground, as measured by the method specified in 265.1063(c).

(c) Any preasure relief dovico that is equipped with a closed-vent systom capable of capturing and tramporting leakage for the preasure relief device to a control device as described in 265.1060 is exempt from the requirements of paragraphs (a) and (b) of this section."

\section{FACILITY REQUIREMENT SOURCE: 40CFR265.1055 Part 265.1055}

"Stendarda: Sampling Connecting Systems

(a) Each sampling connection system shall be equipped with a closed-purge system or closed-vent system.

(b) Each closed-purge or closed-vent system as required in paragraph (a) shall:

(1) Return the purged hazardous waste stream directly to the hazardous waste management process line with no detectable emissions to the atmosphere, or

(2) Collect and recycle the purged hazardous waste stream with no detectable emissions to the atmosphere, or

(3) Be designed and operated to capture and transport all the purged hazardous waste stream to a control device that complies with the requirements of 265.1060 .

(c) In situ sampling systems are exempt from the requirements of paragraphs (a) and (b) of this section."

\section{FACIITY REQUTREMENT SOURCE: 40CFR265.1057 Part 265.1057}

"Standards: Valves in Gas/Vapor Service or in Light Liquid Service

(a) Each valve in gas/vapor service or light liquid service shall be monitored monthly to detect leaks by the methods specified in 265.1063 (b) and shall comply with paragraphs (b) through (e) of this section, except as provided in paragraphs ( $f),(g)$, and (b) of this section' and 265.1061 and 265.1062 .

(b) If an instrument reading of $10,000 \mathrm{ppm}$ or greater is measured, a leak is detected.

(c)(1) Any valve for which a leak is not detected for two successive months may be monitored the first month of every succeeding quarter, beginning with the next quarter, until a leak is detected.

(2) If a leak is detected, the valve shall be monitored monthly until a leak is not detected for 2 successive months. 


\section{REQUIREMENTS IDENTIFICATION DOCUMENT \\ HIGH LEVEL WASTE STORAGE TANK FARMS \\ Environmental Protection \\ Revision 0}

(d)(1) When a leak is detected, it shall be repaired as soon as practicable, but no later than 15 caleadar days after the leak is dotected, except as provided in 265.1059.

(2) A first attempt at repair shall be made no later than 5 calendar days after the leak is dotected.

(e) First attempts at repair include, but are not limited to, the following best practices where precticable:

(1) Tightening of boanet bolts.

(2) Replecement of bonnet bolts.

(3) Tightening of packing gland nuts.

(4) Injection of lubricant into lubricant packing.

(f) Any valve that is designated, as described in $265.1064(8)(2)$, for no detectable emissions, as indicated by an instrument reading of less than $500 \mathrm{ppm}$ above background, is exempt from the requirements of paragraph (a) of this section if the valve:

(1) Has no external actuating mochanism in contact with the hazardous waste stream.

(2) Is operated with emissions less than $500 \mathrm{ppm}$ above background as determined by the method specified in 265.1063(c).

(3) Is tested for compliance with paragraph $(f)(2)$ of this section initially upon designation, annually, and at other times as requested by the Regional Administrator.

(g) Any valve that is desigaated, as described in $265.1064(\mathrm{~b})(1)$, as an unsafe-to-monitor valve is exempt from the requirements of paragraph (a) of this section if:

(1) The owner or operator of the valve determines that the valve is unsafe to monitor because monitoring personnel would be exposed to an immediate danger as a consequence of complying with paragraph (a) of this section.

(2) The owner or operator of the valve adheres to a written plan that requires monitoring of the valve as frequently as practicable during safo-to-monitor times.

(h) Any valve that is designated, as described in $265.1064(\mathrm{~h})(2)$, as a difficult-to-monitor vaive is exempt from the requirements of paragraph (a) of this section if:

(1) The owner or operator of the valve determines that the valve cannot be monitored without elevating the monitoring personnel more than 2 meters above a support surface.

(2) The hazardous waste management unit within which the valve is located was in operation before June 21, 1990.

(3) The owner or operator of the valve follows a written plan that requires monitoring of the valve at least once per calendar year." 


\section{REQUTREMENTS IDENTIFICATION DOCUMENT HIGH LEVEL WASTE STORAGE TANK FARMS \\ Environmental Protection \\ Revision 0}

FACIITY REQUIREMENT SOURCE: 40CFR265.1058 Part 265.1058

"Standards: Pumps and Valves in Heavy Liquid Service, Pressure Relief Devices in Light Liquid or Heavy Liquid Service, and Flanges and Other Connectors

(a) Pumpe and valves in heavy liquid service, pressure relief devices in light liquid or heavy liquid service, and flanges and other connectors shall be monitored with 5 days by the method specified in $265.1063(\mathrm{~b})$ if evidence of a potential leak is found by visual, audible, olfactory, or any other detection method.

(b) If an instrument reading of $10,000 \mathrm{ppm}$ or greater is measured, a leak is detected.

(c) When a leak is detected, it shall be repaired as soon as practicable, but not later than 15 calendar days after it is detected, except as provided in 265.1059 .

(2) The first attempt at repair shall be made no later than 5 calendar days after each leak is detected.

(d) First attempts at repair include, but are not limited to, the best practices described under 265.1057(e)."

FACILITY REQUIREMENT SOURCE: 40CFR265.1059 Part 265.1059

"Standards: Delay of Repair

(a) Delay of repair of equipment for which leaks have been detected will be allowed if the repair is technically infeasible without a bazardous waste management unit shutdown. In such a case, repair of this equipment shall occur before the end of the next hazardous waste management unit shutdown.

(b) Delay of repair of equipment for which leaks have been detected will be allowed for equipment that is isolated from the hazardous waste management unit and that does not continue to contain or contact hazardous waste with organic concentrations at least 10 percent by weight.

(c) Delay of repair for valves will be allowed if:

(1) The owner or operator determines that emissions of purged material resulting from immediate repair are greater than the emissions likely to result from delay of repair.

(2) When repair procedures are effected, the purged material is collected and destroyed or recovered in a control device complying with 265.1060 .

(d) Delay of repair for pumps will be allowed if:

(1) Repair requires the use of a dual mechanical seal system that includes a barrier fluid system.

(2) Repair is completed as soon as practicable, but not later than 6 months after the leak was detected. 


\section{REQUIREMENTS IDENTIFICATION DOCUMENT HIGH LEVEL WASTE STORAGE TANK FARMS \\ Environmental Protection \\ Revision 0}

(e) Delay of repair beyond a bazardous waste management unit shutdown will be allowed for a valve if valve assembly replacement is necessary during the hazardous waste management unit shutdown, valve assembly supplies have been depleted, and valve assembly supplies had been sufficiently stocked before the supplies were depleted. Delay of repair beyond the next hazardous waste management unit shutdown will not be allowed unless the next hazardous waste management shutdown occurs sooner than 6 months after the first hazardous waste managemeat unit shutdown."

\section{SITE REQUIREMENT SOURCE: DOE/EH0173T Section 3.1, Paragraph 1, Sentences $2-4$}

"The criteria listed in Table 3-1 <DOE/EH-0173T > are based on the projected effective dose equivalent in one year to a member of the public (in rem). Additional airborne emission requirements for DOE-controlled facilities that are required under DOE 5400.1 and DOE 5400.5 are given in the summary and discussed in this chapter. The monitoring effort should be commensurate with the importance of the sources during routine operation and from potential accidents with respect to their potential contribution to public dose or to contamination of the environment."

\section{STTE REQUIREMENT SOURCE: DOE/EH0173T Section 3.3, Sentences 1-4}

"The frequency requirements for airborne emission monitoring (continuous monitoring and/or sampling) programs are summarized in Table 3-1. Application of these criteria to an individual facility (DOE-controlled site) or source (DOE-controlled facility) requires that an adequate study of the expected releases, potential exposure pathways, and resulting dose be conducted. For all new facilities or facilities that have been modified in a manner that could affect effluent release quantity or quality or that could affect the sensitivity of monitoring or surveillance systems, a preoperational assessment $\langle>$ be made and documented in the site Environmental Monitoring Plan to determine the types and quantities of airborne emissions to be expected from the facility, and to establish the associated airborne emission monitoring needs of the facility. The performance of the airborne emissions monitoring systems should* be sufficient for determining whether the releases of radioactive materials are within the limits or requirements specified in DOE 5400.5."

\section{FACILITY REQUIREMENT SOURCE: DOE5400.1 Chapter IV, Section 8.b(1)}

"Air Monitoring - Environmental Surveillance

(1) Ambient air quality monitoring programs should be designed to accomplish the following:

(a) Establish background concentration levels of pertinent chemical species;

(b) Determine the highest concentrations of the pertinent pollutant species expected to occur in the vicinity of DOE operations;

(c) Determine representative pollutant concentrations at areas where public health and other concerns should be considered; and

(d) Evaluate the effects of emissions on ambient levels of pertinent contaminants." 


\section{REQUIREMENTS IDENTIFICATION DOCUMENT \\ HIGH LEVEL WASTE STORAGE TANK FARMS \\ Environmental Protection \\ Revision 0}

\section{FACILITY REQUTREMENT SOURCE: WAC-246-247 Section 080, Paragraphs $1,2,6,8$}

"(1) The department may conduct an environmental surveillance program to assure that radiation exposures to the public from a airborne emission sources are in compliance with applicable standards.

(2) As part of the surveillance program, the department may require the operator of any facility under the jurisdiction of the department to conduct stack sampling, ambient air monitoring, or other testing as necessary and to report the results to the department. Such testing may include computer dose modeling and verification.

(6) To determine compliance with applicable standards, radionuclide emissions shall be determined and dose equivalent to members of the public shall be calculated using EPA-approved sampling procedures, EPA codes AIRDOS-EPA and RADRISK, or other procedures, including those based on environmental measurements, that the departinent has determined to be suitable. In most cases, compliance will be determined by calculating the dose to members of the public at the point of maximum air concentration in an unrestricted area.

(8) In order to demonstrate compliance with this chapter, the department may require that a test be made of the emission source. The operator of the source may be required to provide a sampling platform and sampling ports for the department to perform an emission test. The department shall be allowed to obtain a sample from any emissions unit. The operator may observe the sampling and may obtain a sample at the same time."

\section{Hazardous Materials}

This subelement provides requirements for a hazardous materials management program that provides for compliance with provisions of SARA Title III, EMERGENCY PLANNING AND COMMUNITY RIGHT-TO-KNOW regulations regarding hazardous and toxic chemicals, and regulations regarding the management of RCRA hazardous wastes. In addition, requirements for monitoring hazardous material releases from Underground Storage Tanks storing diesel fuel, and monitoring of surface impoundment liners for the LERF are provided.

\section{FACILITY REQUIREMENT SOURCE: WAC-173-360 Section 350(2)(b)}

\section{"Methods of Release Detection for Piping}

Suction piping. Underground piping that conveys regulated substances under suction shall either have a line tightness test conducted at least every three years and in accordance with subsection (3)(b) of this section, or use a monthly monitoring method conducted in accordance with subsection (3)(c) of this section. No release detection is required for suction piping that is designed and constructed to meet the following standards:

(i) The below-grade piping operates at less than atmospheric pressure;

(ii) The below-grade piping is sloped so that the contents of the pipe will drain back into the storage tank if the suction is released;

(iii) Only one check valve is included in each suction line; 


\section{REQUIREMENTS IDENTIFICATION DOCUMENT HIGH LEVEL WASTE STORAGE TANK FARMS Environmental Protection Revision 0}

(iv) The check valve is located below and as close as practical to the suction pump; and

(v) A method is provided that allows compliance with subsection (2)(b)(ii) through (iv) of this section to be readily determined."

\section{FACILITY REQUIREMENT SOURCE: WAC-173-360 Section 350(3)}

"Methods of Release Detection for Piping

Each method of release detection for piping used to meet the requirements of WAC 173-360-335 shall be conducted in accordance with the following:

(a) Autiomatic line leak detectors. Methods which alert the operator to the presence of a leak by restricting or shutting off the flow of regulated substances through piping or triggering an audible or visual alarm may be used only if they detect leaks of three gallons per hour at ten pounds per square inch line pressure within one hour. An annual test of the operation of the leak detector shall be conducted in accordance with the manufacturer's requirements.

(b) Line tightness testing. A periodic test of piping may be conducted only if it can detect 0.1 gallon per hour leak rate at one and one-half times the operating pressure.

(c) Applicable tank methods. Any of the methods in WAC 173-360-345(6)(f) through (i) may be used if they are designed to detect a release from any portion of the underground piping that routinely contains regulated substances."

\subsubsection{Radiological Effluents}

This subelement specifies the requirements for the facility to monitor radioactive effluents in air and water media and to perform an assessment of the potential radiation dose to members of resulting from site operations. Fac:

SITE REQUIREMENT SOURCE: 40CFR61 Part 61.93.b (1)(2)

"Emission Monitoring and Test Procedures

Radionuclide emission rates from point sources (stacks or vents) shall be measured in accordance with the following requirements or other procedures for which EPA has granted prior approval:

(1) Effluent flow rate measurements shall be made using the following methods:

(i) Reference Method 2 of Appendix A to part 60 shall be used to determine velocity and volumetric flow rates for stacks and large vents.

(ii) Reference Method 2A of Appendix A to part 60 shall be used to measure flow rates through pipes and small vents.

(iii) The frequency of the flow rate measurements shall depend upon the variability of the effluent flow rate. For variable flow rates, continuous or frequent flow rate measurements shall be made. For relatively constant flow rates only periodic measurements are necessary. 


\section{REQUIREMENTS IDENTIFICATION DOCUMENT HIGH LEVEL WASTE STORAGE TANK FARMS \\ Environmental Protection \\ Revision 0}

(2) Radionuclides shall be directly monitored or extracted, collected and measured using the following methods:

(i) Reference Method 1 of Appendix A part 60 shall be used to select monitoring or sampling sites.

(ii) The effluent stream shall be directly monitored continuously with an in-line detector or representative samples of the effluent stream shall be withdrawn continuously from the sampling site following the guidance presented in ANSI N13.1-1969 "Guide to Sampling Airborne Radioactive Materials in Nuclear Facilities" (including the guidance presented in Appendix A of ANSI N13.1) (incorporated by reference-see 61.18). The requirements for continuous sampling are applicable to batch processes when the unit is operation. Periodic sampling (grab samples) may be used only with EPA's prior approval. Such approval may be granted in cases where continuous sampling is not practical and radionuclide emission rates are relatively constant. In such cases, grab samples shall be collected with sufficient frequency so as to provide a representative sample of the emissions.

(iii) Radionuclides shall be collected and measured using procedures based on the principles of measurement described on Appendix B, Method 114. Use of methods based on principles of measurement different from those described in Appendix B, Method 114 must have prior approval from the Administrator. EPA reserves the right to approve measurement procedures.

(iv) A quality assurance program shall be conducted that meets the performance requirements described in Appendix B, Method 114."

\section{SITE REQUIREMENT SOURCE: 40CFR61 Part 61.93.b (4)}

"Emission Monitoring and Test Procedures

(i) Radionuclide emission measurements in conformance with the requirements of paragraph

(b) of this section shall be made at all release points which have a potential to discharge

radionuclides into the air in quantities which could cause an effective dose equivalent in excess of $1 \%$ of the standard. All radionuclides which could contribute greater than $10 \%$ of the potential effective dose equivalent for a release point shall be measured. With prior DOE approval, DOE may determine these emissions through alternative procedures. For other release points which have a potential to release radionuclides into the air, periodic confirmatory measurements shall be made to verify the low emissions.

(ii) To determine whether a release point is subject to the emission measurement requirements of paragraph (b) of this section, it is necessary to evaluate the potential for radionuclide emissions for that release point. In evaluating the potential of a release point to discharge radionuclides into the air for the purpose of this section, the estimated radionuclide release rates shall be based on the discharge of the effluent stream that would result if all pollution control equipment did not exist, but the facility operations were otherwise normal."

\section{SITE REQUIREMENT SOURCE: DOE/EH0173T Section 3.5.8.3}

"The following criteria are guidelines to be considered for monitors that measure specific radionuclides.

Tritium Monitors. ANSI N42.18-1974 (R 1980) specifies a minimum level of detectability (MLD) for tritium of 5E-6 micro-Curies per $\mathrm{mL}$ for continuous monitors used in gaseous 


\section{REQUIREMENTS IDENTIFICATION DOCUMENT HIGH LEVEL WASTE STORAGE TANK FARMS Environmental Protection

\author{
Revision 0
}

effluent streams. IEC N.761-5 specifies a minimum level of detectability of 2E-6 micro-Curies per $\mathrm{mL}$. The ANSI MLD is a 1974 minimum standard, and it specifies measurable concentrations at a $95 \%$ confidence level after 4 hours of sample concentration. However, the detectability level may not be obtainable with mixtures of radionuclides, and instrument response is limited by natural airborne radioactive materials (radon and thoron in equilibrium with their decay products). Additional concerns that should be considered in instrument design for tritium monitors based on the IEC standard (IEC N.761-5) are as follows:

Temperature control during sample transport to prevent condensation (much of the tritium may be in the form of airborne water vapor); and

Trapping or retention of water by a filter or sorbent (since much tritium is commonly in the form of HTO).

Radioiodine Monitors. Iodine cartridges used to collect radioiodine may be monitored at the collection point with a shielded detector, usually a single-channel thallium activated sodium iodide [NaI(TI)] detector. Typical systems have one or more charcoal cartridges in a series, preceded by an absolute particulate filter. In-line measurements of low concentrations of radioiodine in air will usually not be feasible because of the presence of other radionuclides or radiation fields. Iodine cartridges must be replaced at least weekly and the measurements verified by laboratory counting (DOE/EP-0096. Minimum levels of detectability for various iodine isotopes for continuous monitors of gaseous effluents must be established for a site, considering state of the art monitoring capabilities. The same general specifications given in the preceding discussion of tritium monitors, based on the IEC standard, should be considered for iodine monitors. "

\section{SITE REQUTREMENT SOURCE: DOE/EH0173T Section 8.1.1}

"The requirements to be followed when calculating public radiation dose are listed in the summary. DOE programs for surface- and ground-water monitoring, reporting, and modeling are under consideration by the DOE Office of Environmental Guidance and Compliance; thus, few details on these subjects are provided in this guide. These requirements will be broad enough to define conditions for radionuclides and associated chemicals that could enter surface or ground waters. Except where mandated otherwise (e.g., compliance with 40 CFR Part 61), the assessment models selected for all environmental dose assessments should* appropriately characterize the physical and environmental situation encountered. The information used in dose assessments should* be as accurate and realistic as possible. Complete documentation of assessments of the radiation dose resulting from the operation of DOE-controlled facilities should* be provided in a manner that supports the annual site environmental monitoring report, Environmental Monitoring Plan, or other application, and show the 1; models used, 2) computer programs used, and 3) input data and data source assumptions made."

\section{FACILITY REQUIREMENT SOURCE: DOE5484.1 Chapter III, Section 1}

"Monitoring New Sites, Processes, and Facilities. An environmental survey shall be conducted prior to actual start up of a new site, facility, or process which has the potential for adverse environmental impact, or which will process, release, or dispose of pollutants. The preoperational survey should begin about 2 years, but not less than 1 year before start up to cover seasonal changes adequately. The survey shall establish background levels of radioactive and toxic pollutants; characterize pertinent environmental and ecological parameters; and identify potential pathways for human exposure or environmental impact as a basis for 


\section{REQUIREMENTS IDENTIFICATION DOCUMENT HIGH LEVEL WASTE STORAGE TANK FARMS \\ Environmental Protection \\ Revision 0}

determining the nature and extent of the subsequent routine operational effluent and environmental monitoring program."

\section{RCRA Facility Inspections}

This subelement specifies the requirements for an internal inspection program to verify that provisions of the dangerous waste permit are being met.

\section{SITE REQUIREMENT SOURCE: WAC-173-303 Section 320}

"WAC 173-303-320 General inspection.

320 (1) The owner or operator shall inspect his facility to prevent malfunctions and deterioration, operator errors, and disciarges which may cause or lead to the release of dangerous waste constituents to the environment, or a threat to human health. The owner or operator must conduct these inspections often enough to identify problems in time to correct them before they harm human health or the environment.

320 (2) The owner or operator shall develop and follow a written schedule for inspecting all monitoring equipment, safety and emergency equipment, security devices, and operating and structural equipment that help prevent, detect, or respond to hazards to the public health or the environment. In addition:

320 (2) (a) He must keep the schedule at the facility;

320 (2) (b) The schedule must identify the types of problems which are to be looked for during inspections;

320 (2) (c) The schedule shall indicate the frequency of inspection for specific items. The frequency should be based on the rate of possible deterioration of equipment, and the probability of an environmental or human health incident. Areas subject to spills must be inspected daily when in use. The inspection schedule shall also include the applicable items and frequencies required for the specific waste management methods described in 40 CFR Part 265 Subparts F through R for interim status facilities and in WAC 173-303-630 through 173-303-680 for final status facilities; and

320 (2) (d) The owner or operator shall keep an inspection log or summary, including at least the date and time of the inspection, the printed name and the handwritten signature of the inspector, a notation of the observations made, an account of spills or discharges in accordance with WAC 173-303-145, and the date and nature of any repairs or remedial actions taken.

The log or summary must be kept at the facility for at least five years from the date of inspection.

320 (3) The owner or operator shall remedy any problems revealed by the inspection, on a schedule which prevents hazards to the public health and environment. Where a hazard is imminent or has already occurred, remedial action must be taken immediately."

\section{RELATED REFERENCES}

1. 40CFR264B Part 264.15.(a) 


\section{REQUIREMENTS IDENTIFICATION DOCUMENT HIGH LEVEL WASTE STORAGE TANK FARMS \\ Environmental Protection \\ Revision 0}

\section{Dangerous Waste Tanks}

This subelement specifies the inspection requirements of WAC-173-303-640 for dangerous waste storage tanks.

\section{FACILITY REQUIREMENT SOURCE: 40CFR264B Part 264.15.(a)}

"640 (6) Inspections.

640 (6) (a) The owner or operator must develop and follow a schedule and procedure for inspecting overfill controls.

640 (6)'(b) The owner or operator must inspect at least once each operating day:

640 (6) (i) Aboveground portions of the tank system, if any, to detect corrosion or releases of waste;

640 (6) (ii) Data gathered from monitoring any leak detection equipment (e.g., pressure or temperature gauges, monitoring wells) to ensure that the tank system is being operated according to its design; and

640 (6) (iii) The construction materials and the area immediately surrounding the externally accessible portion of the tank system, including the secondary containment system (e.g., dikes) to detect erosion or signs of releases of dangerous waste (e.g., wet spots, dead vegetation).

Note: WAC 173-303-320 requires the owner or operator to remedy any deterioration or malfunction be finds. Subsection (7) of this section requires the owner or operator to notify the department within twenty-four hours of confirming a leak. Also, 40 CFR Part 302 may require the owner or operator to notify the National Response Center of a release.

640 (6) (c) The owner or operator must inspect cathodic protection systems, if present, according to, at a minimum, the following schedule to ensure that they are functioning properly:

640 (6) (i) The proper operation of the cathodic protection system must be confirmed within six months after initial installation and annually thereafter; and

640 (6) (ii) All sources of impressed current must be inspected and/or tested, as appropriate, at least bimonthly (i.e., every other month).

Note: The practices described in the National Association of Corrosion Engineers (NACE) standard, "Recommended Practice (RP-02-85)--Control of External Corrosion on Metallic Buried, Partially Buried, or Submerged Liquid Storage Systems," and the American Petroleum Institute (API) Publication 1632, "Cathodic Protection of Underground Petroleum Storage Tanks and Piping Systems," may be used, where applicable, as guidelines in maintaining and inspecting cathodic protection systems.

640 (6) (d) The owner or operator must document in the operating record of the facility an inspection of those items in (a) through (c) of this subsection." 


\section{REQUIREMENTS IDENTIFICATION DOCUMENT HIGH LEVEL WASTE STORAGE TANK FARMS \\ Environmental Protection \\ Revision 0}

FACILITY REQUIREMENT SOURCE: WAC-173-303 Section 640(6)

"640 (6) Inspections.

640 (6) (a) The owner or operator must develop and follow a schedule and procedure for inspecting overfill controls.

640 (6) (b) The owner or operator must inspect at least once each operating day:

640 (6) (i) Aboveground portions of the tank system, if any, to detect corrosion or releases of waste;

640 (6) (ii) Data gathered from monitoring any leak detection equipment (e.g., pressure or temperature gauges, monitoring wells) to ensure that the tank system is being operated according to its design; and

640 (6) (iii) The construction materials and the area immediately surrounding the externally accessible portion of the tank system, including the secondary containment system (e.g., dikes) to detect erosion or signs of releases of dangerous waste (e.g., wet spots, dead vegetation).

Note: WAC 173-303-320 requires the owner or operator to remedy any deterioration or malfunction he finds. Subsection (7) of this section requires the owner or operator to notify the department within twenty-four hours of confirming a leak. Also, 40 CFR Part 302 may require the owner or operator to notify the National Response Center of a release.

640 (6) (c) The owner or operator must inspect cathodic protection systems, if present, according to, at a minimum, the following schedule to ensure that they are functioning properly:

640 (6) (i) The proper operation of the cathodic protection system must be confirmed within six months after initial installation and annually thereafter; and

640 (6) (ii) All sources of impressed current must be inspected and/or tested, as appropriate, at least bimonthly (i.e., every other month).

Note: The practices described in the National Association of Corrosion Engineers (NACE) standard, "Recommended Practice (RP-02-85)--Control of External Corrosion on Metallic Buried, Partially Buried, or Submerged Liquid Storage Systems, " and the American Petroleum Institute (API) Publication 1632, "Cathodic Protection of Underground Petroleum Storage Tanks and Piping Systems," may be used, where applicable, as guidelines in maintaining and inspecting cathodic protection systems.

640 (6) (d) The owner or operator must document in the operating record of the facility an inspection of those items in (a) through (c) of this subsection."

\section{Surface Impoundments}

This subelement specifies the requirements of WAC 173-303-650(4) for monitoring and inspection of surface impoundments. 


\section{REQUIREMENTS IDENTIFICATION DOCUMENT HIGH LEVEL WASTE STORAGE TANK FARMS \\ Environmental Protection \\ Revision 0}

FACILITY REQUIREMENT SOURCE: WAC-173-303 Section 650(4)

"650 (4) Monitoring and inspection.

650 (4) (a) During constructica and installation, liners (except in the case of existing portions of surface impoundments exempt from subsection (2)(a)(i) of this section) and cover systems (e.g., membranes, sheets, or coatings) must be inspected for uniformity, damage, and imperfections (e.g., holes, cracks, thin spots, or foreign materials). Immediately after construction or installation:

650 (4) (i) Synthetic liners and covers must be inspected to ensure tight seams and joints and the absence of tears, punctures, or blisters; and

650 (4) (ii) Soil-based and admixed liners and covers must be inspected for imperfections including lenses, cracks, channels, root holes, or other structural nonuniformities that may cause an increase in the permeability of the liner or cover.

650 (4) (b) While a surface impoundment is in operation, it must be inspected weekly and after storms to detect evidence of any of the following:

650 (4) (i) Deterioration, malfunctions, or improper operation of overtopping control systems;

650 (4) (ii) Sudden drops in the level of the impoundment's contents;

650 (4) (iii) The presence of liquids in leak detection systems, where installed to comply with subsection (3) of this section; and

650 (4) (iv) Severe erosion or other signs of deterioration in dikes or other containment devices.

650 (4) (c) Prior to the issuance of a permit, and after any extended period of time (at least six months) during which the impoundment was not in service, the owner or operator must obtain a certification from a qualified engineer that the impoundment's dike, including that portion of any dike which provides freeboard, has structural integrity. The certification must establish, in particular, that the dike:

650 (4) (i) Will withstand the stress of the pressure exerted by the types and amounts of wastes to be placed in the impoundment; and

650 (4) (ii) Will not fail due to scouring or piping, without dependence on any liner system included in the surface impoundment construction.

\section{Quality Assurance}

This subelement defines the quality assurance requirements associated with environmental monitoring and surveillance activities. The requirements specified are associated with sampling, analytical quality control, instrumentation, quality of records, etc. The requirement for recordkeeping is specified by NRC Regulatory Guide 4.15 and is considered a best management practice. 


\section{REQUIREMENTS IDENTIFICATION DOCUMENT HGH LEVEL WASTE STORAGE TANK FARMS Environmental Protection \\ Revision 0}

\section{STTE REQUTREMENT SOURCE: DOE/EH0135 TS.5.2}

"All points of potential release of radioactive and hazardous material to the environment from each facility are monitored sufficiently to provide assuranco that the quantities and qualities of the reloase are known."

\section{STTE REQUTREMENT SOURCE: DOE/EH0135 TS.5.7}

"Instrumentation is periodically calibrated and has proper accuracy and range."

\section{SITE REQUIREMENT SOURCE: DOE/EH0173T Section 10.3.2}

"Each 'site is required to maintain an analytical QC program adequato to document and control the accuracy and precision of the analytical results. If analytical work is performed by a subcontractor, the subcontractor is required to meet the same $Q C$ requirements. Guidance on content of analytical QC programs is provided by Belanger (1984), Goldin (1970), Rosenstein and Goldin (1964), EPA-600/9-76-005, EPA-600/7-77-088, EPA-600/8-78-008, and EPA-600/4- 79-019.

DOE 5400.5 requires that all organizations performing effluent or environmental monitoring participate in the DOE quality assessment program for those nuclides and media that they regularly measure. Samples are distributed by the Environmental Measurements Laboratory (EML) twice a year, and participants analyze both sets of samples. DOE monitoring organizations should participate in other interlaboratory QC programs such as the EPA Environmental Radioactivity Laboratory Intercomparison Studies Program (EPA600/4-78-032).

Radiation measuring equipment, including portable instruments, environmental dosimeters, in situ monitoring equipment, and laboratory instruments, should* be calibrated with standards traceable to NIST calibration standards (NCRP 1978; National Bureau of Standards Special Publication 609)"

\section{FACILITY REQUIREMENT SOURCE: DOE5400.1 Chapter IV, Section 10.a}

"Quality Assurance and Data Verification - Quality Assurance. A quality assurance program consistent with DOE 5700.6B shall be established covering each element of environmental monitoring and surveillance programs commensurate with its nature and complexity. The quality assurance program shall include, but not be limited to, the following:

(1) Organizational responsibility;

(2) Program design;

(3) Procedures;

(4) Field quality control;

(5) Laboratory quality control;

(6) Human factors; 


\section{REQUIREMENTS IDENTIFICATION DOCUMENT HIGH LEVEL WASTE STORAGE TANK FARMS \\ Environmental Protection \\ Revision 0}

(7) Recordkeeping;

(8) Chain-of-custody procedures;

(9) Audits;

(10) Performance reporting; and

(11) Independeat data verification."

SITE REQUTREMENT SOURCE: DOE5400.1 Chapter IV, Section 5 (a) (2) (d) s/b S.a(2)(d)

"5401.1.IV.5.a(2)(d) Monitoring Data Recordkeeping. Auditable records shall be established in accordance with the requirements of DOE 5700.6C QUALITY ASSURANCE."

\section{STTE REQUIREMENT SOURCE: NRC-4.15 Section C.5}

"Quality Control in Sampling (lncluding Packaging, Shipping, and Storage of Samples)

Continuous sampling of liquids and gases involves the measurement of sample flow rates and/or samples volumes. The accuracy of the devices used for this purpose should be determined on a regularly scheduled basis, and adjustments should be made as needed to bring the performance of the devices within specified limits. The results of these calibrations should be recorded. The frequency of these calibrations should be specified and should be based on the required accuracy, purpose, degree of usage, stability characteristics, and other conditions affecting the measurement. Procedures for continuous sampling should use methods that are designed to ensure that the sample is representative of the material volumes sampled. The collection efficiencies of the samplers used should be documented; usually such documentation is available from manufacturers of the sampling equipment.

Procedures for grab samples should include steps designed to ensure that the sample is representative of the material sampled. Representative grab samples should be taken periodically to determine the reproducibility of sampling.

Procedures for sampling, packaging, shipping, and storage of samples should be designed to maintain the integrity of the sample from time of collection to time of analysis."

\section{Underground Storage Tanks}

This subelement specifies the requirements for release detection of underground tanks and piping conveying regulated substances.

\section{FACILITY REQUIREMENT SOURCE: WAC-173-360 Section 335}

"Release Detection For Petroleum UST Systems

(1) Owners and operators of new and existing petroleum UST systems shall provide a method, combination of methods, of release detection that: 


\section{REQUTREMENTS IDENTIFICATION DOCUMENT FIGH LEVEL WASTE STORAGE TANK FARMS \\ Environmental Protection \\ Revision 0}

(a) Can detect a release from any portion of the tank and the connected underground piping that routinoly contains a regulated substance;

(b) Is installed, calibrated, operated, and maintained in accordance with the manufacturer's instructions, including routine maintenance and service checks for operability or running condition; and

(c) Meets the performence requirements in WAC $173-360-345$ or $173-360-350$.

(2) Owners and operators of petroleum UST systems shall monitor tanks and piping for relanses as follows:

(a) Tanks. Tanks aball be monitored at least every thirty days for releases using one of the methods listed in WAC 173-360-345(6)(e) through (6)(i) except as provided in WAC 173-360-345(2) through (5).

(b) Piping. Underground piping that routinely contains regulated substances shall be monitored for releases as required under WAC 173-360-350.

(3) Owners and operators of any existing UST system that cannot apply a method of release detection that complies with the applicable requirements of WAC 173-360-330 through 173-360-355 shall complete the closure procodures in WAC 173-360-380 through 173-360-398 by the date on which release detection is required for that UST system under WAC 173-360-330.

\section{FACILITY REQUIREMENT SOURCE: WAC-173-360 Section 350(1)}

"Any method of release detection for piping shall meet the performance requirements of this section, with any performance claims and their manner of determination described in writing by the equipment manufacturer or installer. In addition, methods used after December 22 , 1990, except for methods permanently installed prior to that date, shall be capable of detecting the leak rate or quantity specified for that method in subsection (3)(a) and (b) of this section with a probability of detection of 0.95 and a probability of false alarm of 0.05 . (That is, under test conditions, a method will correctly detect at least ninety-five of one-hundred actual releases, and will falsely indicate a release no more than five times in one hundred tests of nonleaking systems.)"

\section{Waste Piles}

This subelement specifies the requirements of WAC 173-303-660(5) for monitoring and inspection of waste piles.

\section{FACILITY REQUIREMENT SOURCE: WAC-173-303 Section 660(5)}

"660 (5) Monitoring and inspection.

660 (5) (a) During construction or installation, liners (except in the case of existing portions of piles exompt from subsection (2)(a) of this section), and cover systems (e.g., membranes, sheets, coatings) must be inspected for uniformity, damage, and imperfections (e.g., holes, cracks, thin spots, foreign materials). Immediately after construction or installation: 


\section{REQUIREMENTS IDENTIFICATION DOCUMENT HIGH LEVEL WASTE STORAGE TANK FARMS \\ Environmental Protection \\ Revision 0}

660 (5) (i) Synthetic liners and covers must be inspected to ensure tight seams and joints and the abeence of tears, punctures, or blieters; and

660 (5) (ii) Soil-banod and admixed liners and covers must be inspected for imperfections including lenses, cracks, channels, root boles, or other structural nonuniformities that may cause an increase in the permonbility of the liner or cover.

660 (5) (b) While a wasto pile is in operation, it must be inspected weekly and after storms to detect evidence of any of the following:

660 (5) (i) Deterioration, malfunctions, or improper operation of run-on and nun-off control systems;

660 (5) (ii) The presence of liquids in leak detection systems, where installed to comply with subsection (3) of this section;

660 (5) (iii) Proper functioning of wind dispersal control systems; and

660 (5) (iv) The presence of leachate in and proper functioning of leachate collection and romoval systems.

This element specifies the requirements for identification of necessary permits, permit application processes, and permit contents. Permitting requirements for water, air, and RCRA TSD facilities are specified, in addition, program requirements for the NEPA program are included.

\section{3 .1}

\section{Clean Water Permits}

Liquid effluent discharges to waters of the US require a permit under the National Pollution Discharge Elimination System (NPDES). While the TWRS does not have a process discharge to surface water, stormwater potentially can contact contaminated equipment, which would result in the requirement for an NPDES Stormwater permit.

\section{FACILITY REQUIREMENT SOURCE: WAC-246-272 Section 090}

"Permit (1) No person shall install or cause to be installed a new on-site sewage system, nor perform any alterations, extensions, or relocations or connections to an existing system without a valid permit issued by the health officer. Larger on-site sewage systems approved by the department are exempt from permit requirements. Permits for alterations or repairs shall be so identified. Application for such permit shall be made in writing in a manner prescribed by the health officer. Each permit application shall include a reminder of the applicant's right of appeal. The authority to issue permits shall not be delegated by the health officer."

\section{3 .2}

\section{Clean Air Permits}

This subelement specifies requirements for sources and emission units to meet Federal and State emission standards, and to obtain and comply with air quality permits. 


\section{REQUIREMENTS IDENTIFICATION DOCUMENT HIGH LEVEL WASTE STORAGE TANK FARMS \\ Environmental Protection \\ Revision 0}

\section{STIE REQUIREMENT SOURCE: 40CFR61 Part 61.96 (b)}

"Application to Construct or Modify

(b) An application for approval under 61.07 or notification of startup under 61.09 does not noed to be filed for any now construction of or modification within an existing facility if the offective dose equivalent, caused by all emissions from the new construction or modification, is less than $1 \%$ of the standard prescribed in 61.92. For purposes of this paragraph the effective dose equivalent shall be calculated using the source term derived using Appendix D as input to the dispersion and other computer models described in 61.93. DOE may, with prior approvai from EPA, use another procedure for estimating the source term for use in this paragraph. A facility is oligible for this exemption only if, based on its last annual report, the facility is in compliance with this subpart."

\section{SITE REQUTREMENT SOURCE: WAC-173 Section 480-60}

\section{"Emission Standards Now and Modified Emission Units}

(1) Whenever the construction, installation or establishment of a new emission unit subject to this chapter is contemplated, the project shall utilize best available radionuclide control tochnology (BARCT).

(2) Addition to, enlargement, modification, replacement, alteration of any process or emission unit or replacement of air pollution control equipment which will significantly change potential radionuclide emissions or significantly change the dose equivalent will require the proposed project to utilize best available radionuclide control technology (BARCT) for emission control."

\section{SITE REQUIREMENT SOURCE: WAC-173-400 Section 110}

"Construction shall not commence, on any new source that is required to register per WAC 173-400-100, until an notice of construction has been approved per WAC 173-403-050. The owner or operator of any source that is required to register per WAC 173-400-100 shall notify the department or cognizant local authority prior to replacement of air pollution control equipment or process equipment other than replacement for routine maintenance and repair. The department or authority may determine that a notice of construction is required. "

\section{FACILITY REQUIREMENT SOURCE: WAC-246-247 Section 060}

"Each operator of radioactive airborne emission sources shall obtain a permit issued by the departmeat $t, j$ operate those sources. The department shall grant these permits only after receipt of the appropriate fees and registration materials and a full review of those materials by the department.

(2) For emission sources at facilities at the United states Department of Energy (DOE) Hanford Site, the department shall issue one permit for each major production, processing, or research area, e.g. 200 east Area." 


\title{
REQUIREMENTS IDENTIFICATION DOCUMENT HIGH LEVEL WASTE STORAGE TANK FARMS Environmental Protection Revision 0
}

\author{
RCRA TSD Facility Permits
}

This subelement specifies programmatic requirements for dangerous waste facilities that must obtain and maintain a RCRA Part B permit.

\section{STTE REQUTREMENT SOURCE: WAC-173-303 Section 141}

"(1) A person shall only offer a designated dangerous waste to a TSD facility which is operating either: Under a permit issued pursuant to the requirements of this chapter; or, if the TSD facility is located outside of this state, under interim status or a permit issued by United States EPA under 40 CFR Part 270, or under interim status or a permit issued by another state which has been authorized by United States EPA pursuant to 40 CFR Part 271.

(2) A person may offer a state only designated dangerous waste (not regulated as a hazardous waste by EPA) to a facility which is located outside of this state and which does not meet the requirements of subsection (1) of this section if:

(a) The facility receiving the waste will legitimately treat or recycle the dangerous waste (disposal is an unacceptable management practice);

(b) The generator has on file a letter or copy of a letter signed by the regulatory authority in the receiving state that the receiving facility may accept the waste;

(c) The generator uses a transporter with a valid EPA/state identification number;

(d) The generator complies with all other applicable requirements, including manifesting, packaging and labeling, with respect to the shipping of the waste. However, the EPA/state identification number for the receiving facility is not required on the manifest or annual report; and

(e) The generator receives from the receiving facility a signed and dated copy of the manifest.

SITE REQUIREMENT SOURCE: WAC-173-303 Section 800 (1-6)

"WAC 173-303-800 Permit requirements for dangerous waste management facilities.

800 (1) The purpose of WAC 173-303-800 through 173-303-840 is to establish the requirements for permits which will allow a dangerous waste facility to operate without endangering the public bealth and the environment.

800 (2) The owner/operator of a dangerous waste facility that transfers, treats, stores, or disposes (TSD) or recycles dangerous waste shrill, when required by this chapter, obtain a permit covering the active life, closure period, ground water protection compliance period, and for any regulated unit (as defined in WAC 173-303-040(75)), and for any facility which at closure does not meet the removal or decontamination limits of WAC 173-303-610 (2)(b), post-closure care period in accordance with WAC 173-303-800 through 173-303-840.

600 (3) TSD facility permits will be granted only if the objectives of the siting and performance standards set forth in WAC 173-303-282 and 173-303-283 are met. 


\section{REQUIREMENTS IDENTIFICATION DOCUMENT HIGH LEVEL WASTE STORAGE TANK FARMS Environmental Protection \\ Revision 0}

800 (4) Permits shall be issued according to the requirements of all applicable TSD facility standards.

800 (5) The owner/operator of a TSD facility is responsible for obtaining all other applicable federal, state, and local permits authorizing the development and operation of the TSD facility.

800 (6) The terms used in regard to permits which are not defined in WAC 173-303-040 shall have the same meanings as set forth in 40 CFR 270.2."

\section{SITE REQUIREMENT SOURCE: WAC-173-303 Section 806(4)a}

" 806 (4) Contents of Part B. Part B of a permit application shall consist of the information required in (a) through (i) of this subsection.

806 (4) (a) General requirements. Part B of the permit application consists of the general information requirements of this subsection, and the specific information requirements in (b) through (h) of this subsection as applicable to the facility. The Part B information requirements presented in (a) through (h) of this subsection, reflect the standards promulgated in WAC 173-303-600. These information requirements are necessary in order for the department to determine compliance with WAC 173-303-600 through 173-303-670. If owners and operators of TSD facilities can demonstrate that the information prescribed in Part B cannot be provided to the extent required, the department may make allowance for submission of such information on a case-by-case basis. Information required in Part B shall be submitted to the department and signed in accordance with requirements in WAC 173-303-810(12). Certain technical data, such as design drawings and specifications, and engineering studies shall be certified by a registered professional engineer. The following information is required for all TSD facilities, except as WAC 173-303-600(3) provides otherwise.

806 (4)(a) (i) A general description of the facility.

806 (4)(a) (ii) Chemical, biological, and physical analyses of the dangerous waste to be handled at the facility. At a minimum, these analyses shall contain all the information which must be known to treat, store, or dispose of the wastes properly in accordance with WAC $173-303-600$.

806 (4)(a) (iii) A copy of the waste analysis plan required by W.AC 173-303-300(5) and, if applicable WAC 173-303-300 (5)(g).

806 (4)(a) (iv) A description of the security procedures and equipment required by WAC 173-303-310, or a justification demonstrating the reasons for requesting a waiver of this requirement.

806 (4)(a) (v) A copy of the general inspection schedule required by WAC 173-303-320(2): Include where applicable, as part of the inspection schedule, specific requirements in WAC 173-303-395 (1)(d), 173-303-630(6), 173-303-640(4) and (6), 173-303-650(4), 173-303-655(4), $173-303-660$ (4) and (5), 173-303-665(4), 173-303-670(7), and 173-303-680(3).

806 (4)(a) (vi) A justification of any request for a waiver(s) of the preparedness and prevention requirements of WAC 173-303-340, or a description of the procedures used to comply with these requirements. 


\section{REQUIREMENTS IDENTIFICATION DOCUMENT HIGH LEVEL WASTE STORAGE TANK FARMS Environmental Protection \\ Revision 0}

806 (4)(a) (vii) A copy of the contingency plan required by WAC 173-303-350: Include, where applicable, as part of the contingency plan, specific requirements in WAC 173-303-640(8), $173-303-650(5)$ and $173-303-660(6)$.

806 (4)(a) (viii) A description of procedures, structures, or equipment used at the facility to:

806 (4) (a) (viii) (A) Prevent hazards and contain spills in unloading/loading operations (for example, ramps, berms, pavement, special forklifts);

806 (4) (a) (viii) (B) Prevent run-off from dangerous waste handling areas to other areas of the facility or environment, or to prevent flooding (for example, berms, dikes, trenches);

806 (4) (a) (viii) (C) Prevent contamination of water supplies;

806 (4) (a) (viii) (D) Mitigate effects of equipment failure and power outages; and

806 (4) (a) (viii) (E) Prevent undue exposure of personnel to dangerous waste (for example, protective clothing).

806 (4)(a) (ix) A description of precautions to prevent accidental ignition or reaction of ignitable, reactive, or incompatible wastes as required to demonstrate compliance with WAC 173-303-395 including documentation demonstrating compliance with WAC 173-303-395

(1)(c).

806 (4)(a) (x) Traffic pattern, estimated volume (number, types of vehicles) and control (for example, show turns across traffic lanes, and stacking lanes (if appropriate); describe access road surfacing and load bearing capacity; show traffic control signals).

806 (4)(a) (xi) Seismic risk consideration. The owner/operator of a proposed facility or expansion of an existing facility shall identify the seismic risk zone in which the facility is intended to be located. Where state or local maps are not available, United States Geological Survey Open File Report number 82-1033 may be used to identify seismic risk zones. The owner/operator shall demonstrate that the facility can and will be designed to resist seismic ground motion and that the design is sufficient to withstand the maximum horizontal acceleration of a design earthquake specified in the demonstration.

806 (4)(a) (xii) An outline of both the introductory and continuing training programs by owners or operators to prepare persons to operate or maintain the TSD facility in a safe manner as required to demonstrate compliance with WAC 173-303-330. A brief description of how training will be designed to meet actual job tasks in accordance with requirements in WAC $173-303-330$ (1)(d).

806 (4)(a) (xiii) A copy of the closure plan and, where applicable, the post-closure plan required by WAC 173-303-610 (3) and (8). Include, where applicable, as part of the plans, specific requirements in WAC 173-303-630(10), 173-303-640(5), 173-303-650(6), 173-303-655(8), 173-303-660(9), 173-303-665(6), and 173-303-680 (2) and (4).

806 (4)(a) (xviii) A topographic map showing a distance of one thousand feet around the facility at a scale of 2.5 centimeters ( 1 inch) equal to not more than 61.0 meters (200 feet). Contours must be shown on the map. The contour interval must be sufficient to clearly show the pattern of surface water flow in the vicinity of and from each operational unit of the facility. 


\section{REQUIREMENTS IDENTIFICATION DOCUMENT \\ HIGH LEVEL WASTE STORAGE TANK FARMS \\ Environmental Protection}

\section{Revision 0}

For example, contours with an interval of 1.5 meters ( 5 feet), if relief is greater than 6.1 meters ( 20 feet), or an interval of 0.6 meters ( 2 feet), if relief is less than 6.1 meters ( 20 feet). Owners and operators of TSD facilities located in mountainous areas should use large contour intervals to adequately show topographic profiles of facilities. The map shall clearly show the following:

806 (4) (a) (xviii) (A) Map scale and date;

806 (4) (a) (xviii) (B) One hundred-year floodplain area;

806 (4) (a) (xviii) (C) Surface waters including intermittent streams;

806 (4) (a) (xviii) (D) Surrounding land uses (residential, commercial, agricultural, recreational);

806 (4) (a) (xviii) (E) A wind rose (i.e., prevailing windspeed and direction);

806 (4) (a) (xviii) (F) Orientation of the map (north arrow);

806 (4) (a) (xviii) (G) Legal boundaries of the TSD facility site;

806 (4) (a) (xviii) (H) Access control (fences, gates);

806 (4) (a) (xviii) (I) Injection and withdrawal wells both on-site and off-site;

806 (4) (a) (xviii) (J) Buildings; treatment, storage, or disposal operations; or other structure (recreation areas, run-off control systems, access and internal roads, storm, sanitary, and process sewerage systems, loading and unloading areas, fire control facilities, etc.);

806 (4) (a) (xviii) (K) Barriers for drainage or flood control; and

806 (4) (a) (xviii) (L) Location of operational units within the TSD facility site, where dangerous waste is (or will be) treated, stored, or disposed (include equipment clean-up areas).

(Note - For large TSD facilities the department will allow $t: 2$ use of other scales on a case-by-case basis.)

806 (4)(a) (xix) Applicants may be required to submit such information as may be necessary to enable the department to carry out its duties under other state or federal laws as required.

806 (4) (a) (xx) Additional information requirements. The following additional information regarding protection of ground water is required from owners or operators of dangerous waste surface impoundments, waste piles, land treatment units, and landfills except as otherwise provided in WAC 173-303-645 (1)(b):

806 (4) (a) (xx) (B) Identification of the uppermost aquifer anci aquifers hydraulically interconnected beneath the facility property, including ground water flow direction and rate, and the basis for such identification (i.e., the information obtained from hydrogeologic investigations of the facility area);

806 (4) (a) (xx) (C) On the topographic map required under (a)(xviii) of this subsection, a delineation of the waste management area, the property boundary, the proposed "point of 


\section{REQUIREMENTS IDENTIFICATION DOCUMENT HIGH LEVEL WASTE STORAGE TANK FARMS \\ Environmental Protection \\ Revision 0}

compliance" as defined under WAC 173-303-645 (6), the proposed location of ground water monitoring wells as required under WAC 173-303-645(8), and, to the extent possible, the information required in $(\mathbf{a})(\mathbf{x x})(\mathrm{B})$ of this subsection;

806 (4) (a) (xx) (D) A description of any plume of contamination that bas entered the ground water from a regulated unit at the time that the application was submitted that:

806 (4) (a) (xx) (D) (I) Delineates the extent of the plume on the topographic map required under (a)(xviii) of this subsection;

806 (4) (D) (II) Identifies the concentration of each constitusnt throughout the plume or identifies the maximum concentrations of each constituent in the plume. (Constituents are those listed in WAC 173-303-9905, and any other constituents not listed there which have caused a managed waste to be regulated under this chapter.);

806 (4) (a) (xx) (E) Detailed plans and an engineering report describing the proposed ground water monitoring program to be implemented to meet the requirements of WAC 173-303-645(8);

806 (4) (a) (xx) (F) If the presence of dangerous constituents has not been detected in the ground water at the time of permit application, the owner or operator must submit sufficient information, supporting data, and analyses to establish a detection monitoring program which meets the requirements of WAC 173-303-645(9). This submission must address the following items specified under WAC 173-303-645(9):

806 (4) (a) (xx) (F) (I) A proposed list of indicator parameters, waste constituents, or reaction products that can provide a reliable indication of the presence of dangerous constituents in the ground water;

806 (4) (a) (xx) (F) (II) A proposed ground water monitoring system;

806 (4) (a) (xx) (F) (III) Background values for each proposed monitoring parameter or constituent, or procedures to calculate such values; and

806 (4) (a) (xx) (F) (IV) A description of proposed sampling, analysis and statistical comparison procedures to be utilized in evaluating ground water monitoring data;

806 (4) (a) (xxi) Contingent ground water protection program. The following actions are required for owners or operators of proposed land-based facilities and may be required for owners/operators of existing land-based facilities, except as provided in WAC $173-303-645(1)(b)$.

806 (4) (a) (xxi) (A) Contingent ground water protection program. The owner or operator shall develop a contingent ground water protection program. The purpose of this program will be to prevent the migration of dangerous waste or dangerous waste constituents from waste management units to the nearest hydraulically downgradient receptor at any time during the life of the facility. For the purposes of this subsection, the downgradient receptor shall be the facility property line, perennial surface water or domestic well, whichever is nearest to the dangerous waste management unit. The contingent ground water protection program shall at a minimum: 


\section{REQUIREMENTS IDENTIFICATION DOCUMENT HIGH LEVEL WASTE STORAGE TANK FARMS \\ Environmental Protection \\ Revision 0}

806 (4) (a) (xxi) (A) (1) Define the local and regional hydrogeologic characteristics. The contingent ground water protection program shall be based on a sufficient understanding of site geology, hydrology, and other factors to allow evaluation of its adequacy by the department. Site characterization shall be performed in sufficient detail to provide, at a minimum, the following information: Site geostratigraphy; site hydrostratigraphy; identification of aquifers, aquitards, and aquicludes; flow models for each stratum (i.e., porus media or fracture flow); the distribution of vertical and horizontal hydraulic conductivity; effective porosity; horizontal and vertical hydraulic gradients; ground water travel time to receptors; and heterogeneity for each stratigraphic unit. Site interpretative models shall include ranges of tested values: The provisions of WAC 173-303-806 (4)(a)(xx) and 173-303-645, shall be used as guidance in the development of the contingent ground water protection program.

806 (4) (a) (xxi) (A) (II) Identify the range of potential release scenarios that could occur during facility operation and the postclosure care period. The scenarios shall incorporate the intended design(s) of the dangerous waste management unit(s), wastes to be placed in the dangerous waste management unit(s), waste and leachate chemistry, waste, and soil and rock geochemical interactions, and the results of site characterization pursuant to WAC 173-303-806(4)(a)(xx) and (xxi);

806 (4) (a) (xxi) (A) (II) Include specific physical action to be taken of dangerous waste or dangerous waste constituents are detected in one or more of the monitoring wells. The physical actions shall be based upon engineering feasibility studies describing remedial actions established from site specific conditions and waste features. Such actions may include installation of a pump and treat system between the monitoring well and the receptor or installation of a section of slurry wall to decrease ground water travel times. The description of the systems shall also provide bow the remediation system will achieve cleanup, its efficiency, and the timeframes involved;

806 (4) (a) (xxi) (A) (IV) Incorporate the design, construction, and sampling methods outlines in WAC 173-303-645(8)(c),(d),(e), (f), and (g);

806 (4) (a) (xxi) (A) (V) Demonstrate to the satisfaction of the department that the owner/operator of the dangerous waste management facility has the financial capability to implement the proposed ground water protection plan; and

806 (4) (a) (xxi) (A) (VI) Include reporting procedures to the department.

806 (4) (a) (xxi) (B) The response actions identified in WAC 173-303-806 (4)(a)(xxi)(A)(III) shall be activated if the presence of dangerous waste or dangerous waste constituents bave been detected at the point of compliance in accordance with WAC 173-303-645 (9)(g), and shall continue until the concentration of dangerous waste or dangerous waste constituents under WAC 173-303-645(4) are reduced to levels below their respective concentration limits specified in WAC 173-303-645(5).

806 (4) (a) (xxi) (C) If the owner/operator does not demonstrate that the ground water protection program will prevent the migration of dangerous waste or its constituents to the nearest receptor, the department will require corrections to be made in the protection program, increase setbacks from the nearest receptor, or deny the permit.

806 (4) (a) (xxii) Additional requirements for incineration facilities. The following actions regarding the protection of human health and the environment must be taken by 


\section{REQUIREMENTS IDENTIFICATION DOCUMENT HIGH LEVEL WASTE STORAGE TANK FARMS \\ Environmental Protection \\ Revision 0}

owners/operators of proposed bazardous waste incineration facilities and may be required for owners or operators of existing incineration facilities.

806 (4) (A) Ambient monitoring program. The owner/operator shall be required to develop an ambient monitoring program. The purpose of this ambient monitoring program will be to: Gather baseline environmental information characterizing on-site and off-site environmental conditions prior to facility operation; and, to identify and measure changes in the environment which may be linked to the construction and operation of the facility. The ambient monitoring program shall, at a minimum:

806 (4) (I) Include a characterization of facility emission sources and pathways of contaminant transport.

806 (4) (II) Characterize local and regional ecosystems, including agricultural, and their sensitivity to the potential contaminants from the facility.

806 (4) (III) Incorporate the findings of the environmental impact statement's health risk assessment and/or other assessments specific to the proposal or available to the scientific community regarding emissions from dangerous waste management facilities and their potential human health and environmental effects.

806 (4) (IV) Identify sensitive indicator plants and animals for biomonitoring, identify specific chemical constituents of concern, sampling locations, sampling frequency, sampling and analytical methods, chain of custody procedures, quality assurance/quality control procedures, reporting times, recordkeeping procedures, and data evaluation procedures.

806 (4) (B) Environmental review procedures. The owner/operator shall establish procedures to allow for public review of facility operation and all monitoring data required by the facility's permit. In developing this process, the owner/operator shall, at a minimum:

806 (4) (I) Coordinate this effort with the public and interested local organizations;

806 (4) (II) Identify the informational needs of the community and develop a public information process which meets these needs; and

806 (4) (III) Develop procedures allowing full access by the public to all monitoring data required by the permit.

806 (4) (C) Impact mitigation plan. Prior to the department issuing a permit, the owner/operator shall submit an impact mitigation plan which demonstrates to the satisfaction of the department that the owner/operator will mitigate all probable significant adverse impacts, including economic, due to facility location and operations. The owner/operator shall use as a basis for identifying probable significant adverse economic impacts those probable economic impacts identified during a public review process, such as the environmental impact statement scoping process, if applicable.

The plan must include, but is not limited to, a description of what the owner/operator will do to reduce or prevent any probable significant impacts before they occur, to mitigatc such impacts should they occur, and to ensure the owner/operator has and will have the financial capability to implement such preventative and mitigative measures. Mitigation measures may include, as an element, financial compensation to adversely affected parties. 


\section{REQUIREMENTS IDENTIFICATION DOCUMENT HIGH LEVEL WASTE STORAGE TANK FARMS Environmental Protection}

Revision 0

This plan may be submitted with environmental reports the department requires for compliance with the State Environmental Policy Act, with the written citizen proponent negotiation report and agreements, or with the Part B permit application. If the plan does not demonstrate that the owner/operator is capable of adequately mitigating the identified probable significant adverse economic impacts, the department will require modification of the plan or of the proposed facility location, or will deny the permit application. The department must be satisfied with the plan prior to the issuance of the permit."

\section{NEPA}

This subelement specifies NEPA program activities provided by 40 CFR 1500. DOE adopted these regulations per 10 CFR 1021.2. Washington state implements NEPA through WAC 197-11 called the "SEPA Rules. " SEPA requires evaluation by the state of environmental impacts associated with an action under its jurisdiction prior to approval by the agency.

\section{SITE REQUIREMENT SOURCE: 40CFR1500 Part 1500.1501.2}

"Apply NEPA Early in the Process

Agencies shall integrate the NEPA process with other planning at the earliest possible time to insure that planning and decisions reflect environmental values, to avoid delays later in the process, and to head off potential conflicts. Each agency shall:

(a) Comply with the mandate of section 102(2)(A) to "utilize a systematic, interdisciplinary approach which will insure the integrated use of the natural and social sciences and the environmental design arts in planning and in decision making which may have an impact on man's environment, " as specified by 1507.2.

(b) Identify environmental effects and values in adequate detail so they can be compared to economic and technical analysis. Environmental documents and appropriate analyses shall be circulated and reviewed at the same time as other planning documents.

(c) Study, develop, and describe appropriate alternatives to recommend courses of action in any proposal which involves unresolved conflicts concerning alternative uses of available resources as provided by section 102(2)(E) of the Act."

\section{SITE REQUTREMENT SOURCE: 40CFR1500 Part 1500.1501.4}

"1501.4 Whether to prepare an environmental impact statement.

In determining whether to prepare an environmental impact statement, the Federal agency shall:

(a) Determine under its procedures supplementing these regulations (described in Section 1507.3) whether the proposal is one which:

(1) Normally requires an environmental impact statement, or

(2) Normally does not require either an environmental impact statement or an environmental assessment (categorical exclusion). 


\section{REQUIREMENTS IDENTIFICATION DOCUMENT HIGH LEVEL WASTE STORAGE TANK FARMS \\ Environmental Protection \\ Revision 0}

(b) If the proposed action is not covered by paragraph (a) of this section, prepare an environmental assessment (Section 1508.9). The agency shall involve environmental agencies, applicarts and the public, to the extent practicable, in preparing assessments required by Section 1508.9(a)(1).

(c) Based on the environmental assessment make its determination whether to prepare an environmental impact statement.

(d) Commence the scoping process (Section 1501.7), if the agency will prepare an environmental impact statement.

(e) Prepare a finding of no significant impact (Section 1508.13), if the agency determines on the basis of the environmental assessment not to prepare a statement. "

\section{SITE REQUIREMENT SOURCE: WAC-197-11 Section 960}

"The State Environmental Policy Act (SEPA), chapter 43.21C RCW, requires all governmental agencies to consider the environmental impacts of a proposal before making decisions. An environmental impact statement (EIS) must be prepared for all proposals with probable significant adverse impacts on the quality of the environment. The purpose of this checklist is to provide information to help (applicants) and the agency identify impacts from the proposal (and to reduce or avoid impacts from the proposal, if it can be done) and to help the agency decide whether an EIS is required."

\section{POLLUTION CONTROL STANDARDS}

This element specifies the requirements for pollution control regulations. Included are groundwater quality standards, air quality standards includiag air toxic releases, and radiological release standards.

18.4.1 Water Quality

This subelement specifies the allowable groundwater quality standards implemented the state of Washington.

\section{SITE REQUIREMENT SOURCE: WAC-173-200 Section:040}

"(2) The following criteria shall apply to all ground waters in the state of Washington:

(a) Ground water concentrations shall not exceed the criteria listed in Table 1, except as described in WAC 173-200-050(3)(b).

(b) For the primary and secondary contaminants and radionuclides listed in Table 1, the criteria shall be the most stringent concentration of the following and those listed in Table 1:

(i) Maximum contaminant level goals;

(ii) Maximum contaminant levels; and

(iii) State maximum contaminant levels published in chapter 248-54 WAC as presently promulgated or subsequently amended or repromulgated. 


\section{REQUIREMENTS IDENTIFICATION DOCUMENT HIGH LEVEL WASTE STORAGE TANK FARMS \\ Environmental Protection \\ Revision 0}

The criteria for primary and secondary contaminants and radionuclide contaminants in Table 1 shall be amended as the federal and state rules are amended and without amendment of this chapter.

(3) For contaminants for which no numeric criteria have been established, enforcement limits shall be establishod in accordance with WAC 173-200-050."

\section{SITE REQUIREMENT SOURCE: WAC-173-303 Section 645 (5)}

"645 (5) Concentration limits.

645 (5) (a) The department will specify in the facility permit concentration limits in the ground water for dangerous constituents established under subsection (4) of this section. The concentration of a dangerous constituent:

645 (5) (i) Must not exceed the background level of that constituent in the ground water at the time that limit is specified in the permit; or

645 (5) (ii) For any of the constituents listed in Table 1 of this subsection, must not exceed the respective value given in that table if the background level of the constituent is below the value given in Table 1; or

645 (5) (iii) Must not exceed an alternate limit established by the department under (b) of this subsection.

Table 1.

Maximum Concentration of Constituents for Ground Water Protection

Constituent Maximum Concentration 1

Arsenic 0.05

Barium 1.0

Cadmium 0.01

Chromium 0.05

Lead 0.05

Mercury 0.002

Selenium 0.01

Silver 0.05

Endrin 0.0002

Lindane 0.004

Methoxychlor 0.1

Toxaphene 0.005

2,4-D 0.1

2,4,5-TP Silvex 0.01

1 Milligrams per liter.

645 (5) (b) The department will establish an alternate concentration limit for a dangerous constituent if it finds that the constituent will not pose a substantial present or potential hazard to human health or the environment as long as the alternate concentration limit is not exceeded. In establishing alternate concentration limits, the department will consider the same factors listed in subsection (4)(b) (i) through (iii) of this section." 


\section{REQUIREMENTS IDENTIFICATION DOCUMENT \\ HIGH LEVEL WASTE STORAGE TANK FARMS \\ Environmental Protection \\ Revision 0}

Air Ouality

This subelement specifies the stendards for emission of particulates, priority pollutants, and toxic chemicals to the atmosphere.

STTE REQUIREMENT SOURCE: WAC-173-400 Section 40

"General standards for maximum emissions.

All sources and emissions units are required to meet the emission standards of this chapter. Where an emission standard listed in another chapter is applicable to a specific emissions unit, such standard will take precedent over a general emission standard listed in this chapter. When two or more emissions units are connected to a common stack and the openator elects not to provide the means or facilities to sample omissions from the individual emissions units, and the relative contributions of the individual emissions units to the common discharge are not readily distinguishable, then the emissions of the common stack must meet the most restrictive standard of any of the connected emissions units. Further, all emissions units are required to use reasonably available control technology (RACT) which may be determined for some sources or source categories to be more stringent than the applicable emission limitations of any chapter of Title 173 WAC. Where current controls are determined to be less than RACT, ecology or the authority shall, as provided in section 8, chapter 252, Laws of 1993 , define RACT for each source or source category and issue a rule or regulatory order requiring the installation of RACT."

\section{RELATED REFERENCES}

1. 10CFR20 Part 20.1.c

\section{FACILITY REQUIREMENT SOURCE: WAC-173-460 Section 040}

"New Source Review

(1)(a) The owner or operator of a new toxic air pollutant source listed in WAC 173-460-030(2) shall notify the authority prior to the construction, installation, or establishment of a new toxic air pollutant source and shall file a notice of construction application with the authority for the proposed emission unit(s). Notification and notice of construction are not required if the source is an exempt source listed in WAC 173-460-030(3) or subsection (2) of this section."

\section{FACILITY REQUIREMENT SOURCE: WAC-173-460 Section 050}

"Requirement to Quantify Emissions

(1) New sources.

(a) When applying for a notice of construction, an owner or operator of a new toxic air pollution source shall quantify those emissions of each TAP or combination of TAPs that:

(i) Will be used for the modeling procedures in WAC 173-460-080; and

(ii) That may be discharged after applying required control technology. The information shall be submitted to the authority. 


\section{REQUIREMENTS IDENTIFICATION DOCUMENT \\ HIGH LEVEL WASTE STORAGE TANK FARMS \\ Environmental Protection \\ Revision 0}

(b) Emissions shall be quantified in sufficient detail to determine whether the source complies with the requirements of this chapter."

\section{SITE REQUIREMENT SOURCE: WAC-173-470 Section 110}

"Particle fallout shall not exceed the standards enumerated in the regulation. In recognition of natural dust in areas of the state, exceptions are provided for areas east of the Cascade range crest."

\section{Radiological Emuents}

This subelement specifies the standards for radiological releases. Guidance for monitoring of these releases is specified in DOE/EH-0173T.

\section{FACILITY REQUIREMENT SOURCE: 40CFR191 Part 191.03(a)}

"Management and storage of spent nuclear fuel or high-level or transuranic radioactive wastes at all facilities regulated by the Commission or by Agreement States shall be conducied in such a manner as to provide reasonable assurance that the combined annual dose equivalent to any member of the public in the general environment resulting from: (1) Discharges of radioactive material and direct radiation from such management and storage and (2) all operations covered by Part 190; shall not exceed 25 millirems to the whole body, 75 millirems to the thyroid, and 25 millirems to any other critical organ."

\section{FACILTY REQUIREMENT SOURCE: 40CFR61 Part 61.92}

"Standard emissions of radionuclides to the ambient air from Department of Energy facilities shall not exceed those amounts that would cause any member of the public to receive in any year an effective dose equivalent of $10 \mathrm{~m} \mathrm{rem} / \mathrm{yr}$."

\section{SITE REQUIREMENT SOURCE: DOE/EH0135 AX.2.18}

"All radioactive releases are evaluated against ALARA program objectives to determine real population exposures."

\section{SITE REQUIREMENT SOURCE: DOE/EH0135 AX.2.4!}

"A periodic review of radioactive effluent records is performed to determine trends and to detect discharges exceeding established limits."

\section{SITE REQUIREMENT SOURCE: DOE5400.5 Chapter II, Section 1.a}

"DOE Public Dose Limit - All Exposure Modes, All DOE Sources of Radiation. Except as provided by II.1.a.(4), the exposure of members of the public to radiation sources as a consequence of all routine DOE activities shall not cause, in a year, an effective dose equivalent greater than $100 \mathrm{mrem}(1 \mathrm{mSv})$. Dose evaluations should reflect realistic exposure conditions." 


\section{REQUIREMENTS IDENTIFICATION DOCUMENT HIGH LEVEL WASTE STORAGE TANK FARMS Environmental Protection \\ Revision 0}

\section{SITE REQUTREMENT SOURCE: DOE5400.5 Chapter II, Section 1.b}

"Airborne Emissions Only, All DOE Sources of Radionuclides. To the extent required by the Clean Air Act, the exposure of members of the public to radioactive materials released to the atmosphere as a consequence of routine DOE activities shall not cause members of the public to receive, in a year, an offective dose equivalent greater than $10 \mathrm{mrem}(0.1 \mathrm{mSv})$. Exposures to, and releases of, radon-220, radon-222, and their respective decay products are subject to DOE limits (See Figure III-3 and Chapter IV, 4.b. and 6)."

\section{SITE REQUIREMENT SOURCE: DOE5400.5 Chapter II, Section 1.b(1)}

"Title 40 CFR Part 61. The public dose limits as outlined in Chapter II, 1.b. are established by EPA regulation 40 CFR Part 61, Subpart $H$, under the authority of the Clean Air Act. These limits apply offsite where the members of the public reside or abide. Subparts $Q$ and $T$ provide radon flux limits for DOE radium storage and disposal facilities (Chapter IV) and DOE inactive uranium mill tailings sites regulated under 40 CFR Part 192."

\section{SITE REQUIREMENT SOURCE: DOE5400.5 Chapter II, Section 1.b(2)}

"AIRDOS/RADRISK Codes. To demonstrate compliance analytically with air emissions for the Clean Air Act Standards, doses to the individuals shall be evaluated using the version of AIRDOS/RADRISK known as CAP-88 or, when available and approved, AIRDOS-PC. Other computer codes or models, such as "Comply Code," which are specifically approved in accordance with 40 CFR Part 61, may also be used."

\section{SITE REQUIREMENT SOURCE: DOE5400.5 Chapter II, Section 1.d}

"Drinking Water Pathway Only. All DOE Sources of Radionuclides. It is the policy of DOE to provide a level of protection for persons consuming water from a public drinking water supply operated by the DOE, either directly or through a DOE contractor, that is equivalent to that provided to the public by the public community drinking water standards of 40 CFR part 141 . These systems shall not cause persons consuming the water to receive an effective dose equivalent greater than $4 \mathrm{rem}(0.04 \mathrm{mSv})$ in a year. Combined radium-226 and radium-228 shall not exceed 5E-9 micro $\mathrm{Ci} / \mathrm{mL}$ and gross alpha activity (including radium-226 but excluding radon and uranium) shall not exceed $1.5 \mathrm{E}-8 \mathrm{micro} \mathrm{Ci} / \mathrm{mL}$.

(1) DOE Drinking Water Systems. The dose limit is consistent ' with the drinking water criteria in 40 CFR Part 141, "National Interim Primary Drinking Water Regulations (Safe Drinking Water Act)."

(2) Dose Components. The dose limit is the effective dose equivalent to individuals whose exclusive source of drinking water contain a radionuclide, or a mixture of radionuclide, at a monthly average level of four percent of the appropriate DCG value. For simplicity, it is assumed that site workers are also exposed to four percent of DCG values or the radium and gross alpha levels in II.1d for drinking water while away from the DOE site.

(3) suppact on Other Systems. The liquid effluents from DOE activities shall not cause private or public drinking water systems downstream of the facility discharge to exceed the drinking water radiological limits in 40 CFR Part 141." 


\section{REQUIREMENTS IDENTIFICATION DOCUMENT HIGH LEVEL WASTE STORAGE TANK FARMS \\ Environmental Protection \\ Rerision 0}

FACILTY REQUTREMENT SOURCE: DOES400.5 Chapter IV, Section 6.b(2)

"Controls shall be designed such that $\mathrm{Rn}-222$ concentrations in the atmospherc above facility surfaces or openings in addition to background levels, will not exceed:

(a) $100 \mathrm{pCi} / \mathrm{L}$ at any given point;

(b) An annual average concentration of $30 \mathrm{pCi} / \mathrm{L}$ over the facility site; and

(c) An annual average concentration of $3 \mathrm{pCi} / \mathrm{L}$ at or above any location outside the facility site.

(d) Flux rates from the storage of radon producing wastes shall not exceed $20 \mathrm{pCi} / \mathrm{sq} . \mathrm{m}$-sec., as required by 40 CFR Part 61."

\section{FACILITY REQUIREMENT SOURCE: DOE5400.5 Chapter IV, Section 6.b(3)}

"Controls shall be designated such that concentrations of radionuclides in the groundwater and quantities of residual radioactive material will not exceed applicable Federal or State standards."

\section{SITE REQUIREMENT SOURCE: WAC-173-480 Section 050}

"(1) All radionuclide emission units are required to meet the emission standards in this chapter. At a minimum, all emission units shall meet WAC 402-10-010 requiring every reasonable effort to maintain radioactive materials in effluents to unrestricted areas, as low as reasonably achievable (ALARA). For the purposes of this chapter, control equipment of facilities operating under ALARA shall be defined as reasonably available control technology (RACT).

(3) Whenever another Federal or State regulation or limitation in effect controls the emission of radionuclides to the ambient air, the more stringent control of emissions shall govern."

\section{SITE REQUIREMENT SOURCE: WAC-173-480 Section 40}

"Emissions of radionuclides in the air shall not cause a maximum accumulated dose equivalent of more than $25 \mathrm{rem} / \mathrm{y}$ to the whole body or $75 \mathrm{rem} / \mathrm{y}$ to a critical organ of any member of the public. Doses due to radon-220, radon-222, and their respective decay products are excluded from these limits. Compliance with the standard shall be determined by procedures in WAC 173-480-070."

FACILITY REQUIREMENT SOURCE: WAC-246-290-310 Section (8) Radionuclides

"(b) The MCLs for radium-226, radium-228, and gross alpha particle radioactivity are as follows:

Radium-226 $3 \mathrm{pCi} / \mathrm{L}$

Combined Radium-226 5pCi/L and Radium-228

Gross alpha particle $15 \mathrm{pCi} / \mathrm{L}$ activity (excluding uranium) 

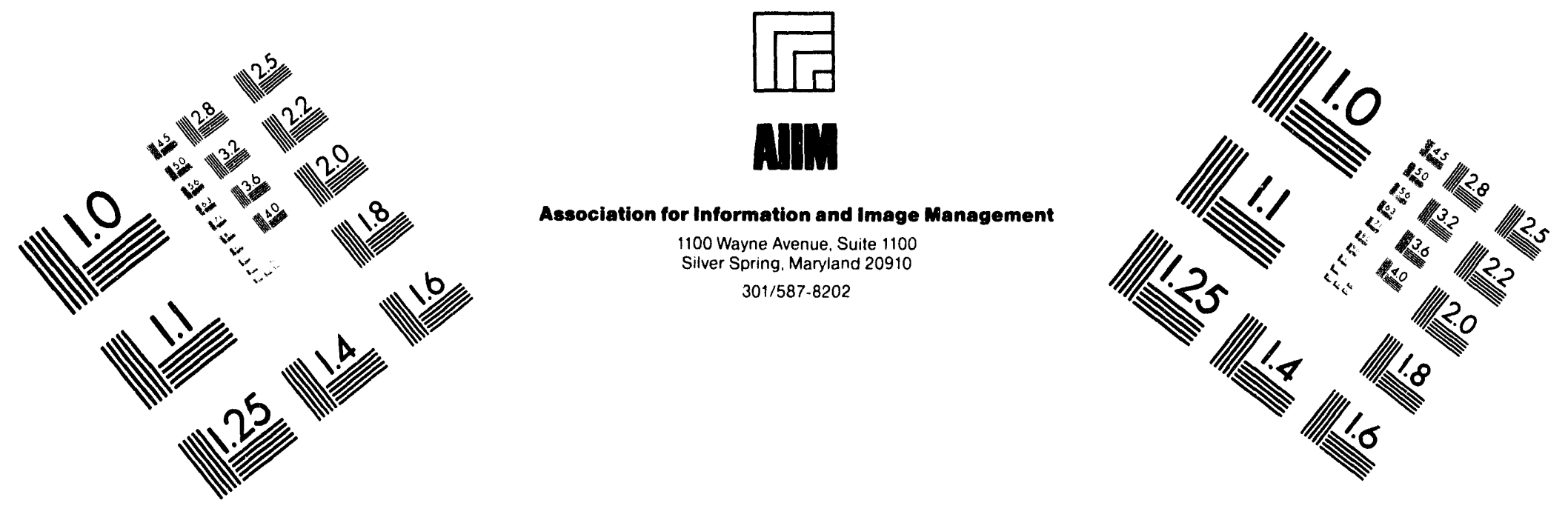

\section{Centimeter}

$\begin{array}{llllllllllllllll}1 & 2 & 3 & 4 & 5 & 6 & 7 & 8 & 9 & 10 & 11 & 12 & 13 & 14 & 15 & \mathrm{~mm}\end{array}$ $\left.\right|_{1}$ Inches
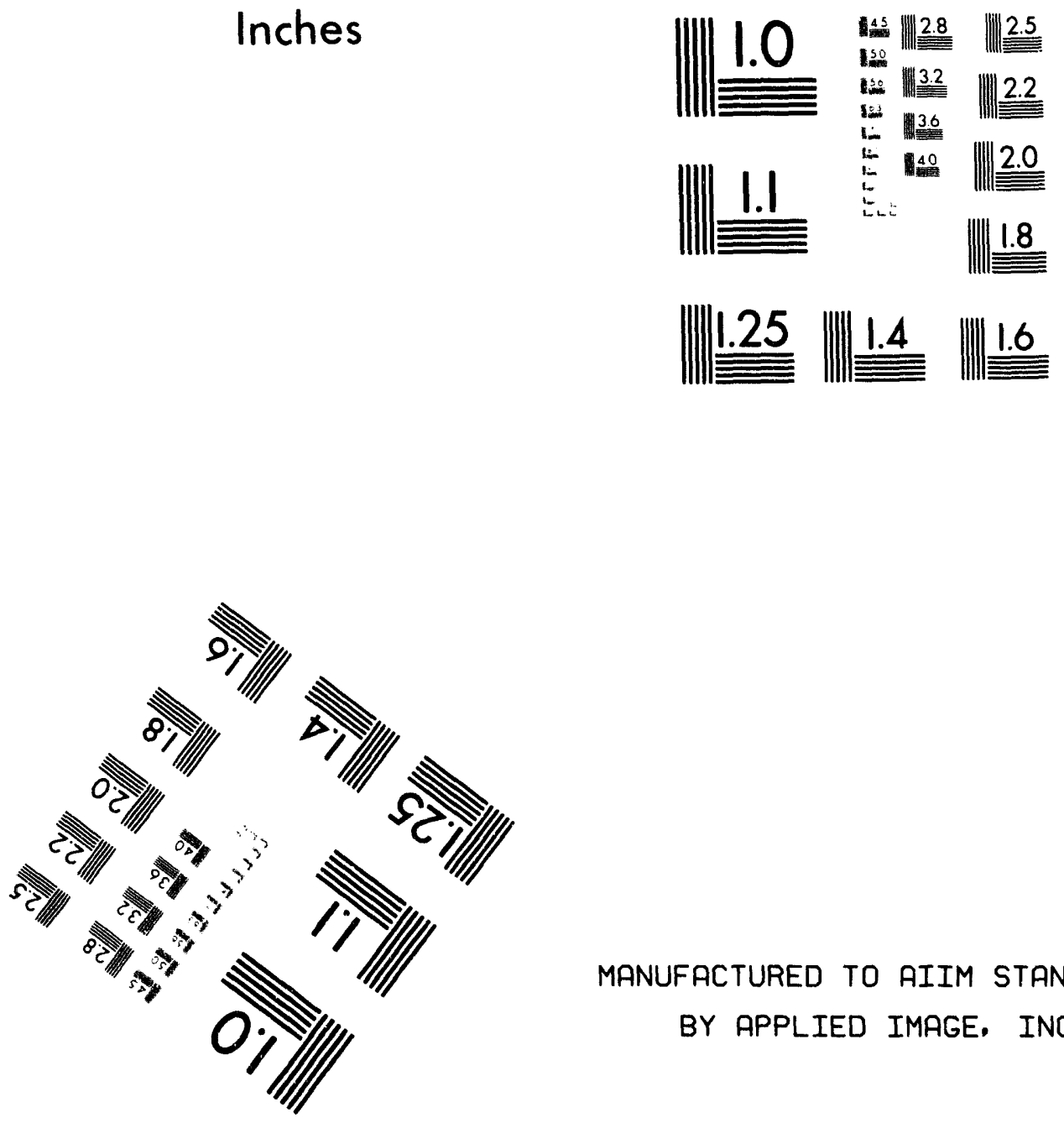

MANUFACTURED TO AIIM STANDARDS BY APPLIED IMAGE, INC.

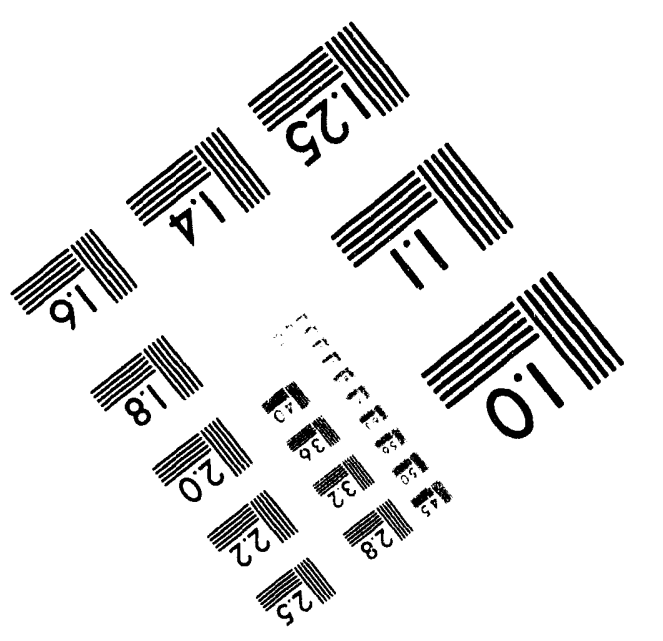



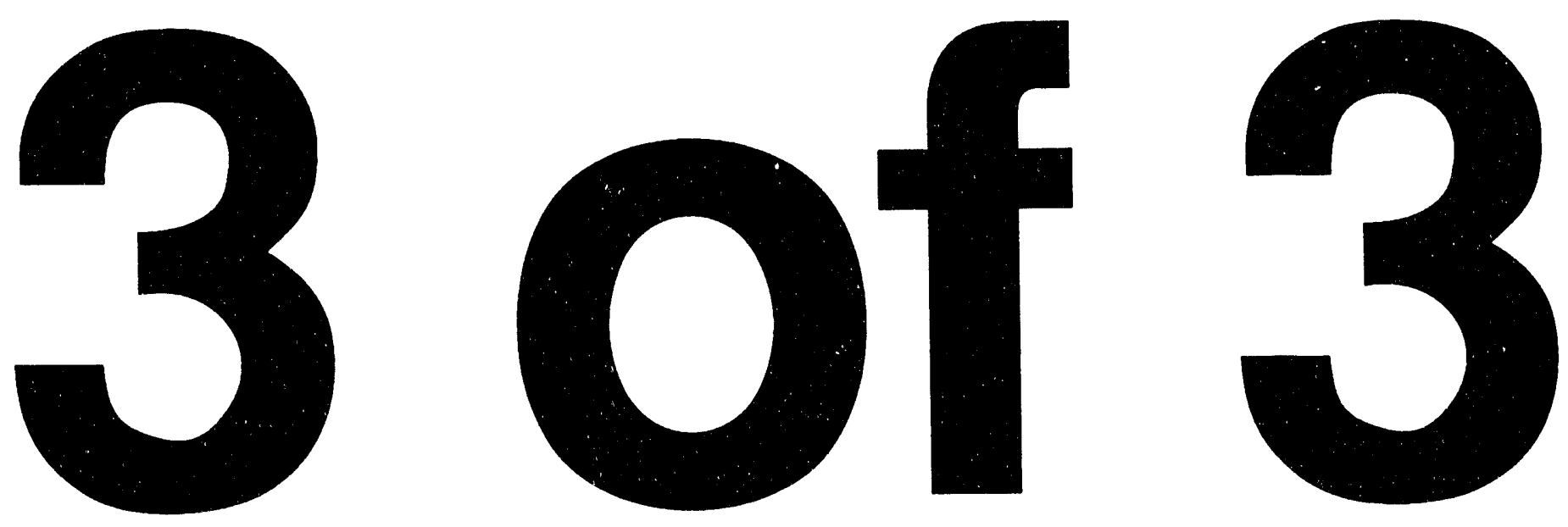


\section{REQUIREMENTS IDENTIFICATION DOCUMENT \\ HIGH LEVEL WASTE STORAGE TANK FARMS \\ Environmental Protection \\ Revision 0}

(c) The MCL for beta and photon radioactivity from man-made radionuclides is that the average annual concentration shall not produce an annual dose equivalent to the whole body or any internal organ greater than four millirem/year.

Compliance with the four millirem/year dose limitation may be assumed if the average concentration for gross beta activity, tritium, and strontium- 90 are less than $50 \mathrm{pCi} / \mathrm{L}, 20,000$ $\mathrm{pCi} / \mathrm{L}$, and $8 \mathrm{pCi} / \mathrm{L}$ respectively, provided that if both radionuclides are present, the sum of their annual dose equivalents to bone marrow shall not exceed four millirem/year."

\section{POLLUTION PREVENTION}

This element specifies requirements for pollution prevention including controls for source reduction, preparedness and prevention, and handling of spills and discharges.

The Pollution Prevention element includes controls for source reduction reporting, recycling, and waste minimization.

\section{SITE REQUIREMENT SOURCE: DOE/EH0135 TS.5.1}

"Site/facility management has taken all reasonable efforts to minimize quantities of radioactive and hazardous materials released to the environment from site/facility operations."

\section{FACILITY REQUIREMENT SOURCE: DOE5000.3B Attachment I, Group 2}

"A. Radionuclide Releases

Emergency

(a) Any release of radionuclide material to controlled or uncontrolled areas in concentrations which, if averaged over a period of 24 hours, would exceed 5 times the respective reportable quantities (RQs) specified for such materials in 40 CFR 302.

Unusual Occurrence

(a) Release of a radionuclide material that exceeds a Federally permitted release by the amount of a CERCLA RQ or, where no Federally permitted release exists, the release exceeds the RQ.

(b) Release of radionuclide material that violates environmental requirements in Federal permits, Federal regulations, or DOE standards.

(c) Release below Emergency levels which requires immediate ( $<4$ hours) reporting to Federal regulatory authorities or triggers specific action levels for an outside Federal agency.

Off-Normal

(a) Any release of radionuclide material to controlled or uncontrolled areas that is not part of a normal monitored release and exceeds 50 percent of a CERCLA RQ specified for such material per 40 CFR 302. 


\section{REQUIREMENTS IDENTIFICATION DOCUMENT HIGH LEVEL WASTE STORAGE TANK FARMS \\ Environmental Protection}

\section{Revision 0}

(b) Any controlled release of radionuclide material that occurs as a monitored part of normal operations which exceeds what historical data and/or analysis show is expected as a result of normal operations.

(c) Any monitored facility or site boundary where exposure or concentrations exceed what historical data and/or analysis show is expected as a result of normal operations.

(d) Any detection of a radionuclide in a sanitary or storm sewer, waste or process stream, or any bolding points where such a material is not expected.

(e) Any controlled, uncontrolled, or accidental release which is not classified as an Unusual Occurrence but which will be reported in writing to State/local agencies in a format other than routine monthiy or quarterly reports.

\section{B. Release of Hazardous Substances/Regulated Pollutants/Oil}

Throughout this Order and particularly within this sub-Group, reporting of spills or releases of ethylene glycol and glycol ethers shall be limited only to those spills or releases in excess of 100 pounds.

\section{Emergency}

(a) Any actual or potential release of material to the environment that results in or could result in significant offsite consequences (e.g., need to relocate people, major wildlife kills, major wetland degradation, major aquifer contamination, need to secure downstream water supply intakes, etc.).

(b) Any release of hazardous substances or regulated pollutants in concentrations which exceed five times the respective RQs specified for such materials in 40 CFR 302.

\section{Unusual Occurrence}

(a) Release of a hazardous substance or regulated pollutant that exceeds a CERCLA RQ per 40 CFR 302 or exceeds a federally permitted release by an $R Q$.

(b) Release of a hazardous substance, regulated pollutant, or oil that violates environmental requirements in Federal permits, Federal regulations, or DOE standards.

(c) Release below Emergency levels that requires immediate ( $<4$ hours) reporting to Federal regulatory agencies or triggers specific action levels for an outside Federal agency.

(d) Any release of 100 gallons or more of oil.

\section{Off-Normal}

(a) Release of a hazardous substance or regulated pollutant to controlled or uncontrolled areas that is not part of a normal, monitored release and exceeds 50 percent of a CERCLA RQ as specified for such material per 40 CFR 302.

(b) Any release of Oil less than the Unusual Occurrence level but $>10$ gallons. 


\section{REQUIREMENTS IDENTIFICATION DOCUMENT \\ HIGH LEVEL WASTE STORAGE TANK FARMS \\ Environmental Protection \\ Revision 0}

(c) Any detection of a toxic or hazardous substance in a sanitary or storm sewer, waste or process stream, or any holding points where such a material is not expected.

(d) Any controlled, uncontrolled, or accidental release which is not classified as an Unusual Occurrence but which will be reported in writing to State/local agencies in a format other than routine monthly or quarterly reports.

(e) Any controlled release of hazardous/regulated material that occurs as a monitored part of normal operations which exceeds what historical data and/or analysis shows is expected as a result of normal operations.

(f) Any general environmental monitoring where concentration increases to a level which exceeds what historical data and/or analysis shows is expected as a result of normal operations.

C. Discovery of hazardous material contamination due to DOE operations.

Emergency

(a) Discovery of contamination that results or could result in significant consequences (i.e. exceeding safe exposure limits to workers or public).

(b) Discovery of onsite or offsite hazardous material contaminations in concentrations that exceed 5 times the respective RQs specified for such materials in 40 CFR 302.

Unusual Occurrence

(a) Discovery of onsite or offsite contamination due to DOE operations which does not represent an immediate threat to the public, that exceeds a reportable quantity for such materials per 40 CFR 302.

(b) Any discovery of groundwater contamination that is not part of an existing plume previously identified in either an annual report or in any CERCLA/RCRA activity or report.

\section{Off-Normal}

Discovery of onsite contamination attributable to DOE operations that exceeds 50 percent of a reportable quantity for such material per 40 CFR 302.

D. Ecological Resources

Unusual Occurrence

Any occurrence causing significant impact to any ecological resource for which the DOE is a trustee (i.e., destruction of a critical habitat, damage to a historic/archeological site, damage to wetlands, etc.).

\section{E. Agreement/Compliance Activities}

Unusual Occurrence 


\section{REQUIREMENTS IDENTIFICATION DOCUMENT HIGH LEVEL WASTE STORAGE TANK FARMS \\ Environmental Protection \\ Revision 0}

(a) Any agreement, compliance, remediation, or permit-mandated activity for which formal notification has been received from the relevant regulatory agency that a site plan is not satisfactory or that a site is considered to be in noncompliance with schedules or requirements.

(b) Any occurrence under any agreement or compliance area that requires notification of an outside regulatory agency within 4 hours or less, or triggers an outside regulatory agency action level, or otherwise indicates specific interest/concern from such agencies.

\section{Off-Normal}

Any occurrence under any agreement or compliance area that will be reported in writing to outside agencies in a format other than routine monthly or quarterly reports."

\section{SITE REQUIREMENT SOURCE: WAC-173-160 Section 500}

"(3) Cuttings and development water shall be managed in a manner consistent with the intent and purposes of the Water Pollution Control Act, the Hazardous Waste Management Act, and implementing regulations." REQUIREMENT AUTHORITY

1. ANS8.7/ANSIN16.5 Section 5.12

\section{RELATED REFERENCES}

1.

$$
\text { 40CFR61 Part 61.14.d }
$$

\section{SITE REQUTREMENT SOURCE: WAC-173-303 Section 340}

"WAC 173-303-340 Preparedness and prevention.

Facilities shall be designed, constructed, maintained and operated to minimize the possibility of fire, explosion, or any unplanned sudden or nonsudden release of dangerous waste or dangerous waste constituents to air, soil, or surface or ground water which could threaten the public health or the environment. This section describes preparations and preventive measures which help avoid or mitigate such situations.

340 (1) Required equipment. All facilities must be equipped with the following, unless it can be demonstrated to the department that none of the hazards posed by waste handled at the facility could require a particular kind of equipment specified below:

340 (1) (a) An internal communications or alarm system capable of providing immediate emergency instruction to facility personnel;

340 (1) (b) A device, such as a telephone or a hand-held, two-way radio, capable of summoning emergency assistance from local police departments, fire departments, or state or local emergency response teams;

340 (1) (c) Portable fire extinguishers, fire control equipment, spill control equipment, and decontamination equipment; and

340 (1) (d) Water at adequate volume and pressure to supply water hose streams, foam producing equipment, automatic sprinklers, or water spray systems. All facility 


\section{REQUIREMENTS IDENTIFICATION DOCUMENT HIGH LEVEL WASTE STORAGE TANK FARMS \\ Environmental Protection}

Revision 0

communications or alarm systems, fire protection equipment, spill control equipment, and decontamination equipment, where required, must be tested and maintained as necessary to assure its proper operation in time of emergency.

340 (2) Access to communications or alarms. Personnel must have immediate access to the signalling devices described in the situations below:

340 (2) (a) Whenever dangerous waste is being poured, mixed, spread, or otherwise handled, all personnel involved must have immediate access to an internal alarm or emergency communication device, either directly or through visual or voice contact with another employee, unless such a device is not required in subsection (1) of this section;

340 (2) (b) If there is ever just one employee on the premises while the facility is operating, he must have immediate access to a device, such as a telephone or a hand-held, two-way radio, capable of summoning external emergency assistance, unless such a device is not required in subsection (1) of this section.

340 (3) Aisle space. The owner or operator must maintain aisle space to allow the unobstructed movement of personnel, fire protection equipment, spill control equipment, and decontamination equipment to any area of facility operation in an emergency, unless it can be demonstrated to the department that aisle space is not needed for any of these purposes.

340 (4) Arrangements with local authorities. The owner or operator shall attempt to make the following arrangements, as appropriate for the type of waste bandled at his facility and the potential need for the services of these organizations, unless the hazards posed by wastes handled at the facility would not require these arrangements:

340 (4) (a) Arrangements to familiarize police, fire departments, and emergency response teams with the layout of the facility, properties of dangerous waste handled at the facility and associated hazards, places where facility personnel would normally be working, entrances to and roads inside the facility, and possible evacuation routes;

340 (4) (b) Arrangements to familiarize local hospitals with the properties of dangerous waste handled at the facility and the types of injuries or illnesses which could result from fires, explosions, or releases at the facility;

340 (4) (c) Agreements with state emergency response teams, emergency response contractors, and equipment suppliers; and

340 (4) (d) Where more than one party might respond to an emergency, agreements designating primary emergency authority and agreements with any others to provide support to the primary emergency authority.

340 (5) Where state or local authorities decline to enter into such arrangements, the owner or operator must document the refusal in the operating record. "

18.6

\section{RECORDKEEPING, REPORTS, AND NOTIFICATIONS}

This element addresses controls for records, contents of these records, duration for maintaining these records, lifetime classification, quality designation and disposition of records. 


\section{REQUIREMENTS IDENTIFICATION DOCUMENT HIGH LEVEL WASTE STORAGE TANK FARMS Environmental Protection}

Revision 0

Water Quality

This subelement specifies requirements for maintenance and control of effluent discharge and surface water quality data collected under State and Federal water quality monitoring programs.

SITE REQUIREMENT SOURCE: WAC-173-160 Section 50

"Every well contractor, within thirty days after completion of a well, is required to submit a complete record on the construction or alteration of the sell to the Department (of Ecology)."

\section{SITE REQUIREMENT SOURCE: WAC-173-160 Section 560}

"(1) If it can be verified that a resource protection well was constructed in accordance with these regulations, it shall be abandoned by filling the casing from the bottom to the surface with grout or bentonite. If the construction cannat be verified, the well shall be abandoned in accordance with WAC 173-160-415(2).

(2) The abandonment procedure shall be recorded on a form provided by the department...

(3) The well abandonment must be recorded and reported to the department within thirty days of abandonment."

\subsection{2 $\quad$ Air Quality}

This subelement specifies the standards for maintenance and control of ambient air and emissions data collected under State and Federal air quality monitoring programs. The requirements specified from 40CFR265.1064 apply only to those waste tank system managing wastes with greater than $10 \%$ by weight organics.

\section{FACILITY REQUIREMENT SOURCE: 40CFR265.1064 Part 265.1064}

"Recordkeeping Requirements

(a)(1) Each owner or operator subject to the provisions of this subpart shall comply with the recordkeeping requirements of this subpart.

(2) An owner or operator of more than one hazardous waste management unit subject to the provisions of this subpart may comply with the recordkeeping requirements for these hazardous waste management units in one recordkeeping system if the system identifies each record by each hazardous waste management unit.

(b) Owners or operators must record the following information in the facility operating record:

(1) For each piece of equipment to which subpart BB of part 265 applies:

(i) Equipment identification number and hazardous waste management unit identification.

(ii) Approximate locations within the facility (e.g. identify the hazardous management unit on a facility plot plan). 


\section{REQUIREMENTS IDENTIFICATION DOCUMENT \\ HIGH LEVEL WASTE STORAGE TANK FARMS \\ Environmental Protection}

Revision 0

(iii) Type of equipment (e.g., a pump or pipeline valve).

(iv) Percent-by-weight total organics in the hazardous waste stream at the equipment.

(v) Hazardous waste state at the equipment (e.g., gas/vapor or liquid).

(vi) Method of compliance with the standard (e.g., "monthly leak detection and repair" or "equipped with dual mechanical seals").

(2) For facilities that comply with the provisions of 265.1033(a)(2), an implementation schedule as specified in $265.1033(a)(2)$.

(3) Where an owner or operator chooses to use test data to demonstrate the organic removal efficiency or total organic compound concentration achieved by the control device, a performance test plan as specified in 265.1035(b)(3).

(4) Documentation of compliance with 265.1060 , including the detailed design documentation or performance test results specified in 265.1035 (b)(4).

(c) When each leak is detected as specified in $265.1052,265.1053,265.1057$, and 265.1058, the following requirements apply:

(1) A weatherproof and readily visible identification, marked with the equipment identification number, the date evidence of a potential leak was found in accordance with 265.1058(a), and the date the leak was detected, shall be attached to the leaking equipment.

(2) The identification on equipment, except on a valve, may be removed after it has been repaired.

(3) The identification on a valve may be removed after it has been monitored for 2 successive months as specified in 265.1057 (c) and no leak has been detected during those 2 months.

(d) When each leak is detected as specified in $265.1052,265.1053,265.1057$, and 265.1058, the following information shall be recorded in an inspection log and shall be kept in the facility operating record:

(1) The instrument and operator identification numbers and the equipment identification number.

(2) The date evidence of a potential leak was found in accordance with 265.1058(a).

(3) The date the leak was detected and the dates of each attempt to repair the leak.

(4) Repair methods applied in each attempt to repair the leak.

(5) "Above 10,000" if the maximum instrument reading measured by the methods specified in $265.1063(\mathrm{~b})$ after each repair attempt is equal to or greater than $10,00 \mathrm{ppm}$.

(6) "Repair delayed" and the reason for the delay if a leak is not repaired within 15 calendar days after discovery of the leak.

(7) Documentation supporting the delay of repair of a valve in compliance with 265.1059 (c). 


\section{REQUIREMENTS IDENTIFICATION DOCUMENT HIGH LEVEL WASTE STORAGE TANK FARMS \\ Environmental Protection}

\section{Revision 0}

(8) The signature of the owner or operator (or designate) whose decision it was that repair could not be effected without a hazardous waste management unit shutdown.

(9) The expected date of successful repair of the leak if a leak is not repaired within 15 calendar days.

(10) The date of successful repair of the leak.

(e) Design documentation and monitoring, operating, and inspection information for each closed-vent system and control device required to comply with the provisions of 265.1060 shall be recorded and kept up-to-date in the facility operating record as specified in 265.1035(c). Design documentation is specified in $265.1035(c)(1)$ and $(c)(2)$ and monitoring, operating, and inspection information in 265.1035(c)(3)-(c)(8).

(f) For a control device other than a thermal vapor incinerator, catalytic vapor incinerator, flare, boiler, process heater, condenser, or carbon adsorption system, monitoring and inspection information indicating proper operation and maintenance of the control device must be recorded in the facility operating record.

(g) The following information pertaining to all equipment subject to the requirements in 265.1052 through 265.1060 shall be recorded in a log that is kept in the facility operating record:

(1) A list of identification numbers for equipment (except welded fittings) subject to the requirements of this subpart.

(2)(i) A list of identification numbers for equipment that the owner or operator elects to designate for no detectable emissions, as indicated by an instrument reading of less than 500 ppm above background, under the provisions of 265.1052(e), 265.1053(i), and 265.1057(f).

(ii) The designation of this equipment as subject to the requirements of 265.1052(e), $265.1053(\mathrm{i})$, and $265.1057(\mathrm{f})$ shall be signed by the owner or operator.

(3) A list of equipment identification numbers for pressure relief devices required to comply with 265.1054(a).

(4)(i) The dates of each compliance test required in 265.1052(e), 265.1053(i), 265.1054, and $265.1057(f)$.

(ii) The background level measured during each compliance test.

(iii) The maximum instrument reading measured at the equipment during each compliance test.

(5) A list of identification numbers for equipment in vacuum service.

(h) The following information pertaining to all valves subject to the requirements of $265.1057(\mathrm{~g})$ and $(\mathrm{h})$ shall be recorded in a log that is kept in the facility operating record:

(1) A list of identification numbers for valves that are designated as unsafe to monitor, an explanation for each valve stating why the valve is unsafe to monitor, and the plan for monitoring each valve. 


\section{REQUIREMENTS IDENTIFICATION DOCUMENT \\ HIGH LEVEL WASTE STORAGE TANK FARMS \\ Environmental Protection \\ Revision 0}

(2) A list of identification numbers for valves that are designated as difficult to monitor, an explanation for each valve stating why the valve is difficult to monitor, and the planned schedule for monitoring each valve.

(i) The following information shall be recorded in the facility operating record for valves complying with 265.1062 :

(1) A schedule of monitoring.

(2) The percent of valves found leaking during each monitoring period.

(j) The following information shall be recorded in a log that is kept in the facility operating record: (1) Criteria required in 265.1052(d)(5)(ii) and 265.1053(e)(2) and an explanation of the criteria.

(2) Any changes to these criteria and the reasons for these changes.

(k) The following information shall be recorded in a log that is kept in the facility operating record for use in determining exemptions as provided in the applicability section of this subpart and other specific subparts:

(1) An analysis determining the design capability of the hazardous waste management unit.

(2) A statement listing the hazardous waste influent to and effluent from each hazardous waste management unit subject to the requirements in 265.1052 through 265.1060 and an analysis determining whether these hazardous wastes are heavy liquids.

(3) An up-to-date analysis and the supporting information and data used to determine whether or not equipment is subject to the requirements in 265.1052 through 265.1060 . The record shall include supporting documentation as required by 265. 1063(d)(3) when application of the knowledge of the nature of the hazardous waste stream or the process by which it was produced is used. If the owner or operator takes any action (e.g., changing the process that produced the waste) that could result in an increase in the total organic content of the waste contained in or contacted by equipment determined not to be subject to the requirements in 265.1052 through 265.1060 , then a new determination is required.

(1) Records of the equipment leak information required by paragraph (d) of this section and the operating information required by paragraph (e) of this section need be kept only 3 years.

\section{FACILITY REQUIREMENT SOURCE: 40CFR61 Part 61.14.f}

"The owner or operator shall maintain records of monitoring data, monitoring system calibration checks, and the occurrence and duration of any period during which the monitoring system is malfunctioning or inoperative. These records shall be maintained at the source for a minimum of 2 years and made available, upon request, for inspection by the Administrator."

\section{SITE REQUIREMENT SOURCE: WAC-173-400 Section 105}

"(1) the owner or operator of a stationary source listed in a source category of WAC 173-400-100 shall upon notification by the director, maintain records on the type and quantity of emissions from the source and other information deemed necessary by the director to 


\section{REQUIREMENTS IDENTIFICATION DOCUMENT HIGH LEVEL WASTE STORAGE TANK FARMS \\ Environmental Protection \\ Revision 0}

determine whether the source is in compliance with applicable emission limitations and control measures."

\section{Hazardous Materials}

This subelement specifies the standards for maintenance and control of hazardous material inventory data collected under State and Federal "right-to-know" programs, and UST records and reporting.

\section{FACILITY REQUIREMENT SOURCE: 40CFR355 Part 401(b)(1)}

"(b) Notice Requirements.

(1) The owner or operator of a facility subject so this section shall immediately notify the community emergency coordinator for the local emergency planning committee of any area likely to be affected by the release and the State emergency response commission of any State likely to be affected by the release. If there is no local emergency planning committee, notification shall be provided under this section to relevant local emergency response personnel."

\section{SITE REQUIREMENT SOURCE: 40CFR370 Part 370.25}

"(a) Basic Requirement. The owner or operator of a facility subject to this Subpart shall submit an inventory form (Tier II) to the commission, the committee, and the fire department with jurisdiction over the facility."

\section{SITE REQUIREMENT SOURCE: 40CFR370 Subart 21}

"(a) Basic Requirement. The owner or operator of a facility subject to this Subpart shall submit an MSDS for each hazardous chemical present at the facility according to the minimum threshold schedule provided in paragraph (b) of section 370.20 to the committee, the commission, and the fire department with jurisdiction over the facility. "

\section{SITE REQUIREMENT SOURCE: 40CFR372 Part 372.30}

"(a) for each toxic chemical known by the owner or operator to be manufactured (including imported), processed, or otherwise used in excess of an applicable threshold quantity in Section 372.25 at its covered facility described in Section 372.22 for a calendar year, the owner or operator must submit to EPA and the State in which the facility is located a completed EPA Form R (EPA Form 9350-1) in accordance with the instructions in Subpart E."

\section{FACILITY REQUIREMENT SOURCE: WAC-173-360 Section 210(1)}

"(1) Reporting. Owners and operators shall submit the information specified in (a) through (e) of this subsection to the department or delegated agency:

(a) Notification for all UST systems (WAC 173-360-200), which includes certification of installation for new UST systems (WAC 173-360-305(5)); 


\section{REQUIREMENTS IDENTIFICATION DOCUMENT HIGH LEVEL WASTE STORAGE TANK FARMS \\ Environmental Protection \\ Revision 0}

(b) Reports of all suspected releases (WAC 173-360-360), confirmed releases (WAC 173-360-372), and spills and overfills (WAC 173-360-375);

(c) Reports required for corrective action under chapter 173-340 WAC;

(d) A notification before permanent closure or change-in-service (WAC 173-360-385); and

(e) The appropriate forms certificates of compliance, and evidence of financial responsibility (WAC 173-360-446).

(f) Checklists required for tank service activities, site checks, and site assessments shall be submitted by tank services providers or persons registered to perform site checks and site assessments, as applicable."

\section{SITE REQUIREMENT SOURCE: WAC-173-360 Section 210(2)}

"(2) Recordkeeping. Owners and operators shall maintain the following information:

(a) Documentation of operation of corrosion protection equipment (WAC 173-360-320);

(b) Documentation of UST system repairs (WAC 173-360-325(7));

(c) Recent compliance with release detection requirements (WAC 173-360-355);

(d) Results of the site assessment conducted at permanent closure (WAC 173-360-398);

(e) Corrective action records in accordance with chapter 173-340 WAC; and

(f) Evidence of financial assurance mechanisms used to demonstrate financial responsibility (WAC 173-360-450)."

FACILITY REQUTREMENT SOURCE: WAC-173-360 Section 210(3)

"(3) Availability and maintenance of records. Owners and operators shall keep the records required either:

(a) At the UST site and immediately available for inspection by the department or delegated agency; or

(b) At a readily available alternative site and be provided for inspection to the department or delegated agency upon request."

FACILITY REQUIREMENT SOURCE: WAC-173-360 Section 360

"Reporting of Suspected Releases

Owners and Operators of UST systems shall report to the department or delegated agency within twenty-four hours, or another reasonable time period specified by the department or delegated agency, and follow the procedures in WAC 173-360-370 when any of the following conditions apply: 


\section{REQUIREMENTS IDENTIFICATION DOCUMENT HIGH LEVEL WASTE STORAGE TANK FARMS \\ Environmental Protection \\ Revision 0}

(1) Owners and operators or others discover released regulated substances at the UST site or in the surrounding area (including but not limited to the presence of free product or its constituents in soils, basements, sewer and utility lines, ground water, and/or surface water).

(2) Unusual operating conditions are observed by owners or operators (such as the erratic behavior of product dispensing equipment, the sudden loss of a regulated substance from the UST system, or an unexplained presence of water in the tank), unless system equipment is found to be defective but not leaking, and is immediately repaired or replaced; or

(3) Monitoring results from a release detection method required under WAC 173-360-355 and 173-360-340 indicate that a release may bave occurred unless: (b) The monitoring device is found to be defective, and is immediately repaired, recalibrated or replaced, and additional misnitoring does not confium the initial result; or (c) In the case of inventory control, a second month of data does not coufirm the initial result, except that owners and operators shall immediately investigate all larger-than-normal or reoccurring variations in inventory control results, and report such variations if they are unaccounted for, without waiting to obtain a second month of data."

\section{Radiological Effluents}

This subelement specifies the standards for maintenance and control of data and records of routine radiological effluent discharges and/or spills to the atmosphere, surface waters, or ground water.

\section{SITE REQUIREMENT SOURCE: 40CFR61 Part 61.94}

"Compliance and Reporting

(a) Compliance with this standard shall be determined by calculating the highest effective dose equivaient to any member of the public at any off-site point where there is a residence, school, business or office. The owners or operators of each facility shall submit an annual report to both EPA headquarters and the appropriate regional office by June 30 which includes the results of the monitoring as recorded in DOE's Effluent Information System and the dose calculations required by $61.93(\mathrm{a})$ for the previous calendar year.

(b) Items 1 - 8 only In addition to the requirements of paragraph (a) of this section, an annual report shall include the following information:

(1) The name and location of the facility.

(2) A list of the radioactive materials used at the facility.

(3) A description of the handling and processing that the radioactive materials undergo at the facility.

(4) A list of the stacks or vents or other points where radioactive materials are released to the atmosphere.

(5) A description of the effluent controls that are used on each stack, vent, or other release point and an estimate of the efficiency of each control device. 


\section{REQUIREMENTS IDENTIFICATION DOCUMENT HIGH LEVEL WASTE STORAGE TANK FARMS \\ Environmental Protection \\ Revision 0}

(6) Distances from the points of release to the nearest residence, school, business or office and the nearest farms producing vegetables, milk, and meat.

(7) The values used for all other user-supplied input parameters for the computer models (e.g. meteorological data) and the source of these data.

(8) A brief description of all construction and modifications which were completed in the calendar year for which the report is prepared, but for which the requirement to apply for approval to construct or modify was waived under 61.96 and associated documentation developed by DOE to support the waiver. EPA reserves the right to require that DOE send to EPA all the information that normally would be required in an application to construct or modify, following receipt of the description and supporting documentation.

\section{SITE REQUIREMENT SOURCE: 40CFR61 Part 61.95}

\section{"Recordkeeping Requirements}

All facilities must maintain reccrds documenting the source of input parameters including the results of all measurements upon which they are based, the calculations and/or analytical methods used to derive values for input parameters, and the procedure used to determine effective dose equivalent. This documentation should be sufficient to allow an independent auditor to verify the accuracy of the determination made concerning the facility's compliance with the standard. These records must be kept at the site of the facility for at least five years and, upon request, be made available for inspection by the Administrator, or his authorized representative."

\section{SITE REQUIREMENT SOURCE: DOE/EH0135 TS.5.6}

"Auditable records are kept which show the radioactive and hazardous material release quantities and qualities."

\section{SITE REQUIREMENT SOURCE: DOE5400.1 Chapter II, Section 8.a}

"Efflueat data for radionuclides should be summarized. The nuclides of concern and the total number of curies in airborne and liquid effluents released to the offsite environment should be included in the portion of the report dealing with air and water monitoring, respectively. In instances where liquid effluents released to different receiving streams result in separate routes of potential exposure, the radioactivity discharged to each receiving stream should be identified. For purposes of reporting radiological effluent data, gross radioactivity measurements are unacceptable, unless specified by applicable federal, state, or local regulations."

\section{SITE REQUIREMENT SOURCE: DOE5400.1 Chapter II, Section 8.b}

"Include a brief description of each of the media sampled as part of the monitoring program or as part of a special study. The type and frequency of sampling and the methods of analysis should be presented. Individual data points are not required, but tables, graphs, or text which clearly and accurately present the overall monitoring results should be provided. A map showing the location of monitoring stations and sampling points also should be included. As a general rule, data should be presented for radioactivity in media for which there are applicable standards or other meaningful bases for interpreting the results. Interpretation should be made, 


\section{REQUIREMENTS IDENTIFICATION DOCUMENT HIGH LEVEL WASTE STORAGE TANK FARMS Environmental Protection \\ Revision 0}

where appropriate, of how the environmental levels (resulting from site operations) compare to relevant parameters such as background radioactivity, and applicable effluent or environmental standards."

\section{SITE REQUIREMENT SOURCE: DOE5400.1 Chapter I, Section 8.c}

"The Environmental Report should contain an assessment of the potential radiation exposure to the public which could have resulted froin site operations during the calendar year. The assessment should be as accurate and realistic as possible. The modeling and calculation methodology used in the dose assessment should be included or referenced. A comparison of results with applicable standards and relevant parameters (e.g., natural and manmade sources of exposure) also should be included."

\section{FACILITY REQUIREMENT SOURCE: DOE5400.5 Chapter II, Section 8}

\section{"Records}

a. Content. Records developed shall include information and data necessary to identify and characterize releases of radioactive material to the enviroument, their fate in the environment, and their probable impact on radiation doses to the public. Basic information used to assess compliance with the requirements of this Order pursuant to paragraph 11.6, and the results of such assessments, shall be incorporated as part of the record.

b. Retention. Information and data developed pursuant to this Order shall be retained consistent with the requirements of DOE $1324.2 \mathrm{~A}$ and other legally applicable requirements."

\section{SITE REQUIREMENT SOURCE: NRC-4.15 Section C.4}

"Records

The records necessary to document the activities performed in the monitoring program should be specified in the quality assurance program.

One key aspect of quality control in maintaining the ability to track and control a sample in its progress through the sequence of monitoring processes. Records to accomplish this should cover the following processes: field and inplant collection of samples for subsequent analysis, including sample description; sample receipt and laboratory identification coding; sample preparation and radiochemical processing (e.g. laboratory notebooks); radioactivity measurements of samples, instrument backgrounds, and analytical blanks; and data reduction and verification.

Quality control records for laboratory counting systems should include the results of measurements of radioactive check sources, calibration sources, backgrounds, and blanks.

Records relating to overall laboratory performance should include the results of analysis of quality control samples such as analytical blanks, duplicates, interlaboratory cross-check samples and other quality control analyses; use of standards (radioactivity) to prepare working standards; preparation and standardization of carrier solutions; and calibration of analytical balances. 


\section{REQUIREMENTS IDENTIFICATION DOCUMENT HIGH LEVEL WASTE STORAGE TANK FARMS Environmental Protection}

\section{Revision 0}

Additional records that are needed should include the calibration of online radiation detection equipment, air samplers, and thermoluminescence dosimetry systems; verification and documentation of computer programs; qualifications of personnel; and results of audits.

The minimum period of retention of the records should be specified."

\section{FACILITY REQUIREMENT SOURCE: WAC-246-247 Section 080}

"Monitoring and Reporting (4) The facility operator or owner shall submit a semiannual inventory of emissions from the source upon a form, and according to instructions, issued by the department.

(5) The semiannual inventory shall specify the quantities of each of the principal radionuclides released to unrestricted areas in airborne emissions during the previous six months. This data shall be reported in a manner that will permit the department to confirm radiation doses to the public. Reports shall be due in writing by May 1 and November 1 of each year."

\section{Spills and Discharges}

This subelement specifies the requirements of WAC 173-303-145 for response to spills and discharges.

\section{FACILITY REQUIREMENT SOURCE: WAC-173-303 Section 145}

"Spills and discharges into the environment

145 (1) Purpose and applicability. This section sets forth the requirements for any person responsible for a spill or discharge, except when such release is otherwise permitted under state or federal law. For the purposes of complying with this section, a transporter who spills or discharges dangerous waste or hazardous substances during transportation will be considered the responsible person. This section shall apply when any dangerous waste or hazardous substance is intentionally or accidentally spilled or discharged (unless otherwise permitted), regardless of the quantity of dangerous waste or hazardous substance.

145 (2) Notification. Any person who is responsible for a nonpermitted spill or discharge shall immediately notify the individuals and authorities described for the following situations:

145 (2) (a) For spills or discharges onto the ground or into groundwater or surface water, notify all local authorities in accordance with the local emergency plan. If necessary, check with the local emergency service coordinator and the fire department to determine all notification responsibilities under the local emergency plan. Also, notify the appropriate regional office of the department of ecology; and

145 (2) (b) For spills or discharges which result in emissions to the air, notify all local authorities in accordance with the local emergency plan. If necessary, check with the local emergency service coordinator and the fire department to determine all notification responsibilities under the local emergency plan. Also, in western Washington notify the local air pollution control authority, or in eastern Washington notify the appropriate regional office of the department of ecology. 


\section{REQUIREMENTS IDENTIFICATION DOCUMENT HIGH LEVEL WASTE STORAGE TANK FARMS \\ Environmental Protection \\ Revision 0}

(145) (2) (c) Notify the appropriate regional office of the department of ecology in the following circumstances:

(145) (2) (i) For spills or discharges occurring outside of secondary containment meeting the requirements of this chapter, regardless of quantity; and

(145) (2) (ii) For spills or discharges occurring and contained in secondary containment meeting the requirements of this chapter, if the quantity of dangerous waste or hazardous substance meets or exceeds ten gallons.

(145) (2) (d) In lieu of notification under (c) of this subsection, for spills or discharges below ten gallons occurring and contained in secondary containment meeting the requirements of this chapter, a brief account must immediately be entered into the operating record, for a TSD facility, or into the inspection log or separate spill log, for a generator. This account must include: The time and date of the spill; the location and cause of the spill; the type and quantity of material spilled; and a brief description of any response actions taken or planned.

145 (3) Mitigation and control. The person responsible for a nonpermitted spill or discharge shall take appropriate immediate action to protect buman bealth and the environment (e.g., diking to prevent contamination of state waters, shutting of open valves).

145 (3) (a) In addition, the department may require the person responsible for a spill or discharge to:

145 (3) (i) Clean up all released dangerous wastes or hazardous substances, or to take such actions as may be required or approved by federal, state, or local officials acting within the scope of their official responsibilities. This may include complete or partial removal of released dangerous wastes or hazardous substances as may be justified by the nature of the released dangerous wastes or hazardous substances, the human and environmental circumstances of the incident, and protection required by the Water Pollution Control Act, chapter $90.48 \mathrm{RCW}$;

145 (3) (ii) Designate and treat, store or dispose of all soils, waters, or other materials contaminated by the spill or discharge in accordance with this chapter 173-303 WAC. The department may require testing in order to determine the amount or extent of contaminated materials, and the appropriate designation, treatment, storage, or disposal for any materials resulting from clean-up; and

145 (3) (iii) If the property on which the spill or discharge occurred is not owned or controlled by the person responsible for the incident, restore the area impacted by the spill or discharge, and replenish resources (e.g., fish, plants) in a manner acceptable to the department.

145 (3) (b) Where immediate removal or temporary storage of spilled or discharged dangerous wastes or hazardous substances is necessary to protect human health or the environment, the department may direct that removal be accomplished without a manifest, by transporters who do not have EPA/state identification numbers.

145 (4) Nothing in WAC 173-303-145 shall eliminate any obligations to comply with reporting requirements which may exist in a permit or under other state or federal regulations." 


\section{REQUIREMENTS IDENTI :CATION DOCUMENT HIGH LEVEL WASTE STORAGE TANK FARMS \\ Environmental Protection \\ Revision 0}

Dangerous Waste

This subelement specifies the requirements for facility recordkeeping for dangerous waste TSD units.

\section{STTE REQUIREMENT SOURCE: WAC-173-303 Section 380}

"WAC 173-303-380 Facility recordkeeping.

380 (1) Operating record. The owner or operator of a facility shall keep a written operating record at his facility. The following information shall be recorded, as it becomes available, and maintained in the operating record until closure of the facility:

380 (1) (a) A description of and the quantity of each dangerous waste received or managed on-site, and the method(s) and date(s) of its treatment, storage, or disposal at the facility as required by subsection (2) of this section, recordkeeping instructions;

380 (1) (b) The location of each dangerous waste within the facility and the quantity at each location. For disposal facilities, the location and quantity of each dangerous waste must be recorded on a map or diagram of each cell or disposal area. For all facilities, this information must include cross-references to specific manifest document numbers, if the waste was accompanied by a manifest;

380 (1) (c) Records and results of waste analyses required by WAC 173-303-300, General waste analysis;

380 (1) (d) Summary reports and details of all incidents that require implementing the contingency plan, as specified in WAC 173-303-360 (2)(k);

380 (1) (e) Records and results of inspections as required by WAC 173-303-320 (2)(d), General inspection (except such information need be kept only for five years);

380 (1) (f) Monitoring, testing, or analytical data where required by 40 CFR Part 265 Subparts F through $R$ for interim status facilities, and by WAC 173-303-630 through 173-303-670 for final status facilities;

380 (1) (g) All closure and post-closure cost estimates required for the facility; and

380 (1) (h) For off-site facilities, copies of notices to generators informing them that the facility has all appropriate permits, as required by WAC 173-303-290, Required notices.

380 (3) Availability, retention and disposition of records.

380 (3) (a) All facility records, including plans, required by this chapter must be furnished upon request, and made available at all reasonable times for inspection, by any officer, employee, or representative of the department who is designated by the director.

380 (3) (b) The retention period for all facility records required under this chapter is extended automatically during the course of any unresolved enforcement action regarding the facility or as requested by the director. 


\section{REQUIREMENTS IDENTIFICATION DOCUMENT \\ HIGH LEVEL WASTE STORAGE TANK FARMS \\ Environmental Protection \\ Revision 0}

380 (3) (c) A copy of records of waste disposal locations and quantities under this section must be submitted to the United States EPA regional administrator, the department, and the local land use and planning authority"

\section{SITE REQUIREMENT SOURCE: WAC-173-303 Section 390}

"WAC 173-303-390 Facility reporting. The owner or operator of a facility is responsible for preparing and submitting the reports described in this section.

(2) Annual reports. The owner or operator of a facility that holds an active EPA/state identification number shall prepare ant submit a single copy of an annual report to the department by March 1 of each year. The report form and instructions in the TSD Facility Annual Dangerous Waste Report - Form 5 (which may be obtained from the department) must be used for this report.

(3) Additional reports. The owner or operator shall also report to the department releases of dangerous wastes, fires, and explosions as specified in WAC 173303-360 (2)(k) and interim status groundwater monitoring data, as specified in 40 CFR 265.94 (a)(2) and (b)(2). "

\section{FACILITY REQUIREMENT SOURCE: WAC-173-303 Section 810(11)}

"810 (11) Monitoring and monitoring records.

810 (11) (a) All permits shall specify:

810 (11) (a) (i) Requirements concerning the proper use, maintenance, and installation, when appropriate, of monitoring equipment or methods; and

810 (11) (a) (ii) Required monitoring including type, intervals, and frequency sufficient to yield data which are representative of the monitored activity including, when appropriate, continuous monitoring.

810 (11) (b) Samples and measurements taken for the purpose of monitoring shall be representative of the monitored activity.

810 (11) (c) The permittee shall retain records of all monitoring information, including all calibration and maintenance records and all original strip chart recordings for continuous monitoring instrumentation, copies of all reports required by this permit, and records of all data used to complete the application for this permit, for a period of at least three years from the date of the sample, measurement, report, or application. This perior may be extended by request of the department at any time.

810 (11) (d) Records of monitoring information shall include:

810 (11) (d) (i) The date, exact place, and time of sampling or measurements;

810 (11) (d) (ii) The individual(s) who performed the sampling or measurements;

810 (11) (d) (iii) The date(s) analyses were performed;

810 (11) (d) (iv) The individual(s) who performed the analyses; 


\section{REQUIREMENTS IDENTIFICATION DOCUMENT HIGH LEVEL WASTE STORAGE TANK FARMS \\ Environmental Protection \\ Revision 0}

810 (11) (d) (v) The analytical techniques or methods used; and

810 (11) (d) (vi) The results of such analyses.

810 (11) (e) The permittee shall maintain all records of ground water quality and ground water surface elevations for the active life of the facility, and for the post-closure period as well."

This element specifies the requirements for operation of underground dangerous waste storage tanks and underground diesel fuel storage tanks as regulated under the Washington Administrative Code. The scope of these requirements excludes WAC 173-303-640 (2) which specifies detailed design and installation requirements for new tank systems.

18.7.1 Tank Systems

This subelement specifies the tank integrity requirements provided in WAC 173-303-640.

\section{FACILITY REQUIREMENT SOURCE: WAC-173-303 Section 640(2)}

"640 (2) Assessment of existing tank system's integrity.

640 (2) (a) For each existing tank system, the owner or operator must determine that the tank system is not leaking or is unfit for use. Except as provided in (b) of this subsection, the owner or operator must obtain and keep on file at the facility a written assessment reviewed and certified by an independent, qualified registered professional engineer, in accordance with WAC 173-303-810 (13)(a), that attests to the tank system's integrity by January 12, 1988, for underground tanks that do not meet the requirements of subsection (4) of this section and that cannot be entered for inspection, or by January 12, 1990, for all other tank systems.

640 (2) (b) Tank systems that store or treat materials that become dangerous wastes subsequent to January 12,1989, must conduct this assessment within twelve months after the date that the waste becomes a dangerous waste.

640 (2) (c) This assessment must determine that the tank system is adequately designed and has sufficient structural strength and compatibility with the waste(s) to be stored or treated, to ensure that it will not collapse, rupture, or fail. At a minimum, this assessment must consider the following:

640 (2) (i) Design standard(s), if available, according to which the tank system was constructed;

640 (2) (ii) Dangerous characteristics of the waste(s) that have been and will be handled;

640 (2) (iii) Existing corrosion protection measures;

640 (2) (iv) Documented age of the tank system, if available (otherwise, an estimate of the age); and

640 (2) (v) Results of a leak test, internal inspection, or other tank system integrity examination such that: 


\section{REQUIREMENTS IDENTIFICATION DOCUMENT HIGH LEVEL WASTE STORAGE TANK FARMS \\ Environmental Protection \\ Revision 0}

640 (2) (A) For nonenterable underground tanks, the assessment must include a leak test that is capable of taking into account the effects of temperature variations, tank end deflection, vapor pockets, and high water table effects; and

640 (2) (B) For other than nonenterable underground tanks and for ancillary equipment, this assessment must include either a leak test, as described above, or other integrity examination, that is certified by an independent, qualified, registered professional engineer, in accordance with WAC 173-303-810(13)(a), that addresses cracks, leaks, corrosion, and erosion.

Note: The practices described in the American Petroleum Institute (API) Publication, Guide for Inspection of Refinery Equipment, Chapter XIII, "Atmospheric and Low-Pressure Storage Tanks," 4th edition, 1981, may be used, where applicable, as guidelines in conducting other than a leak test.

640 (2) (d) If, as a result of the assessment conducted in accordance with (a) of this subsection, a tank system is found to be leaking or unfit for use, the owner or operator must comply with the requirements of subsection (7) of this section.

640 (2) (e) The owner or operator must develop a schedule for conducting integrity assessments over the life of the tank to ensure that the tank retains its structural integrity and will not collapse, rupture, or fail. The schedule must be based on the results of past integrity assessments, age of the tank system, materials of construction, characteristics of the waste, and any other relevant factors.

\section{FACILITY REQUIREMENT SOURCE: WAC-173-303 Section 640(4)(a)}

"640 (4) (a) In order to prevent the release of dangerous waste or dangerous constituents to the environment, secondary containment that meets the requirements of this subsection must be provided (except as provided in ( $f$ ) and $(g)$ of this subsection):

640 (4) (i) For all new tank systems or components, prior to their being put into service;

640 (4) (ii) For all existing tank systems used to store or treat Dangerous Waste Nos. F020, F021, F022, F023, F026, and F027, within two years after January 12, 1989;

640 (4) (iii) For those existing tank systems of known and documented age, within two years after January 12,1989, or when the tank system has reached fifteen years of age, whichever comes later;

640 (4) (iv) For those existing tank systems for which the age cannot be documented, within eight years of January 12,1989; but if the age of the facility is greater than seven years, secondary containment must be provided by the time the facility reaches fifteen years of age, or within two years of January 12,1989, whichever comes later; and

640 (4) (v) For tank systems that store or treat materials that become dangerous wastes subsequent to January 12,1989 , within the time intervals required in (a)(i) through (iv) of this subsection, except that the date that a material becomes a dangerous waste must be used in place of January 12,; $1989 . "$ 


\section{REQUIREMENTS IDENTIFICATION DOCUMENT \\ HIGH LEVEL WASTE STORAGE TANK FARMS \\ Environmental Protection \\ Revision 0}

FACIITY REQUIREMENT SOURCE: WAC-173-303 Section 640(4)(b)

"Section 640(4)(b)

640 (4) (b) Secondary containment systems must be:

640 (4) (i) Designed, installed, and operated to prevent any migration of wastes or accumulated liquid out of the system to the soil, ground water, or surface water at any time during the use of the tank system; and

640 (4) (ii) Capable of detecting and collecting releases and accumulated liquids until the collected material is removed."

\section{FACILITY REQUIREMENT SOURCE: WAC-173-303 Section 640(4)(c)}

"640 (4) (c) To meet the requirements of (b) of this subsection, secondary containment systems must be at a minimum:

640 (4) (i) Constructed of or lined with materials that are compatible with the waste(s) to be placed in the tank system and must have sufficient strength and thickness to prevent failure owing to pressure gradients (including static head and external hydrological forces), physical contact with the waste to which it is exposed, climatic conditions, and the stress of daily operations (including stresses from nearby vehicular traffic);

640 (4) (ii) Placed on a foundation or base capable of providing support to the secondary containment system, resistance to pressure gradients above and below the system, and capable of preventing failure due to settlement, compression, or uplif;

640 (4) (iii) Provided with a leak-detection system that is designed and operated so that it will detect the failure of either the primary or secondary containment structure or the presence of any release of dangerous waste or accumulated liquid in the secondary containment system within twenty-four hours, or at the earliest practicable time if the owner or operator can demonstrate to the department that existing detection technologies or site conditions will not allow detection of a release within twenty-four hours; and

640 (4) (iv) Sloped or otherwise designed or operated to drain and remove liquids resulting from leaks, spills, or precipitation. Spilled or leaked waste an accumulated precipitation must be removed from the secondary containment system within twenty-four hours, or in as timely a manner as is possible to prevent harm to buman health and the environment, if the owner or operator can demonstrate to the department that removal of the released waste or accumulated precipitation cannot be accomplished within twenty-four hours.

\section{FACILITY REQUIREMENT SOURCE: WAC-173-303 Section 640(4)(d)}

"640 (4) (d) Secondary containment for tanks must include one or more of the following devices:

640 (4) (i) A liner (external to the tank);

640 (4) (ii) A vault; 


\section{REQUIREMENTS IDENTIFICATION DOCUMENT \\ HIGH LEVEL WASTE STORAGE TANK FARMS \\ Environmental Protection \\ Revision 0}

640 (4) (iii) A double-walled tank; or

640 (4) (iv) An equivalent device as approved by the department."

\section{FACILITY REQUIREMENT SOURCE: WAC-173-303 Section 640(4)(e)}

"640 (4) (e) In addition to the requirements of (b), (c), and (d) of this subsection, secondary containment systems must satisfy the following requirements:

640 (4) (i) External liner systems must be:

640 (4) (A) Designed or operated to contain one hundred percent of the capacity of the largest tank within its boundary;

640 (4) (B) Designed or operated to prevent run-on or infiltration of precipitation into the secondary containment system unless the collection system has sufficient excess capacity to contain run-on or infiltration. Such additional capacity must be sufficient to contain presipitstion from a twenty-five-year, twenty-four-hour rainfall event.

640 (4) (C) Free of cracks or gaps; and

640 (4) (D) Designed and installed to surround the tank completely and to cover all surrounding earth likely to come into contact with the waste if the waste is released from the tank(s) (i.e., capable of preventing lateral as well as vertical migration of the waste).

640 (4) (ii) Vault systems must be:

640 (4) (A) Designed or operated to contain one bundred percent of the capacity of the largest tank within its houndary;

640 (4) (B) Designed or operated to prevent run-on or infiltration of precipitation into the secondary containment system unless the collection system has sufficient excess capacity to contain run-on or infiltration. Such additional capacity must be sufficient to contain precipitation from a twenty-five-year, twenty-four-hour rainfall event;

640 (4) (C) Constructed with chemical-resistant water stops in place at all joints (if any);

640 (4) (D) Provided with an impermeable interior coating or lining that is compatible with the stored waste and that will prevent migration of waste into the concrete;

640 (4) (E) Provided with a means to protect against the formation of and ignition of vapors within the vault, if the waste being stored or treated:

640 (4) (I) Moets the definition of ignitable waste under WAC 173-303-090(5); or

640 (4) (II) Meets the definition of reactive waste under WAC 173-303-090(7), and may form an ignitable or explosive vapor.

640 (4) (F) Provided with an exterior moisture barrier or be otherwise designed or operated to prevent migration of moisture into the vault if the vault is subject to hydraulic pressure.

640 (4) (iii) Double-walled tanks must be: 


\section{REQUIREMENTS IDENTIFICATION DOCUMENT HIGH LEVEL WASTE STORAGE TANK FARMS \\ Environmental Protection \\ Revision 0}

640 (4) (A) Designed as an integral structure (i.e., an inner tank completely enveloped within an outer shell) so that any release from the inner tank is contained by the outer shell;

640 (4) (B) Protected, if constructed of metal, from both corrosion of the primary tank interior and of the external surface of the outer shell; an

640 (4) (C) Provided with a built-in continuous leak detection system capable of detecting a release within twenty-four hours, or at the earliest practicable time, if the owner or operator can demonstrate to the department, and the department concludes, that the existing detection technology or site conditions would not allow detoction of a release within twenty-four hours.

Note: The provisions outlined in the Steel Tank Institute's (STI) "Standard for Dual Wall Underground Steel Storage Tanks" may be used as guidelines for aspects of the design of underground steel double-walled tanks

\section{FACILITY REQUIREMENT SOURCE: WAC-173-303 Section 640(4)(f)}

"640 (4) (f) Ancillary equipment must be provided with secondary containment (e.g., trench, jacketing, double-walled piping) that meets the requirements of (b) and (c) of this subsection except for:

640 (4) (i) Aboveground piping (exclusive of flanges, joints, valves, and other connections) that are visually inspectod for leaks on a daily basis;

640 (4) (ii) Welded flanges, welded joints, and welded connections, that are visually inspected for leaks on a daily basis; and

640 (4) (iii) Sealless or magnetic coupling pumps and sealless valves, that are visually inspected for leaks on a daily basis; and

640 (4) (iv) Pressurized aboveground piping systems with automatic shut- off devices (e.g., excess flow check valves, flow metering shutdown devices, loss of pressure actuated shut-off devices) that are visually inspected for leaks on a daily basis.

\section{FACILITY REQUIREMENT SOURCE: WAC-173-303 Section 640(4)(g)}

"640 (4) (g) The owner or operator may obtain a variance from the requirements of this subsection if the department finds, as a result of a demonstration by the owner or operator that alternative design and operating practices, together with location characteristics, will prevent the migration of any dangerous waste or dangerous constituents into the ground water, or surface water at least as effectiveiy as secondary containment during the active life of the tank system or that in the event of a release that does migrate to ground water or surface water, no substantial present or potential hazard will posed to human health or the environment. New underground tank systems may not, per a demonstration in accordance with (g)(ii) of this subsection, be exempted from the secondary containment requirements of this"

\section{General Operating Requirements}

This subelement specifies the tank operating requirements provided in WAC 173-303-640. 


\section{REQUIREMENTS IDENTIFICATION DOCUMENT \\ HIGH LEVEL WASTE STORAGE TANK FARMS \\ Environmental Protection \\ Revision 0}

FACILITY REQUIREMENT SOURCE: WAC-173-303 Section 640(5)

"640 (5) General operating requirements.

640 (5) (a) Dangerous wastes or treatment reagents must not be placed in a tank system if they could cause the tank, its ancillary equipment, or the containment system to rupture, leak, corrode, or otherwise fail.

640 (5) (b) The owner or operator must use appropriate controls and practices to prevent spills and overflows from tank or containment systems. These include at a minimum:

640 (5) (i) Spill prevention controls (e.g., check valves, dry disconnect couplings);

640 (5) (ii) Overfill prevention controls (e.g., level sensing devices, high level alarms, automatic feed cutoff, or bypass to a standby tank); and

640 (5) (c) The owrer or operator must comply with the requirements of subsection (7) of this section if a leak or spill occurs in the tank system.

640 (5) (d) All tank systems holding dangerous waste shall be marked with labels or signs to identify the waste contained in the tank. The label or sign shall be legible at a distance of at least fifty feet, and shall bear a legend which identifies the waste in a manner which adequately warns employees, emergency response personnel, and the public of the major risk(s) associated with the waste being stored or treated in the tank system(s). (Note -- If there already is a system in use that performs this function in accordance with local, state or federal regulations, then such system will be adequate.)

640 (5) (e) All tank systems holding EHW which is acutely or chronically toxic by inhalation must be designed to prevent escape of vapors, fumes, or other emissions into the air."

\section{Leak Response}

This subelement specifies the tank leak response requirements provided in WAC 173-303-640.

\section{FACILITY REQUIREMENT SOURCE: WAC-173-303 Section 640(7)}

"640 (7) Response to leaks or spills and disposition of leaking or unfit- for-use tank systems.

A tank system or secondary containment system from which there has been a leak or spill, or which is unfit for use, must be removed from service immediately, and the owner or operator must satisfy the following requirements:

640 (7) (a) Cessation of use; prevent flow or addition of wastes. The owner or operator must immediately stop the flow of dangerous waste into the tank system or secondary containment system and inspect the system to determine the cause of the release.

640 (7) (b) Removal of waste from tank system or secondary containment system.

640 (7) (i) If the release was from the tank system, the owner/operator must, within twenty-four hours after detection of the leak or, if the owner/operator demonstrates that it is not possible, at the earliest practicable time, remove as much of the waste as is necessary to 


\section{REQUIREMENTS IDENTIFICATION DOCUMENT HIGH LEVEL WASTE STORAGE TANK FARMS \\ Environmental Protection}

Revision 0

prevent further release of dangerous waste to the environment and to allow inspection and repair of the tank system to be performed.

640 (7) (ii) If the material released was to a secondary containment system, all released materials must be removed within twenty-four hours or in as timely a manner as is possible to prevent harm to human health and the environment.

640 (7) (c) Containment of visible releases to the environment. The owner/operator must immediately conduct a visual inspection of the release and, based upon that inspection:

640 (7) (i) Prevent further migration of the leak or spill to soils or surface water; and

640 (7) (ii) Remove, and properiy dispose of, any visible contamination of the soil or surface water.

640 (7) (d) Notifications, reports.

640 (7) (i) Any release to the environment, except as provided in (d)(ii) of this subsection, m'st be reported to the department within twenty- four hours of its detection. Any release above the "reportable quantity" must also be reported to the National Response Center pursuant to 40 CFR Part 302.

640 (7) (ii) A leak or spill of dangerous waste is exempted from the requirements of (d) of this subsection if it is:

640 (7) (A) Less than or equal to a quantity of one pound, or the "Reportable Quantity" (RQ) established in 40 CFR Part 302, whichever is less; and

640 (7) (B) Immediately contained and cleaned-up.

640 (7) (iii) Within thirty days of detection of a release to the environment, a report containing the following information must be submitted to the department:

640 (7) (A) Likely route of migration of the release;

640 (7) (B) Characteristics of the surrounding soil (soil composition, geology, hydrogeology, climate);

640 (7) (C) Results of any monitoring or sampling conducted in connection with the release (if available). If sampling or monitoring data relating to the release are not available within thirty days, these data must be submitted to the department as soon as they become available;

640 (7) (D) Proximity to downgradient drinking water, surface water, and populated areas; and

640 (7) (E) Description of response actions taken or planned.

640 (7) (e) Provision of secondary containment, repair, or closure.

640 (7) (i) Unless the owner/operator satisfies the requirements of (e)(ii) through (iv) of this subsection, the tank system must be closed in accordance with subsection (8) of this section. 


\section{REQUIREMENTS IDENTIFICATION DOCUMENT HIGH LEVEL WASTE STORAGE TANK FARMS \\ Environmental Protection \\ Revision 0}

640 (7) (ii) If the cause of the release was a spill that has not damaged the integrity of the system, the owner/operator may return the system to service as soon as the released waste is removed and repairs, if necessary, are made.

640 (7) (iii) If the cause of the release was a leak from the primary tank system into the secondary contrinment system, the system must be repaired prior to returring the tank system to service.

640 (7) (iv) If the source of the release was a leak to the environment from a component of a tank system without secondary containment, the owner/operator must provide the component of the system from which the leak occurred with secondary containment that satisfies the requirements of subsection (4) of this section before it can be returned to service, unless the source of the leak is an aboveground portion of a tank system that can be inspected visually. If the source is an aboveground component that can be inspected visually, the component must be repaired and maybe returned to service without secondary containment as long as the requirements of (f) of this subsection are satisfied. If a component is replaced to comply with the requirements of this subitem, that component must satisfy the requirements for new tank systems or components in subsections (3) and (4) of this section. Additionally, if a leak has occurred in any portion of a tank system component that is not readily accessible for visual inspection (e.g., the bottom of an inground or onground tank), the entire component must be provided with secondary containment in accordance with subsection (4) of this section prior to being returned to use.

640 (7) (f) Certification of major repairs. If the owner/operator has repaired a tank system in accordance with (e) of this subsection, and the repair has been extensive (e.g., installation of an internal liner; repair of a ruptured primary containment or secondary containment vessel), the tank system must not be retumed to service unless the owner/operator has obtained a certification by an independent, qualified, registered, professional engineer in accordance with WAC 173-303-810 (13)(a) that the repaired system is capable of handling dangerous wastes without release for the intended life of the system. This certification must be submitted to the department within seven days after returning the tank system to use.

Note: See WAC 173-303-320 for the requirements necessary to remedy a failure. Also, 40 CFR Part 302 may require the owner or operator to notify the National Response Center of certain releases.

\section{Ignitable, Reactive, and Incompatible Tank Wastes}

This subelement specifies the requirements for ignitable, reactive and incompatible wastes provided in WAC 173-303-640.

\section{FACILITY REQUIREMENT SOURCE: WAC-173-303 Section 640(10)}

"640 (10) Special requirements for incompatible wastes.

640 (10) (a) Incompatible wastes, or incompatible wastes and materials, must not be placed in the same tank system, unless WAC 173-303-395 (1)(b) is complied with.

640 (10) (b) Dangerous waste must not be placed in a tank system that has not been decontaminated and that previously held an incompatible waste or material, unless WAC 173-303-395 (1)(b) is complied with." 


\section{REQUIREMENTS IDENTIFICATION DOCUMENT HIGH LEVEL WASTE STORAGE TANK FARMS \\ Environmental Protection \\ Revision 0}

\section{FACILITY REQUIREMENT SOURCE: WAC-173-303 Section 640(9)}

"640 (9) Special requirements for ignitable or reactive wastes.

640 (9) (a) Ignitable or reactive waste must not be placed in tank systems unless:

640 (9) (i) The waste is treated, rendered, or mixed before or immediately after placement in the tank system so that the resulting waste, mixture, or dissolution of material no longer meets the definition of ignitable or reactive waste under WAC 173-303-090, and 173-303-395 (1)(b) is complied with; or

640 (9) (ii) The waste is stored or treated in such a way that it is protected from any material or conditions which may cause the waste to ignite or react; or

640 (9) (iii) The tank system is used solely for emergencies.

640 (9) (b) The owner or operator of a facility which treats or stores ignitable or reactive waste in covered tanks must locate the tanks in a manner equivalent to the National Fire Protection Association's buffer zone requirements for tanks, contained in Tables 2-1 through 2-6 of the NFPA-30 Flammable and Combustible Liquids Code 1981, or as required by state and local fire codes when such codes are more stringent. The owner or operator shall also comply with the requirements of WAC 173-303-395 (1)(d).

\section{Underground Storage Tanks}

This subelement specifies the requirements applicable to the underground diesel storage tanks provided in WAC 173-360.

\section{FACILTY REQUIREMENT SOURCE: WAC-173 Section 360-310(1)}

"Upgrading Requirements For Existing UST Systems

(1) Alternatives allowed. Not later than December 22, 19998, all existing UST systems shall comply with one of the following requirements:

(a) New UST system performance standards under WAC 173-360-305; (b) The upgrading requirements in subsections (2) through (4) of this section; or (c) Closure requirements under WAC 173-360-380 through 173-360-398, including applicable requirements for corrective action under WAC 173-360-399.

\section{FACIITY REQUIREMENT SOURCE: WAC-173 Section 360-315}

"(1) Spill and Overflow Control Requirements Owners and operators shall ensure that releases due to spilling or overflowing do not occur. The owner and operator shall ensure that the volume available in the tank is greater than the volume of regulated substances to be transferred to the tank before the transfer is made and that the transfer"

\section{FACILITY REQUIREMENT SOURCE: WAC-173 Section 360-345(6)(c)}

"Monthly tank gauging. 


\section{REQUIREMENTS IDENTIFICATION DOCUMENT HIGH LEVEL WASTE STORAGE TANK FARMS \\ Environmental Protection \\ Revision 0}

Only tanks that store fuel solely for use by emergency power generators with a nominal capacity of two thousand gallons or less may use monthly tank gauging as a method of release detection. Such tanks with nominal capacity of five hundred fifty-one to two thousand gallons shall also have an annual tank tightness test conducted in accordance with (d) of this subsection. Monthly tank gauging shall meet the following requirements:

(i) Inventory volume measurements for regulated substance inputs, withdrawals, and the amount still remaining in the tank are recorded whenever inputs or withdrawals occur;

(ii) Tank liquid level measurements reconciled with inventory volume measurements are taken monthly at the beginning and ending of a period of at least twenty-one days, except when extreme snowfall or other travel obstructions occurring in remote locations and preventing access are specifically documented by the owner and operator;

(iii) Level measurements are based on an average of two consecutive readings at both the beginning and ending of the period (that is, four measurements shall be taken, two consecutive measurements at the beginning and two consecutive measurements at the end of the period);

(iv) The equipment used is capable of measuring the level of regulated substance in the tank over the full range of the tank's height to the nearest one-eighth of an inch or a corresponding amount of gallons;

(v) The measurement of any water level in the bottom of the tank is made to the nearest one-eighth of an inch at least once a month;

(vi) If the variation between beginning and ending measurements exceeds the monthly standard in the following table, a leak may be occurring and the requirements of WAC 173-360-360 through 173-360-375 shall be followed:

Nominal Tank Capacity Monthly Standard (average of four tests)

$\begin{array}{ll}550 \text { gallons or less } & 5 \text { gallons } \\ 551-1,000 \text { gallons } & 7 \text { gallons } \\ 1,001-2,000 \text { gallons } & 13 \text { gallons }\end{array}$

FACILITY REQUIREMENT SOURCE: WAC-173-360 Section 305(1)(b),(2)(b)

"Performance Standards for Cathodic Protection

If the tank and/or piping (1) routinely contains regulated substances, (2) is in contact with the ground, and (3) is constructed of steel (e.g., not of fiberglass-reinforced plastic or of a steel-fiberglass-reinforced-plastic composite), then it must be cathodically protected in the following manner:

(i) The tank and/or piping is coated with a suitable dielectric material;

(ii) The tank is equipped with a factory-installed or field-installed cathodic protection system designed by a corrosion expert, and field-installed cathodic protection systems for piping are designed by a corrosion expert;

(iii) Cathodic protection systems are designed and installed to include provisions for testing to allow a determination of current operating status as required in WAC 173-360-320(2) and to 


\section{REQUIREMENTS IDENTIFICATION DOCUMENT HIGH LEVEL, WASTE STORAGE TANK FARMS \\ Environmental Protection \\ Revision 0}

facilitate testing by Ecology or delegated agency in accordance with WAC 173-360-325 (5) and (6); and

(iv) Cathodic protection systems are operated and maintained in accordance with WAC 173-360-320, or according to guidelines established by Ecology or delegated agency, or the codes and standards listed in WAC 173-360-305 (1)(b)"

\section{FACILITY REQUIREMENT SOURCE: WAC-173-360 Section 305(3)(a),(b)}

\section{"Spill and Overflow Prevention Equipment}

Unless the UST system is filled by transfers of less than 25 gallons at one time, or Ecology-approved alternative equipment is used, then owners and operators will use the following spill and overfill prevention equipment to prevent spilling and overfilling associated with transfer of regulated substances to the UST system:

(i) Spill prevention equipment that will prevent the release of regulated substances to the environment when the transfer hose is detached from the fill pipe (for example, a spill catchment basin); and

(ii) Overfill prevention equipment that will:

(A) Automatically shut off flow into the tank when the tank is no more than $95 \%$ full;

(B) Alert the transfer operator when the tank is no more than $90 \%$ full by restricting the flow into the tank or triggering a high-level alarm; or

(C) Restrict flow thirty minutes prior to overfilling, alert the operator with a high-level alarm one minute before overfilling, or automatically shut off flow into the tank so that none of the fittings located on top of the tank are exposed to regulated substances due to overfilling.

Note: Overflow prevention equipment that will automatically shut off or restrict flow into the tank should not be used where a pressurized fuel transfer system may be employed since an overflow may occur when the flow is suddenly shut off or restricted."

\section{FACIITY REQUIREMENT SOURCE: WAC-173-360 Section 320}

"All owners and operators of stoel UST systems with corrosion protection shall comply with the following requirements to ensure that releases due to corrosion are prevented for as long as the UST system is used to store regulated substances:

(1) All corrosion protection systems shall be operated and maintained to continuously provide corrosion protoction to the metal components of that portion of the tank and piping that routinely contain regulated substances and are in contact with the ground.

(2) All UST systems equipped with cathodic protection systems shall be inspected for proper operation by a licensed supervisor of cathodic protection installation and testing in accordance with the following requirements: (a) Frequency. All cathodic protection systems shall be tested when they are installed, and again between one and six months after installation, and at least every three years thereafter or according to another reasonable timeframe established by Ecology or delegated agency; and (b) Inspection criteria. The criteria that are used to 


\section{REQUIREMENTS IDENTIFICATION DOCUMENT \\ HIGH LEVEL WASTE STORAGE TANK FARMS \\ Environmental Protection \\ Revision 0}

determine that cathodic protection is adequate as required by this section shall be in accordance with a code of practice developed by a nationally recognized association.

Note: National Association of Corrosion Engineers Standard RP-02-85, "Control of External Corrosion on Metallic Buried, Partially Buriod, or Submerged Liquid Storage Systems, " may be used to comply with this subsection.

(3) UST systems with impressed current cathodic protection systems shall also be inspected overy 60 days to ensure the equipment is running properly.

(4) For UST systems using cathodic protection, records of the operation of the cathodic protection shall be maintained to demonstrate compliance with the performance standards in this section. These records shall provide the following:

(a) The results of the last throe inspections required in subsection (3) of this section; and

(b) The results of testing from the last two inspections required in subsection (2) of this section.

(5) Tank services providers who perform any of the tank services described in this section shall certify that such services comply with the requirements of this section by submitting the appropriate checklist(s) to Ecology in"

FACILTY REQUIREMENT SOURCE: WAC-173-360 Section 345(6)(d)

"Tank tightness testing.

Tank Tightness testing (or another test of equivalent performance) shall be capable of detecting at least a 0.1 gallon per hour leak rate from any portion of the tank that routinely contains a regulated substance while accounting for the effects of thermal expansion or contraction of the regulated substance, vapor pockets, tank deformation, evaporation or condensation, and the location of the water table."

\section{GENERAL TSD REQUIREMENTS}

This element specifies general TSD requirements for performance standards and handling of ignitable, reactive, or incompatible wastes applicable to Tank Farms.

\section{SITE REQUIREMENT SOURCE: WAC-173-303 Section 395(2)}

"Compliance with other environmental protoction laws and regulations. In receiving, storing, handling, treating, processing, or disposing of dangerous wastes, the owner/operator shall design, maintain and operate his dangerous waste facility in compliance with all applicable federal, state and local laws and regulations (e.g., control of stormwater or sanitary water discharge, control of volatile air emissions, etc.)."

\subsubsection{Performance Standards}

This subelement specifies the requirements of WAC 173-303-283 for general performance standards for designing, constructing, operating, and maintaining dangerous waste facilities. 


\section{REQUIREMENTS IDENTIFICATION DOCUMENT HIGH LEVEL WASTE STORAGE TANK FARMS \\ Environmental Protection \\ Revision 0}

SITE REQUTREMENT SOURCE: WAC-173-303 Section 283

"WAC 173-303-283 Performance Standards.

283 (1) Purpose. This section provides general performance standards for designing, constructing, operating, and maintaining dangerous waste facilities.

283 (2) Applicability. This section applies to all dangerous waste facilities permitted under WAC 173-303-800 through 173-303-840. These general performance standards shall be used to determine whether more stringent facility standards should be applied than thoss spelled out in WAC 173-303-28C, 173-303-290 through 173-303-400 and 173-303-600 through 173-303-670.

283 (3) Performance standards. Unless authorized by state, local, or federal laws, or unless otherwise authorized in this regulation, the owner/operator shall design, construct, operate, or maintain a dangerous waste facility that to the maximum extent practical given the limits of technology prevents:

283 (3) (a) Degradation of ground water quality;

283 (3) (b) Degradation of air quality by open burning or other activities;

283 (3) (c) Degradation of surface water quality;

283 (3) (d) Destruction or impairment of flora and fauna outside the active portion of the facility;

283 (3) (e) Excessive noise;

283 (3) ( $f$ ) Conditions that constitute a negative aesthetic impact for the public using rights of ways, or public lands, or for landowners of adjacent properties;

283 (3) (g) Unstable hillsides or soils as a result of trenches, impoundments, excavations, etc.;

283 (3) (b) The use of processes that do not treat, detoxify, recycle, reclaim, and recover waste material to the extent economically feasible; and

283 (3) (i) Endangerment of the health of employees, or the public near the facility."

\section{Ienitable and Reactive Wastes}

This subelement specifies the requirements of WAC 173-303-395(1) for ignitable and reactive wastes.

\section{FACILITY REQUIREMENT SOURCE: WAC-173-303 Section 395(1)}

"395 (1) Precautions for ignitable, reactive, or incompatible wastes.

395 (1) (a) The owner or operator must take precautions to prevent accidental ignition or reaction of ignitable or reactive waste. This waste must be separated and protected from sources of ignition or reaction including, but not limited to, open flames, smoking, cutting and welding, hot surfaces, frictional beat, sparks (static, electrical, or mechanical), spontaneous 
ignition (e.g., from heat-producing chemical reactions), and radiant heat. While ignitable or reactive waste is being handled, tho owner or operator must confine smoking and open flame to specially designated locations. "No smoking" signs must be conspicuously placed wherever there is a hezard from ignitablo or reactive waste.

395 (1) (b) Where specifically required by other sections of this chapter 173-303 WAC, the treatment, storage, or disposal of ignitable or reactive waste, and the mixture or commingling of incompatible wastes, or incompatible wastes and matorials, must be conducted so that it does not:

395 (1) (i) Generate extreme heat or pressure, fire or explosion, or violent reaction;

395 (1) (ii) Produce uncontrolled toxic mists, fumes, dusts, or gases in sufficient quantities to threaten buman bealth or the environment;

395 (1) (iii) Produce uncontrolled flammable fumes or gases in sufficient quantities to pose a risk of fire or explosions;

395 (1) (iv) Damage the structural integrity of the facility or device containing the waste; or

395 (1) (v) Through other like means, threaten human health or the environment.

395 (1) (c) When required to comply with (a) and (b) of this subsection, the owner or operator must document that compliance in the operating record required under WAC i73-303-380(l). This documentation may be based on references to published scientific or engineering literature, data from trial tests, waste analyses, or the results of the treatment of similar wastes by similar treatment processes and under similar operating conditions.

395 (1) (d) At least yearly, the owner or operator shall inspect those areas of his facility where ignitable or reactive wastes are stored. This inspection shall be performed in the presence of a professional person who is familiar with the Uniform Fire Code, or in the presence of the local, state, or federal fire marshal. The owner or operator shall enter the following information in his inspection log or operating record as a result of this inspection:

395 (1) (i) The date and time of the inspection;

395 (1) (ii) The name of the professional inspector or fire marshal;

395 (1) (iii) A notation of the observations made; and

395 (1) (iv) Any remedial actions which were taken as a result of the inspection."

\section{KEY PROGRAM INTERFACE}

This element describes key functional interfaces. The key interfaces for Environmental Protection are Training and Qualification and Quality Assurance.

\section{Training and Oualification}

Training requirements applicable to environmental protection are specified in WAC 173-303-330. These requirements are listed in the ER\&WM functional area and are not 


\section{REQUIREMENTS IDENTIFICATION DOCUMENT HIGH LEVEL WASTE STORAGE TANK FARMS \\ Environmental Protection \\ Revision 0}

repeated bere. The Training and Qualification functional area specifies the programmatic requirements applicable to Environmental Protection.

\section{Quality Assurance}

DOE 5400.1 requires that the environmental protection program establish auditable records in accordance with DOE 5700.6C. In addition, DOE 5400.5 requires a environmental protection quality aesurance program be extabliabed in accordance with DOE 5700.6B. Therefore, requirements ideatified by the Quality Assurance functional aree apply to the environmental protection activities identified in this document.

\section{REFERENCE SECTION}

The following reference documents were used to prepare the Environmental Protection functional area document.

1) Washington Administrative Code 118-40, "Hazardous Chemical Emergency Response Plar.uing and Community Right-to-Know roporting."

2) Weshington Administrative Code 173-160, "Minimum Standards for Construction and Maintenance of Wolls."

3) Washington Administrative Code 173-200, "Water Quality Standards for Groundwater of the State of Washington."

4) Washington Administrative Code (WAC) 173-303, Dangerous Waste Regulations."

5) Washington Administrative Code 173-307, "Plans"

6) Washington Administrative Code 173-360, "Underground Storage Tank Regulations."

7) Washington Administrative Code 173-400, "General Regulations for Air Pollution Sources."

8) Washington Administrative Code 173-460, "Controls for New Sources of Toxic Air Pollutants."

9) Weshington Administrative Code 173-470, "Ambient Air Qưality Standards for Particulate Matter."

10) Washington Administrative Code (WAC) 173-480, "Ambient Air Quality Standards and Emission Limits for Radionuclides."

11) Washington Administrative Code 197-11, "Washington State Environmental Policy Act (SEPA) Rules."

12) Washington Administrative Code 246-247, "Radioactive Waste."

13) Washington Administrative Code 246-272, "On-Site Sewage System"

14) Wrshington Administrative Code 246-290, "Public Water Supplies."

15) 40 CFR 60, "Standards of Performance for Now Stationery Sources." 


\section{REQUIREMENTS IDENTIFICATION DOCUMENT \\ HIGH LEVEL WASTE STORAGE TANK FARMS \\ Environmental Protection \\ Rerision 0}

16) 40 CFR Part 61, "National Emiesions Standards for Hezardous Air Pollutants."

17) 40 CFR Part 122, "EPA National Pollutant Discharge Elimination System Permit Regulations."

18) 40 CFR Part 191, "Environmeatal Protection Stendards for Management and Disposal of Speat Nuclear Fuol, High-Lovel, and Transuranic Radioactive Wastes."

19) 40 CFR 265, "EPA Intorim Status Stundards for Ownen and Operators of Hazardous Waste Facilitios."

20) 40 CFR Part 241, "Guidelines for the Land Disposal of Solid Westes."

21) 40 CFR Part 264, "EPA Regulations for Owners and Operators of Permitted Hezardous Waste Facilitios."

22) 40 CFR Part 355, "Emergency Planning and Notification."

23) 40 CFR Part 370, "Hazardous Chemical Reporting; Community Right to Know."

24) 40 CFR 1500, "Purpose, Policy, and Mandate."

25) DOE Order 5400.1, "General Eavironmental Protection."

26) DOE Order 5400.5, "Radiation Protection of the Public and the Environment."

27) DOE Order 5484.1, "Environmental Protection, Safety, and Health Protection Information Reporting Requirements."

28) DOE Order 5820.2A, "Radioactive Waste Management."

29) DOE/EH-0173T, "Radiological Effluent Monitoring and Environmental Surveillance."

30) DOE/EH-0135, "Performance Objectives and Criteria for Technical Safety Appraisals at Department of Energy Facilities and Sites."

31) NRC 4.15, "Environmental Surveillance and Monitoring Quiality Assurance."

The following references were reviewed but not included in preparation of the Environmental Protection S/RID for the PUREX/UO3 Deactivation Project.

1) Federal Agency Hazardous Waste Compliance Docket July 18, 1991, Raymond B. Ludwiszowski.

2 EPA Pollution Provention Strategy, 56FR 7849, February 26, 1991.

3 Effluent Monitoring Reporting Requirements, 10CFR Part 70.59.

4) Whole Effluent Toxicity Testing and Limits, WAC-173-205.

5) Superfund Implementation, Executive Order 12580. 


\section{REQUIREMENTS IDENTIFICATION DOCUMENT \\ FIGH LEVEL WASTE STORAGE TANK FARMS \\ Environmental Protection}

Reviaion 0

6) Implemeatation of Section 311 of the Foderal Water Pollution Control Act, Executive Order 12777.

7) Federal Complience with Pollution Control Standards, Executive Order 12088.

8) Storm Water Waste Managemeat For Lnduatrial Activities Summary Guidance. 

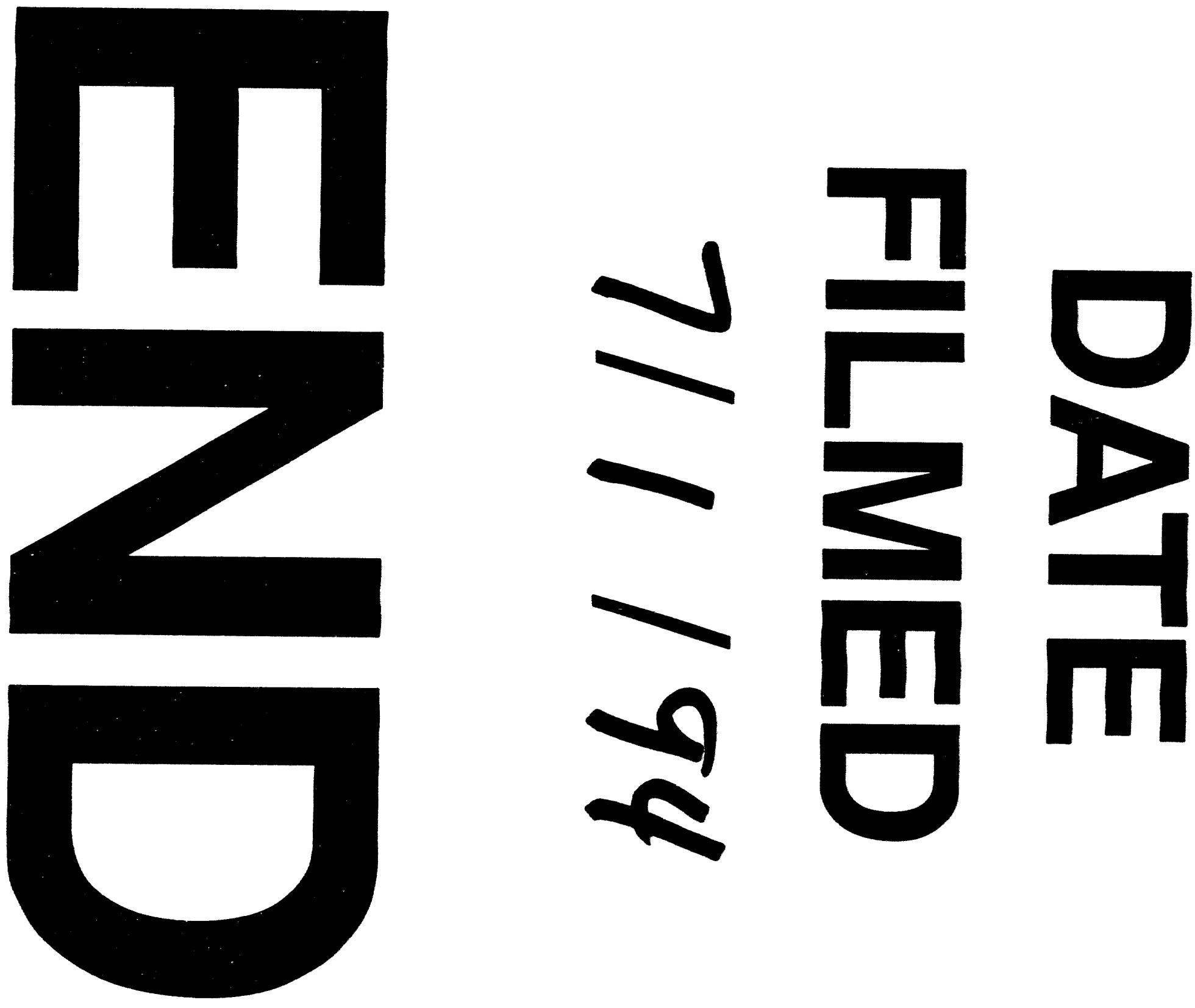
